

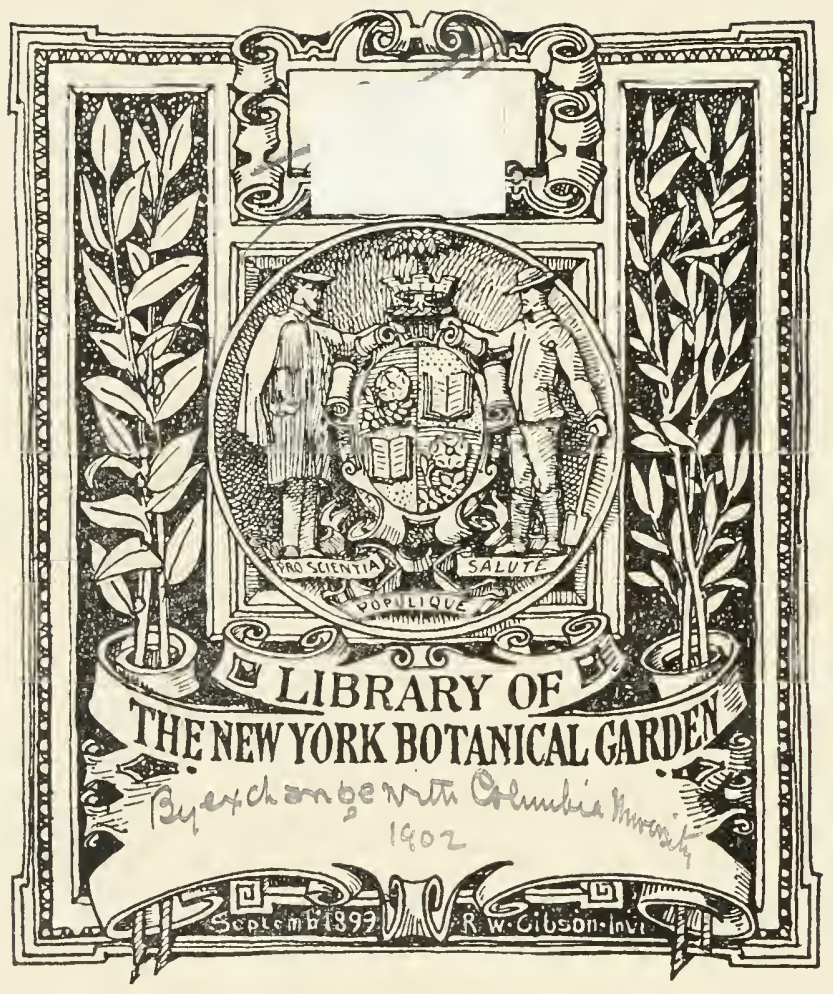







\section{Botanische Mittheilungen aus den Tropen}

herausgegeben

von

Dr. A. F. W. Schimper,

a. o. Professor der Botanik an der Universität Bonn.

Heft 8.

Protobasidiomyceten.

Von

Alfred Möller.

Mit 6 Tafeln.

Jen a,

VERIAA $\backslash$ YON GUSTAV FISCHER.

1895. 


\begin{abstract}
Protobasidiomyceten.
\end{abstract}
Untersuchungen aus Brasilien

von

\title{
Alfred Möller.
}

Mit 6 Tafeln.

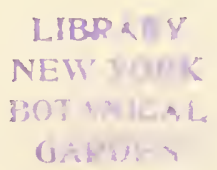

Jena,

VERLAG VON GUSTAV FISCHER.

1895. 
QKb26

.M6 


\section{Vorwort.}

Als ich mich anschickte, zu längerem Aufenthalte und zum Zwecke mykologischer Untersuchungen nach Sïdbrasilien zu gehen. da stand der Gedanke im Vordergrunde, die durch Professor Brefeld begründeteu Methoden zur kïnstlichen Krultur der Fadenpilze, die ich in mehrjähriger Arbeit in seinem Laboratorium kennen und ausiiben gelernt hatte, nun anzuwenden an Ort und Stelle auf die Pilze des brasilischen Urwaldes. Dieser Absicht entsprechend war meine Ausriistung beschafft. Den Arbeitsplan näher und in Einzelheiten zu bestimmen, etwa besoudere Gruppen oder Familien in erster Linie ins Ange zu fassen, das war nach Lage unserer beschränkten Kenntnisse von der Pilzflora Südbrasiliens im voraus nicht möglich. Es konnte nur die Hoffnung gehegt werden, dass Formen möchten gefunden und der künstlichen Kultur zugänglich gemacht werden, welche als Ausgangspunkte, als niederste Entwickelungsglieder der grossen, in so unendlich zahlireichen Abwandlungen zur Herrschaft gelangten Reilien der Ascomyceten und Basidiomyceten sich darstellteu, welche eben durch diese ihre Stellung für die von Brefeld in grossen Züigen festgelegten Auffassungen ïber das System der Pilze Bestätigungen oder Ergäuzungen liefern könnten. Es konnte auch vielleicht daran gedacht werden, neue Pilze zu entdecken, die als Mittelglieder 
zwischen bisher nicht verwandtschaftlich zu verbindenden Formen und Formemreihen von Bedeutung sich erwiesen, Hoffnungen, wie sie im besonderen Falle z. B. durch die im vorigen Hefte dieser Mittheilungen beschriebene Protubera erfüllt worden sind. Ueber derartige allgemeine Erwägungen hinaus war ein specieller Plan nicht möglich.

Die Arbeit am Stationsorte begann mit unsicherem Umhersuchen in dem fremden, durch die Ueberfülle seiner Gestalten verwirrend, ja bisweilen erdriickend wirkenden Walde. Von planmässigem Suchen konnte zunächst keime Rede sein. Die allerverschiedensten Dinge wurden anfgenommen, betrachtet, nntersucht, verworfen, bis Einzelnes zu genauer Untersuchumg herangezogen wurde. Monate aber vergingen bei täglicher mansgesetzter Arbeit, bis in der Fülle der Auregungen einzelne Ziele auftauchten, denen nachzugehen Aussicht auf Erfolg verhiess und zu deren Erreichung das Material in besouders reicher Fülle vorhanden schien. Nun erst konnte das Sammeln im Walde planmässig betrieben werden, uu erst ging ich zum Sammelı hinans, mit der bestimmten Absicht, dies oder jenes zu suchen. Es ist eine mehrfach bestätigte Erfahrung. dass erst von diesem Augenblicke an die Ausbeute sich in erheblichem Grade steigert, und dass erst bei plammässigem suchen Material gewomnen wird, welches durch grössere Vollständigkeit allgemeinere Fragen zu lösen gestattet.

Keineswegs num lagen die in der beschriebenen Weise gewommenen Anküupfungspunkte, die Arbeitscentren also, immer auf den Gebieten, die ich von vornherein vor der Abreise erhofft oder auf welche ich die Gedanken rornehmlich gerichtet hatte. Vielmehr stellten sich von ganz merwarteter seite Fragen ein, die meinem Anschanmoskreise vordem fremd waren, an die ich anch gar nicht latte denken kömnen. Aber sie gewannen allmällich feste Gestalt mi zwangen dem Beobachtel Anfmerksamkeit ab. So erging es mir zunächst mit den Schleppameisen und ihren 
mnterirdischen Pilzknltmren. Tch hatte nicht geglanbt, bei ihnen mykologische Arbeit zu finden, und anch nachdem ich sie fliichtig kennen gelernt und gelegentlich einen Blick in das eine oder andere ihrer Nester geworfen hatte, glaubte ich zunächst nicht, dass ich mich mit ihnen jahrelang wiirde zu beschäftigen haben und dass ihre Pilzkulturen mir so werthvolle mykologische Erkenntnisse vermitteln wïrden, wie sie es nachmalen gethan haben. Aber die Ameisen, denen ich täglich begegnete, die zahlreichen Nester, welche iiberall im Walde angetroffen wurden, im Garten oftmals zu vertilgen waren, ja mnter der Schwelle des Hauses selbst sich vorfanden, drängten sich fast wider Willen auf; es zeigte sich in jedem Neste dieselbe Pilzmasse, und nachidem diese erst zwei und dreimal genauer betrachtet worden war, so war der Anstoss zur Arbeit gegeben, die ich dann planmässig in Angriff nahm.

Aehnlich erging es mir mit den Pilzblumen, welclıe ich im vorigen Hefte dieser Mittheilungen beschrieben habe. Es konnte nicht von vornherein meine Absicht sein, mit Phalloideen mich eingehend zu beschäftigen. Nur wenige Formen waren ans ganz Siidamerika bekamnt, fast stets nur in je einem oder wenigen Fxemplaren gefunden, es stand auch nicht zu erhoffen, dass ilıre Untersuchming nach den ron mir ins Ange gefassten Richtungen hin erhebliclıe Aufschlïsse wïrde liefern können. Allein nachdem ich wenige entwickelte Fruchtkörper dieser wunderbaren Gestalten lebend zu Gesicht bekommen hatte, so wurde durch sie die Aufmerksamkeit mächtig angezogen, und zahlreiche nun mit der Absicht sie zu suchen unternommene Ausflïge im Lanfe der Jahre brachten mich in Besitz eines Materiales, welches alle vorher etwa berechtigten kiwartungen weit iibertraf.

Ganz anders wie in den beiden erwähnten Fällen liegt es mit den Untersuchungen, ïber die ich diesmal zu berichten habe. Diese Untersuchungen lagen ganz und gar in meinem Plane. Auf Protobasidiomyceten richtete ich von Anfang an meine Hanptanfmerksamkeit, und nachdem ich für das Sammeln und Suchen 
in Herrn Gärtner einen Gehïlfen gefunden hatte, so machte ich ihn immer und immer wieder darauf aufmerksam, ja nichts zu übersehen, was durch gallertige oder sclıleimige Beschaffenheit der Fruchtkörper auf eine Zugehörigkeit zu diesem Formenkreise etwa deuten könnte.

Noch war ja nicht lange Zeit vergangen, seit Brefelds VII. und VIII. Band der Untersuchungen erschienen war, jenes grosse Werk, das gerade durch die sorgsame, an Erfolgen so reiche Untersuchung der Protobasidiomyceten eine Fülle neuer Aufklärungen gebracht hatte, welche für die Systematik der Basidiomyceten in erster Linie, dann aber für die gesammite Pilzsystematik von grundlegender Bedeutung sich erwiesen. Unter dem frischen Eindruck, den dieses Werk mir hinterlassen hatte, ging ich nach Brasilien. Was war natïrlicher, als der lebhafte Wunsch, aus der Reihe der Protobasidiomyceten, deren Formenanzahl vorläufig beschränkt war, die auch nach Brefelds Vermuthumgen sicherlich noch viele aussereuropäische Vertreter haben mussten, neue ergänzende Funde zu machen. Durch das damalige fast vollständige Fehlen der ansländischen Protobasidiomyceten in den europäischen Sammlungen konnte meine Hoffunı 1 so weniger entmuthigt werden, als diese Pilze sich meist schlecht dazu eignen, getrocknet, zwischen Papier gepresst, den Herbarien einverleibt zu werden, und als sie um dieser Eigenschaften willen von den meisten Sammlern rernachlässigt wordelı waren. Dazu kommt, dass die anatomische Struktur, insbesondere der Bau des Hymeniums, in vielen Fällen sicher nur erkannt werden kann, wem frisches Material zur Untersuchung vorliegt, während eine grïndliche Beurtheihung des Hülfsmittels der küustlichen Kultur in Nährlösungen gar nicht entrathen kamm. Derartige Versuche waren in den 'Tropen bis dahin überhaupt noch nicht gemacht. Hier also musste ich hoffen, etwas leisten zu kömmen. Meine Erwartungen wuden durch die Wirklichkeit weit iibertroffen. Es zeigte sich, dass der sïdbrasilische Wald ganz ansserordentlich 
reich ist an Vertretem dieser Familie, und unter ilmen fand ich neue Typen, welche die Vorstellungen voul diesem Formenkreise in wesentlichen Punkten bereicherten, andere, welche durch die Resultate der künstlichen Kultur systematisch wichtige Schlïsse gestatteten, Formen, welche dem entsprachen, was ich bei meiner Abreise mir als Ziel der Arbeit erträumt hatte, und deren Auffindung ich die grösste Freude, die schönsten Tage meines brasilischen Aufenthaltes danke.

Zu derselben Zeit, als ich diesen Pilzen in Blumenau meine Aufmerksamkeit zuwendete, hat Herr von Lagerheim in Ecuador ebenfalls Protobasidiomyceten gesammelt und z. Th. auch an Ort und Stelle untersucht. Sie wurden nach Frankieich gesendet und unter Zuhïlfenahme der Lagerheimschen Aufzeichumgen von Herm Patouillard in verschiedenen Aufsätzen, hauptsäclllich in den "Champignons de l'Équateur" (Bull. de la soc. Mycol. de France“ 1891-93) veröffentliclıt. Unter den a. a. O. anfgefiilırten neuen Pilzen befinden sich manche, welche den vor mir untersuchten z. Th. sehr nahe stehen. Insbesondere ist es gewiss ein merkwïrdiges Zusammentreffen, dass die bis dahin ganz unbekamnte, so eigenartige und interessante Gattung Sirobasidium Pat. von mir im März 1892 gefunden und untersucht und im December desselben Jahres von Patouillard im Journal de botaniqque aus Ecuador veröffentlicht wurde. Ich war nicht wenig erstauut, eine nahe Verwandte meiner fïr ganz neu von mir gehaltenen brasilischen Form bereits abgebildet zu finden, als ich im Jahre 1894 die französische mykologische Literatur der letzten Jahre zu durchmustern Gelegenheit fand. Der wesentlichste Unterschied meiner Untersuchungen und Mittheilungen gegenuiber denen der Herren Patouillard und Lagerheim liegt darin, dass ich uiberall, wo es irgend mögliclı war, die Untersuchung im Wege der kïıstlichen Kultur naclı Brefelds Methode fiihrte. Ich werde weitere Beweise dafül beibringen, dass Brefeld nicht nur für die Tremellineen im engeren, sondern für den grössten Theil der ganzen Klasse 
der Protobasidiomyceten Recht hatte, wemm er zum Schrecken vieler Systematiker sich dahin äusserte, dass bei der Beurtheilung, ja bei der Benennung dieser Pilze allein die Cultur der Sporen und die Entwickelungsgeschichte entscheiden miisse. (Brefeld VII Seite 129.)

Die hier mitgetheilten Thatsachen sind ohne Ansnahme in meinem Laboratorium in Blumenan in Brasilien festgestellt worden. Die Photographien sind nach dem frischen Material an Ort und Stelle aufgenommen, alle Zeichnungen in Blumenan ansgefiihrt und die Notizen über alle Funde und Einzelheiten der Untersuchungen sind stets sofort aufgezeichnet worden.

Die von mir benutzten zwei Mikroskope stammen aus der Fabrik von W.\& H. Seibert in Wetzlar. Ich erfülle manfgefordert gern an dieser Stelle eine Pflicht der Dankbarkeit, wem ich besonders hervorhebe, wie diese Instrumente bei fast täglichem Gebranche in dem tropischen Klima sich drei Jahre hindurch in jeder Beziehung ausgezeichnet bewährt haben. Insbesondere ist mir ein von den Herren Seibert für die Zwecke der Beobachtung wachsender Pilzmycelien im offenen Tropfen eigens construirtes Objektiv (V) mit anssergewöhnlich weitem Focal-Abstande bei der täglichen Durchmusterung meiner Objektträgerkulturen von grösstem Nutzen gewesen.

Auf die möglichst sorgsame. naturgetrene Ansführung der Zeichnungen ist viel Muihe verwendet worden. Dass diese Mühle aber nicht vergebens war. sondern für die Herstellung der lithographischen T'afehn bis in alle Eimzelheiten ausgenutzt worde, ist das Verdienst der lithographischen Anstalt des Herrn Giltsch in Jena, dem ich hier für die liebenswürdige Sorgfalt danke, welche er den Tafeln angedeihen liess.

Es lag mir daran, alles, was ich über die Protobasidiomyceten hatte feststellen können, in zusammenhängender Darstellung vorzntragen, und dies war nicht möglich ohne eine genanere Berücksichtigmmg der einschlägigen Literatur und ohne eine dadurch be- 
dingte einheitliche Nenbearbeitung des gesammten Stoffes. Diese Arbeit ist in Berlin im Winter 189495 ansgefülurt worden unter Benutzung der Literatur im Königlichen botanischen Museum. Wie in Vorwort des vorigen Heftes, so habe ich auch hier wieder Herrn Geheimrath Professor Engler meinen Dank zu sagen für die mir jeder Zeit gewährte Erlaubuis zur Benutzung der Hülfsmittel des Instituts; auch den Herren P. Hennings und Dr. Lindau bin ich nach wie vor zu aufrichtigem Danke verbunden fiur das liebenswïrdige Interesse, welches sie meiner Arbeit zuwandten, und für ihre stets bereitwillig gewälırte Hülfe und Unterstïtzung. Herr Dr. Lindan hat die Miihe nicht geschent, mir wiederum bei den Correkturen freundlichst zu helfen.

Den allerherzlichsten Dank aber gerade bei Gelegenheit dieser Arbeit anszusprechen ist mir Pflicht gegeniiber meinem hochverehrten Lehrer Herrn Professor Brefeld. Ist doch diese ganze Arbeit nur möglich gewesen auf dem sicheren Grunde der Anschanungen, wie sie von ihm vornehmlich in seinem VII. und VIII. Bande der Untersuchungen aus dem Gesammtgebiete der Mykologie niedergelegt worden sind. Zeigen zu kömnen, wie beliebige, bis dalin nie beobaclitete, vom Boden des brasilischen Urwaldes aufgelesene Pilzformen, eine nach der anderen und olme Ausnahme als unwidersprechliche Zeugen auftraten für die Richtigkeit jener Ansclranungen, bestätigend bis in die winzigsten Einzelheiten, ergäuzend nach oftmals vorhergeseheneu und schon angedeuteten Riclıtungen hin, niemals, auch nicht bei unparteiischster Prüfung, widersprechend, das ist mir die grösste und nachlıaltigste Freude gewesen.

Idstein, Juli 1895. 



\section{Inhaltsübersicht.}

Einleitung Seite

Eintheilung der Protobasidiomyceten . . . . . . . 9

I. Auriculariaceen . . . . . . . . . . . . 12

1. Stypinelleen . . . . . . . . . . . . . . . . . 12

a) Stypinella . . . . . . . . . . . . . . . 12

b) Saccoblastia . . . . . . . . . . . . 16

2. Platygloeen......... . . . . . . . 22

a) Jola . . . . . . . . . . . . . . 22

b) Platygloea . . . . . . . . . . . . . . . . . . . . 29

3. Auricularieen . . . . . . . . . . . . . . . . 36

Auricularia . . . . . . . . . . . . 36

II. Uredinaceen . . . . . . . . . . . . . . . . . . . . 46

III. Pilacraceen . . . . . . . . . . . . . 48

a) Pilacrella . . . . . . . . . . . . . . . . 48

b) Pilacre . . . . . . . . . . . . . . . . 61

IV. Sirobasidiaceen . . . . . . . . . . . . . . . 65

Sirobasidinm . . . . . . . . . . . . 65

V. Tremellaceen . . . . . . . . . . . . . 75

1. Stypelleen . . . . . . . . . . . . . 75

Stypella . . . . . . . . . . . . 75

2. Exidiopsideen . . . . . . . . . . . . . 79

a) Heterochaete . . . . . . . . . . . . 79

b) Exidiopsis . . . . . . . . . . . . . . . . 82

c) Sebaciua . . . . . . . . . . . . . . . . . . 94

3. Tremelliueen . . . . . . . . . . . . . . . . . 949

a) Exidia . . . . . . . . . . . . . . . . 94

b) Ulocolla. . . . . . . . . . . . . . . . 98

c) Craterocolla . . . . . . . . . . . . . . . . 99

d) Tremella . . . . . . . . . . . . . . . 99

e) Gyrocephalns . . . . . . . . . . . . . . 128 
Seite.

4. Protopolyporeen. . . . . . . . . . . . . . . 129

Protomerulius . . . . . . . . . . . . . 129

5. Protohydneen . . . . . . . . . . . . . . . . . 131

a) Protohyduum . . . . . . . . . . . . . . . . 131

b) Tremellodon . . . . . . . . . . . . . . . . . . 133

VI. Hyaloriaceen . . . . . . . . . . . . . . . . . . . . . . 137

Hyaloria . . . . . . . . . . . . . . . 137

Uebersicht der Ergebnisse . . . . . . . . . . 141

Zusammenstellung der durch die vorliegende Arbeit veränderten

und der Beschreibungen neuer Gattungen und Arten. . . . . 161

Erklärung der Abbildungen . . . . . . . . . 175 


\section{Einleitung:}

Die Klasse der Protobasidiomyceten klar und scharf abgegrenzt, in ihrem morphologischen Werthe deutlich erkannt und dementsprechend benamnt zu haben, ist das grosse Terdienst Brefelds. Im Jahre 1887 im VII. Bande seiner „Untersuchumgen aus dem Gesammtgebiete der Mykologie" gab er die Mittheilungen über umfangreiche Untersuchungen einer grossen Anzahl hierher gehöriger Pilze und begründete auf die neuen dort sicher festgestellten Thatsachen hin die an derselben Stelle zum ersten Male als Protobasidiomyceten ron ihm bezeichnete Klasse. Es gehören hierher alle Basidiomyceten mit getheilten Basidien. Bei weitem die Mehrzahl der bis dahin bekannten derartigen Formen besitzt Fruchtkörper von schleimig gallertiger Beschaffenheit und meist äusserst unregelmässige und unbestimmte Gestalt. Die äussere Gestalt der Fruchtkörper ist es nun gewesen, die ron den älteren Mykologen bei der Beurtheilung der Terwandtschaftsverhältnisse für die höheren Pilze zu Grunde gelegt wurde und so lange massgebend sein musste, als die optischen Hülfsmittel und die technische Gewandtheit den Beobachtern einen zweifelfreien Einblick in den anatomischen Bau dieser Pilze und besonders ihres Hymeniums nicht gestattete. So ist es gekommen, dass die als natürliche Klasse nun sicher erkannten Protubasidiomyceten thatsächlich 
ungefähr zusammenfallen mit frïheren systematischen Einheiten, welche ohne geniigende Kenntnisse der wichtigsten Eigenschaften ihrer Glieder aufgestellt worden waren. Sie decken sich im wesentlichen mit dem, was Tulasne nnter dem Titel: Fungi Tremellini et leurs alliés im Jahne 1872 in den Annales des sciences nat. behandelt hat. Aber sie decken sich diunit anch nur zum Theile. Gar mancher Pilz fand sich unter den Tremellinen im alten Simne, der bei g'enanerer Untersuchung als gar nicht dorthin gehörig sich erwies. Namentlich waren es die Dacryomyceten, welche man eben wegen ihrer der der 'Tremellinen oftmals ähnelnden Fruchtk̈̈rperbeschaffenheit mit ihnen zusammenfassen zu müssen meinte, obwohl sie mngetheilte Basidien besitzen und dadurch unzweifelhaft bekunden, dass sie in einem nahen blutsverwandtschaftlichen Verhältnisse za den Tremellinen nicht stehen. Dass anch Ptychogaster, jene zu Oligoporns ustilaginoides gehörige, von Brefeld (VIIL S. 126) genan mutersuchte Chlamydosporenform irrthümlicherweise bei den ,alliés" der 'T'remellinen gestanden hat, sei nur erwähnt.

Indessen war Tulasne, zumal im Jahre 1872, als seine letate mit dem angeführten Titel bezeichnete Verölfentlichnng über diesen Gegenstand erschien, bereits weit ïber jenen standpunkt der Beurtheilung hinausgegangen, welcher sich an der Berïcksichtigung der äusseren Fruchtkörperformen genügen liess. Er hatte die Hymenien einer grossen Anzahl seiner 'Tremellinen genauer untersucht und seine Befunde in vielen Abbildungen dargestellt. Er unterschied anch richtig drei 'Typen der Basidienbildung. nämlich den der hentigen Aurienlariaceen mit langen, fadenförmigen, horizontal getheilten Basidien, welchen er z. B. für Pilacre und für seinen Hypochnus purpureus (gleich Helicobasidum Pat.) feststellte, den zweiten mit kugligen über Krenz senkrecht getheilten, für die heutigen Tremellaceen charakteristisel, endlich den der Dacryomyceten mit gahelig gestalteten zweisporigen ungetheilten Basidien. Die scharfe mol für die Morphologie der Basidiomyteten so 
wichtige Scheidmng aber, der ungetheilten und der getheilten Basidie. vollzog er nicht. Diese in ihrer wahren Bedeutung herrorzuheben blieb Brefeld rorbehalten.

Unabhängig vou Brefeld hat, und zwar in demselben Jahre 1887, auch Patouillard in seinem Buche ,les Hymémonycètes d'Europe" die 'Tremnng der Basidiomyceten mit getheilten und der mit morheilten Basidien als erstes Eintheilungsprinzip aller Basidiomyceten aufgestellt. Er nennt die ersteren Heterobasidiés und die anderen Homobasidiés, und diese Namen finden sich in der französischen Literatur anstatt der von Brefeld gewählten, Proto- und Autobasidionyceten häufig verwendet. Es ist möglich, dass eine literar-historische Untersuchung eine Priorität der Patouillardschen Bezeichnungen vor den Brefeldschen wïrde feststellen können. Dennoch bleiben jene fiir nus unannehmbar, weil ihr Begriinder selbst durcl seine weiteren Mittheilungen, durch die Art, wie er bekannte und später nen aufgefundene Formen seinen beiden Klassen einreiht, mzweifelhaft zeigt, dass das, was er mnter Heterobasidiés verstanden wissen will, den Werth einer natïrlichen Klasse oder Ordnung nicht hat. Dies zu begründen wird im weiteren Terlanfe dieser Mittheilungen noch öfters Gelegenheit sich finden. Hier sei num soviel hervorgeholuen, als nötig ist, un den Terfasser zu rechtfertigen dafür, dass er an der Bezeichnung Protobasidiomyceten als an ler einzig zutreffenden festhalten zu sollen ineint.

Das grosse Terdienst Brefelds um die Systematik der höheren Pilze, welches er sich in den VII. mul VIII. Bande seiner Untersuchungen erwarb, bestand nul zo einem Theile in der grundsätzlichen Scheidung der Formen nit getheilten mud der mit ungetheilten Basidien. Ton riel tieferer Bedentung war es, dass in jenem ITerke der bis dahin ganz unbestimmte Begriff der Basidie selbst morphologisch festgestellt wurde. „So alt die Namen Ascomyceten nud Basidiomyceten sind, so ,allbekannt und geläufig die "Ascen" nu! die "Basidien" in den 
„Schlauchfriichten und in den Schwämmen ihrer Erscheinung nach „jedem Botaniker geworden sind, so neuen Datums ist gleichwohl "die wirkliche Erkemntniss des morphologischen Werthes beider "Fruchtformen und im Znsammenhange hiermit die richtige Be"urtheilung des Charakters beider Pilzklassen." (Brefeld IX, Seite 1.)

Brefeld erst hat nachgeriesen, richtig erkannt und gelehrt, dass die Basidie aufzufassen sei als der zu bestimmter Form und Sporenanzahl fortgeschrittene Conidien-T'Täger, so wie der Ascus das zu bestimmter Form und Sporenanzahl vorgeschrittene Sporangium. Erst mit dieser Erkenntniss war eine Scheidung der niederen ron den höheren Pilzen gegeben, der Hyphomyceten und Mesomyceten von den Mycomyceten, in dieser Erkenntniss lag der Schlüssel zum Terständniss der verwandtschaftlichen Beziehnngen im ganzen Reiche der Fadenpilze. Dies näher zu begriinden, ist hier nicht der Ort. Brefeld hat es in eingehender Weise im VII.-X. Bde. seines Werkes gethan. In kïrzer'er Zusammenfassung ist eine Darstellung dieser V'erhältnisse ron r. Tavel in seiner Morphologie der Pilze (Jena, Gustar Fischer, 1892) gegeben worden. Trotzdem aber ist das Verständniss für die überall durch sichere und muzweidentige Thatsachen belegten Auffassungen nur erst einem seln kleinen Theile der Mykologen aufgegangen. Patouillard, der Begründer der Heterobasidiés, zeigt uns durch viele seiner Beschreibungen nener Pilze, dass er die wahre Bedentung der Basidie nicht erkamnt hat. Er fühırt z. B. unter seinen Heterobasidiés eine neue Gattung Helicobasidion zunächst mit der Art H. purpureum ein (vergl. Bull. soc. bot. de France 1885 S. 171; ebenda 1886 S. 335. Ferner: Tabulace analyticate fungormu No.461 und Hyménomycètes d'Europe 1887.) Auf den Zeichnungen in den Hyménom. d'Europe - sehen wir einen bischofstabartig eingekrïmmten Faden, der sich in eine unbestimnte Anzahl ron Abtheilungen durch Querscheidewände theilt; sodann kommen seitlich ans einer oder zwei der Theilzellen sterigmenartige Fortsätze herror. Dass eine solche 
Bildung, wie sie der Autor hier darstellt, als Basidie nicht anzusprechen ist*), kann keinem Zweifel unterliegen. Es fehlt jede Bestimmtheit der Form und Sporenzahl. Durch die Abbildungen in den Tabulae analyticae wird die Unklarheit nur noch grösser. Dort kommen sogar aus einer Theilzelle zwei Sterigmata. Noch schlimmer steht es mit dem aus Venezuela beschriebenen Helicobasidium cirrhatum, wo nur eine Endzelle eines gekriummten Fadens ein Sterigma mit einer Spore hervorbringt (Champ. de Venezuela in Bull. soc. myc. de France Bd. 4 Seite $7 \mathrm{ff}$.). - Die in derselben Abhandlung net aufgestellte Gattung Delortia, welche auch ich in Brasilien mehrfach gesehen habe, bildet am Ende dümner Fäden dicke mehr oder weniger gekrümmte oder eingerollte Fadenenden, welche durch Querwände in eine unbestimmte Anzahl von Theilzellen zerfallen. Nie wurde ein Sterigma oder eine Spore gesehen, und trotzdem mit dieser vorlänfig höchstens zu den Fungi imperfecti zu stellenden Form eine nene Gattung der Heterobasidiés begründet. Ans diesen Andentungen schon geht klar hervor, dass Patouillard den Begriff seiner Heterobasidiés nicht scharf gefasst hat, dass seine Heterobasidiés sich mit den scharf mmgrenzten Protobasidiomyceten Brefelds nicht decken, seine Bezeichnungen also für unseren Standpunkt der Beurtheilung nicht verwerthbar sind. Dies folgt ferner mit Nothwendigkeit daraus, dass Patouillard die Dacryomyceten mit unter seine Heterobasidiés einbegreift. Die Dacryomyceten aber haben nach den zahlreichen Untersuchungen 'Tulasnes und Brefelds mngetheilte Basidien. Jene Querscheidewände in unteren Theile des Sterigma, welche der französische Mykologe in seinen Hyménomycètes d'Europe abbildet,

*) In Wirklichkeit ist dieses Helicobasidinm, wie Costantin auch angiebt (Journal de botanique II S. $229 \mathrm{ff}$.), nichts als der von Tulasne beschriebene und wahrscheinlich nicht ganz correkt abgebildete Hypochnus purpureus (Ann. d. se. nat. bot. $1872 \mathrm{Pl}$. X), der allerdings mit grosser Wahrscheinlichkeit den Anriculariaceen zugerechnet werden kann. Was indess Patouillard über diesen Pilz mittheilt, rechtfertigt seine Einordnung nuter die Protobasidiomyceten nicht. 
kommen nirgends in Wirklichkeit vor. Die zahlreichen nenen Dacryomycetenformen, welche ich in Brasilien entdeckte. nntersuchte und kultivirte, und ïber die ich im nächsten Hefte dieser Mittheilungen zu berichten hoffe, verlielten sich in dieser Beziehmng durchaus iibereinstimmend mit den von Tnlasne und Brefeld untersuchten. Wenn also die Dacryomyceten zil den Heterobasidiés Patouillards gehören, so fallen sie doch gaanz sicher nicht unter die Protobasidiomyceten Brefelds, mit denen allein wir hier zn thun haben. Es kamn nicht dentlich genug betont werden, dass die Dacryomyceten Antobasidiomyceten sind, welche wahrscheinlich mit den Clavarieen nähere verwaultschaftliche Beziehungen haben, und dass ans ihrem bisweilen dem der Tremellinen älnlichen Habitus gar nichts für ilıre Zugehörigkeit zu diesen letzteren zu folgern ist. Es ist anfs höchste wunderbar, dass der verstorbene Schröter, ein so grïndlicher Kenner und scharfsinniger Beurtheiler der Pilzformen. er, der die Trennmng der Amicnlarieen, Tremellinen und Dacryonyceten in seinen Pilzen Schlesiens als einer der ersten bewusst vollzog, in der Bearbeitung der Pilze für Engler und Prantls natïrliche Pflanzenfamilien ein Schema der Verwandtschaftsrerhältnisse der einzelnen Formenkreise aufstellte, welches die Dacryonyceten mit den Tremellinen unter dem neuen, aber nicht glücklich gewählten Namen Schizobasidieen zusammenfasste. Einer solchen Gruppirung ist anf das entschiedenste entgegenzutreten. Die ron Schröter neueingeführten Namen Schizobasidien and Phragmobasidien werden im Folgenden nicht angewendet werden. Sie betonen einen Unterschied der getheilten Basidien mit wagerechten Wänden einerseits, mit senkrechten andererseits, welcher, wie ich zeigen werde. in Wirklichkeit nicht in dieser Schärfe besteht, vielmehr durch Zwischenglieder, welche besonders in der neuen (rruppe der Sirobasidiaceen gegeben sind, fast vollständig ansgeglichen wird.

Toch sei es gestattet, elie ich zul Mittheilung der T'ntersuchumgen selbst ïbergehe, iiber die Bedentung, welche ich im 
Folgenden mit den Ansdrücken spore und conidie rerbinde, eine kurze Anmerkmng zu machen. Diese beiden Ausdrïcke werden in der neueren mykologischen Literatur ohne scharfen Tnterschied für dieselben Bildungen abwechsend augewendet. Fast stillschweigend ist man dagegen ïbereingekommen, die in den Ascen und auf den Basidien entstehenden Bildungen ausschliesslich als Sporen, nie als Conidien zu bezeichnen, während man andere an beliebigen Conidienträgern abgegliederte Zellen ebensowohl Conidien wie auch sporen nemnt. Nachdem wir num klar erkannt haben, welches der Unterschied zwischen dem Conidienträger und der Basidie ist, genau wissen, dass die Basidie und damit die ganze Klasse der Basidiomyceten eben da anfängt, wo der nach Form und Conidienzahl unbestimmte Conidienträger zur Bestimmtheit der Form und Sporenzahl übergeht, erscheint es mir zunächst für die Basidionyceten zweckmässig, unter Sporen schlechthin hier nur Basidiensporen zu verstehen, und alle anderen der Fortpflanzung und Terbreitung der Art dienenden Conidienformen nur als Conidien und nie als Sporen zu bezeichnen. Eine Ausnahme bilden die Sekundärsporen, auf die ich im Laufe der Arbeit noch näher zu sprechen komme. Sie sind wesensgleich mit den Basidiensporen. Die Ausdrücke Promycelium und Sporidien sind nach dem jetzigen Standpunkte unserer Kenntnisse ganz überflüssig gewrorden. Das Promycelium mit den Sproridien bei den Uredinaceen ist eine echte Basidie, die Sporidıen sind hier Sporen. Die mit dem gleichen Namen bei Ustilagineen bezeichnete Bildung ist ein Conidienträger, die Sporidien sind hier Conidien.

Ich kann bei dieser Gelegenheit die Bemerkung nicht unterdrücken, dass es mir höchst zweckmässig und im Interesse einer kurzen, Missverständnisse ausschliessenden Ausdrucksweise zu sein scheint, wemn man allgemein für alle Mycomyceten unter "Sporen“ nur die in Ascen oder auf Basidien gebildeten Sporen versteht. Nimmt man dann noch die Ausdrücke Chlamydosporen mn Oidien in dem von Brefeld festgestellten simne (Brefeld VII, S, $211 \mathrm{ff}$.) 
und Conidien hinzu, so kaun man alle weiteren Bezeichnungen für der Fortpflanzung und Verbreitung dienende Zellen, insbesondere die nur Verwirrung stiftenden Namen "Spermatien“, "Stylosporen“, "Sporidien" entbehren, und die im Laufe langer Jahre durch die Arbeit der Mykologen allmählich gewonnene und von Brefeld aufs einlenclitendste dargelegte klare Auffassung aller verschiedenen Fruchtformen kommt alsdann anch in der Terminologie zum einfaclıen Ausdruck. Wo es notluwendig ist, kann man die verschiedenen Formen der Conidien als Sprossconidien, Macro- und Microconidien n. s. w. näher bezeichnen. 


\section{Eintheilung der Protobasidiomyceten.}

Wir theilen die Protobasidiomyceten in sechs Familien, über deren vergleichsweisen Terth und verwandtschaftliche Beziehungen zu einander wir am Schlusse der Arbeit sicherer urtheilen werden.

\section{Auriculariaceen.}

Sie besitzen wagerecht getheilte viersporige Basidien und beginnen mit Formen, welche diese Basidien frei am Mycel, in umregelmässiger Anordnung tragen. Die Steigerung der Formen zu solchen mit Fruchtkörpern rollzieht sich mit Bezug auf die Hauptfruchtform, die Basidie, und führt zu g y m n o ka r pe n Fruchtkörperu ron hoher polyporeenartiger Ausbildung.

Die Auriculariaceen zerfallen in drei Gruppen:

1. Stypinelleen.

2. Platygloeen.

3. Auricularieen.

\section{Uredinaceen.}

Sie besitzen dieselben Basidien, wie die vorhergehende Familie, aber die Basidien treten stets frei und nicht in Fruchtkörpern 
anf mul brechen immer ans chlamydosporen (Telentosporen) hervor. Die Steigerung der Formen zu solchen mit Frnchtkörpern vollzieht sich mit Bezug auf die Chlamydosporen mud die kleinen, früher als Spermatien bezeichneten Conidien. Parasitische Lebensweise hat allen Angehörigen dieser Familie einen besonderen Charakter verliehen. Ueber die Eintheilung der Familie, welche in Folgenden nicht eingehender behandelt wird, vergleiche n. a. v. Tavel Tergleichende Morphologie d. Pilze S. $123 \mathrm{ff}$.

\section{Pilacraceen.}

Sie besitzen dieselben Basidien wie die rorangegangenen Familien. Die Steigerung der Formeu vollzieht sich mit Bezug auf die Hanptfruchtform. die Basidie, und fülnt zoll a ng i o k a r per Fruchtkörperbildung:

\section{Sirobasidiaceen.}

Sie besitzen Basidien, welche, wenigstens in manchen Fällen, eine Zwischenstufe zwischen denen der vorangehenden und denen der folgenden Familien einnelımen, im Ganzen aber den letzteren näher stehen. Die Basidien werten in langen Ketten hinter einander von demselben Mycelfaden gebildet. Die nur erst wenigen bekannten Formen lassen eine Fruchtkörperbildung kaum in den ersten Anfängen erkennen.

\section{Tremellaceen.}

Sie besitzen lotrecht getheilte, rmndliche, oder ei- oder kenlenförmige Basidien mit vier Theilzellen und vier sporen. Cienan entsprechend den Auriculariaceen begimnen sie mit fruchthörperlosen Formen, mit freien Basidien. Die Steigermng vollzieht sich mit Bezug auf die Hanptfichtform (danehen in seltenen Fällen. wie bei (raterocolla, mit Bezng anf eine der Nebenfiuchtformen) 
und führt zu gymukarpen Fruchtkörperu von hoher Ausbildung. Hierher gehören die höchst entwickelten l'rotobasidionnceten. Die Tremellaceen zerfallen in fünf Gruppen, nämlich:

1. Stypelleen.

2. Exidiopsideen.

3. Tremellineen,

4. Protopolyporeen,

5. Protohydneen.

\section{Hyaloriaceen.}

Sie besitzen Basidien von derselben Form, wie die vorlergehende Familie. Die einzige bisher aufgefundene Form dieser Familie zeigt in genaner Parallele mit den Pilacraceen die Anfä̈nge angiokarper Fruchtkörperbildung. 
I.

\section{Auriculariaceen.}

\section{Stypinelleen.}

\section{a. Stypinella Schuröter.}

Die von Schröter (Pilze Schlesiens S. 383) aufgestellte Gattung enthält die am einfachsten gebauten, niedersten aller bis dahin bekannten Auriculariaceen. Sie zeigt einen unregelmässig verwirrten Hyphenfilz, an dessen Fäden die Basidien einzeln ohne bestimmte Anordnung auftretell. Hierher gehört ein Pilz: Stypinella orthobasidion nor. spece, den ich im März 1893 an vermodernden Rindenstiickchen am Boden des Waldes entdeckte (unweit von Bhmenau am (aetébache, Aufstieg zum Spitzkopf). Er bildet auf der dunklen Rinde kleine, weisse. unregelnässig rundlich umschriebene, lockere Flöckchen von 1 bis $3 \mathrm{~mm}$ Durchmesser und kaum $1 \mathrm{~mm}$ Ḧ̈he. Die Flöckchen stehen in grosser Zahl bei einander, berïhren sich lä̈ufig und verschmelzen dann mit einander. Sie werden gebildet von dickwandigen, ungefähr $6 \mu$ starken Hyphen, welche locker verflochten, am Grunde unregelmässig rerwirrt sind, nach dem Rande und nach oben hin sich reich verzweigen und zu verschiedener Höhe ausstrahlen, ohne ein glattes Lager hervorzubringen. Die dem Substrat nächsten Fäden 
sind schwach gelblich gefärbt, die übrigen rein weiss. Der Verlauf der Fäden ist stark wellig verbogen, oftmals geknickt. Zahlreiche Scheidewände sind vorhanden, und an jeder derselben bemerkt man eine grosse leicht kemntliche Schnallenzelle (Traf. IV Fig. 1). Die Verzweigungen der Fäden gehen fast regelmässig von den Schnallen aus. Die äussersten Enden des Fadengewirres, aber keineswegs alle, werden zu Basidien, deren Höhe über dem Substrat in weiten Grenzen schwankt. Manche Basidien ragen ihrer ganzen Länge nach frei aus dem Fadengeflecht heraus, andere wieder haben ihre Ansatzstelle so tief, dass kaum die oberste Spore über die benachbarten Fäden heraussieht. Die Basidien sind ganz gerade, fast regelmässig $30 \mu$ lang, und gegen den Faden durch selır viel zartere Membran unterschieden. Sie theilen sich durch wagerechte Wände in je 4 Zellen. Die pfriemenförmigen, 2,5 « langen Sterigmen sprossen immer dicht unter der Scheidewand aus und tragen länglich ovale Sporen von 7 « Länge und 4-5 $\mu$ Breite. Die Sporen nehmen den ganzen Inlıalt der Basidie in sich auf, und wemn sie abgeworfen sind, so schnmpft die leere Basidie zusammen und ist wegen der Zartheit ihrer Wände nur schwer noch zu erkennen (vergl. die Fig 1). Diejenige Fadenzelle, welche die Basidie trägt, zeigt eine Neigung zu bestimmterer Form, als sie den übrigen Zellen zukommt. Sie ist kürzer als die übrigen und ein wenig mehr geschwollen. In ihr sammelt sich, ehe die Basidie austritt, das Protoplasma auch aus den zunächst rückwärts liegenden Fadentlıeilen, welches beim Austreiben der Basidie verzehrt wird. Dicht unter der tragenden Zelle, und zwar auf der Scheidewand derselben gegen die nächstfolgende Zelle, tritt gewöhnlich ein Seitenzweig auf, welcher die entleerte Basidie übergipfelt und nun selbst wieder eine Basidie hervorbringt. In dieser Weise setzt der kleine Rasen sein centrifugales Wachsthum fort, der Protoplasmainhalt der hinteren und unteren Fäden wandert in die fortwachsenden Spitzen. Basidien in allen Bildungszuständen sieht man stets neben einander. 
Zwischen den Fäden des Pilzes fanden sich oftmals abgefallene Sporen, welche eine Sekundärspore getrieben latten (vergl. die Fig. 1). Sobald ich aber Sporen in Wasser oder Nährlösung auffing, so zog sich ihr Inhalt auf $2 / 3$ des Raumes zusammen, und in diesem Zustande verblieben sie, so lange ich sie beobachten konnte, ohne dass je eine Keimung eingetreten wäre.

Es ist ausser Zweifel, dass die eben beschriebene Form der Schröterschen Stypinella purpurea selı nahe steht. Bei letzterer sind die Basidien bogenförmig zurïckgekriummt, und das ganze Lager des Pilzes hat braune bis blutrotle Färbung. Die Stypinella purpurea ist nach Schröter gleichbedentend mit dem schon friiher (s. S. 5) erwähnten, von Tulasne (Ann. sc. nat. T. Série Tome XT Tafel 10) abgebildeten Hypochnus purpureus. Es ist wohl ziemlich sicher, dass anch diese Stypinella purpurea regelmässig viertheilige Basidien besitzt, wie unsere St. orthobasidion, obwohl das aus den 'T'ulasneschen Figuren nieht ganz zweifellos hervorgeht. Wir müssen aber berücksichtigen, dass bei vielen Auriculariaceen die Bildung der Sporen an der Basidie nicht auf eimmal. sondern nach und nach geschieht, dass die entleerten Basidienzellen undentlich werden, dass die scheidewände innerhalb der Basidie auch oftmals sehr dümn sind, und dass 'T'ulasne, dem die bestimmte Form der Basidie nicht als ihr wichtigster Charakter bekamnt war, keine Veranlassung hatte, genan zu prüfen, ob an jeder Basidie regehmässig vier 'Theilzellen aufträten. Es belarf' nur geringer' Ergänzungen, insbesondere der Einfügung einiger 'Theilungswände. un ans der 'Tulasneschen Zeichnung das vermuthlich richtige Bild der stypinella purpurea zu gewimnen.

Sein feines Formgefïhl bekundete aber 'Tulasne anch durch die Bemerkung, welche er über den damals noch nicht abgebildeten Hypochnns purpureus in einer früheren Abhandhung aus dem Jahre 1865 (Amm. se. nat. bot. V. Sér. 'T'ome IV) gemacht hat, wo e's heisst: „On sera certainement frappé comme nous, de la ressemblance singulière qu'olirent les crosses fertiles de l'Hypochnus 
purpureus avec le promycelium des Puccinies et autres Lrédinées" und weiter: "La similitıde n'est même pas moindre pour les corps reproducteurs, spores ou sporidies, et nous trourons certainement li un exemple des analogies qui peurent relier deux membres, d'ailleurs très dissemblables, d'une famille régétale." Diese in del That für Tulasnes Scharfblick höchst charakteristische Aensserung ist wohl geeignet, uns die letzten Zweifel an der Zugehörigkeit jenes „Hypochnus purpureus“ zu den Auriculariaceen zu nehmen. Schröter hat num mit vollem Rechte den nenen Gattungsnamen Stypinella eingesetzt. da Hypochnus zu den Autobasidionyceten gehört, aber den T'ulasneschen Artnamen beibehalten.

Nun ist, wie ebenfalls schon angedentet wurde, wahrscheinlich derselbe Pilz von Patouillard zuerst im Jahıe 1885 im Bulletin de la Soc. bot. de France unter dem Namen Helicobasidium purpureun beschrieben worden; Schröter hat, und meines Erachtens wiederum mit rollem Rechte, hiervon keine Notiz genommen. Wie ich schon oben andeutete, enthält die lange Beschreibung Patouillards nichts von dem, was uns den ron ihm untersuchten Pilz als einen Basidiomyceten oder gar als Protobasidionyceten kemnzeichnet. Die Basidien sind ganz unregehmässig gebildet, die Anzahl der Scheidewände durchaus sch wankend, ebensowohl die der Sterigmen. Die lange Ergänzung zu seiner Beschreibung, welche der Autor im Jahre 1886 (Bull. Soc. bot. de France, 1886, p. 335) nachgetragen hat, klärt uns über die wichtigsten Punkte nicht besser auf. Hier wird auch eine Conidienfruktifikation des Pilzes beschrieben. Doch fehlt es an jedem Versuche eines Beweises, dass sie nicht einem fremden Pilze, sondern wirklich dem „Helicobasidiun" zugehört. Es ist wohl möglich, dass der Patouillardsche Pilz unsere Stypinella ist, und die oben bereits angefülurte Bemerkung Costantins (s. S. 5) scheint das zu bestätigen. Da aber Patouillard, der die Tulasneschen Abbildungen doch kemnen musste, nichts darüber erwähnt, und seine Worte und Zeichnungen keine Auriculariacee darstellen, so habe ich es für richtig gehalten, den Schröterschen 
Namen beizubehalten. Schröters Gattungsbeschreibung ist kiar und deutlich. Aus derselben muss nur die Bemerkung über die Kriimmung der Basidien wegfallen. Diese Krümmung clıarakterisiert die Stypinella purpurea im Gegensatze zu der nenen Art Stypinella orthobasidion.

Eine weitere Art seines Genus Helicobasidium hat Patonillard unter dem Namen H. cirrhatum in seinen Champ. de Vénézuela (Bull. soc. mycol. de France Bd. 4 S. 7) beschrieben. Auch hier giebt die Beschreibung und die Abbildung der scheinbar einsporigen sogenannten Basidie keinen Anhalt dafür, dass wir es mit einem Basidiomyceten zu thun haben, und man kann dies Helicobasidium cirrhatum vorläufig nur unter den „Fungi imperfecti" aufführen, jener Sammlung von Pilzen, über die zur Zeit unsere Kenntnisse so "imperfekt" sind, dass ihre Stellung in dem System atuch nicht annähernd zu bestimmen ist.

\section{h. Salccoblastia nor. gren.}

In die Familien der Stypinelleen gehören zwei weitere Formen, die ich mu einer Figenthiimmlichleit bei der Basidienbildung willen mit dem neuen Gattungsnamen Saccoblastia bezeichnet habe. Die erste der beiden: Saccoblastia orispora nor. spec. wurde am 3. September 1892 an der Rinde eimes stehenden abgestorbenen Stanmes gefunden. Sie bildete einen dünnen, fast durchsichtigen lockeren weissen Ueberzug. der in ganz unregelmässiger Umgremzung mehrere Centimeter in jeder Richtung sich ansdehnte. Bei sehr feuchtem Wetter sieht dieser Ueberzug fast schleimig aus, da das Gewirr der Fäden Wasser zwischen sich festhält, bei trocknerem Wetter dagegen bemerkt man nur einen lockeren Hyphenfilz, der bei rolständigem 'Trocknen zur Insichtbarkeit znsammenfüillt. Aus einem wirren, dem Substrat sich anselumiegenden Filze von Fäden, die reich rerzweigt sind, höchstens $6 \mu$ Dicke haben, viele Scheidewände, zahlreiche Fadenbrïcken, aber keine schnallen besitzen, erheben sich senkrecht mol ambähernd 
parallel, die etwas dünneren Hyphen, welche an ihren Enden die Basidien erzengen (Taf. IT Fig. 3a). Ans dem untersten Theile einer Fadenendzelle sprosst seitwärts eine Art birnenförmigen Sackes. Dieser Sack wendet sich nach unten mnd längt, wemn er seine rolle Grösse erreicht hat, wie eine Birne an dem senkrecht aufstrebenden Faden (Fig. 3a, b, c). Die Grösse ist nicht ganz bestimmt, im Durchschnitt 30 " in der Länge und $8 \mu$ in der grössten Breite. Dieser Sack füllt sich mit strotzendem Protoplasma. Während er sich bildet, wächst aus dem oberen Ende derselben Fadenzelle die künftige Basidie in Gestalt eines schlanken Fadens hervor (Fig. 3c, d). Diese Basidie erreicht aber ihre volle Länge immer erst. nachdem der Sack rollständig ausgebildet und mit Protoplasma erfiillt ist. Sie misst jetzt etwa $100 " \mu$ in der Länge. Nan kann mun deutlich rerfolgen, dass allmälılich der ganze Inlıalt des Sackes ron nnten anfangend (Fig. $3 \mathrm{c}$ ) in die sich verlängernde Basidie hineinwandert. Ebenso geschieht es mit dem Inhalt der den Sack und die Basidie tragenden Fadenzelle. Ist auch diese vollständig entleert, so wird sie ron der num ausgewachsenen Basidie durch eine Scheidewand abgetrennt (Fig. 3a, b) und dann erst geht die Tiertheilung in der Basidie ror sich. Pfriemförmige Sterigmen sprossen, und zwar gewöhnlich ungefähr aus der Mitte jeder Basidientheilzelle, und bringen an ihrer Spitze eine typische Auricularia-Spore ron eiförmiger Gestalt herror (Fig. 3 b). Sie tragen sie mit dem für Auricularia charakteristischen kurzen, der Spore anliegenden Syitzchen (vergl. lierzu Brefeld, Heft I'TI, Tafel IV, Fig. 3). Die Ausbildung der Sporen geschieht hier ziemlich regelmässig in der Reihenfolge von oben nach unten. Die langen fadenförmigen Basidien sind niemals ganz gerade, sondern unregelmässig hin und hergebogen. Da sie an der leeren 'Tragzelle kaum einen Halt haben und einzeln an den Fäden sitzen, so stehen sie nicht immer grade aufrecht, sondern lagern oft in unregelmässigem Gewirre auf dem Pilzrasen. Wie wir es bei Stypinella kennen lernten, so bildet sich 
anch hier unter der entleerten, die Basidie tragenden Fadenzelle ein aufstrebender Seitenzweig, der die erst gebildete Basidie dann ïbergipfelt und so fort (vergl. Fig. 3a). Die Reifung und Abschlenderung der Sporen geht sehr sclmell vor sich. Die entleerte Basidie sinkt zusammen und ist schwer sichtbar (Fig. 3 a links). Ansitzende Sporen haben $13 \mu$ Länge und 7-8 " Breite. Nach der Abschleuderung beginnt fast unmittelbar die Keimung mit einer Anschwellung: So findet man unter den zahlreichen in dem Fadengewirr verstrent liegenden losen Sporen viele, die bis zu $26 \mu$ Länge und $10 \mu$ Breite laben. Auch weitere Keimungserscheinungen lassen sich an diesen auf der natürlichen Unterlage nmher liegenden Sporen beobaclıten. Häufig findet sich Sekundärsporenbildung (Fig. 3e); oder' aber die Spore theilt sich durch meist eine, bisweilen zwei. noch seltener drei Querwände in mehrere Zellen. Alsdann kann jede der 'Theilzellen eine Sekundärspore erzeugen (Fig. 3e links). Andere Sporen wiederum erzengen anstatt der Sekundärsporen sehr kleine (2,5 „ D)urchmesser) runde Conidien. Diese Conidien sitzen auf' winzigen Ansstülpungen der Spore. Solche Ansstülpung kamm zn gleicher Zeit zwei c'onidien tragen und sie kamn hintereinander mehrere Conidien bilden, die damn die mit Scheidewänden verselsene oder anch ungetleilte Spore umgeben. Endlich kann anch Sekundärsporen- und ('onidienbildung zugleich an derselben spore anftreten.

Soriel beobachtet man schon an den auf dem Pilzrasen herumliegenden Sporen. Fin kleiner Rasen des Pilzes wirft in der fenchten Kammer im Verlanfe einer Stnnde grosse Mengen reifer Sporen ab, die in Nährlösmg aufgefangen alsbald zu keimen begimnen. Hier unterbleibt die Sekundärsporenbildnng; als Regel theilt sich die Spore durch eine Scheidewand (obwohl auch melnere vorkommen) und treibt dam Keimschläuche. Ich sah bis zu vier ans einer Spore anstreten (Eig. 3e). Die früher an der Spore selbst auftretende conidienbildung rückt num an die Enden der Keimschlänche. I)iese spitzen sich nicht etwa zu, sondern die 
Conidien bilden sich an ihrem abgernndeten Ende. Es können zwei neben einander ansitzen. Dasselbe Fadenende kann nach und nach eine grosse Anzahl Conidien hervorbringen. Seltener als an den Fnden der Fäden kommen Conidien auch seitwärts vor. Sie sitzen damn aber immer am oberen Ende einer Theilzelle, dicht mnter der Scheidewand. Nicht zu verwechseln sind diese Conidien mit den runden, stark lichtbrechenden Inlaltsbestandtheilen. welche in jeder reifen Spore und auch in den Keimschlänchen angetroffen werden.

Diese winzigen Conidien, welche in derselben Nählrlösung, in der sie gebildet rurden, niemals eine Sjur ron Anschwellung oder Keimung erkennen liessen, müssen ron einem Hofe einer unsichtbaren schwach klebrigen Snbstanz umgeben sein, welche sie längere Zeit zusammenlıält. Gekeinte Sporen, wie die in Fig. $3 \mathrm{f}$ dargestellte, mit den die Enden der Keimschlänche umgebenden ('onidien sah ich mehrfach in dem Flüssigkeitstropfen der Kultur frei mmherschrimmen. ohme dass dabei die gegenseitige Lage der Conidien sich inn geringstem änderte.

Innerhalb der ersten acht Tage der Kultur ging das Fadenrachsthum nur sehr langsam roran. Die kleinen Conidien aber wurden in ungeheuerer Anzalıl gebildet, so dass der ganze Kulturtropfen ron ihnen erfüllt ward. Eine einzige Spore kann in Nährlösung jedenfalls viele hundert solcher Conidien erzengen. Tom 10. Tage an aber fing die Bildung der Conidien an nachzulassen und die Füden der jungen Mycelien wuchsen dafüı schneller und verzweigten sich reich. Ich hielt die Kulturen rom 4. September bis zom 20. Oktober unter Aufsicht und erzielte auf dem Objektträger Hyphengeflechte. welche den in der Natur vorgefundenen an Dicke und Ueppigkeit gleichkamen. Tereinzelt wurden immer, anch später noch, Conidien ron den Fäden gebildet. Basidien dagegen traten in der kïnstlichen Kultur nicht anf.

Der eben beschriebenen Form steht, besonders durch die Bildung des merkwürdigen sackes, nahe eine andere Art, welche ich 
Saccoblastia sphaerospora nov. spec. genamnt habe. Diese Form habe ich nur ein einziges Mal im Jahre 1891 gefunden. Sie besteht aus ganz winzig kleinen, für das blosse Ange nur eben sichtbaren Mycelflöckchen, welche im besonderen Falle der Rinde eines au Boden modernden Stanmes ansassen. Nur bei sehr fenchtem Wetter wird man Aussicht haben, sie iiberhaupt zu bemerken. Die Hyphen, welche hier das sterile untere Geflecht bilden, sind dickwandiger, als bei der vorigen Form, sie erinnern selır an die für Stypinella orthobasidion beschriebenen, und tragen auch, wie jene, an jeder Scheidewand eine grosse dentliche Schnallenzelle. Der Bildung der Basidien geht die Bildung eines kugligen Sackes rorans, welcher sich beziiglich seines Inhalts und seines Verhältnisses zu der heranreifenden Basidie genan so verhält, wie bei S. orispora. Nur ist er nicht mit solcher Regelmässigkeit wie dort dem unteren Ende der die Basidie tragenden Fadenzelle angefügt (Taf. IV Fig. 2). Sein Durchmesser beträgt nur 11 " höchstens, mul dementsprechend ist auch die Länge der Basidie geringer, als im rorigen Falle, nämlich 11ur 45-60 ${ }^{\prime}$. Die kurzen fadenförmigen sterigmen treten häufig, aber durchaus nicht immer, dicht unter der nächst oberen Scheidewand ans der Theilzelle. sie sind alle gleich lang und bringen eine kuglige Spore ron 6-8 "Durchmesser herror, in die sich das Protoplasma der Basidie entleert. Die Reihenfolge der sporenbildung ist mubestimmt; am häufigsten sah ich im Gegensatz zu anderen Auriculariaceen die mitere Spore znerst sich bilden.

Die abgeschleuderten und in Nähnlïsung anfgefangenen Sporen haben ein kurzes Spitzchen, die Ansatzstelle des Sterigma. Sie keimen an dem auf die Aussaat folgenden Tage an beliebiger stelle, auch direkt aus dem Spitzchen. Die Keimungen waren spärlich. Die Keimschläuche blieben kurz, und wurden nicht sehr viel länger als die gezeichneten (Fig. 2). Der Inhalt der spore wanderte bisweilen in die spitze des Keimschlauchs. Weitere Entwickelung kounte ich nicht erzielen, da ich bei dem spärlichen 
Naterial nur wenige Kulturen hatte, die durch einen ungïnstigen Zufall zerstört wurden. In den nächsten zwei Jahren fand ich den Pilz nicht wieder.

Brefelds Untersuchungen verdanken wir die Erkenntniss, dass in den Uredinaceen eine Familie der Protobasidiomyceten zweifellos vorliegt. Die Uredinaceen haben freie Auriculariabasidien, die immer aus den 'Teleutosporen hervorkeimen.

Wer die Bilder jener Basidien, wie sie T'ulasne in den Annales des sciences nat. im .Tahre 1854 gezeichnet hat, mit den hier beschriebenen freien Auriculariabasidien rergleicht, dem wird keine Möglichkeit des Zweifels an der nahen verwandtschaftlichen Beziehung der beiden Familien übrig bleiben. Die Telentospore sammelt den Baustoff auf, um die Basidie zu erzengen. Sie muss meist den Tinter überdanern und hüllt sich desshalb in eine schützende dicke Membran. Thre Funktion erfiillt bei der Sacco blastia der Sack, er sammelt den Inhalt für die Basidie. Da die Nothwendigkeit einer Pause in der Entwickelung nicht vorliegt. so kommt es auch nicht zur Bildurg einer stärkeren Membran.

Anch unter den Uredinaceen giebt es ja Formen, bei denen die 'Teleutospore ohne längere Ruhepause ummittelbar zur Basidie anskeimt. Durch diese Formen wird die nahe Terwandtschaft unserer Saccoblastia-Arten mit den Uredinaceen besonders deutlich. Dass bei den letzteren die Teleutospore mehrzellig wird und jede ihrer Theilzellen eine Basidie erzengt, bleibt schliesslich fast als einziger Unterschied gegen den einzelligen Sack der Saccoblastia iibrig. Und nicht minder wird die Blutsrerwandtschaft der beiden, in Folge verschiedener Lebensweise so weit aus einander gegangenen, Familien bekräftigt durch das Torhandensein jener winzigen, in ungehenerer Menge gebildeten, nicht keimfälnigen Conidien bei Saccoblastia ovispora. Conidien genau wie diese sind die "Spermatien" der Uredinaceen. Auch diese "Spermatien" sind durch schleimige Gallerthïllen mit einander verklebt, wie wir sie bei monseren Auriculariaceen schon angetroffen haben. Im Wesen 
diesèr Bildnngen besteht zwischen beiden Fällen kein Interschied. Nur werden die Conidien (Spermatien) der Uredinaceen in besonderen fruchthörperartigen Behälter'n gebildet, wie demn überhaupt die Steigerung der Formen durch Fruchtkörperbildung bei den Uredinaceen rorzugsweise mit Riicksicht auf die Nebenfiuchtformen sich vollzogen hat. Jene oben citirten (Seite 15), man kamn wohl sagen vorahnend von Tulasne geäusserten Worte iiber' die Beziehungen zwischen Auriculariaceen und Tredinaceen finden die glänzendste Bestätigung ihrer imneren Wahrheit durch dic Saccoblastia-Arten.

\section{Platygloeen.}

\section{a. Jola nov. gen.}

Das leitende Princip, welches bei Ascomyceten mud Basidiomyceten von den niederen zu den höheren Formen fühnt, ist die Fruchtkörperausbildnng. Nachdem ans dem nubestimmten Sporangium del Ascus, aus dem unbestimmten Conidienträger die Basidie geworden ist, bleibt die Grundgestalt dieser beiden Fruchtformen unverändert, ist keiner weiteren Steigerung fähig:

Die grosse Klasse der Ascomyceten theilt man in Exoasci nnd Carpoasci. Die ersteren tragen ihre Schlänche frei, nicht zn Fruchtkörpern vereint, so wie unsere Stypinelleen ihre Basidien tragen. Mit dem Augenblicke, wo die einzelnen Asci zu fruchtkörperartigen Bildnngen zusammentreten, beginnen die carpoasci. In genau entsprechender Weise vollzieht sich die Formsteigerung unter den Protobasidionyceten, nicht ander's auch unter den Autobasidiomyceten. Indem die vereinzelt stehenden Basidien sich zı Lagern zusammenschliessen, diese Lager dnch einen stiel in die Höhe heben, oder sie durch Ausbuchtungen, Falten, Blätter, Röhren, Stacheln an Oberflächenraum bereicher'n, nm immer mehr und melı Basidiensporen ins Freie zur T'erbreitung zu bringen, sehen 
wir die Formen ansteigen zu immer reicheren Bau, immer höherer Tollendung: Neben einander in den verschiedenen Reihen der Basidiomyceten sehen wir dasselbe Princip mit oftmals gleichem Erfolge wirksam. Ist doch das Bammaterial ïberall das gleiche, einfache Hyphen. So sehen wir zu gleichen oder ähnlichen Fruchtkörver’gestalten die Protobasidiomyceten ansteigen, wie die Autobasidiomyceten, wir werden aucl unter den ersteren im weiteren Verlaufe der Betrachtung Hydneen und Polyporeenformen wiederelkennen.

Die ersten Anfänge der Fruchtkörperbildung sind immer dadurch gekennzeichnet, ${ }^{*}$ ) dass die rorher frei und einzeln an den Fäden auftretenden Ascen oder Basidien sich dicht zusammenordnen und in gleicher Hölıe dem Hyphengeflecht entspringend ein I ager bilden. Diesen Weg rerfolgen auch die Auriculariaceen. Wenn die langen fadenförmigen Basidien dieser Pilze enge zusammentreten, so können die ron den untersten Theilzellen gebildeten Sporen die freie Oberfläche des Lagers nicht anders erreichen als dadurch, dass ihre Sterigmen sich verlängern und die Spore zwischen den benachbarten Basidienfäden in die Höle tragen, an den äusseren Rand des Lagers. Bei den Stypinelleen sind alle vier Sterigmen ron gleicher, aber selır geringer Länge. Bei alien zur Fruchtkörperbildung fortschreitenden Auriculariaceen aber treffen wir ungleich lange Sterigmen an, und die längsten sind die ron der untersten Basidientheilzelle ausgehenden. Diese längeren Sterigmen werden 1 m so nothwendiger' als bei den meisten For'men mit dem Beginn der Frtuchtkörperbildung eine Gallertaussclıeidung der Fäden Hand in Hand geht, welche das frïher filzige Hyphengeflecht zu einem. geschlossenen gallertigen Polster macht, und die ron den unteren Basidienzellen gebildeten Sporen vollständig einscllliessen würde. wenn sie nicht durch lange Sterigmen über die Gallerte linaus-

*) Man rergleiche z. B. die Brefeldschen Kulturergebnisse bei Polyporus vaporarius $\mathrm{Bd}$. VIII, S. 108. 
gehoben wiirden. Am Anfange der Reilse, welehe ron freien Basidien zn einem glatten Basidienlager iiberzngelıen sich anschickt, steht muter den Amiculariaceen eine Form, die ich dola Hookeriarum nor. spec. genanut liabe.

Wenn der brasilische Urwald in allgemeinen nicht arm ist an Vertretern ans dem Reiche der Moose. so fällt doch dem Enropäer gar bald auf. dass die schönen, das Ange erfrenenden Moosrasen. wie wir sie in unsern Wäldern vorzngsweise von den Hурnеen an den Bamstämmen und anf dem Boden oftmals gebildet sehen. in dieser Ausdehnmg kamm jemals im Tropenwald anzutreffen sind. L'm so elier haftet das Ange daher an Stellen, wo wenigstens in kleinem Maasstabe ein frendig grimer Moosasen einen Urwaldstamm rerschönt. So betrachtete ich an einem fenchten 'Tage, an einem Bachufer' hinanfkletternd, einen umgefallenen Stamm, auf dessen dunkler Rinde ein Moos durch lenchtendes helles Grïn auffiel. Seine Stengel lagen der Lnterlage flach an und waren lebermonsartig zusammengedrïrkt. nund zahlleiche schlank gestielte Lapseln erhoben sich ron ilnent. Da fiel mir ant: dass hier und da die hapseln von einer feinen, weissen, schwach glänzenden Hülle umgeben waren, mod an andern stellen sall ich anch an den Fruchtstielen eine bald mehr. bald weniger ausgebreitete dïme. Weisse Kinste (Taf. IT Fig. 4 a). Die Untersuchung ergab, dass diese weissen Flöckchen von einer parasitischen A uriculariacee gebildet wurden. Als icls später bei trockinerem Wetter nach dem Pilze suchte. so fand ich iln nur mit grosser Mühe wieder. Er bildet bei trockenem Wetter an den befallenen stellen der lloose nur einen winzigen, fül das blosse Ange kanm wahrnehmbaren Flanm. Danacls lat er den Namen Jola erhaltenl (iocios Flaum, wovon Fries schon 1)itiola bildete). Der Pilz ist ein echter Parasit, a befällt junge Kapseln und junge Fruchtstengel der Moose und durehwuchert sie mit semen Fädeen ganz nud gar, so dass in den befallenen Kapseln eine Moos-Sporenbildung nieht zu Stande kommt. Ich fand ihn nur anf zwei Mloosen, welche Herr Dr. Carl 
Müller in Halle zu bestimmen die Fremdlichkeit latte. Fs sind Hookeria albata ('. Müll. und Hookeria jungermanniopsis C. Mrüll. Nachdem ich den Pilz näher kennen gelernt, und in küustlichen Nälnlösungen kultivirt hatte, gelang es mir später, junge Fruchtanlagen der Hookerien damit zu inficiren, an älteren, der Reife näher stehenden Mooskapseln blieben die Infektionen erfolglos.

Das Ifycel des Pilzes durchwuchert, wie schon gesagt. die Haube der Mooskapsel, bildet zwischen Haube und Kapsel ein dichtes Fadengewirr, mnd dringt dam in das Innere ein. wo es sich reich rerzweigt. Die Hyphen sind 4 " stark. riemlich gleichmäsin; reich septirt, doch ohne Schnallen. Sie hilden nun anssen um die befallene Kapsel oder um den befallenen stiel herum ein wirres Lager von geringer Dicke. und ans diesem Lager erheben sich die Basidien bildenden Fäden .dichtgedrängt in radialer Richtung. Diese Fäden sind reich septirt, und ilne Theilzellen zeigen nicht mehr die gleichmässige Licke der früheren Fäden. sie sind viehmehr in unregelmässiger Weise angeschwollen, oft anch rerbogen. in ähnlicher Teise, wie es bei vielen Pilzen rorkommt, rem Fäden sich zur Psendoparenchyombildung anschicken (Fig. 4 b). Zu einer Pseudoparenchymbildung kommt es indessen hier nicht. Die Berührung der benachbarten Fäden wird niemals eine ummittelbare. Besieht man den Pilz in fenchtem Zustande, so erscheint das kleine weisse Polster fast glänzend. und man möchte eine die Fäden einbettende sehr dïme Gallerte volaussetzen. Mit dem Miliroskop hat sich eine solche allerdings nicht nachweisen lassen.

Die jedesmal letzte Zelle eines Fadens schwillt stärker noch an, als die ibrigen. und aus iln sprosst dam. so wie der Keimschlanch aus einer keimenden Spore, die lange fadenförmige Basidie (Fig. 4b). In diese, welche beträchtliche Länge (bis zu 90 «) erreicht, entleert sich allmählich der ganze Protoplasmainhalt aus der letzten angeschwollenen Fadenzelle, machdem vorher schon die weiter zuräickliegenden Zellen ihr Protoplasma nach dem 
Ende des Fadens hin abgegeben haben. Eist wemn der gesammte Inlaalt des tragenden Fadens aufgenommen ist, grenzt siclı die Basidie durch eine Scheidewand von ihrer Urspringstelle ab, und unmittelbar darauf erfolgt ilıre Quertheilung durch drei Scheidewände, von denen die mittlere znerst angelegt wird. Aus jeder Theilzelle sprosst nmm ein Sterigma in Gestalt eines verhältnissmässig dicken Fadeus. Dies Sterigma kann noch an beliebigen Stellen der 'Theilzellen anstreten, wie die Figuren erkemnen lassen. Sehr' luäufig wächst die oberste Theilzelle unmittelbar zum Sterigma aus (Fig. 4c). doch kann auch aus ihn das Sterigma seitlich hervorbrechen (Fig. 4d). Die Länge der Sterigmen ist unbestimmt. Sie wachsen im Allgemeinen so lange, bis sie ilne Spitze über das Gesammtpolster des Pilzes erhoben haben, damn spitzen sie sich zu und erzengen eine sichelförmig gebogene spore (Fig. 4c und e). Der Entwickelungszustand aller Basidien ist im allgemeinen in je einem Lager des Pilzes anuähernd derselbe. Betrachtet man einen befallenen Moosstengel, an dem die Basidien des Pilzes reif sind, olne Znsatz ron Fliissigkeit mit dem Mikroskop, so sieht mam ans dem damn mondurchichtigen Lager des l'ilzes iiberall die sichelförmigen sporen herausragen (Fig. $4 \mathrm{e}$ ). Ein solcher Stengel, sorgsan über einem mit IVasser oder verdümnter Nührlösung beschickten Objektträger aufoehängt. Wirft in Verlaufe weniger

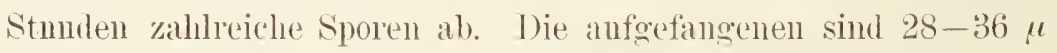
lang, ca. 6 " breit. sie sind an der Imenseite der Sichel meist etwas geschweift; das eine Ende ist lang zngespitzt, es ist dasjenige. mit dem sie am Sterigma ansassen, das andere dagegen etwas stmmpfer germndet (Fig. 4f). Nachdem sie eine Niltht iiber ín Masser oder Nährlösmng gelegen haben. schwellen sie wenig an, so dass die Schweifmng eben $n$ m etwas undeutlicher wird, mol dann erfolgt die Keimung. l)iese begimnt an einem oder an beiden Enden gleichzeitig. Ein Keimschlanch tritt aus, in den sich allmählich der Inhalt der spore entleert, die entleerten Rämme werden nach linten zn durch Wände abgegrenzt. Wo der Keinschlanch sich 
in die Luft erheht, kommt es zur Bildumg von Sekundär-Sporen (Fig. $4 \mathrm{~g}$ ). Bisweilen scheint es. als ob eine Conidienbildung zu Stande kommen sollte. Wemn nämlich die Keimung am spitzen Ende der Spore anheht, so verdickt sich der Keimschlanch zunächst beträchtlich, und es scheint eine Conidie der Spore anfzusitzen. Diese scheinbare Conidie aber löst sich nicht ab, und ich sah sie in allen beobachteten Fällen nachträglich zum einfachen Keimschlauch auswachsen, wohei es mir schien, als wem an dem dünnen Ende der Spore nachträglich eine etwas ausgleichende Verdickung eingetreten wäre (Fig: $4 \mathrm{~g}$ ). Ueber die geschilderten Ergebnisse war in der Kultur nicht hinanszukommen. Sie stimmen ziemlich genau mit den von Brefeld für Tachaphantium tiliae mitgetheilten überein. Ueberhaupt ist einlenchtend, dass unser Moospilz mit Tachaphantium Brefeld = Platygloea Schröter die nächste Terwandtschaft besitzt. Ich halte es trotzdem fïr geboten, ihn zum Vertreter einer nenen Gattming zu machen, weil er erstens in der Frnchthörperbildung noch nicht soweit vorgeschritten ist, wie Platygloea. und weil er zweitens in den sporenartig angeschwollenen Fadenzellen, ans denen die Basidien hervorgehen, ein eigenartiges Merkmal besitzt, welchem eine besondere Bedeutung zukommt. Auch die parasitische Lebensweise unterscheidet ilm nicht unwesentlich ron Platygloea. Während letztere ferner ein echtes wachsartiges Hymenium hat. in dem die Basidien eine geschlossene, durch Gallertbildung geeinte Schicht bilden, so ist von einer solchen bei Jola noch nicht in demselben Maasse die Rede. Die Basidien entspringen noch in etwas ungleicher Höhe und eine dentlich sichtbare Gallerte ist nicht vorhanden. Ferner ist aucl von einer bestimmten Begrenzung des Tager's keine Rede. Dasselbe kann als Ḱnöpfchen auf der Hanbe des Mooses sitzen, oder diese ganz einlunillen oder am Stengel in unregelmässiger Lrstreckung entlang gehen. Bei Betrachtung der angeschwollenen Endzelle des Fadens, der die Basidie trägt, erinnern wir mins, dass schon bei Stypinella orthobasidion die Andentung einer solchen in 
ihrer Form bestimmten Zelle mus anffiel. Bei den SaccoblastiaArten fanden wir dieselbe Zelle wieder und an ihr als eine banchige, durch keine Wand abgetremte Erweiterung den charakteristischen Sack. Alle diese Bildungen erfüllen dieselbe Aufgabe, den Baustoff fïr die Basidie anzusammeln; alle diese Bildungen entsprechen morphologisch der Teleutospore der Uredinaceen. Man betrachte nnsere Fig. 4b und denke sich nul die Membran der basidientragenden Zelle verdickt, so lenchtet die mmittelbare Tebereinstimmung*), z. B. mit der von 'Tulasne abgebildeten Keimung der Telentospore von Tromyees fabae order Endophyllum Euphorbiae silvaticae olne weiteres ein.

In weiteren Terlaufe mserer Betrachtung wird sich noch nehrfach Gelegenheit finden anf die Parallelität hinzuweisen, welche bei Auto- und Protobasidiomyceten sich in der Art geltend macht, wie die Formen von niederen fruchtkörperlosen ansteigen zu Fruchtkörper bildenden der verschiedensten Gestalt. In den Stypinelleen lernten wir eine Gruppe kennen. welcher nnter den Antobasidiomyceten die Tomentelleen entsprechen. Bei beiden stehen die Basidien frei an den Fäden. Hier in Jola haben wir vor uns eine Form, welche anf gleicher Hölle der Fruchtkörperentwickelnug angelangt ist. wie die niedersten Thelephoreen mit nicht begrenztem Fruchtlager' (z. 13. 'Thelephora crustacea). Genan entsprechende (iruppen werden wir bei den Tremellaceen, in den stypelleen mol Exidiopsideen wicdererkemen.

Die nächste Gattnug. P'atygloea gelıt, wie ich oben erwähnte, schon einen kleinen schritt weiter. Unter den beschriebenen P'latygloeaformen möchte P. effisa Schröter dem Pilze der Moose am nächsten kommen wegen des nicht begrenzten Lagers.

Es ist woll zu bemerken, dass bei nuserer Jola im Anklange an viele niedere Formen die Sterigmen noch an beliebiger stelle.

*) Sie wird anch hei Stypinella dentlich, wenn wir daranf achten. wie die Basidien tragende Zelle durch eine verstärkte Jembran sich ron der zarten düunwandigen Basidie selbst unterscheidet (Taf. IV Fig. 1). 
meist aus der Mitte der 'Theilzellen entspringen, wähnend sie weiterhin regelnässig unter die nächst obere Scheidewand, so weit wie möglich nach oben rüicken. Wie sich in dieser Bezielınng die ron Schröter beschriebenen Platygloea-Arten verhalten, ist. nicht ersichtlich, und es ist sehr zu bedauern, dass wir von ilnenen keine Abbildungen laben. Denn bei der geringen Anzahl der ïberluapt bekannten Auriculariaceen ist eine bildliche Darstellung wenigstens der Basidien jeder einzelnen fast unentbehrlich für die richtige Beurtlıiluıg.

\section{b. Platygloea Scluöter.}

Eine weichwachsartige Beschaffenheit des Fruchthörpers, wie sie den Platygloea-Arten zukommt, zeichnet auch die P'atyghloea blastomyces nor. spec. aus, welche ich an vermodernden Rindenstücken in September 1892 zuerst fand. Die kleinen, unregelnässig umgrenzten, sclıwach gewölbten Polsterclen sind in Fig. 5 a in natülicher Grösse dargestellt. Sie bestehen aus dicht verflochtenen. 2-3 $\mu$ dicken Fäden. Sie sind etwa 5 mm dick an den üppigsten Stellen, und haben eine grauweisse, schwach gelblich angehanchte Farbe, welche, wie ein Schnitt zeigt, im Innern des Polsters nacl unten zu ein wenig dunkler wird. Dort sind auch die Hyphen besonders dicht verflochten. Die Oberfläche wird bedeckt vou dem Hymenium, welches aus den seh" langen (bis $200 \mu$ ), fadenförmigen, pallisadenartig dicht zusammengeordneten Basidien gebildet ist (Fig. 5b). Zwischen den 4 , starken Basidien sieht man in grosser Anzalıl dïnnere, paraphysenartige Fäden. Das Hymenimm zeigt wachsartige Consistenz. Es ist, wie stets bei den eigentlichen Auriculariaceen, recht schwer zu untersuchen, da die Basidien selı dünmandig sind, und es gelingt nur mit vieler Mülıe, eine Basidie frei zu präpariren. Alsdann sieht man aber deutlich, dass nuan es mit typischen Auriculariabasidien zu thum hat (Fig. 5b). Die lang fadenförmigen Sterigmen entspringen stets dicht muter der 
oberen Scheidewand und wachsen so lange, bis sie die Oberfläcle des Lagers erreichen. Dort erzengen sie in der bekannten Weise eine längliche Spore von $12 \mu$ Länge und $6 \mu$ Breite (Fig. 5c).

Schon an den auf dem natiirlichen Hymenium umher liegenden Sporen bemerkt man oftmals Sekundärsporenbildung, niemals aber eine Scheidewand im Innern. Die Sporen sind leicht in Wasser oder Nährlösung aufzufangen. Besonders im Tasser und in dünnen Nährlösungen sieht man häufig einen Keimschlauch anstreten, der seine Spitze über die Flüssigkeit erhebt und dort eine Sekundärspore hervorbringt. In Nährlösung sclıwellen die Sporen selır unbedentend an und keimen dann entweder mit einem oder mehreren Keimschläuchen oder mmittelbar mit Hefeconidien (Fig. 5d). Durch das Torkommen echter Hefesprossung ist die vorliegende Form ganz besonders bemerkenswertl. Dem Hefeconidien sind bisher noch bei keiner Anriculariacee beobaclutet worden. Die nit Hefen keimende Spore bildet zunächst eine sehr kleine polsterförmige Aussackuıg (Fig. 5d), ganz ähnlich, wie sie bei Dacryomyceten als Ursurungstelle der Conidien fast regelmässig vorkolumt, nud aus diesen Polster sprosst die erste Conidie von länglicher Form. Diese lïst sich alsbald los und schwillt nachträglich noch etwas an. sie elreicht im ätussersten Falle $8 \mu$ Länge und 4 " Breite in der Mitte und lässt alsbald wiedler eine Conidie an einem Fnde aussurossen. Auch diese löst sich sofort nach ihrer Bildung ab. Surosskolonien kommen nicht zu Stande. Die Termehrung der Hefen geht in der üblichen Treise so schnell vor sich, dass schon mach drei Tagen der Kulturtropfen dicht ron Hefemassen erfüllt ist. Jedes kleine Polster an der Spore kinn nach einander eine grosse Reihe von Sprossconidien hervorbringen und schliesslich erschöpft hierbei die spore ihren Inhalt. In der Regel hatte jede spore nur ein solches Polster. Ausnahmsweise kommen aber anch nuehrere vor. Anch kamı gleichzeitig Fadenanskeimung nud Conidienbildung rorkommen (vergl. die Figuren). Endlich kommen auch sporen vor. 
die zunächst nur mit Fäden keimen und damn an den Enden der Keimschläuche und auch seitwärts derselben Conidien treiben.

Sehr bald findet man auch gekeimte Hefeconidien, welche an einem oder beiden Fnden Keimschlänche besitzen (Fig. 5e). Auch an diesen können wiederum Hefen aussprossen. Meine Kulturen erhielt ich einen ganzen Monat durch, und die Hefesprossung blieb während dieser ganzen Zeit im Gange und überwog die Mycelbildung. Es kommen nur kleine, wenig verzweigte Mycelien auf dem Objektträger zu Stande.

Es ist von grossem Interesse, an dieser Form zu sehen, dass die Hefeconidien, welche nun in den allerverschiedensten Familien der Ascomyceten und Basidiomyceten. und darüber limaus schon bei den Hemiasci und Hemibasidii nachgewiesen sind, und welche unter den Tremellaceen in ganz besonders iippiger, fast allgemeiner Verbreitmng anftreten, auch der Auriculariaceenfamilie nicht fehlen.

Wir kümnen die Gruppe der Platygloeen nicht verlassen, olme eine Reilıe neu aufgestellter Gattungen kritisch zı würdigen, welche entweder mit einer gewissen Wahnscheinlichkeit in die Verwandtschaft der Platygloeen gehören, oder aber irrthiumlicher Weise im Zusammenhange mit den Auriculariaceen von ihren Autoren aufgeführt worden sind.

Am meisten interessiert uns hier eine Bemerkung, welche sich in Ludwigs Lehrbuch der niederen Kryptogamen auf Seite 474 findet mit folgenden Worten: "Nenerdings hat nun r. Lagerheim „eine saprophytische Auriculariaceengattung, Campylobasidium, ent"deckt, welche, wie die Rostpilze, eine Art 'T'eleutosporen, also "Chlamydosporen hat, aus denen bei der Reife die quergetheilten "Basidien entstehen." Etwas weiteres iiber diesen jedenfalls höchst bemerkenswerthen Fund $v$. Lagerheims ist mir in der Literatur nicht zugänglich geworden. Wir können aber schon 
der kurzen Notiz entnehmen, dass es sich hier um eine Form handelt, welche den Uebergang von mserer Saccoblastia zn den Uredinaceen, den wir oben näher berücksichtigt haben, aufs einlenchtendste herstellt, und es ist eine nähere Beschreibung und Untersuchung dieses Campylobasidium jedenfalls aufs lebhafteste zn wïnschen.

In zweiter Liuie haben wir die ron Patouillard (Champignons de l'Équateur, pugill. II, Bull. Soc. myc. de France, Seite 11) begründete Helicogloea zu betrachten. Die leider selı flüchtigen und beziiglich der Scheidewände in den Basidien ganz sicher mrichtigen Zeichnungen lassen keinen Zweifel dariiber, dass es sich um einen Pilz laandelt, der entweder zu Stypinella oder zu Platygloea gehört. Ein Grund, ihn mit besonderem Gattungsnamen zn belegen, besteht nicht. In der Gattungsdiagnose sagt Patouillard: „Sporae oroideae, lyalinae, sub germinatione filamentum brevissimmm emittentes, in conidimm micum sporisque simillimum apice productum", nud nachdem er dam in der Artbeschreibung die Länge dieses sogenannten Pronycelimm mo die Grösse der sogenamnten sporidien angegeben hat, so fiigt er hinzu: ., le mode de prodnetion des conidies le (sc. Helicogloea) sépare nettement de ces denx gemes (sc. Helicobasidium = stypinella nud Platygloea $)^{*}$. Diesr Angaben beweisen ein gänzliches Missrerständniss des Beobachteten, nurd nilissen nothwendig näher belenchtet werden, mu die zn Unrecht gegrinmlete Gattmng Helicogloea rerschwinden zil machen.

Was Patouillard hier und an anderen Stellen. z. B. bei manchen seiner Platygloea-Arten als Promycelium mit einer Sporidie bezeichnet und a. a. Orte anf 'Tafel XI Fig. 1c allerdings sehr oberflächlich abbildet. ist nichts als die allbekannte Sekundärsporenbildung, die sich. wie wir ans 'T'ubsnes und Brefelds Untelsuchungen wissen, bei Pilzen ans den allerverschiedensten Terwandtschaftskieisen, insbesondere aber bei den allermeisten Protobasidionyceten findet. Inie Seknndirsporenbildung tritt im all- 
gemeinen ein, wenn eine Spore nicht in den für ilne normale Keimung gïnstigen Umständen der Lage oder der Ernährungsmöglichkeit sich befindet. So sehen wir bei Aussaatversuchen Iıäufig, dass eine zu tief unter der Flïssigkeitsschichte liegende Spore einen Faden treibt, in den ihr Protoplasma alsbald hineinwandert, wie es z. B. eben noch für Platygloea blastonyces beschrieben und dargestellt worden ist. Dieser Faden wird so lang als nöthig ist, um mit der Spitze die Lnft zu erreichen, danu bildet sich am Ende des Fadens die Sekundärspore, welche in der Form und in der Art des Ansitzens ganz genan die Primärspore wiederholt. Sie ist nur kleiner als diese, mnd zwar in um so erheblicherem Grade, je länger der Faden war, der sie in die günstigere Lage brachte. Es scheint so, als ob bei der Sekundärsporenbildung eine Zunalme, eine Ernährmng von aussen nicht stattfände. Die in der Spore angehäuften Banstoffe mïssen den Keimschlauch und die nente Spore herstellen, die letztere fällt deshalb kleiner ans. Unzählige Beispiele, vor allem bei 'L'ulasne und Brefeld, belehren mins iiber diesen Sachverhalt. Wer aber dort nicht nachschlagen will, findet anch Beispiele der Art in unseren Figuren 1, 3, 4, 5, 12 abgebildet. Die Sekundärspore hat mit den den betreffenden Pilze zugehörigen Conidienformen ebenso wenig Aehnlichkeit, wie die Primärspore; es kann nur Verwirrung stiften, wemn man sie als Conidie bezeichnet. Sekundärsporenbilduug findet lä̈nfig schon auf' dem Hymenimm des betreffenden Pilzes statt. Es scheint, dass es sich bei den von Patonillard aufgefiihrten Fällen immer uu um solche Beobachtınngen handelt, an Sporen, die auf dem Hymenimm des Pilzes in Seknndärsporenbildung angetroffen wurden. Tem daher diese Beobachtungen mit den mehrmals wiederkehrenden Worten mitgetheilt werden: „germinatione promycelium enittentes in conidium unicmm apice productum", und wemn mit Bezug hierauf bei Beschreibungen von Platygloea-Arten der Zusatz sich findet "germinatio generis“, so ist nicht anzumehmen, dass hier vielleicht heimversuche vorliegen. 
Wir wissen ja - ich erimere nur als Beispiel an die beschriebenen Formen Stypinella orthobasidion oder Jola Hookeriarum —, dass man oftmals die Sekundärsporenbildung leicht beobachtet, die wirkliche Keimung aber noch nicht geselien hat. Wo Patouillard bei Platygloea-Beschreibungen (Champ. de l'Équateur III S. 14-15) sagt: „Germinatio generis“, ist die Keimmng der betreffenden Formen thatsächlich unbekannt.

Aus den oben zusammenfassend anfgefülıten Thatsachen folgt ferner, dass es gar keine Bedeutung hat, die Länge des die Sekundärspore erzengenden Fadens und die Grösse der Sekundärspore zu messen; demn diese Maasse sind fuir jeden Fall, je nach der Lage der Primärspore verschiedene. Die Charaktere, mit welchen Patouillard seine Helicogloea ansstattet, sind also solche, wie sie den allermeisten Protobasidiomyceten zukommen. und deshalb ganz ungeeignet, eine neue Gattung zu begründen. Helicogloea ist demnach zu streichen.

Dass solche Irrthïmer die Mykologie noch im Jahre 1892 beschweren, ist 1 m so unbegreiflicher, als schon Tulasne die Sekundärsporenbildung vielfältig und ungleich sorgfältiger als Patouillard abgebildet, den richtigen Namen dafür eingeführt und daranf anfmerksam gemacht hat, dass die Sekumdärspore der primären rollkommen gleicht und inmer etwas kleiner ist. Er sagt (Amn. d. sc. nat. III. série 19. 15.;3, also ror fist 40 Jahren): je n'ai pu encore constater d’une manière sûre quel était le sort de ces spores secondaires; si elles sont destinées à germer comme un grand nombre d'entre les spores primaires, elles représenteraient la puissance germinative ou reproductive élevée à sa seconde puissance, puisqu'elles sont, en effet. le fruit d'une élaboration spéciale, ajoutée à celle qui a produit les spores primaires."

Da ich die Sekundärsporenbildung in dieser Arbeit bereits erwähnt habe und noch oft erwähnen muss. so erschien es der ganz falschen Bemrtheilung Patonillards gegenüber notwendig, den wahren, längst feststehenden sachverhalt wenigstens an einer Stelle kur\% wiederholend darzulegen. 
Wir kommen num zur Gattmng Septobasidium, begriindet ron Patouillard, mitgetheilt im .Journal de botanique 16. Februar 1892. Die abgebildeten fraglichen Basidien des Pilzes machen es einigermassen wahrscheinlich, dass eine Form vorliegt, welche in die Nähe ron .Tola gehört, bei der die Basidien tragende Zelle in bestimmter Weise teleutosporenartig aufgeschwollen ist. Da aber weder Sterigmen noch Sproren an dem untersuchten trockenen Naterial aufgefunden worden sind, so kamn man meines Erachtens gar kein sicheres Urtheil abgeben, und es wäre wohl besser gewesen, den vorläufig gänzlich bedeutungslosen Fund auf sich beruhen zu lassen. So lange keine sporentragende Basidie gesehen ist, kann die Gattung Septobasidium unter die Auriculariaceen jedenfalls nicht aufgenommen werden.

Wir kommen zur Gattung Delortia Patouillard (s. Bull. de la soc. mycol. de France Bd. 4 S. 7 ff.. Champ. de Veneznela). Sie wird als Gattmug der Heterobasidiés von dem Autor aufgeführt. obwohl sie weder bei diesen, noch weniger bei den Protobasidiomyceten vorläufig untergebracht werden kann. Ich habe den fraglichen Pilz in Brasilien vielfach zu allen Zeiten des .Tahres gesammelt und untersucht, wiirde ihn aber iiberhaupt nicht erwïhnt haben, weil wir über seine Stellung nnd Bedeutung im Systeme nichts sagen kümnen. Er bildet hell glasige, schleimige Fruchtkörper an faulenden Palmblätter'n mod Stämmen, welche nur wenige Millimeter Durchmesser erreichen mo im äusseren an eine Tremella erinnern. $1 n$ den schleim eingebettet finden sich sehr feine, radial ausstrahlende Fäden. Diese Fäden bilden an ihrem Ende eine spindelförmig etwas aufgeschwollene Endzelle, nnd auf dieser, die Patouillard Basidie nennt, bildet sich das, was er als die Spore bezeichnet. Dies ist ein wurstartig eingekriimmtes Fadenende, wohl viermal so stark im Durchmesser als der 'Tragfaden, und es theilt sich nach ihm durch Querwände in drei Zellen. Ich habe nun durch Vergleich selır vieler Stiicke festgestellt, dass diese als Syore bezeichnete Biłdnng allerdings an 
dürftigen Exemplaren dreizellig ist, dass sie aber an iippigeren Stücken auswächst zn einer zwei-, ja dreifach spiralig eingerollten Bildung, welche in mehr als 12 Theilzellen zerfallen kann. Wir haben es hier also mit einer sehr wandelbaren conidienartigen Bildung zu thun, keineswegs aber mit einer Basidienspore. Selbst wenn man aber mit Patouillard die letzte schwach angeschwollene Zelle des Tragfadens (vergl. die Figuren bei Pat. a. a. O.) als Basidie denten wollte, so läge doch unmöglich eine Protobasidie vor. Delortia ist also eine Form, über deren systematische Stellung nichts bekamnt ist, die zu den Protobasidiomyceten zu stellen gar kein Grund vorliegt, die höchstens bei den Fungi imperfecti und meines Erachtens besser überhaupt nicht aufzuführen wäre.

Endlich ist von Giesenhagen (Flora 1890 S.130) eine Gattung Urobasidium als Protobasidiomycetengattung beschrieben worden, die aber gar nicht hierher gehört, sondern, soweit die dïrftigen Angaben reichen, bei den Tomentelleen ihre natürliche Stellung findet, wie Lindan in seinem Literaturbericht in Englers Bot. Jahrbüichern 18. Bd. 5. Heft $189+$ s. 73 sehr richtig hervorgehoben hat.

\section{Auricularieen.}

\section{Auricularia Bulliard.}

Die Gattung Laschia wurde im Jahıe 1830 (Limmaea I. S. 533) von E. Fries begrïndet mit der einzigen Art Laschia delicata. Das Material stammte aus Guinea. Der Pilz, den Fries damn unzweidentig beschrieb, ist nachmalen oft gesammelt und in die Herbarien Europas gebracht worden. Er scheint eine der gemeinsten Arten durch die Tropen und Subtropen der alten mid neuen Welt zu sein. So giebt Hennings sein Yorkommen an von den Liukiu-Inseln, Okinowa, den Bonin-Inseln (Warburg), von Pondoland (Bachmamn), von Nauritius, Nadagascar, Togo (Station Bis- 
marcksburg), und in Brasilien gehört er zu den allergemeinsten Erscheinungen unter den Pilzen. Das Originalexemplar ans dem Herbarium Willdenow (dort als Merulius favosus bezeichnet), welches Fries in Händen gehabt hat, befindet sich noch im Berliner Herbarium. und ich konnte mich davon iiberzeugen. dass es mit dem so vielfach von mir in Brasilien gesammelten Pilze gleichbedeutend ist.

Die Friessche Beschreibung der Laschia delicata lautete:

Novum genus e familia Tremellinarum. Receptaculum gelatinosum, expansum, pileato-dimidiatum, supra sterile, subtus fructificans, favoso-reticulatum, persistens.

Laschia delicata (Merulius? favosus Willd,) pileo glabro, ad truncos in Guinea. In variis herbariis vidi. Sicca papyro tenuior, rigidula, lumectata maxime flaccida, tenacella, minus vero quam Tremellae, quibus in statı exsiccato similis, turget. Pileus suborbicularis, postice prope marginem adnatus, $1-1^{1 / 2}$ unc. longus, glaber rugulosus, margine integro. Pagina inferior lıymenina (licet nullım lymenium adsit) cum contextı tenerrimo pilei contigua, favoso reticulata, dissepimentis tenuibus, membranaceis, inaequalibus, saepe dentato productis et interruptis. Color fuscescens.

Mit dieser, man darf wohl sagen für die damalige Zeit ansgezeichneten Beschreibung halte man die beiden photographischen Abbildungen unserer Tafel I, Fig. 1d und e, welche in lialber natïrlicher Grösse gegeben sind, zusammen, so wird man eine klare Torstellıng von dem Pilze gewinnen, 1 m den es sich handelt, und der richtig nur als Amricularia anricula Judae zu bezeichnen ist.

Der für alle Zeiten grosse schrredische Systematiker lratte von seinem Standpunkte vollkommen recht, wemn er fiir diese Form eine nene Gattung schuf. Es war die erste Gattming unter den damaligen "Tremellinen“, welche zu einem polypornsartigen Fruchtlager fortgeschritten war. Fries hatte die Basidien weder gesehen, noch komnte ihm bekaunt sein, dass der wesentliche Charakter der "Tremellinen" (also der jetzigen Protobasidio- 
myceten) in der getheilten Basidie lag. Die spätere genanere Untersuchung der Form. wie sie z. B. von Patouillard (Journal de botaniqne 1881) ansgefüln't worden ist, lat aber den richtigen Takt, den Fries bei seiner Bestimmmug des Pilzes entwickelt hat, bestätigt.

Patouillard behandelte a. a. O. Laschia tremellosa Fr., welche mit der delicata vollkoummen zusanmmenfällt. In Saccardos Sylloge findet man linter einander zwei lange Beschreibungen von Laschia delicata und tremellosa, die zwar recht verschieden abgefasst sind, aber demuch die an Schlusse der Laschia delicata stehende, fïr den bestimmenden systematiker kamm ermuthigende Bemerkung rechtfertigen: „L. tremellosa ab hac non distingnenda est“. Patonillard, wie gesagt, war der erste. der die U'ntersuchung der Basidien unternahn. Er fand, dass sie cylindrisch, lang nud schlank, von lichtbrechendem Protoplasma strotzend nud in drei oder vier Abtheilungen durch wagerechte Wände getheilt wären, „totalement dépourvils de stérigmates an sommet". Die letztere Bemerkung giebt Saccardo wieder mit den Worten: "sterigmatibus nullis". Meine zn vielen Malen wiederholten Untersuchungen der allerding's recht schwer dentlich sichtbar zn machenden Basidien lassen keinen Zweifel darüber. diss sie stets in vier Theilzellen zerfallen, dass die oberste 'Theilzelle zu einem bald längeren, bald kürzeren fadenförmigen Sterigna answächst, nnd dass die gleichen Sterigmen anch an den muteren Zellen, und zwar je eins immer dicht nuter der oberen Scheidewand entstehen, nit einem Worte, dass eine bis in die kleinsten Finzelheiten gehende Uebereinstimmung besteht mit den Basidien, welche für Anricularia sambucina Mart. von Brefeld im VII. Hefte seiner Untersucliungen beschrieben mid anf'T'uf. II I Fig. 3 daselbst mit grösster 'T'rene abgebildet worden sind. Man weiss ans diesen Untersuchnngen, dass meistens die vier Sterigmen nach einander entstehen, dass anch die vier Sporen nicht gleichzeitig zur Entwickelung kommen, und dass häufig die oberste Theilzelle einer Basidie schon entleert sein 
kann, wemn die nuterste noch kaum das Sterigma hervorgetrieben hat. Solche Basidien kömnen dann seln leicht für dreizellig gehalten werden. - Patouillard kam anf Grund seiner Benbachtungen zu dem von ihm klar ausgesprochenen richtigen Schlusse. dass die fragliche Pilzform (welche ausserdem noch L. velutina und nitida unter sich begreife) bei der Gattung Auricularia ilıre richtige Stelle zu finden habe und dort Tertreterin einer besonderen Sektion mit wabigem Hymenium sein mïsse. Um so mehr ist es num zu verwundern. dass der Autor diese von ihm bestimmte Stelle der Laschia nicht angewiesen hat, sondern dass er sie weiterhin als Laschia behandelt und unter eben diesem Gattmosnamen nun eine Reihe weiterer neuer Pilze beschreibt, welche mit der Friesschen Laschia nicht mehr Terwandtschaft laben, als irgend eine andere Polyporee. Es ist dadurch eine geradezu erschreckende Terwirrung angerichtet. Die von Patonillard als Laschia beschriebenen Formen sind, wie er richtig angiebt, mit viersporigen, einfachen, ungetheilten Basidien ausgeriistet. Sie gehören einer Gruppe an, welche in den Tropeu häufig zu sein scheint. und von der ich viele verschiedene Vertreter auch in Brasilien sammelte. Die ihnen näclstrerwandte bekannte Gattung ist Farolus.

Es hatte nicht einen Schatten von Berechtigung, sie mit der Friesschen Laschia zu vereinen, und wemn Patouillard das Resultat seiner Arbeit zieht, indem er die Gattung "Laschia Fries emend." aufstellt, ihren Charakter mit ungetheilten Basidien bestimmt, die nenen farolusartigen Formen als Arten anffülırt, und schliesslich die von Fries als Laschia bezeichnete Amiculariacee, auf die hin gerade Laschia begrïndet wurde, als ron der Gattung. auszuschliessende Art anführt. so ist das Verfahren meines Erachtens nicht zu rechtfertigen.

Eine Folge dieser unseligen Terwilrung ist die für unsere heutigen mykologischen Anschaumgen gerarlezu mnglanbliche Anordnung bei Saccardo, wo Laschia als Autobasidiomyceten-Gattung. 
bei den Polyporeen stelıt und in Untergattungen zerfällt, von denen die erste, Eu-Laschia, mngetheilte viersporige Basidien, die zweite, Auriculariella, mehrzellige Basidien haben soll.

Nach dem bisherigen Standpunkt unserer Kenntnisse wäre es allein richtig gewesen, für die Form, mit der wir uns beschäftigen, den alten Namen Laschia delicata Fr. beizubelıalten. Laschia wäre damn eine Gattung der Auriculariaceen gewesen, welche ein polyporeenartiges Hymenimm besitzt. und die Patonillardscle Gattung Laschia verlöre die Berechtigung zn ilırem Namen. Nene bisher nicht beachtete Thatsachen machen auch die eben angedentete Stellungnahme ınmöglich.

Wälırend der ganzen Zeit meines Anfenthaltes in Brasilien labe ich den auffallenden .Judasohren meine Anfmerksamkeit zngewendet. Sie gehören neben Polyporns sanguinens und Schizophyllum commune zil den allergemeinsten Pilzen des Landes. Sie kommen zu jeder Jahreszeit vor, und nach jedem Regen findet man sie an morschen Stämmen in grossen Massen, so dass man sie leicht körbeweis sammeln kömnte. Indem ich num Naterial von den verschiedensten Standorten in Menge sammelte und rergleichend untersuchte, so kan ich bald zu der Ueberzengmng, dass ich es hier mit einer in Form. Farbe nund Grösse ganz ausserordentlich schwankenden Art zn thm hatte. Es finden sich Fruchthörper, deren hymeniale Fläche fast oder vollständig glatt ist (Taf. I Fig. 1a und b). Sie sind mehr oder weniger flach oder hohl, und sie erweisen sich als vollkommen numberscheidbar von dem europäischen .Judasohr. Thatsächlich wird auch dieses in den Sammlungen ans verschiedenen tropischen Ländern anfgefühıt. Bei Fig. 1b sehen wir schon aderige Falten in Hymenimm angedentet. Wir finden solche $n$ in in jeder denkbaren Stärke der Ausbildung an den verschiedenen Fruchtkörpern. Fig. 1c zeigt schon recht deutliche. hie nud da Wabenbildungen hervorrufende Falten. Aber anch zwischen diesem Znstand nud dem der Fignren d und e, welche das fast regelmässige wabige Frucht- 
lager der Laschia delicata Fr. darstellen, finden sich alle denkbaren Uebergänge. An keiner Stelle ist zwischen all diesen Formen eine Grenze zu ziehen. Fïr die Grösse der Fruchthörper lassen sich kaum Maasse angeben. Ton den kleinsten Bildnngen steigen sie an bis zu Handtellergrösse; bis zu $15 \mathrm{~cm}$ Durchmesser habe ich in einzehnen Fällen gemessen. Im Umrisse ist ja die bekannte Ohrform vorherrschend, aber keineswegs ausnahmelos. Der Stielansatz findet sich in der Mehrzahl der Fälle seitlich riickwärts, so wie bei b, d und e. Bei c liegt er ziemlich in der Mitte, da wo der tiefere Schatten sich findet; bisweilen ist er vollkommen central und der Fruchtkürper bildet eine glatte, kreisrunde, pezizaartige Scheibe. Die häufigste Farbe ist röthlich braun, sie geht bis nahezı zum schwarz in einigen Fällen, z. B. bei dem Fruchtkörper a der Figur, und andererseits durch hellere Schattirungen bis zum vollkommensten weiss, das ich an einzelnen Fruchthörpern beobachtete. Alle diese äusserlich so sehr verschiedenen Formen sind indessen geeint durch dieselbe knorpelig, gallertige Beschaffenheit. Bei allen ist die Oberseite, für das blosse Auge zumal, in feuchtem Zustande fast vollkommen glatt. Bei mikroskopischer Untersuchung findet man sie besetzt mit kurzen Haaren, welche meist biischelweise zusammenstehen, ohne eigentlich verfilzt zu sein. Die mittlere schichte des in der Dicke sehr wechselnden Fruchtkörpers hat stets einen lockeren Zusammenhalt. Die Fäden verlaufen dort mit grösserem Zwischenraum in reichlicherer Gallerte. Man kann daher in angefeuchtetem Zustande stets leicht die obere sterile und die untere fertile Seite ïber den ganzen Fruchtkörper hin von einander trennen. Das Hymenium und die Sporen sind bei allen Formen bis in alle Einzelheiten gleich. Die Beschreibung. welche man hei Brefeld (a. a. O.) für Auricularia sambucina Mart. = Auricularia auricula Judae L. findet, passt auf sie alle.

Dieselbe fast erstaunliche Uebereinstimmung aller fand ich in zahlreichen Kulturen, die ich zu vielen Malen von den glatten 
sowohl wie von den wabigen Fruchtkörpern herleitete. Manche dieser Kulturen habe ich monatelang beobachtet. Auf ilıre Ergebnisse gele ich nicht ein. Ich habe der ausführlichen Schilderung Brefelds nichts zuzusetzen. Ich will aber nicht unerwälnnt lassen, dass iclı gerade in diesem Falle an der Hand der Brefeldschen Ausführungen meine Kulturen ron Tag zu Tag prïfte, und dass ich auch bezïglich der von wabenartig ansgebildeten Fruchtkörpern stammenden Sporen alle Einzelheiten über die Keimung, die Bildung der Theilwände in der Spore, die bald friiher bald später, spärlicher oder üppiger eintretende Fruktifikation in den charakteristischen Häkchenconidien Wort für Wort bei den brasilischen Pilzen bestätigt gefunden habe. Die Conidienfruktifikation erschien gleicherweise, ob meine Aussaatsporen von glatten, mit Aur. auricula Judae ïbereinstimmenden, oder von der Friesschen Laschia delicata herstammten. — Die Länge der Sporen schwankte bei den beobachteten Formen wenig um $12 \mu$, die Breite um 4-5 $\mu$. Bei Brefeld sind die Maasse bedeutend grösser $(20-25 \mu$ und $7-9$ и) angegeben. Nachdem aber Herr Professor Brefeld die Güte hatte, mir seine Originalpräparate zum Vergleiche zu senden, kounte ich mich ïberzeugen, dass lier nur Unterschiede in dem angewendeten Messinstrumente, keine wesentlichen in der wirklichen Grösse der Sporen rorliegen.

Das Ergebniss der Untersuchung lässt sich dahin zusammenfassen, dass Auricularia auricula Judae L. (= sambucina Mart.) eine über die ganze Welt verbreitete ansserordentlich abändernde Art ist, welche in den Tropen besonders hänfig rorkonment und dort oftmals zu einem polyporeenartig ausgebildeten Fruclıtlager vorgeschritten angetroffen wird. Falten und Netzleisten im Hymenium finden sich auch schon an europäischen Formen. Die genannte. längst bekannte Art begreift unter sich als ihre höchst entwickelte Form die Laschia delicata $F_{r}$.

Auch in Brasilien hörte ich, dass diese Auricularia, jedoch 
nur in Eimangelung besserer Speise, von den neu im Urwalde angesiedelten polnischen Kolonisten gegessen wurde.

Der leitende Gedanke, welcher uns bei den Antobasidiomyceten den Fortschritt ron den Thelephoreen zu den Hydneen und Polyporeen und Agaricineen verständlich macht, ist der der Oberflächenvergrösserung. Wenn, ohne dass erheblicher Mehraufwand ron Baustoffen für den Fruchtkörper veranlasst werden soll, dennoch möglichst zahlleiche Basidiensporen an ihm zur Ausbildung kommen müssen, so kann dies nur erreicht werden, indem das glatte Hymenium der Thelephoreen sich entweder mit Leisten bedeckt, deren senkrecht zum Lager stehende Wäntle nun anch Basidien erzengen, oder indem netzförmig verbundene Wälle sich erheben, welche schliesslich röhrenartige Hohlräume umschliessen, in die hinein die sporen gebildet werden, oder indem einzeln stehende Erhebungen aufragen, welche sich ringsum mit dem Hymenium bedecken. Alle diese Fälle sehen wir unter den Antobasidiomyceten verwirklicht. Nannigfaltige Uebergänge zwischen den verschiedenen Typen der Oberflächenvergrösserung sind denkbar, und beinahe alle finden wir in Wirklichkeit bisweilen ansgebildet. Ich werde hoffentlich Gelegenheit haben, im weiteren Verlaufe dieser Nittheilungen auf manche besonders bemerkenswerthe Uebergänge von Thelephoreen zu Agaricineen einerseits, zu Polyporeen und weiter Hydneen andererseits, endlich anch von Agaricinen zu Polyporeen in genanerer Darstellung hinzuweisen. Dabei werden wir bemerken, dass noch hente manche Formen in ihrem Entwicklungsgange Zustände durchlaufen, welche sie der Reilıe nach z. B. zu den 'Thelephoreen, damn zu den Polyporeen, endlich zu den Hydneen zu stellen erlauben wïrden, Thatsachen, die auch den ernsthaften Systematikern, Elias Fries an der Spitze, nicht unbekannt geblieben sind, ob sie gleich eine auf genügend reiches Material gestützte zusammenhängende Bearbeitung bisher nicht erfahren haben.

Die Protobasidiomyceten bilden zu den Antobasidiomyceten eine parallele Reihe, und indem wir feststellen, dass dasselbe Prinzip der 
Oberflächenvergrösserung bei ihren Fruchtkörpern in Wirksamkeit tritt, und dieselben Folgen mit sich bringt, die Protobasidiomyceten also in ihren höchsten Vertretern wiederum zu Protothelephoreen, Protohydneen und Protopolyporeen führt, erkennen wir deutlich die Natürlichkeit und die Selbstständigkeit der ganzen Familie. Eine Protopolyporee unter den Auriculariaceen ist also Auricularia, unter den 'Tremellaceen werden wir als solche den Protomerulius brasiliensis kennen lernen, makroskopisch nicht von der Gattung Merulius zu unterscheiden, demnoch im Besitze der 'Tremellinenbasidie, und dadurch seinen weiten Abstand in der Blutsverwandtschaft bekundend. Tremellodon und Protohydnum endlich vertreten unter den Protobasidiomyceten die Hydneen, während den Agaricinen entsprechende Arten bisher noch nicht bekannt geworden sind.

Es hat sich in der Praxis der Systematik fuir die Autobasidiomyceten der Grundsatz heransgebildet, dass wir den Formen ilue systematische Stellıng anweisen da, wohin sie die jeweilen höchste Fruchtkörperausgestaltumg verweist. Ich habe beobachtet, dass Schizophyllum in geeigneten Kulturen häıfig Zustände durchläıft, in denen es einem pezizaartigen Becher ähnelt mit glatter. basidienbedeckter Scheibe. und erst nachträglich treten die Lamellen darin auf. Tom Polyporus vaporarius wissen wir aus Brefelds Untersuchumgen (Bd. VIII S. 108), dass er in kïnstlichen Kulturen erst freie Basidien. dann glatte thelephoraartige Lager von Basidien bildet, ehe die Röhren angelegt werden. Genan so verhielt sich in Kulturen auch der durch die Tropen der alten und neuen Welt gemeinste Polyporus sanguneus. In Henningsia geminella nov. gen. et nov.spec, einem 'Typus der Polyporeen. werden wir eine Form antreffen. welche regehmässig einen verhältnissmässig hochorganisirten 'Thelephoreenzustand durchläuft, ehe die Röhren des höher entwickelten Fruchtkörpers in die Erscheinmo treten. Kein Nensch wiirde desshalb die eben genannten Pilze zu den Thelephoreen stellen. Wenn wir diese Thatsache bedenken, so erscheint es nur folge- 
richtig, die Auricularia auricula Judae abzutrennen von denjenigen Auricularia-Arten, welche das wabige Fruchtlager noch nicht besitzen, also z. B. von A. mesenterica. Die letztere wïrde zu den den Thelephoreen entsprechenden Protobasidiomyceten (Protothelephoreen) zu zählen sein, die Aur. anric. Judae hingegen zu den Protopolyporeen. Wollte man diesen Erwägungen folgen, so miisste unbedingt der Friessche, mit feinem Verständniss begrïndete Name Laschia für unsere Auricularia wieder in seine Rechte treten.

Einzig und allein der Umstand, dass in unserem Falle die höchste Fruchtkörperausbildung nicht von allen Individuen, ja im Ganzen genommen vielleicht nur von einer Minderzahl unter besonderen Verlältnissen schliesslich erreicht wird, lässt es mir richtiger erscheinen, sie im Rahmen der alten Gattung Auricularia zu belassen. Nan möchte nämlich nach dem Vorangegangenen wohl erwarten, dass bei Auricularia junge Fruchtkörper immer glatt seien, dass dam mit zunehmendem Alter die Falten aufträten, häufiger wïrden und schliesslich zu dem wabigen Hymenimm iiberleiteten. Dem ist aber nicht so. Zahlileiche Beobachtungen iiberzengten mich, dass die wabigen Fruchtkörper schon in den jüngsten Zuständen ihren Charakter zeigen, und dass die glatten nicht rumzelig werden, wemn sie auch noch so sehr an Grösse zumehmen. Im grossen Ganzen bemerkt man sogar, dass meist die in einem 'Trupy an ein und demselben Stamme zusammenstelıenden Einzelwesen, die also wahrscheinlich ein und demselben Mycel entspringen, in der Art und Form der Ausbildung ihres Hymeniums mit einander iibereinstimmen. Auch diese Regel leidet jedoch viele Ausnahmen. Ich habe bei mehrfachem Sucheu häufig Stellen gefunden, wo im dichten Trupp glatte, gefurchte und wabige Fruchtkörper enge bei einander und durch einander vorkamen. 


\section{II.}

\section{Uredinaceen.}

Die grosse und weit verbreitete artenreiche Familie der Rostpilze wird zweckmässig als zweite Familie der Protobasidiomyceten anfgefïhrt. Wir haben ilıre nahen Beziehnugen zu den niederen Auriculariaceen, insbesondere zu den als Saccoblastia neu bezeichneten Pilzen im Vorhergehenden kennen gelernt. Die Ludwigsche Bemerkung über das von von Lagerheim entdeckte Campylobasidimm bestärkt uns in der Ansicht, dass es wohl möglich ist, die Uredinaceen ron den niederen Auriculariaceen natiirlich abzuleiten. Durch die Anpassung an parasitische Lebensweise wurde die phylogenetische Entwickelung dieser Formenreilıe in eigenartige Bahnen gelenkt. Die Nebenfruchtformen entwickelten sich in einem Reichthum, wie er sonst im Pilzreiche kaum zum zweiten Male angetroffen wird. Conidien traten in eigenen geschlossenen Behältern auf (den fiüheren „Spermogonien“). Ganz besonders aber wurde die Chlanydosporenfruchtform gefördert, welche bei manchen Arten in dreierlei verschiedenen Wandlungen ihrer Gestalt, als Uredospore, Teleutosprore und Aecidiospore auftrat. Tede dieser Chlanydosporenformen kann damn noch zal mehr oder weniger loch entwickelten, fruchtkörperartigen Blldungen ansteigen. 
Unter der Summe so vielgestaltiger Nebenfruchtformen verschwand dem Beobachter die Hauptfruchtform. die Basidie, zu scheinbar untergeordneter Bedeutung, und erst Brefeld blieb es rorbehalten, durch seine vergleichend mykologischen Studien die wahre und entscheidende Bedentung dieser Basidie, die Tulasne schon dunkel gealmt hatte (vgl. oben Seite 14-15), ins rechte Licht zu setzen, und damit die ganze Familie der Uredinaceen unter die Protobasidionyceten endgültig einzureihen. (Brefeld VIII S. $229 \mathrm{ff}$.)

Eine Uebersicht über die Eintheilung der in so zahlreichen Vertretern über die ganze Welt verbreiteten Familie findet man hei von 'Tavel: Vergleichende Morphologie der Pilze, Seite $123 \mathrm{fr}$.

Die nicht eben zahlreichen Uredinaceen, welche ich in Brasilien sammelte, hat Herr Hemnings zu beschreiben fremdlichst übernommen. Entwickelungsgeschichtliche Untersuchungen habe ich mit ihnen nicht angestellt. 


\section{III.}

\section{Pilacraceen.}

\section{a. Pilacrella Schröter.}

Die brasilische Pilacrella, welche ich hier zu beschreiben habe, ist mit dem Namen delectans ausgezeichnet, weil ich wohl sagen kam, dass von all den Ergebnissen, welche mir über 9000 Objektträgerkulturen im Zeitraune von beinahe 3 Jahren lieferten, keine mich so hoch erfrenten, wie die hier zu schildernden. Schon dadurch, dass der Pilz der künstlichen Kultur sich ïberaus leicht fiigte und in ihr zur Bildung von Fruchtkörpern gelangte, welche den in der Natur gefundenen in keinem Stiicke nachstanden, bildete er fïn mich ein willkommenes Objekt. Zum werthvollsten Gegenstande meiner Beobachtungen wurde er aber durch die in Lanfe der Kultur in die Erscheinung tretenden Nebeufruchtformen, und deren schrittweise Ansteigerung bis zur Basidien- und endlich zur vollendeten Fruchtkörperbildung. Diese Pilacrella lehrte wie kein anderer Pilz klar und unzweifelhaft, in welcher Weise wir uns die Entstehung der Auriculariabasidien aus dem conidientragenden Faden zu denken haben. Pilacrella gab aber atch Aufschliisse über die gemeinhin als Spermatien bezeichnete Conidienform, sie zeigt den Ursprung dieser Bildungen unverkennbar deutlich uns anf, und in dem Besitze dieser" "Spermatien" giebt sie uns einen nenen 
und erwünschten Beleg für die zwischen den Uredinaceen und Auriculariaceen bestehenden rerwandtschaftlichen Beziehungen. Ueber all dieses aber hinaus gewährt uns diese her'liche Form einen Einblick in die Abtheilung der Werkstätte der Natur, in der die Fruchtkörper der Pilze gebildet werden. Hier ist die Einzelentwickelungsgeschichte in der unzweifelhaftesten Art eine Niederholung der Stammesgeschichte. Während aber deren Phasen sonst fast stets in so beschleunigtem Zeitmasse durchlaufen werden, dass es schwer fïllt, die einzelnen Bilder von einander abzutremnen, so werden sie uns ron Pilacrella langsam nach einander vorgeführt, so dass auch das blödeste Auge folgen kamm und einsehen und rerstehen muss, wie der vollendete Fruchtkörper entstand. Im besonderen zeigt sie uns den Teg an zu der angiokarpen Fruchtkürperform, welche noch höher ausgebildet in Pilacre erreicht wird.

Pilacrella delectams nov. spec. tritt in den Wälleru der UTmgegend Blumenaus stets gesellig anf. wie es auch für P. Solani Cohn et Schröter angegeben wird, und zwar habe ich sie nur an Blatt- und Stammesten der Euter pe oleracea, der bei Blumenau so luäufigen Kohlpalme angetroffen. Wem man einen solchen Palmitenstamm durch einen tiefen Kerb rerwundet, so bedeckt alsbald ein zäher Schleim die Wundstelle, und während der Warmen Jahreszeit kann man ziemlich sicher darauf rechnen. nach 3 bis 4 Wochen die zierliche Pilacrella in dichten Trupps darauf amzutreffen. Aber aucl lange, aufgespraltene Palmitenstämme, die im Wralde liegen geblieben waren, habe ich ganz und gar ron Pilacrella besiedelt angetroffen. Der Pilz gewälnt einen wunderhiibschen Anblick. Auf einem feinen, fast wasserhellen, kaum $4 \mathrm{~mm}$ hohen sitielchen sitzt ein weisser Kopf, ein weisses kngliges schleimklümpchen. welches höchstens $\% / 4 \mathrm{~mm}$ Durchmesser erreicht. Die ganze Er'scheinung gleicht makroskopisch der ron Dictyostelium mucoroides. Auf dem dunklen Wundschleim del Enterpe-stänme sehen die zahlreich neben einander stehenden Pilacrellaküptchen wie weisse glänzende Perlen aus.

Sehimper's Mittheilungen, Heft 8. 
Betrachten wir zunächst die Entstelınng und Beschaffenheit der Fruchtkörper, wie sie sich aus dem Vergleiche der an natürlichen Standorte neben einander gefundenen Stücke ergiebt. Der Pilz entstelt auf der Unterlage als ein kleiner, wässerig durchscheinender Hyphenknäuel, in dem eine regelmässige Lagerung der Hyphen noch nicht erkenubar ist. Ans der Spitze dieses bis $1 \mathrm{~mm}$ lıohen, bald kegelförmigen Ḱnäuels erhebt sich, mit erheblicher Verdünnung gegenïber der Spitze des Kegels, der Stiel des Fruchtkörpers, welcher aus deutlich parallel gelagerten Hyphen zusammengesetzt ist. Schon von unten an biegt ab und zu eine Hyphe aus und endet, haarartig den Stiel bekleidend, frei in der Luft. Weiterhin aber, wenn an der Spitze des Stieles der wenig verdickte kopf sich bildet, so biegen unter diesem alle Hyphen seitlich $a b$ und wachsen haarartig aus. indem sie gleich dem Kelche einer Blithe nach oben wieder mehr oder weniger zusammenschliessen. Die Fig. 18 'Taf. I zeigt ein solches abgesclmittenes und in einen Wassertropfen gelegtes Köpfchen mit seinem Haarkelche. Nach anssen ungeben es die alsbald in grossen Mengen abfallenden und in Wasser sich verbreitenden Sporen. Im Inneren des Haarkelches enden die mittleren Hyphen des Stieles, welche dort ein bald meln' länglich ovales, bald kugliges oder anch nur flach gewölbtes Köpfchen bilden und ihre sämmtlichen Endigungen zn Basidien umbilden. Obschon in der Regel die äusseren Hyphen die Hülle. die inneren die Basidien erzengen, so finden sich doch in der Jebergangszone genug Beispiele, wie das in Fig. 19 dargestellte, wo ein und derselbe Faden sich rerzweigend nach aussen an der Hïllbildung. nach innen an der Basidienbildung sich betheiligt. Die Bildung der Hüllfäden wird ebenfalls ans der Fig. 19 ersichtlich. Der mehrzellige Hauptfaden ist stets schwach nach oben und innen eingebogen. Zahlleiche Seitenäste gehen ron ilmm nur an seiner äusseren Seite ab. Sie entspringen immer dicht unter der oberen Scheidewand und bilden je für sich eine scheidewand dicht über der An- 
satzstelle. Die Seitenzweige betheiligen sich mit entsprechender Stellung und Krïmmung an der Bildung der haarkelchartigen Hülle.

Betrachten wir nun die das ganze Köpfchen bedeckenden Basidien (Fig. 20). Wir sehen sofort, dass wir es mit typischen Auriculariaceenbasidien zu thun haben. Sie sind im Durchschnitte 60 " lang', 5-6 $\mu$ breit und deutlich in je vier 'Theilzellen getheilt. Die reife Basidie zeigt eine charakteristische Tmkrümmung im oberen Drittel ihrer Länge. Die Sporen sprossen ohne Sterigma hervor. Der Ort ihres Austretens ist noch nicht bestimmt. Meist liegt er dicht an einer Scheidewand. Oftmals brechen die vier Theilzellen nachträglich aus einander (Fig. 20).

Der weisse Pilz besitzt, wie elwähnt, ein weisslich glänzendes Köpfchen. Dies wird gebildet ron einer wässrigen Flïssigkeit, welche durch die haarartige Hïlle zusammengehalten ist und ron deu zahllosen in ihr umherschwimmenden Sporen weissgefärbt scheint. Man hat nur nöthig, mit einer Nadel solch Köpfchen zu berïhren, um eine beliebig grosse Menge von Sporen abzunehmen, welche sich leicht in Trasser oder Nährlösung rertheilen. Die so abgenommenen ovalen Sporen schwanken in der Länge ron 14-18, in der Breite ron 7-8 $\%$. Sie keimen in Nährlösung fast ummittelbar nach der Aussaat. und zwar treten zunächst zwei kräftige Keimschläuche aus den Enden der Spore. Die Fig. 21 zeigt ein bereits velzweigtes, doch nur 12 Stunden altes Iycel. Schnell breitet sich das kräftige Fadengeflecht im Kulturtropfen weiter aus. Schon nach 24 Stunden beginnt hier und da die alsbald immer üppiger auftretende Conidienfruktifikation (Fig. 22 und 23). Aus der Spitze je eines Fadens sprosst eine Conidie. welche in Form und Grösse der Basidienspore sehr ähnlich ist. Sobald die volle Grösse erreicht ist, wird sie abgestossen und das Faddenende bringt eine nene Conidie hervor. Nur selten sieht man zwei Conidien neben einander ansitzen (Fig. 22), zum Beweise, dass der Austrittspunkt nicht stets mathe- 
matisch genau derselbe ist. Die eben abgestossenen Conidien liegen noch eine Zeit lang parallel neben der neu sich bildenden (Fig. 22). Weiterhin sprossen die Conidien auch seitlich aus den Fäden, wie die Figuren es in mannigfacher Abwechselung darstellen. Selten kommt es vor. dass eine Conidie, noch an der Ursprungsstelle ansitzend, ilnerseits wieder Conidien bildet (Fig. 22 unten rechts). Es kommen dadurch Bilder zu Stande, welche in auffallender Weise an Hefesprossung erimern. Von einer solchen kann aber bei Pilacrella sonst nicht die Rede sein, demn alle abgefallenen Conidien keimen alsbald mit Keimschläuchen. genau wie die Sporen, nnd bilden ebensolche conidientragende Mycelien, wie wir sie eben betrachtet haben. Obschon die Conidien den Basidiensporen selır ähneln. so sind sie doch in der Form weniger bestimnt; jene schwanken zwischen 14 und $18 \mu$ in der Länge, die äussersten Masse der Conidien aber sind 12 und 26 " bei einer Breite von $6-9 \mu$.

Meine ersten Kulturen stammten rom 29. December 1891. Die znerst anftretenden Conidien wurden an den Spitzen der Fäden gebildet, nachdem die Mycelien schou beträchtliche Ausbreitung gewomen hatten. Durch einen rom Brefeld gelehrten (und zum Beispiel bei der Kultur von Pilacre mit Erfolg angewendeten) Kunstgriff. nämlich absichtlich schlechte Erıähırung der Mrcelien, gelingt es, die Conidienfruktifikation gewissermassen zurïckzuschieben, und Bilder (wie Fig. 22) zu gewinnen, wo man die Conidie in unzweifellhafter Weise anf die keimende Basidienspore zurückverfolgen kann. Auf die an den Spitzen gebildeten Conidien folgen bald die seitlich der Fürlen auftretenden, am 3. Januar aber fand ich in mehreren Kulturen, dass einzehe der in der Nähnlisung ausgebreiteten Zweigsysteme zur Bildmg freier echter Basidien iibergingen (Fig. 30). Im allgemeinen hört an solchen Fäden, die zur Basidienbildung sich anschicken, die Conidienerzeugumg auf. Bei sorgfältigem Durchsuchen solcher Kulturen, in denen die ersten Basidien eben auftreten, luält es 
aber nicht schwer, Bilder zu finden, wie das wiedergegebene, wo die Conidien- nnd Basidienbildung nmmittelbar neben einander in nnzweifelhaftem Znsammenhange studirt werden kömen. Verfolgen wir nun, ehe wir anf die im besonderen höchst bemerkenswerthen Beziehungen beider Fruchtformen zn einander eingehen, den weiteren Verlauf der erst angelegten Kulturen. Die Basidienbildung ïberwiegt allmällich immer mehr und mehr die ganz zurïcktretenden Conidien. Nach 14 Tagen laben die Fadengeflechte auf dem objektträger eine solche Festigkeit in sich erlangt, dass man sie im ganzen abheben nnd anf nene Objektträger mit frischer Nährlösmng iibertragen kann. Tetzt sieht man aus dem Fadengeflechte hier und da zarte Fadenbündel in die Luft sich erheben bis zu 1 oder $2 \mathrm{~mm}$ Höhe. Sie sind so zart, dass sie schon beim Anhanchen umfallen. Nähere Tntersuchung zeigt, dass sie die Spitzen darstellen von kleinen Kegeln, die in dem Fadengeflecht sich bilden durch engeren Zusammenschluss der Hyphen, und welche mit Basidien nach allen Seiten besetzt sind. Wir sehen in diesen Kegeln die niedersten Basidienfruchtkörper. Anch die feinen eben erwähnten in die Luft ansstralılenden Hyphen der Spitze tragen Basidien. Allmälılich, wie die Kultur kräftig weiter wächst, treten kräftigere Frnchtkörper auf, das in die Luft ragende Fadenbiindel wird stärker und die Basidien rücken höher an dem so gebildeten Stiele hinanf, während ilıre Bildung im unteren Theile nachlässt. So entstehen coremienartige Bildnngen, die aber nicht mit (onidien, sondern mit Basidien besetzt sind. Fig. 31 stellt eine solche schon etwas weiter vorgeschrittene Bildung dar, wie sie in der dritten und vierten Toche nach Aussaat der Sporen häufig vorkommen. Hier ist die Hauptmasse der Basidien bereits in die Nitte des 'Trägers emporgerückt, doch kommen bis zur feinen Spitze hin Basidien vor und auch am mnteren Theile ist noch eine basidienbesetzte Ranke zn finden. Noch ist der Stiel nicht scharf begrenzt, seine Wände sind noch unregelmässig in lose Haare zerfleddert, mnd auch zwischen deu 
Basidien ragen überall haarartige Hyphen hervor. Doch von Tag zn Tage werden $n$ m gleichzeitig mit der Terstärkung und Kräftigung der Iycelgeflechte immer vollkommenere Fruchtkörper angelegt. Weiter riickt die Basidiemmasse nach oben, der Stiel bildet sich ans als eine glatte, nicht mehr in Haare aufgelöste Sänle. An seiner Spitze tritt die kopfige Terdickung in die Erscheinung. Auf ihr bilden die Basidien ein geschlossenes Lager und unter den Basidien sprossen die haarartigen Hyphen hervor, welche als ein Kelch das Hymenium des fertigen Pilzes schïtzend umgeben. Zuerst am 1. Februar, nach 34tägiger Kultur, trat ein normaler Fruchtkörper in meinen Kulturen auf, in allen Theilen denen gleich, welche ich in der Natur gefunden hatte und von denen ich ausgegangen war. Nachmalen erzielte ich deren eine grosse Zahl mo manche waren kräftiger als die üppigsten, welche ich im Walde gefunden hatte. Die in Fig. 32 und 33 dargestellten Fruchtkörper sind in künstlicher Küultur erzogenl. Es kamen, wie man da sieht, vereinzelt Fälle ror, wo der Stiel an seiner Spitze sich spaltete und mehrere, bis zu vier, von Haarkelchen numgebene Basidienköpfe bildete. Später bei vielem Snchen im Walde entleckte ich solche ungewöhnlich iippig entwickelte Fruchtkörper, freilich als Ausnahmen, auch im Freien.

Es kann einem \%weifel nicht unterliegen, dass wir in den zu immer höherer Formgestaltung ansteigenden verschiedenen Fruchtkörperbildungen. wie sie ehen beschrieben wmden. Bilder vor nus haben, welche die im Laufe der Zeiten vollendete Entstehumg'sgeschichte der heutigen Pilacrella aus niederer, den Stypinelleen verwandten For'n uns arläutern. Die am Aycel zerstrenten Basidien rïcken zusammen. Hyphenbildungen treten anf, mit dem Zwerk, die Basidien ither das Substrat hinausuleben, der Luft auszusetzen. sie sichtbar zu machen. 1)iese Hypheubildungen verstärken sich, nehmen an Höhe zu. und die Basidien rïcken melı und mehr an die Spitze des entstehenden Stieles. bis sie endlich auf einen bestimmt geformten kopfartigen T'heil beschränkt 
und zum echten Hymenium dort zusammengeordnet werden. Erst ganz zuletzt treten die Haare auf, eine schiitzende Hïlle zu bilden, und die sporen. welche nicht abgeschlendert werden. ror zu schnellem Herabtropfen zu bewahren.

Die Möglichkeit einer so fesselnden Beobachtung wird allein der künstlichen Kultur verdankt. In der fieien Natur habe ich solche Zwischenstufem, wie die in Fig. 31 dargestellte coremienartige Bildung nie aufgefunden. und rem schon die Möglichkeit eines solchen Torkommens auch im Freien nicht gelengnet werden soll, so ist es doch jedenfalls sehr selten. Den Grund dafïr können wir leicht dem Terständniss zugänglich machen. Trem die Spore der Pilacrella in starker Nährlösung keimt, so wird am ersten Tage ein kräftiges Mycel gebildet, ohne Conidien, die Conidienbildung tritt erst am Ende des zweiten Tages auf. In armen Nährlösungen wird das Mycel weniger ïppig entwickelt, einzene Conidien aber treten schon am elsten Tage in die Frscheinung. Ganz ebenso gelingt es durch kräftige Ernährung die ersten Basidien zuriickzuhalten bis zum sechsten 'Tage nach der Aussaat. Dann gehen plïtzlich ganze Fadensysteme zu reicher Basidienbildung über und Conidien kommen dazwischen gar nicht vor: Ist die Ernährung schlechter oder die Kultur durch Bakterien beeinträchtigt. so können schon am dritten Tage einzehe Basidien auftreten. und damn meist an solchen Fäden, die iiberwiegend noch Conidien tragen. Es scheint also. dass das Mreel, wem ihm gimstige Lebensbedingungen geboten sind. immer einen gewissen Grad der inneren Kraft erreicht und damn die nächsthöhere Fruchtform in ihrer Tollendung plötzlich kräftig erzengt; wenn die Lebensbedingungen ungïnstigere sind. so wird die regetative Ausbildung nach Maassgabe der geringeren Mittel vollendet. Der Trieb, die höchste Fruchtform herrorzubringen. macht sich aber dennoch geltend, und sie erscheint, in geringerer Ueppigkeit und frïher als sonst geschehen wäre, die Fntrickelung abschliessend. für deren normale Zeitdauer die vorlıandenen Nährstoffe nicht aus- 
reichend gewesen wären. Genau so können wir uns vorstellen, dass anf dem reichen Nährboden. wie die Natur ihn bietet, die Pilacrellamycelien zu üppiger Kraft heranwachsen, ohne Basidien hervorzubringen, und erst wenn das höchste Maass regetativer Entwickelung erreicht ist. werden mit einem Male die Basidien erzeugt. und zwar dann gleich in der höchsten Fruchtkörperausbildung, zu der die Form bis luente vorgeschritten ist. Auf den Glasplatten der kïnstlichen Kultur droht Nahrungsmangel, und ehe das Ende eintritt, bricht der Trieb zur Basidienfruchtkörperbildung sich Bahn. So lange die Mycelien noch nicht genïgend gekräftigt sind, kam der ganz entwickelte Fruchtkörper nicht erzengt werden. Die Pflanze begnïgt sich mit geringerer leistung und greift zurïck auf niedere Fruchtkörperformen, wie sie zu früheren Zeiten den Gipfelpunkt ilner Entwickelung mögen bezeichnet haben. Indem die Nycelien durch tägliche Tebertragung auf nene Objektträger und immer neue Nahrungszufuhr mehr und mehr gekräftigt werden, steigen auch die Fruchtkörper zu höherer Tollendung, bis endlich die letzte hent mögliche Stufe der Ausbildmg erreicht wird. - Eine Eiche auf frischem kräftigen Boden im freien Stande bringt Frïchte erst rom 70. Jahre an, auf schlechtem Boden, im Druck u. s. w. kann der Zeitpunkt der Fruchterzengung schon im 20. Jahre eintreten.

Die vergleichende Untersuchung zahlleicher reifer Fruchtkörper zeigt, dass die Länge und Ausbildung des Haarkelches, an demselben Standorte sogar, sehr erheblichen Schwankungen unterliegt. Mitunter ist er nur kurz offen, das Köpf chen in der unteren Hälfte umgebend (Fig. 33). Ton da an finden sich alle $\mathrm{Ab}$ stufungen bis zu dem in Fig. 18 dargestellten Falle, wo er nach oben zusammenschliessend eine Art Hülle bildet. Ich glaube, dass es gerechtfertigt ist, diese haarartigen Hyphen, deren Beschaffenheit oben näher geschildert wnrde, wesensgleich zu setzen mit den haarartigen Gebilden, welche die lockere Peridie des Pilacre bilden (vgl. Bref. VII Taf. 1) und es ist mir deshalb nicht zweifel- 
haft, dass Pilacrella ror Pilacre zur Zeit die bestmögliche Stellung im Systeme zu finden hat.

Die Sporen werden nicht abgeschlendert. Sie bilden ein weissglänzendes schleimiges Kunöpfchen am Gipfel des Stieles, das durch den Haarkelch zusammengehalten wird. Es ist möglich. dass die basidienbildenden Fäden auch Flüssigkeitstropfen abscheiden, welchen die wässrige Substanz des Knöpfchens ilıren Trsprung verdankt, obwohl man dies nicht numittelbar beobachten kann. Jedes Insekt, welches die Pilacrellafruchtkörper berührt, trägt ans dem Tröpfchen eine Menge Sporen mit sich fort und dient der Verbreitung der Form. Dass für die Sporenverbreitung in ausgiebigster Weise gesorgt wird, dafiir zeugt der Umstand, dass wo man auch inmer im Walde eine Palmite zweckentsprechend verwundet, nach vier Wochen Pilacrella gefunden wird. es mïsste denn ausnahmsweise trockene Witterung oder die Kälte im Juni bis Angust hindernd dazwischentreten.

Meine ersten Kulturen gewam ich. indem ich mit einer reinen Nadel dem Kopf eines in der Natur gefundenen Fruchtkörpers Sporen entnahm. Jeder, der sich mit solchen Kulturen beschäftigt hat, wird wissen, dass in diesem Wege niemals reine Kulturen zu gewinnen sind. Stets gelangen Bakterien mit in den Kulturtropfen. Wenn Pilacrella in meinen Nährlösungen nicht ein so giinstiges Substrat gefunden, nicht so schmell und ïppig gewachsen wäre, wie es gliicklicher Weise der Fall war, so würde ich schwerlich Erfolg erzielt haben, denn die Bakterien hätten die Ueberhand gewomnen. So aber wuchs der Pilz trotz der Bakterien in der beschriebenen Weise. Te mehr Interesse aber die Conidienbildungen und das erste Auftreten der Basidien boten, um so lebhafter wurde der Wunsch, in ganz reinen Kulturen diesen Bildungen erneute Beobachtung zuwenden zu können. Lnd dieser Wunsch wurde erfiillbar mit dem Moment, wo in den Kulturen die in die Luft ragenden Fruchtkörper auftraten. Aus ihnen konnte ich, sobald die ersten Basidien reif waren, Aussaat- 
material entnehmen, welches ganz rein war, und es wurde nun eine neue grosse Reihe ron Kulturen angelegt, deren Resultate die darauf verwendete monatelange Mühe in unerwartetem Maasse belohnten.

Die Conidienbildung trat alsbald ein, wie frülher. Aber besser konnte ich jetzt erkennen, wie die Conidie aus dem dïnnen Ende des Fadens sprosst, und wenn sie ihre endguiltige Grösse erreicht hat, durch eine Scheidewand abgegrenzt wird, um dann abzufallen. Auch konnte ich verfolgen, dass eine Fadenspitze wohl mehrere Conidien hinter einander, aber kaum jemals mehr als vier oder höchstens fünf herrorbringt. Aufs höchste überrascht aber wurde ich schon am zweiten Tage durch das Auftreten einer nenen zweiten Conidienform, die in den frïheren durch Bakterien verunreinigten Kulturen zu sicherer Beobachtung nicht hatte gelangen können. Bei Keimung in Wasser oder sehr düuner Nährlösung tritt auch diese Conidienform bald und nalıe der keimenden Spore auf. In Fig. 26 sehen wir eine Basidienspore mit zwei Keimschläuchen. An dem oberen bildet sich eine grosse Conidie, an den Verzweigungen der unteren sehen wir die nenen kleinen Conidien entstehen. Sie sprossen aus den gleichen Fadenenden wie die grossen, sie sind aber rundlich. haben nur 2 " Durchmesser und werden von ein und derselben Spitze nach und nach in grossen Mengen gebildet. Die abgeschnürten kleinen Conidien ordnen sich vor der Fadenspitze, wenn der Kulturtropfen nicht leftig erschiittert wird, in eine lange Doppelreihe (Fig. 27 b und 24), und es ist klar, dass sie je für sich von einer Gallerthülle umgeben sind, welche die einzelnen mit einander lose verklebt. Mit welcher Schnelligkeit die Bildung dieser spermatienartigen Conidien vor sich geht, lässt sich aus den Fig. 2ちa-d entnehmen. Wir sehen da um 9 Uhr an einer Fadenspitze fünf freie Conidien liegen, eine sechste sitzt noch an. Um 9 Uhr 20 Min. finden wir auch diese frei; das Fadenende ist einfach abgermdet. Um 9 Uhr 40 Min. sprosst schon wieder eine Conidie hervor, die wir um 
10 Uhr 20 Min. abgestossen finden, so dass num 7 freie Conidien daliegen. Von welchen Bedingungen es abhängt, ob grosse oder kleine Conidien gebildet werden, rermag ich nicht zu sagen. Die Spore Fig. 24, welche an ihren Keimschläuchen in so grosser Zahl kleine Conidien bildet, lag mitten zwischen vielen anderen, deren keine solche Bildungen herrorbrachte. Die am weitesten von der abschnürenden Spitze entfernten Conidien liegen am wenigsten regelmässig geordnet und zeigen eine Anschwellung. Diese Anschwellung kann (Fig. 27 a) so weit gehen. dass eine vollkommene Uebereinstimmung mit den kleinsten Stiicken der grossen Conidienform zu Stande kommt. Während die letztere aber stets kräftig und sofort keimt, ist den kleinen die Keimkraft ausserordentlich geschwächt, wo nicht ganz verloren gegangen. Sie liegen in grossen Massen in dem Kulturtropfen umher und kommen ïher die Anschwellung nicht hinaus.

Ganz dieselben wie die hier rorkommenden kleinen Conidien haben wir früher schon bei Saccoblastia orispora kemnen gelernt. Es ist dort schon darauf hingewiesen. dass wir sie als wesensgleich mit den sogenamnten Spermatien der Uredinaceen anzusehen haben. Pilacrella aber giebt uns über ihre Herkunft noch weiteren Aufschluss. Während nämlich in weitaus den meisten Fällen ein Fadenende nur grosse oder nur kleine Conidien bildet, so wurden bei langem und vielfachem Durchmustern zahlreicher Kulturen endich auch Fadenenden gefunden, welche nach einander erst grosse, keimkräftige und dann kleine, nicht keimende C'onidien erzengten (Fig. 27c). Nach diesem Befunde kann an der Wesensgleichheit beider Gebilde ein Zweifel nicht wohl bleiben. Die Conidienfruktifikation ist hier gespalten in zwei rerschiedene Formen. Wir nissen, dass beide Conidienformen je für sich weitere Steiger'ungen der Ausbildung erfahren haben. Die Fäden, welche die kleinen Conidien erzengen, rücken zusammen zu einem Lager, dieses Lager wird dichter und dichter und kleidet schliesslich den Imnenraum einer urnenartigen Höhlung aus. So 
entstanden die Spermogonien der Tredinaceen. Die grosse Conidienform aber schritt weiter vor zur Bildung des in Form und Conidienzahl bestimmten Conidienträgers, den wir Basidie nennen, und danach weiter zur Fruchtkörperbildung. Die nalren Beziehungen der conidienbildenden Fäden zu den Basidien wurden in den reinen Kulturen der Pilacrella eingehend studirt. Die Uebereinstimmung in der Entstehmngsweise und in der Formansbildung der Conidien und der Basidiensporen kamn Niemandem entgehen. Nan betrachte aber ferner Bildungen, wie bei Fig. 28, wo ein Mycelseitenzweig in zwei Zellen zerfällt, von denen jede eine Conidie erzengt, oder die andere, Fig. 29, wo ein Faden in Zellen von noch ungleicher Länge getheilt ist, ans deren jeder oben eine Conidie, unten ein conidienerzengender Seitenzweig entspringt, man vergleiche diese und die anderen Figuren mit den fertigen Basidien der Fig. 29, 30 und 20, und man wird die Entstehungsgeschichte der Auriculariaceenbasidie in aller Dentlichkeit vor dem geistigen Ange rorüberziehen sehen. Auch unter den Basidien eines reifen Fruchtkörpers wird man bei sorgfältigem Nachsuchen, freilich nur selten, umregelmässige Bildungen antreffen (Fig. 20 links), welche als Rückschlag auf die Conidienbildung allein. damn aber sehr natürlich zu erklären sind. In Fig. 30 ist eine unter Flïssigkeit am Farlen frei gebildete Basidie dargestellt; rergleicht man sie mit den ans dem Fruchtkörper entnommenen (Fig. 20). so wird man finden, dass sie noch kaum andentungsweise die bei den anderen so charakteristische Krümmung im oberen Drittel zeigt. Ind diesen Unterschied konnte ich stets wahrnehmen. Die ersten. ganz freigebildeten Basidien sind gerade, die Krïmmung tritt erst auf, wenn die Anfänge der Fruchtkörperbildung bemerkt werden, mnd die Bildung der Sporen geschieht stets an der concaven Seite der Basidie.

Nachdem Pilacrella delectans uns so werthrolle Aufschlïsse durch ihre leicht auszuführende Kultur ergeben hat, wird es zu einem dringenden Bedürfnisse, auch die wahrscheinlich wohl mahe 
verwandte emropäische Form Pilacrella Solani Cohn et Schröter ernenter Untersuchung mit den Hülfsmitteln der künstlichen Kultur zul unterziehen.

\section{b. Pilacre in der Charakterisirung ron Brefeld.}

Pilacre Petersii ist durch Brefelds Untersuchung im VII. Bande seines Werkes zu einem der am genanesten bekannten unter allen Pilzen geworden. Er diente als erstes glänzendes Beweisobjekt für die nachher zu immer grösserer Klarheit und Schärfe ansgebildete Anschanung, welche in der Basidie den zu bestimnter Form und Sporenzahl vorgeschrittenen Conidienträger erblickt. Bei dem hohen Interesse, welches die Entwickelungsgeschichte dieses Pilzes beansprucht, war es mir seln erwïnscht, anch in Brasilien einen Pilacre anzutreffen und vergleichend untersuchen zu können. Irh war noch kaum fünf Wochen in Lande, da fand ich an trocknen. an Boden liegenden masrigen Aststïcken ron sehr hartem Holze im Oktober 1890 reife Fruchtkörper. in denen ich bei mikroskopischer Untersuchung sofort Pilacre erkannte. Die Fruchtkörper waren kleiner als die von Brefeld beschriebenen, und hatten kaum über $1 \frac{1}{2} \mathrm{~mm}$ Höhe, in ihrem Bau, zumal in der Peridie und dem Basidienlager aber komnte ich keinen Unterschied gegeniiber Pilacre Petersii entdecken. Die reifen Sporen waren auch hier in der Grösse verhältnissmässig stark schwankend und im grossen Durchschnitt vielleicht um 1 ॥ höchstens kleiner als die der Münsterschen Form, von der ich Präparate unmittelbar vergleichen komnte. Die Keimung, welche nie vor dem zweiten 'Tage; und anch damn niemals allgemein erfolgte. begann mit dem Anstritt eines Keimschlanchs an der nabelartig eingedriickten Ansatzstelle der Spore, ganz wie bei Pilacre Petersii, und die Kulturen verhielten sich auch weiterhin genau so, wie es Brefeld geschildert hat. Meine Kulturen bliebeu ganz rein und die Mycelien entwickelten sich kräftig weiter, bis kleine Mycelscheiben von iiber $1 \mathrm{~cm}$ Durchmesser auf dem Objektträger 
gebildet wurden, welche in ihrer ganzen 'Tracht mich aufs genaneste an diejenigen erimnerte, die ich selbst unter Herru Professor Brefelds Leitung im Laboratorium zu Münster aus den Pilacre-Sporen gezogen hatte und in Präparaten aufbewahrte. Ton 'J'ag zu 'T'ag musterte ich meine Kulturen. mit immer wachsender Spannung nach den Conidienträgern suchend, die doch nun sicher auftreten mussten. Aber sie erschienen nie. Ich habe die Kulturen jenes brasilischen Pilacre rom 20. Oktober 1890 bis zum 21. Februar 1891 gepflegt, olne je eine Spur von den charakteristischen Conidienträgern zu finden, und in diesem negativen Ergebniss lag der einzige greifbare Unterschied der brasilischen Form gegen die Müustersche. Iclı habe die Kulturen von Pilacre in Brasilien mit verschiedenem Sporenmaterial im Jalne 1891 wiederholt und auch dann uiemals Conidienträger gefunden, welche an den Münsterschen Kulturen fast ganz regelmässig anftraten. Jedoch nur "fast". Anch in Münster habe ich Pilacremycelien auf dem Objektträger erzogen, welche ausnahmsweise steril blieben, während andere, von Sporeu desselben Fruchtkörpers stammend, zur Conidienbildung ïbergingen. Es diirfte also der negative Befund bei dem brasilischen Pilacre nicht genïgen, um ihn als selbststäudige Art zu clarakterisinen.

Im Anfang des Juni 1891 beobachtete ich anf dem Boilen des von mir bewohnten Hauses an den ganz trockenen, ans sehr hartem Holze (Cedrela sp.) geschnittenen Dachsparcen truppreise weisse gestielte höj)fchen. welche sich bei mikroskopischer Untersuchumg als junge Fruchtköruer desselben, schon im vorigen Jahre gefundenen Pilacre ansmiesen. Es war noch keiner der Fruchtkörper reif, die Köpfchen waren reinweiss. Die Reifung ging sehr langsam vor sich. Erst im Juli ging die Farbe der Fruchtkörper in grauweiss über und Anfang Angust sah man die braunen, im Innern gebildeten Sporen durch die graue Peridie durchschimmern. Erst Fnde August wurden wirklich reife Fruchtkörper gefunden. Die Zeit bis zur Reife war also noch länger 
als bei den von Brefeld in Münster beobachteten Pilzen, wo sie nur sechs Wochen betrug. Bei weiterem Suchen im Wralde fand ich an der Rinde eines morschen, ganz ausgefaulten und nicht melı' bestimmbaren Baumes denselben Pilz an 21. Juli. Del' Reifezustand war hier ein klein wenig weiter volgeschritten als bei den in Hanse gefundenen. Einige Fruchtkörper waren schon vollkommen reif. Dass aber auch im Freien die Entwickelung sich ungemein langsam vollzieht, konnte ich feststellen, als ich denselben Standort am 29. August wieder besuchte. Viele von den schon fünf Wochen vorher mit deutlichem grauweissen Kopfe versehenen Pilze waren auch jetzt noch nicht ganz reif.

Soweit meine Befunde einen Schluss darüber zulassen, so ist auch in Brasilien die Zeit des Auftretens des Pilacre die kalte Jahreszeit. Die Fruchtkörper werden etwa im Mai, Juni angelegt, und reifen im August. September: Auch für den dentschen Pilacre hat Brefeld festgestellt, dass er in den Wintermonaten auftritt. Die Zeitdauer der Fntwickelung scheint in Südbrasilien um etwa einen Monat länger zu sein als in Deutschland.

Die Photographie 'Taf. I Fig. 4 giebt in natürlicher Grösse den Befund an den Dachsparren am 15. Juli 1891 wieder. Was am meisten auffällt im Vergleich mit dem Münsterschen Pilacre Petersii ist die kleinere zartere Statur der brasilischen Form. Auch sind die Köpfchen weniger kuglig, vielmehr ein wenig abgeplattet. Zu einer Abtrennung als besondere Art scheint mil aber kein genügender Grund vorhanden zu sein. Wir haben vor uns eine forma brasiliensis von Pilacre Petersii. deren geringe $A b-$ weichungen auf die Anpassung an das fremde Klima zurückzuführen sind. Thre Reifezeit ist auf der siidlichen Halbkugel um ein halbes Jahr verschoben.

Immer grösser wird mit dem Bekanntwerden der aussereuropäischen Pilzflora die Zahl der kosmopolitischen Pilze. Eine Zusammenstellung derselben, die in nicht zu ferner Zeit möglich sein dürfte, wiurde einen werthvollen Beitrag' zur Pflanzengeog'raphie 
bilden, und einer solchen Zusammenstellung auch den Pilacre Petersii zuzuführen, ist Hauptzweck dieser Mittheilung.

Noch habe ich über den von mir angenommenen Namen Pilacre Petersii eine Ammerkung zu machen. Boudier hat im Journal de botanique II No. 16 (Note sur le rrai genre Pilacre.) festgestellt, dass Fries bei der Gründung seines Genus Pilacre im Tahre 1829 unter diesem Namen Ascomyceten verstanden habe, freilich olme Ascen gesehen zu haben, und er fülırt weiter aus, warum der Pilacre Petersii eigentlich Ecchyna genannt werden müsse. Was Brefeld unter Pilacre Petersii verstanden lrat, ist klar und Jedermann deutlich. Durch Brefelds Untersuchung, die ron weittragendster Bedeutung für die Mykologie war. hat der Pilz und der Name eine klassische Bedeutung erlangt. Die früheren Angaben sind so umbestimmt, so bedeutungslos für den gegenwärtigen Stand unserer Kenntnisse, dass ich mich nicht veranlasst fühle, ron dem Namen abzuweichen, den Brefeld angewendet hat. Unter diesem Namen ist der eigenartige, wichtige Pilz zum ersten Male fest charakterisirt worden. so dass er zu jeder Zeit wiedererkannt werden kam, olme Hülfe ron doch nicht ewig dauernden Exsiccatensammlungen. Wer immer vergleichende Morphologie der Basidiomyceten studiren will, wird die nach Prioritätsregeln möglicher Weise Ecchyna zu nennende Pilzform unter dem Namen Pilacre Petersii kemnen lernen. Nur der vergleichenden Morphologie der Pilze ist aber diese Arbeit gewidmet. 
IV.

\section{Sirobasidiaceen.}

\section{Sirobasidium Lagerheim et Patouillard.}

Sirobasidium Brefeldianm nov. spec. Wurde auf der Rinde an Boden liegender '/weige zuerst im März 1892 nud weiterhin zn vielen Malen in den Wäldern der Umgegend Blumenans angetroffen. Es bricht in Gestalt kleiner, glasig heller 'Tropfen ans den äussersten, dünnen, abblätternden Rindenschichten der Zweige hervor. Besonders ïppige Entwickelung erzielt man, wem man die von dem Pilze bewohnten Zweigstückchen einig' 'Tage nnter' einer Glocke feucht hält. Nach mehrtägigem Anstrocknen wieder angefenchtet, erwachen die Fruchtköruer sofort zu neuem Leben. Ueber sehr bescheidene Grösse kommen die Polsterchen nicht hinans. Sie haben höchstens $3 \mathrm{~mm}$ Durchmesser. Die jüngsten sind fast wasserhell, die älteren mattweiss, mulurchsichtig, gallertig: Bringt man die jüngsten Zustände mer das Mikroskop, so sieht man, dass sie aus im wesentlichen sternförmig von einem Punkte ansstrahlenden verzweigten Hyphen bestehen, welche nur locker verflochtell nud in eine wässerige, kam sichtbare Gallertflüssigkeit eingebettet sind. Fig. 38 'laf. TI stellt diese Hyphen dar, welche bis zu 3 " Durchmesser labell und mit dichtem Protoplasma erfüllt sind. In Allgemeinen nimmt die Dicke der Fäden 
nach den Fnden zu. An jeder der zahlreich rorhandenen Scheidewände bemerkt man eine Schnallenzelle. Eine genane Betrachtmo: zeigt, dass der Raum derselben stets mit der unteren Hyphenzelle in offener Terbindung steht, ron der oberen dagegen durch eine Trand abgegrenzt ist. Trotz dieses allgemeinen Befundes lelnt aber die Beobaclıtung an den in küustlicher Kultur wachsenden Fäden, dass die Schmalle stets entsteht als eine Ausbuchtung, gewissermassen nach unten gerichtete Velzweigung der jüngsten obersten Zelle.*) Sie legt sich der unteren alsbald dicht an und tritt mit ihr in offene Terbindung: rährend sie ron der $\mathrm{Ur}^{\mathrm{r}}$ sprungszelle sehr bald durch eine Sclreidewand abgegrenzt wird. Diese Trandbildnmg vollzieht sich so schnell, und gerade zu der Zeit, wo das Protoplasma am mdurchsichtigsten ist, dass man leicht zu der falschen Auffassung kommen kümnte. es sei die Schnalle eine von der mnteren Zelle ansgehende, der oberen sich enge anschmiegende Terzweignng. - Thatsächlich wird im weiteren Verlanfe nicht selten die Schnalle zum Ansgangsumkt eines sich weiter entwickenden seitenzweiges.

Das Spitzenwachsthmm der geschilderten Hyphen hört sehr bald anf, und man sieht 1 mn (Fig. 38 und 48 rechts), dass die letzten Zellen eines jeden Fadens zu länglich eiförmiger Gestalt anfschrellen. In ihrem dichten Protoplasmainhalte wird alsbald eine grosse Taknole sichtbar, die sich ummittelbar in zrei solche theilt (s. d. Abbildungen). Sobald die beiden Takuolen dentlich sind. bemerkt man die Anlage einer anfangs seln dïnmen. bald erstarkenden Scheidewand, welche, von seltenen Ansmahmen abgesehen, stets schräg quer durch die eiförnige Zenle verlänft. Kinm ist the Scheidewand aufgetreten, so sprosst hefeartig; d. h. olune sterigma. ans jeder der Theilzellen eine spore hervor. welche wiederm länglich orale Gestalt annimmt nud beim allmählichen Heranwathsen den ge-

*) Ganz ebenso ist die Schnallenbildung fül Coprinus vou Brefeld Bd. 1 II Taf. 1 dargestellt. Ebenso anch entstehen die schnallen bei Dictyophora s. Bd. VII dieser Mittheihungen S. 128. 
sammten Inhalt der Mutterzelle in sich aufnimmt. Tn der Regel tritt die obere Sprore nahe der Spitze der Basidie herror, die untere dicht unter der scheiderand. Seltene Ausnahmen ron dieser Regel finden sich. Wir bezeichnen die angeschwollene oberste Fadenzelle. wie eben geschehen. als Basidie. denn sie ist fest bestimmt in ilner Zweitheilung durch eine Wand und in der Zweizahl der Spmen, welche sie herrorbringt.

Noch ehe aber die Sporenbildung an der obersten zur Basidie gewordenen Fadenzelle beendet ist, hat bereits die nächstuntere begomnen. in derselben Weise wie jene anzuschwellen (Fig. 48). Sie theilt sich dmrch dieselbe scluäge Wand und lässt zwei Sporen herrorsprossem. mit deren Bildung ihr Inhalt erschöpft wird.

Währent die Sporen der zweiten Basidie reifen. Werden die der ersten algeworfen. die pntleerte Hiille der ersten Basidie füllt faltig znsammen und bleibt auf der zweiten Basidie sitzen.

Der eben beschriebene Torgang setzt sich num nach nuten zu an den Fäden weiter fort in der durch die F'ig. 48 näher erlänterten Weise. Fast niemals sind mehr als zwei auf einander folgende Basidien gleichzeitig in 'Theilung und sporenbildung begriffen. Die entleerten Häute bleiben eine über der anderen sitzen. werden aber mit der Zeit immer durchsichtiger und undeutlicher. Bei Fig. 48 links sehen wir deren fünf atuf der noch nicht zur Sporenbildung vorgeschnittenem letzten Basidie. Beobachtet wurden Reihen von ïlser ein Thutzend entleerter Basidien.

Sehr eigenartig rerhalten sich die. wie schon erwähnt, hefenartig aussurossenten sporen. Sie nehmen eine länglich tiförmige Gestalt an (Fig. 49b) und erreichen 22--24 "Lünge bei 7 -8 ". grösster Breite. Wem man einen reifen Fruchtkörper durch Schnitte zerlegt oder durch Zerzupfen mit einer Nadel für die mikloskopische Betrachtung herrichtet. so sieht man. dass die Sporen sehr leicht roin der Basidie abfallen. Man findet nur wenige ihrer Ursprungsstelle ansitzend und die grosse Mehrzahl in dem Präparate frei mmlierliegend. Alle aber haben dieselbe 
Gestalt (Fig. 49h). Anfs hïchste erstannt war ich nun, als ich, um für die künstliche Kultur Anssaaten zu gevinnen, die Fruchtkürper in feuchter Kammer iiber dem mit einem Tropfen Nährlösung beschickten Objektträger auslegte mnd nach wenigen Stunden die sporen betrachtete, welche, abgeschlendert, nun in dem Nährlïsungstropfen frei mmherlagen. Hier fand ich nämlich nur kugelrunde spren (Fig. 49a) von 12-24" Durchmesser, keine einzige längliche war dabei, nud ich glanbte nicht anders, als dass mein Sinobasidium keine Sporen abgeworfen hätte, und dass ein fremder, vorher nicht beachteter Pilz mit ilnm zusammen anf dem ausgelegten Rindenstïckchen angesiedelt sei, nud sich duch seine kugligen sporen nm bemerkibar mache. Ich strich nm mit einer Nadel iiber den Sirobasidimmfinchtkörjer lıin und nahm dabei eine Menge sporen ab. die ich in Tährlösmog ïbertrug. mul siehe da, sie hatten alle die urspringlich beobachtote längliche Form, nu nach langem suchen fand ich einige wenige von lingliger Gestalt darmuter. Die anf diest Weise hergestellten Kulturen sind aber wegen der dabei morrmeillichen Terunreinignngen duch Bakterien nicht brauchbar. lch sammelte ron anderen Standorten nenes Material nud legte die Pilze wiedermun zun sporenwerfen

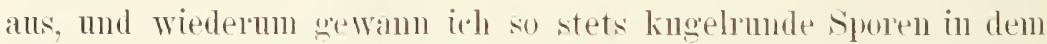
anffangenden 'T'ropfen, während ich bei Butrachtnong der abwerfenden Frolchtkïrpel nu längliche entelecken konnte. Fist in der Tänge der \%eit hei zahlreich wiederholten Versuchen klärte sich die anfangs nuverständliche 'Thatsache anf. Dic ovalen Sporen des Sirobasilimn werden. Wenn sie reif sind. also Wahrscheinlich wemn sie den Inhalt der Mntterzelle vollständig in sich anfgenonmen haben. abgeschlendert. und gehen. während sie durch die Luft Hiegens. von der lïnglichen zur kngelrunden Gestalt ïber. So lange die sporen noch nicht reif sind, kïnnen sie dnuch äussere Einflïsse sehr leicht von ilner Ansatzstelle getlennt weden. rou dieser Zeit hat aber ihe luhalt noch nirlat die strotzende Fiille. nud die mechanische Eimrichtnog der Membran ist noch nicht der- 
artig, dass die Aufblähung zur Kugel eintritt. Die abgenommenen Sporen sind also länglich, die abgeschleuderten kuglig. Xin die kugligen Sporen keimen. und zwar sofort. niemals die länglichen. Bringt man die letzteren in Nährlösung, so kamn man beobachten. dass im Lauf ron 2 bis 3 Tagen sie sich ganz allmählich zur kugligen Form umgestalten. und damn tritt auch bei ihnen die Keimung ein.

Für die Keimung ist die Figm 49 bezeiclmend. Sie zeigt rerschiedene Formen. Häufig sprossen aus der Spore unmittelbar Hefeconidien, welche ihrerseits wieder hefeartig weiter sprossen; es kömnen mehrere solcher Conidien gleichzeitig ans einer spore keimen. Andere sporen treiben einen Keimschlanch, in den sich ihr Inhalt allmählich entleert. Endlich kömnen beide Keimungsarten zugleich an derselben spore auftreten. Der am hänfigsten beobachtete Fall ist in Fig. 43 dargestellt. Hier tritt allmählich der gesammte Protoplasmakörper in das vordere wachsende Ende des einen Keimschlanchs, die rückwärts liegenden entleerten Theile werden nach und nach durch Scheidewände abgegrenzt. Nachdem eine gewisse, meist nicht bedentende Länge erreicht ist, so findet man an der Spitze des Keimschlanchs erst einen Seitenzweig; dam bald mehrere, welche sich bïschelartig ansstrahlend weiter verzweigen und ein Mycelflöckchen hervorbringen. welches seinen gemeinsamen Ausgangspunkt eben an der Spitze jenes Fadens hat, und auf diesem mit der entleerten Spore verbundenen, gleichwie auf einem Stiele sitzt (Fig. 39). Das Wachsthum des Flöckchens geht nur langsam vor sich, dem alle Iycelspitzen gehen nun zur Erzengung von Hefeconidien ïber (Fig. 39 und 43) und erschüpfen in diesen Bildungen einen gnten Theil ihrer Kraft. Um die Fig. 39 zeichnen zu können, mnsste das Objekt mit einem Deckglase bedeckt werden, nnd hierbei ist die Mehrzahl der Conidien abgefallen.

Die soweit vorgeschrittenen Bildungen wurden täglich mit einer ansseglülıten Platimadel in einen nenen Tropfen Nähr- 
lösmug übertragen. Sie waren immer von einem garanen Hofe von Hefezellen umgeben, da die leicht abfallenden Conidien sofort hefeartig weiter sprossten (Fig. 40 und 42). An den Mycelfäden traten nun dieselben Schnallenbildnngen anf, welche wir an den in der Natur gefundenen Fruchtkörper'n schon kemnen lernten. Acht Tage nach der Anssaat zeigte die erste der Kulturen an den Spitzen einiger Mycelfäden tie Anschwellung der Fndzelle, welche alsbald zur Basidienbildnng fühnte. In dem Maasse, wie die Basidienbildung zunahm, wurde die Conidienbildung schwächer und hörte schliesslich gallz allf.

Die ersten Basidien bildeten sich an mutergetanchten Fäden, mond es ward bald deutlich, dass ihre Bildung noch nicht eine in allen Theilen so fest bestimmte war'. wie wir sie an fertigen Fruchtkörperı (z. B. Fig. 41 und 48) angetroften haben. wo jede Basidie ziemlich genan der anderen glich. Hier in den kinstlichen Kulturen kamen zunächst eine Fiille von Bildıugsabweichungen zur Beobachtung, die morphologisch rom höchsten Interesse sind. Einige daron sind in Fig. 44-46 wiedergegeben. An scheinbar ganz beliebig moter vielen gleichen heransgegriffenen Fäden tritt die Basidienbildung hier anf. Nur erst selten findet man eine grössere Anzahl in regelmässiger Ausbildung hinter einander gereiht, wie es später doch zur Regel wird. Es kamen Fälle ror, wo wie bei Fig. 45 zwischen zwei Basidien ein Fadenstück als solches danemd erhalten bleibt. In solchen Falle gewinnt die mntere Basidie eine ausserondentliche Aehulichkeit mit einer Chlamydospore. Die Lage der schrägen scheidewand ist noch weniger scharf bestimmt. Bei Fig. 44 links sehen wir sie fast senkrecht gestellt, so dass die zwei sporen an der spitze der Basidie neben einander erscheinen.

Nicht eben selten beobachtete ich an nutergetallehten Basilien, dass während die eine Theilzelle in regelrechter Weise eine spore erzengte, die andere zmm Faden auswnehs, der an seiner spitze einer Conidie den Ursprumg gab (s. Fig. 46). Im grossen Ganzen 
gewinnt man in solchen Kulturen den Eindruck, dass zunächst die 'Basidien noch frei an beliebigen Stellen der Fäden, unbeeinflusst durch den Drang zur Fruchtkörperbildung entstehen. Wir sehen lier für kurze Zeit einen Zustand wieder in die Wirklichkeit versetzt, der den Endpunkt der Entwickelung des Sirobasidium bezeichnet hat zu einer Zeit, als die Fruchtkörperbildung auch in der bescheidenen Andentung, wie sie jetzt vorliegt, noch nicht eingetreten war. Lnd wie uns diese frei entstehenden Basidien in die Entstehungsgeschichte der Frnchtkörper einen Einblick gewähren. so zeigen sie mns anch die Basidie selbst noch in einer früheren weniger bestimmten Formausbililung. Alhmählich jedoch beginnen num an den älteren Kulturen, während die Conidienbildung ganz verschwindet, von dem kleinen Mycelflöckchen ans nach allen Seiten, anch in die Luft, strahlenatig geordnete Fäden dicht neben einander anszutreiben. Die in die Luft ragenden sondern helle Flüssigkeitströpfohen ab, welche znsammenfliessen und den Schleim darstellen, welcher die reifen Fruchtkörper des Pilzes anszeichnet. Alle jene Fäden beginnen num von der Spitze her in Reihen von regelmässigen zweisporigen Basidien in ler oben beschriebenen Weise sich muzubilden. In der Zeit von 14 'Tagen erzog ich auf dem Objektträger Fruchtkörper, welche von den in der Natur gefundenen in nichts, nicht einmal in der Grösse mehr verschieden waren, und fiir die das Bild der Fig. 41 in oleicher Treise zutreffend erscheint.

Es bleibt uns noch iibrig, auf das weitere Verhalten der Conidien einen Blick zu werfen. Ihre hefeartige Anssprossung ist schon oben erwähnt. Sie bietet der Beobachtung keinerlei schwierigkeiten. Die normale Form der Hefen ist rundlich bei einem Durch messer von 6 - $8 \mu$. Grössere etwas angeschwollene Conidien können kleinen Sporen recht ähnlich sehen. Grössere Sprossverbände als der in Fig. 42 dargestellte, kommen nicht zu Stande, da die Conidien sehr leicht von einander fallen. Beim Bedecken einer Kultur mit dem Deckglase werden alle Verbände gelöst, und man 
findet danu unr noch Znstände, wie in Fig. 40. Die Neigung zur Hefesprossung ist nicht so stark ausgebildet, wie z. B. bei manchen Tremella-Arten, wo man die Hefen nie wieder zur Fadenanskeimmng ïbergehen sieht. Stets findet man vielmehr einzelne Conidien auch mit Fällen keimend (Fig. 40), nnd es ist wohl nicht zweifelhaft, dass auch solche Fäden wieder zu nenen Fruchtkörperı heranwachsen können.

Es ist anf den ersten Blick einlenchtend, dass wir an dem eben beschriebenen Sirobasidium einen nenen, rom rergleichend morphologischen Gesichtspunkte aus sehr bemerkenswerthen Typus der Protobasidie vor uns haben. Während die änssere Form der' Tremellabasidie sich nähert, so weist die eine. zwar nicht genau wagerecht, aber doch schräg stehende Wand anf die Verwandtschaft mit der Anriculariaform hin. Die Abstammung anch dieser Basidie von dem conidientragenden Faden ist noch nnverkennbar. Wie die Conidien an den Fäden olne Sterigma, gewöhnlich dicht unter der nächstoberen Scheidewand oder an der Spitze anssprossen, genan so thm es auch die Basidiensporen. Die conidienerzeugenden Fäden sind von unbestimmter Länge und bringen eine unbestimmte Zahl von Conidien hervor, während die Basidien sich darstellen als Fadenstïcke von bestimmter Länge, welche anschwellen zu bestimmter Form und stets zwei Sporen erzengen. Eine leichte Verschiebung ist indessen doch eingetreten, indem die Sporen grösser sind als die Conidien. und bei der iibrigens in allen P'unkten gleichen Keimmosart die Fadenauskeimung vor der Hefesprossung betonen, während umgekehrt die letztere bei der Keimmng der Conidien bevorzugt ist.

Als ich diesen interessanten Pilz im Jahre 1892 znerst fand, und kultivirte, da ahnte ich nicht, dass etwa gleichzeitig im Norden Südamerikas, in Ecuador im Krater des Puhılahna Herr von Lagerheim zwei der sïdbrasilischen nächstrerwandte Formen entdeckte und untersuchte, welche zon meinem Funde die denkbar glïcklichste Ergänzmng bilden und rergleichend mit ihm be- 
trachtet, für die Systematik der Protobasidionyceten von nicht zu untersehätzender Bedentung werden. Die beiden Pilze aus Ecuador sind unter dem Namen Sirobasidinm albidum und sanguineum bereits im Jahre 1892 von v. Lagerheim und Patonillard im Journal de botanique $\mathrm{Nr}$. 24 beschrieben und abgebildet worden. Ihre nahe Verwandtschaft mit dem S. Brefeldianmm bekunden sie durch ganz gleich gebante Fruchtkörper nud durch die hier wie dort in Ketten hinter einander angeordneten Basidien. Leider sind die Pilze aus Ecuador nicht entwickelungsgeschichtlich untersucht worden, so dass wir über die Keimung ilner sporen und die muthmasslich auch dort vorhandene Nebenfiuchtform der Hefeconidien nichts wissen. Der Besitz der Schnallen ist allen drei Arten der Gattnng gemeinsam. Während aber S. Brefeldianum stets nur eine schrägstelıende 'Theilwand in seinen Basidien anfweist, so finden wil bei den beiden von v. Lagerheim gesammelten Arten unzweifelhafte, ïber Kreuz getheilte Tremellabasidien. Wie wir die Auricnlariabasidie aus dem conidientragenden Faden entstanden zn denken haben, hat uns Pilacrella delectans handgreiflich gezeigt. Wie die Tremellabasidie entstand, sehen wir an den relschiedenen Arten ron Sirobasidinm. Es ist kein Zweifel, dass die beiden Arten ans Ecuador durch Hinzukommen einer weiteren Theilungswand über Sirobasidium Brefeldianum um einen Schritt hinausgehen. Jede der ursprünglich vorhandenen zwei Basidientheilzellen wird abermals getheilt. Geschähe dieser Vorgang durch Wände, welche der nrsprünglichen Wand parallel sind, so würden wir aus S. Brefeldianmm eine Auriculariacee hervorgehen sehen; hier aber stossen die beiden neuen Theilwände in der Mitte der alten zusammen und bilden die 'Tremellabasidie. Keine andere Form ist so geeignet, uns den nahen Zusammenhang der beiden Protobasidientypen so deutlich zu machen, wie Sirobasidium. Dass wahrscheinlich alle Tremellabasidien in ähnlicher Weise entstanden zu denken sind, wird dadurch wahrscheinlich, dass sich bei so vielen Tremellaceen ge- 
legentlich, als Ansnahmen (Rïckschläge), im Hymenium Basidien finden, welche nur eine Scheidewand besitzen und den Basidien unseres S. Brefeldianum durchans gleichen (vergl. z. B. Taf. IV Fig. 6, Fig. 10, Fig. 12 mnd Taf. V Fig. 34 und 37 ). Wie der oben theoretisch eläuterte Fall, dass nämlich die nenen zweiten Theilwände sich mit der erstangelegten nicht krenzen, mnd dadırch eine an Auricularia erimnernde Basidie hervorbringen, in Wirklichkeit rorkommen kann, dafür ist die merkwüıdige, bei Trentella compacta als Ansmahme gefundene. in Fig. 12 rechts abgebildete Basidie ein sprechendes Zenguiss.

Die Sirobasidiaceen sind die Torlänfer der T'remellaceen, zu denen sie ihre nahe Beziehmo anch durch den Besitz der dort so reichlich vorhandenen Hefeconidien bekmuden. Die Befunde bei Sirobasidinm zeigen dentlich, dass zwischen der Anricnlaria- und der 'Tremellabasidie kein principieller' Tnterschied besteht, kein Abstand so gross, wie der zwischen Proto- und Antobasidie ist. Sie. zeigen, dass es nicht räthlich ist, durch Einfühnumg von Namen, wie Schizo- mul P'hramobasidien, eine scharfe Theilung zwischen den rerschiedenen Typen rorzumehmen.

Dass beim Fortschreiten der Formen zu einer echten Fruchtkörperbildung, einer solchen, wie sie z. B. bei den Tremellinen vorliegt, die Anordnung der Basidien in hetten aufhören muss, ist leicht begreiflich. Nmr die oberste Zelle eines Fadens, welche mit del Luft in Berïhnmg ist. behält die Mäglichkeit, zur Basidie zu werden. Von den unteren, in den Fruchtkörper eingebetteten ans wiuden die sporen nicht frei werden kömnen. Bei Sirobasidimm ist die Fruchtkörperbildung nur erst in den allerersten Anfängen. Die Fäden liegen noch fiei neben einander, berïhren sich nicht mmuittelbar, mnd die zwischen ilnen gebildete fast wässerige fliissige Gallerte ist eher förderlich als hemmend fïr die Verbreitumg anch der an den riirkwälts liegenden Basidien gebildeten sporen. 


\section{V. \\ Tremellaceen.}

\section{Stypelleen.}

\section{Stypella nov. gen.}

Indem ich tïir die hier zu besprechenden Tremellaceen den Gattungsmamen stypella wählte, so wollte ich darauf hinweisen, dass sie muter den T'remellaceen genan den Stypinelleen unter den Anriculariaceen entsprechen. Ws sind Formen mit 'Tremellabasidien, bei denem ein Hymenium noch nicht vorhanden ist, die Basidien noch in unregelmässiger Anordnung an dem Fadengeflecht auftreten. Sie stehen in genanester Parallele anch zn den Tomentelleen, der Familie, welche durch freie, nicht zu Hymenien verbundene Autobasidien gekennzeichnet wird. Sie erfüllen in hervorragender Weise die Toranssetzungen Brefelds, der schon 1887 (Bd. VII S. 24) es auf Grund seiner Immfassenden Untersuchungen ïber die damals bekamten Protobasidionycetenformen als lıöchst wahlıscheinlich bezeichnete, dass derartige Formen wïrden gefunden werden.

Stypella papillata nov. spec. ist ein äusserst unscheinbarer Pilz, den ich zweimal, im August 1891 und im Angust 1892, nach nassem Wetter an ganz vermoderten, an Boden liegenden Holzresten im Walde bei Blumenau gefunden labe. Er bildet kleine, 
umregehmässig nmschriebene, kaum 1/2 nmm starke Ueberziige, die sich in den beobachteten Fällen. nar'h keiner Richtnng in grösserer Erstreckung als $1_{2}^{1}$ en ausdehnten, meist jedoch dies Maass längst nicht erreichten. In nassem Tretter haben diese Ueberziige mattglasiges Anssehen, mnter guter Lupenvergrössermng erscheinen sie rauh von winzigen, nmegelmässig verstrenten papillösen Erhebungen, beim Fintrocknen verschwindet der unscheinbare Pilz fïr das blosse Auge vollständig. Bei mikroskopischer Betrachtung finden wir ilm zusammengesetzt ans sehr feinen, locker und umregehmässig verflochtenen Hyphen. Fs ist wohl anzunehmen, dass diese in eine ansserordentlich dimme wasserhelle Gallerte eingebettet sind. der dann das mattglasige Aussehen in fenchtem Zustande zu verdanken sein wïrde. Nachznweisen ist eine solche Gallerte indessen nicht. Die Tntersuchung lehrt ms ferner. dass die papillösen Hervorragnngen zn verdanken sind eigenthümlichen langen schlanchartigen Zellen, welche. mit den gewöhnlichen diinnen Hyphen am Grunde zusammenlängend, das Fadengewirr durchziehen und über dasselbe hindusteichen (Taf. IV Fig. 6). Diese schlauchartigen. vou dichtem Protoplasmainhalt erfüllten scheidewandlosen Zellen sind ron ungleicher. bis zll 200 " ansteigender Länge und haben bis zu 10 "Durchmesser. sie rellaufen nicht gerade. sondern wellig geschlängelt, ansuahmsweise wurden anch einfach verzweigte angetroffen. An den Enden der dïmnen Fäden sitzen in umregehmässiger Vertheilung bald höher, bald tiefer, die nach 'Tremellinenart über Krenz getheilten rundlichen Basidien. Sie haben 9 " Durchmesser. Die Sterigmen, welche je eines ans jeder Theilzelle hervorgehen, wechseln in der Länge nicht bedentend. sie sind ebenfalls im Imohschnitt 9 " lang. Sie tragen an einem seithoh in der bekannten Art verschobenen spitzchen (Fig. 6) die rundlichen sporen ron 4 " Durchmesser. Sekmndärsporen findet man hänfig an abgefallenen, anf dem Fadengeflechte des Pilzes haften gebliebenen sporen.

Unsere stypella ist ein gutes Beispiel fuir den oben (s. S.32-3t) 
anseinandergesetzten T'nterschied zwischen der ron Patouillard als germinatio bezeichneten Sekundärsporenbildung nud wirklicher Keimung. Wähnend erstere sehr häufig nnd leicht zn heobachten war, gelang es mir trotz mehrfacher Versuche niemils. die wirkliche Keimmo der bald in Wasser, bald in Nährlösungen aufgefangenen sporen zu beobachten.

Unter den zumeist krenzweise getheilten Basidien fanden sich bei dieser form verhältnissmässig läufig solche, welche nur eine Scheidewand besassen und mor zwei Sterigmen demnächst hervorbrachten, also eine vollkommene Cebereinstimmung mit den bei Sirobasidium Brefeldianm allgemein rorkommenden aufweisen (Fig. 6).

Stypella minor. nor. spec. wurde an gleicher Unterlage und unter gleichen Terhältnissen wie die vorige Form im Angust 1891 gefunden. Sie stellt nur einen winzigen grauen Flaum dar, bei starker Lupenvergrösserung bemerkt man anch hier sehr schwache papillöse Erhebungen an der Oberfläche. Die Dicke dieses zarten Gebildes ist kamm bestimmbar, die äussere Ungrenzung ganz unregehmäsig. Das Ganze ist aus sehr feinen, locker verwirrten Fäden gebildet, zwischen denen bündelartig angeordnet dickere bis höchstens 3 " starke Fäden verlaufen. Diese Bündel ragen über die Obertläche des Mycelgewirres in der Weise hervor, wie es die Zeichnming (T'af. IV Fig. 7) andentet. Die Basidien. Weiche an den dimnen Fïiden in durchaus unregehmässiger Anordnung entstehen, sind aussergewöhnlich klein; sie haben nur $4-5 \mu$ Durchmesser und sind ïber Kreuz getheilt. Die Sterigmen sind meist gleich lang, im Durchschnitt $7 \iota$, die Sporen oval, $6 \mu$ lang, $3 \mu$ breit. Sie sitzen an den sterigmen mit dem seitlichen spitzchen. welches fast allen genau untersuchten 'T'remellaceen eigenthinmlich ist. Ich fing die Sporen in Wasser und Nährlösung anf, beobachtete aber anch hier keine Keimung. Jedoch machte ich bei Gelegenheit dieser Keimungsverstche eine Beobachtung. welche der Mittheilung werth 
erscheint. Ich hatte das kleine. die Stypella tragende Holzstïckchen in gewohnter Weise momekehrt in der feuchten Kammer etwa $1 \mathrm{~cm}$ hoch ïber einem mit Nährlösmg beschickten Objektträger ansgelegt. Als ich die anfoefangenen sporen dnrchmmsterte, fielen mir unter den głeichmässig geformten, hörhstens 6 " langen Sporen der Stypellar andere auf. Welhe ron demselben Snbstrate abgeschlendert waren mud bei ganz ähnlicher Form durchweg $9 \mu$ Länge besassen. Im weiteren Verlaufe der Kultmren stellte sich herans, dass diese grösseren Sporen erheblich bis anf das $11 / 2$ fache ilmes mrsprïnglichen Durchmessers anschwollen mol hie nud da sogar mit einem dicken Keimschlanche keinten, während die kleineren Sporen alle muverändert blieben. Es war klar, dass neben der stypella noch ein zweiter Pilz ant meinem Holzstiokchen rorlanden war, der ebenfalls sporen geworfen luatte. Da ich mit der Lnue einen solchen indess nicht zn entrlecken rermochte, so mutersuchte ich nikloskopiselı alle die kleinen mogegelmässig begrenzten granen Teberzüge, welche ich zunächst für gleichartig gehalten latte. Da stellte sich dem lerans dass einige ron ilmen ron einem Antobasilionyerten gebildet waren, der monserer Stypella mikroskop,isch mol anch bei der Betrachtumg mit der Lnue vollkommen glich. Er war wie diese ans wirven, aber dmolıweg dwas stälieren Fïden gebildet, die Basidien standen auch hier an den Fuden der Fäden in nuregelmässiger Tertheilung, nidht zu rinem Hymenimum zusimmengeschlossen: sie

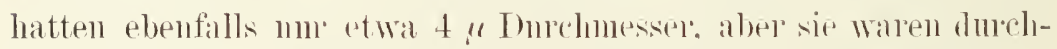
weg nngetheilt. Jede Basidie trug vier sterigmen ron etwa derselben Länge wie bei Stypella minor: aber die anf den Suitzen dieser Sterigmen sitzemben Sproren waren nm \$ $\mu$ länger als bei dem

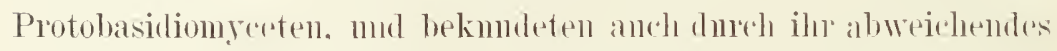
Terhalten in Nährlösmo die Abstammmg von rinem anderen Pilze. Hier lag also eine in die Telwandtschaft der 'Tomentelleen gelörige Form vor, welshe in ilıem Ban nud in ihrer ansseren Exscheinng mit der stypella in geradezn überraschender ITeise ïber- 
einstimmte. Sie unterschied sich nur mikroskopisch durch etwas dickere Hyphen, durch das Fehlen der bündelweise auftretenden Schlanchzellen, durch die ungetheilten Basidien und die etwas grösseren Sporen. Soll man wohl annehmen, dass derartige Tomentelleen ans Protobasidiomyceten entstanden sind durch Terlust der Scheidewände in den Basidien? Ein Fund, wie der eben geschilderte legt die Frage nahe genug. Sie muss indessen auf Grund mserer derzeitigen Kenntnisse verneint werden. Die Tremmng der getheilten und ungetheilten Basidien ist eine grundsïtzliche. Noch keine Form ist bekannt geworden, bei der sorgsame Prüfung der zarten und kleinen Objekte vorausgesetzt beiderlei Basidieu zusammen gefunden worden wären. So wie Hypochnus in manchen Formen der Stypella ähnelt, so ähnelt Exidiopsis manchen Corticien (aber' anch dem Ascocorticium unter den Ascomyceten), so ähnelt 'Tremellodon und Protohydnum manchen Hydneen, so Protomerulius dem echten Merulius. Es liegt kein Grund vor, zwischen diesen je sich entsprechenden Formen einen engen Terwandtschaftszusammenhang anzunehmen. Tielmehr ist der richtige Schluss aus den angeführten Thatsachen der, dass Protobasidien und Antobasidien getrennt waren, ehe die Pilze zur Frnchthörperbildung rorschritten, dass jede dieser Formen für sich zur Hymenien- und weiter zur Fruchtkörperbildung gesteigert wurde. Gleiche Bildungsgesetze wirkten anf beide ein, das Bannaterial der Fruchtkörper, die einfachen Hyphen waren bei beiden dieselben; so kommen äusserlich gleiche oder älnliche, dennoch nicht umnittelbar blntsverwandte Formen zn Stande.

\section{Exidiopsideen.}

\section{a. Heterochaete l'atouillard.}

Die Gattung Heterochaete ist im Jahre 1892 von Patonillard (Champ. de l'Équateur pugillus II. Soc. Myc. de France Tome VIII.) 
begründet worden. Es wurden damals zwei Arten aufgestellt, denen sich in der dritten Aufähhlung der Clampignons de l'Équateur (1893) sechs weitere anschlossen. Die Patouillardsche Diagnose der Gattung lautete: „Fungi heterobasidiosporei, effusi, membranaceo-floccosi rel coriaceo-gelatinosi, undique setulosi; setulis parenclynnaticis, sterilibus. Basidia globoso-ovoidea, cruciatim partita apice sterigmata bina vel quaterna gerentia. Sporae continuae, hyalinae, rectae vel curvulae, germinatione promycelimm emittentes, in conidium unicum apice productum."

Nach dem schon frïher Gesagten (vergl. Seite 32-34) können wir die letzten Worte über die sogenamte germinatio zunächst als völlig belanglos bei Seite lassen. Wir sehen dann, dass wir es hier mit Tremellaceen zu thun lıben, welche einfache, dem Substrate anliegende Ueberziige darstellen und durch Borsten ansgezeichnet sind, die sich auf dem Hymenium erheben. Sie stehen, was die Höhe ihrer Fruchtkörperbildung betrifft, zu den Stypelleen in genau demselben Yerhältniss, wie die Platygloeen zu den Stypinelleen. Es ist der Anfang einer Fruchtkörperbildung durch Zusammentritt der Basidien zu geschlossenen, vorerst glatten Lagern angedeutet.

Nach sorgsamer Durchsicht aller von Patouillat gegebenen Beschreibungen seiner nenen Heterochaete-Arten kann ich nicht zweifeln, dass der von mir gefundene, in Fig. 8 Taf. IT dargestellte Pilz den dort beschriebenen aufs nächste verwandt ist. Jedoch die Angabe, dass die ,setulae“ parenchymatisch sein sollen, bleibt mir unverständlich. Die setulae sind nichts als die bei vielen Exidia-Arten seit langer Zeit bekamnten „Papillen“ des Hymeniums, Bündel enge zusammenschliessender Hyphen, welche in verschiedener, für die einzelnen Arten charakteristischer Form auftreten, und die in besonderen Falle bei Heterochate durch sehr engen Zusammenschluss der einzelnen Fäden viellei‘ht bei flïchtiger Betrachtmo an Pseudoparenchym erimern, in Wirklichkeit aber nicht eimmal dieses, geschweige dem ein wirkliches 
Parenchym darstellen. Derartige Bildungen nun kommen in der Gattung Exidia auf dem Hymenium häufig vor, und Brefeld hat mit Recht hervorgehoben. dass sie als Gattungsmerkmal von sehr untergeordneter Bedeutung sind. Dem Habitus nach und anch mach der Form der Basidien und Sporen würde Heterochaete sich der ron Olsen als Unutergattung ron Exidia begründeten Exidiopsis anschliessen, welche durch ein corticiumähnliches Auftreten gekemzeichnet ist. Ich werde weiterhin ausführen, dass es zweckmässig scheint, diese L'ntergattung Exidiopsis, welche in den 'Tropen viele Vertreter zu haben scheint, zur selbstständigen Gattung zu erheben, nach der weiterhin die Gruppe der Fxidiopsideen, mit der wir es zu thun laben, benannt wurde.

Es liegt num ein wesentlicher Charakter ron Exidia sowohl als von Exidiopsis in dem Besitz jener eigenthïmlichen. häkchenfürmig gekrïmmten conidien, deren regelmässsiges Vorkommen bei allen genau untersuchten Arten von Brefeld nachgewiesen worden ist. Alle Patonillardschen Heterochaete-Arten würden ohne weiteres zu Exidiopsis zu zählen sein. sobald es gelänge, sie zu kultiviren, also ihre wirkliche germinatio, nicht die ron Patouillard als solche bezeichnete Sekundärsporenbildung zu beobachten und das etwaige, ja mit einiger Wahrscheinlichkeit zu erwartende Torkommen der Häkchenconidien festzustellen. Dies ist bis jetzt nicht geschehen. Auch die ron mir gefundene Heterochaete war zur Keimung nicht zul bringen.

Allein aus dem angegebenen Grunde erscheint es mir zweckmässig, die Gattung Heterochaete vorlänfig beizubehalten und in ihr diejenigen exidiopsisartigen Tremellaceen zusammenzustellen, über deren wahrscheinlich vorhandene Nebenfiuchtformen wir noch nichts wissen und die nebenbei durch die allerdings auffallend kräftig ausgebildeten Borsten auf dem Hymenium ausgezeichnet sind.

Heterochaete Sae Catharinae nor. spec. wurde auf abgestorbener Rinde zwischen Lebermoosen angetroffen. Sie bildet dort wenige Milimeter in Durchnnesser haltende, ganz unregel- 
mässig umschriebene, reinweisse, kaum $1 \mathrm{~mm}$ starke Polsterchen, welche, von kleinen Stacheln dicht besetzt, unter der Lupe den Anblick eines winzigen resupinaten Hydnum gewähren. Alle die einzelnen, zahlıeich über die Fläche verstreuten Polsterchen hängen durch einen feinen Hyphenfilz mit einander zusammen, welcher hauchartig dümn das Substrat überzieht. Das Hymenium bedeckt die ganze Oberfläche der Polster, lässt aber die Stacheln frei (Taf.IV Fig. 8). Diese letzteren erheben sich aus dem Hymenium bis zu $150 \mu$ Höhte. Sie bestehen, wie die Zeichnung andeutet, aus bïndelweise vereinten Hyphen, sie sind dicht besetzt mit eigenthïmlichen verdickten und wenig zugespitzten Hyphenenden. welche unter dem Mikroskop eine rauhe Oberfläche erkemnen lassen. Diese Enden ragen etwa 20 " im Durchschnitt ans dem Körper der Stacheln hervor und mögen an der dicksten Stelle bis $7 \mu$ Durchmesser haben. Ihre Nembran ist sehr stark rerdickt, mnd bei sehr starker Verorösserung stellt man fest, dass diese Verdickung lokalisirt auftritt und dadurch die rauhe Oberfläche hervorruft.

Die Basidien, welche eine geschlossene Hymenialschicht zwischen den Stacheln bilden. sind länglich oval. 21 " lang. 12.2 breit. Sie sind iiber Krenz getheilt und tragen vier Sterigmen von ziemlich gleicher, höchstens 20 " betragender lünge.

Die ovalen Sporen sind etwas gekrümmt und mit einem seitlichen Splitzchen und einer Vakuole inn Innern rersehen. Sie gleichen dnrchaus den Sporen ron Fxidia nul Exidiopsis. Sie sind $12-15 \mu$ lang.

\section{b. Fxidiopsis Olsen.}

In Brefelds Untersuchnngen Bd. VII S. 94 ist die Untergattung Exidiopsis aufgestellt und begründet worden. Die dort beschriebene Form, Ex. effusa, bildet eine wachsartige, papierdünne, gelatinöse glatte Hant, weist also noch nicht melı als die ersten Anfänge der Fruchtkörperbildung anf. Da ich in Brasilien ron dem An- 
fange meines Aufenthaltes an, den Protobasidiomyceten meine besondere Aufmerksamkeit zuwendete, so fand ich bald und sehr lıäufig Formen, welche, wie die Kulturen zweifellos ergaben, zu Exidiopsis zu rechnen waren, dïnne schleimig-gallertige Ueberzïge auf faulendem Holze, welche echte Exidia-Basidien und Sporen besassen, und deren Sporen, in Nährlösung ausgesäet, mit dïnnen Fäden auskeinten und zur Bildung der höchst charakteristischen Häkchenconidien übergingen. Die Anzahl solcher Formen, die mir bei den Exkursionen zumal nach Regenwetter in die Hände kamen. wuchs von Monat zu Monat. Die Unterscheidung der einzelnen von einander war oft recht schwierig. Bei diesen einfachen Formen, die nach demselben Typus gebant sind, ist wenig Gelegenheit zur Ausbildung scharfer Merkmale vorhanden. Geringe Grössenunterschiede in den Basidien und Sproren, in der Länge der Sterigmen oder in der Dicke der Fäden. verschiedene Farbentöne des ganzen Gebildes, deuteten wohl oftmals darauf hin, dass verschiedene Arten vorhanden waren; oftmals musste ich aber auch die Frage offen lassen, ob zwei solche "Teberzïge" zu einer Art zu rechnen oder als zwei Arten aufzufassen seien. Manche Formen indessen zeigten bestimmtere charaktere, und diese sind es, die ich bei meiner Beschreibung hier in erster Linie berïcksiclitigen will.

Ich lialte es für angezeigt, Exidiopsis als selbstständige Gattung vor Exidia zu stellen, ja sogar die Exidiopsideen mit der vorläufigen Gattung Heterochaete, sowie mit Exidiopsis und Sebacina als besondere Gruppe vor den Tremellineen in engerem simne zu belandeln. welche letzteren die Gattung Exidia in sich begreifen. Fs folgt das aus dem hier angenommenen Princip der Eintheilung der Gruppen nach der Höhe ihrer Fruchtkörperausbildung. In diesem Betracht nänlich stehen die Exidiopsideen zu den Tremellineen wiederum in genau demselben Terhältniss, wie es vorher zwischen den Platygloeen und den Auricularieen bestand. Exidiopsis weist 11 m freilich mit der Gattung Exidia soviel Uebereinstimmung auf, 
vorzuiglich durch das bei beiden Gattungen gleichmässige Vorkommen der charakteristischen Häkchenconidien, dass es unnatïrlich scheinen könnte, sie zu trennen. Indessen wenn wir berïicksichtigen, dass ganz genan dieselben, fast ununterscheidbar gleichen Conidien auch bei der Gattung Auricularia rorkommen, die doch jedenfalls einer anderen Verwandtschaftsreihe angehört, wenn wir uns ferner erinnern, dass Hefeconidien von gleicher Gestalt bei Pilzen aus den verschiedensten Verwandtschaftskreisen angetroffen werden, so kommen wir zu dem Schlusse, dass die Uebereinstimmung in der Conidienform für sich nicht immer genügen kann, die nahe Blutsverwandtschaft zu beweisen. Ganz anders liegt es im umgekehrten Falle. Durchgreifende Unterschiede in den Conidienformen können wohl als Grund dienen, zwei sonst der Tracht nach ähnliche Pilze generisch zu trennen. Dieser Grund ist z. B. bei Aufstellung der Brefeldschen Gattungen Ulocolla und Craterocolla maassgebend gewesen, auf die wir weiter unten zurückkommen. Im vorliegenden Falle soll nun keineswegs die nahe Verwandtschaft von Exidiopsis zn Exidia durch die hier getroffene systematische Anordnung bestritten werden. Der U'ebergang von jener zu dieser Gattung vollzieht sich vielmehr so allmählich, dass man z. B. bei unserer demuächst zu beschreibenden Exidiopsis ciliata zweifelhaft sein könnte, ob sie nicht bei Exidia besser unterzubringen sei. Es ist ein praktisches Bedürfniss der iibersichtlichen Anordnung, welches die Scheidnng in Exidiopsideen und Tremellineen zweckmässig erscheinen lässt, zmmal diese Scheidung die Parallelität der Tremellaceenreihe mit der der Auriculariaceen aufs beste erläutert.

Exidiopsis also verkörpert uns die niederste Stufe der Fruchtkörperbildung unter den Tremellaceen. Man könnte die Gattmng, wenn sie nicht schon benannt wäre. recht passend auch Protocorticium nemnen, wodurch die augenfällige Parallele mit dem schon oben zum Tergleich herangezogenen Ascocorticimm eine treffliche Hervorhebung erfahren wïrde. 
Exidia geht, wie wir sehen werden, schon einen beträchtlichen Schritt weiter auf der angezeigten Bahn. Dort treten im Lager der Basidien Aufwölbungen, Buckel und Falten auf. Ein dicker Körper von Gallertgewebe wird gebildet, der zunächst allseitig, bei den höchsten Formen jedoch nur noch an bestimmten Stellen das Hymenium hervorbringt; ja endlich werden sogar consolenartig rom Substrate abstehende Fruchtkörper dort angetroffen.

Exidiopsis cerina nor. spec. wurde in den Wäldern der Umgegend Blumenaus zu verschiedenen Malen gefunden. Sie bildet papierdünne, graue, wachsweiche, gelatinöse Ueberzüge an morschem Holze, an alten Bambusscheiden u. s. w. Der feine Ueberzug legt sich dem Substrate eng an; ist dieses runzlig uneben, so erscheint auch die Exidiopsis so, auf glatter Unterlage ist sie dagegen vollkommen glatt. Die Farbe ist gleichfalls vom Substrat abhängig. Besteht dieses aus hellerem Holz, so erscheint auch der Pilz hell durchscheinend, in anderen Fällen erscheint er blaugrün, röthlichgrau, blauschwarz u. s. w. Obwohl hie und da Unébenheiten auf der Fläche des Hymeniums sich finden, so ist doch von einer regelmässigen Papillenbildung nicht die Rede. Die in gleichmässiger Schicht angeordneten Basidien sind ein wenig oval mit 12 "grösstem Durchmesser, die Sporen länglich gekrïmmt, wie bei fast allen Exidien, 8-9 " lang und 6 " breit. Ein leicht auffindbares Nerkmal besitzt diese Form in eigenthümlichen Schläuchen, welche pallisadenartig; aber in ungleichem Abstande von einander im Hymenium stehen, über dessen Fläche aber nicht nach aussen hervorragen. Diese Schläuche haben 22 bis 30 " Länge bei ungefähr 7 " Breite. Sie sind mit gelblichem dumkleren Inhalte erfüllt. Es sind Bildungen, welche den bei Stypella beschriebenen, dort viel längeren Schläuchen wahrscheinlich wohl wesensgleich zu setzen sein dürften. Auch bei trocken oder in Alkohol aufbewahrtem Material erhalten sich diese Schläuche für immer kenntlich durch ihren dunkleren Inhalt, während die 
ausserordentlich feinhäutigen Basidien an aufbewahrtem Material nur mit grösster Muihe und nie mehr ganz zweifellos dentlich in den Einzelheiten ilıres Banes erkannt werden.

Zahlreiche Knlturen in Nasser und in Nährlössungen habe ich besonders im Jahre 1891 angestellt und später wiederholt. Ihr Ergebuiss deckt sich in allen Einzelheiten mit dem durch Brefeld im VII. Hefte seiner Untersuchnugen mitgetheilten ïber die dentschen Exidien. Die ans der Spore anstretenden Keimschlänche sind ausserordentlich fein und verzweigen sich reich. Sie bilden dichte Hycelrasen auf dem Objektträger und aus deu Rasen erheben sich später die conidientragenden Fäden, welche die stark gebogenen Häkchen in grossen Mengen, köpfchenartig angeordnet, tragen. In dümnen Nährlösungen tritt die Conidienbildung im Allgemeinen friiher auf als in reichen. Sie greift dann zuriick bis in die numittelbare Nähe der Spore. Die Brefeldschen Zeichnungen auf Taf. $Y$ a. a. $O$. sind ohme weiteres gültig für diese an Boden des brasilischen Urwaldes anfgegriffene Exidiopsisform. Anch dass die Häkchenconidien ihrerseits wieder zu Mycelien auskeimen, habe ich mehrfach feststellen können. Im Ganzen machten sie freilich hier den Eindruck, als sei ihre Keimkraft geschwächt. Dem die Keimung trat nicht allgemein auf und es vergingen meln als 8 'Tage, ehe ein kleines verzweigtes Mycel zu Stande kam. Tebrigens ist anch die Keimung del Sporen hier wie bei den meisten rerwandten Formen niemals ganz allgemein. Zwischen den kräftig ansgekeimten sporen liegt immer eine grössere Zahl von solchen, welche keine Keimnng zeigen.

Sekundärsporenbildung auf dem Hymenium und bei Anssaaten in Wasser ist läufig.

Exidiopsis reruculosa nor. spec. bildet anf abgestorbener Rinde, anf am Boden liegenden Zweigstiickchen n. \&. w. höchst feine, weisse, kaum seidenpapierstarke Hänte mit umregelmässiger Umgrenzung. Unter der Lupe erscheint die Haut ganz fein gekörnelt von zerstrent stehenden, sehr kleinen Papillen, die sich 
unter dem Mikroskop nur als sterile Fadenbündel erweisen von höchstens 70 " Höhe. Es ist klar, dass diese Wärzchen oder Papillen nur durch geringere Grösse von den „setulae“ der Hymenochaete unterschieden sind. Man würde die Exidiopsis verruculosa sicher zu Heterochaete stellen nüssselı, wenn nicht die Keimung der Sporen und die Conidienbildung uns darïber belehrte, dass sie zu Exidiopsis gehört. Die Basidien stehen ziemlich dicht, sie haben nur 10 " Durchmesser und sind über Kreuz getheilt. Die Sterigmen sind fast genau gleichlang; ebenfalls etwa 10 ॥. Auch die Länge der Sporen beträgt 9--10 ^, ilne Breite $4 \mu$. Sie sind etwas gekriimmt und mit einer Vakuole versehen, wie die meisten Sporen dieser und der folgenden Gattung. Hierbei muss bemerkt werden, dass die Vakuole nur bei frischaufgefangenen Sporen bemerkt werden kann. Sporen von altem in Sammlungen konservirten Material verändern ihren Jnhalt in verschiedener Weise. Die Angabe „sporis guttulatis“, die Patouillard oftmals macht, bezieht sich nur auf solch conservirtes Material und ist fast werthlos, weil sie nur angiebt, wie im besonderen Falle die toten und veränderten Sporen ausgesehen haben.

Die Sekundärsporenbildung kommt vor. Die Keimung geschieht in Wasser und in Nährlösnngsaussaaten; es wurden reich verzweigte Mycelien erzielt, in denen fiuher oder später die Conidienträger auftraten. Die Conidien sind die bekannten Häkclıenconidien. Alle Einzelheiten der Erscheinumg decken sich mit den von Brefeld geschilderten. Die Conidien keinen leicht und kräftig wiederum aus und erzengen nene conidientragende Mycelien.

Bemerkenswerth ist die bei Tremellaceen verhältnismässig soust seltene Schnallenbildung, welche an älteren Mycelien dieser Form mehrfach beobachtet wurde.

Patouillard beschreibt eine Heterochaete lividofusca und giebt dabei an: sporis ovoideis subrectis $(20-24 \times 10 \mu)$; conidiis globosis, hyalinis (10 „ latis). Man könnte also vermuthen, dass hier eine 
vielleicht mit unserer Exidiopsis verwandte Form volläge. Es muss daher immer wieder betont werden, dass Patouillard keine Conidien von Heterochaete gesehen hat, es handelt sich bei jener Angabe, die nur zu leicht Irrthïmer stiften kann, immer nur sm Sekındärsporen.

Erwähnen will ich noch, dass ich neben dieser Exidiopsis verruculosa unter gleichen Standortverhältuissen eine andere Art (Nr. 785 meiner Sammlung) fand, welche bei Betrachtung mit blossem Ange und mit der Lupe nicht von ihr zu unterscheiden war. Die Basidien waren aber hier länglich oval, 21 " lang, anch die Sterigmen lıatten die Länge von etwa $21 \mu$, die gekrümmten Sporen maassen $15 \mu$ Länge, $7-8$ " 4 Breite. Die Basidien zeigten oftmals ein Auseinanderklaffen der Theilzellen, wie es besonders deutlich bei Tremellodon angetroffen wird. Die feinfädigen. aus den Sporen erzogenen Mycelien unterschieden sich nicht vou denen der vorigen. Da aber Bakterien die Kulturen verunreinigten, so gelang es mir nicht, die Conidienbildung festzustellen, welche der For'm höchst wahrscheinlich auch zukonment. Ich unterlasse es desshalb auch, sie mit Tamen zu bezeichnen.

Exidiopsis tromellisporal mor. spec. bildet papierstarke, grane, wachsartig weiche, schwach gallertige T'eberziige mit ganz unregelmässiger Tmgrenzung auf abgestorbener Rinde. Tnter der Lupe erscheint die Fläche höchst fein und regelmässig nit Tärzchen besetzt, welche sich bei genaner Untersuchung als sterile Hyphenbündel erweisen, die kam mehr als 100 " ïber die Fläche hinausragen. Gauz gleiche Bildungen trafen wir bei Ex. verruculosa und es wurde dort schon ilure Uebereinstimmung mit den „setula" der Heterochaete-Arten hervorgehoben. Ihren besonderen Charakter erhält die rorliegende Form durch eigenthümliche Schlänche. welche genan wie bei Fx. cerina in Hymeniun, senkrecht zur Fläche, zahlreich, doch in nuregehmässiger Tertheilnng angetroffen werden. Diese schlänche sind aber hier weit länger als dort. Sie erimnern in inrer Forn sehr an die bei stypella 
beschriebenen und abgebildeten (s. Taf. IV Fig. 6-7) und haben mit jenen auch das gemein, dass sie oftmals iiber die Hymeniumfläche mit ihren Enden ins Freie hinansragen, was bei den Schlänchen der Ex. cerina nie vorkam. Diese Schlänche lassen ihren Ursprung von den sehr dünnen Fäden. welche das Lager des Pilzes bilden, deutlich erkemnen. Sie erreichen bis zu 100 и Länge, bei wechsehnder, meist ron $t-8 \mu$ schwankender Stärke. Sie sind von gleichartigem, körnerfreiem, dichtem Protoplasma strotzend erfüllt. Die Basidien finden sich nicht dicht gedrängt, wohl aber in einer im wesentlichen horizontalen gleichmässigen Schicht angeordnet vor. Sie sind rundlich ïber Krenz getheilt, mit 20-22" Durchmesser. Die Länge der Sterigmen schwankt ansserordentlich, und dies hängt damit zusammen. dass bei dieser Form die Gallertbildung, welche sich weiterhin immer mehr steigert, bereits dentlich auftritt. Wir haben bei den Auriculariaceen gesehen, dass bei den niedersten Formen (Stypinelleen) die Sterigmen kurz und meist von unter einander gleicher Länge waren, dass aber mit dem Auftreten gallertiger Fruchtkörper bei den Platygloeen die Sterigmen länger und ingleich wurden. Genau dasselbe treffen wir nun hier bei den Tremellaceen wiederholt. Mit dem Auftreten der Gallerte wird aus dem früheren lockeren Fadengeflechte ein in sich geschlossener Körper. Die Batsidien liegen mehr oder weniger in Gallerte eingebettet unter der Oberfläche und die Sterigmen müssen je nachdem länger oder kürzer auswachsen, um die Spore ins Freie befördern zи können. Die längsten Sterigmen unserer Form hatten bis zu 63 „ Länge, die kürzesten sind nicht länger als die Basidie selbst.

In der Form der Sporen weicht die Ex. tremellispora erheblich von den frïher besprochenen und ron den meisten Verwandten ab. Sie nähert sith mehr der rmdlichen Gestalt, welche für die Gattmig Tremella charakteristisch ist. Die Sporen messen $16 \mu$ in der Länge und $11 \mu$ in der Breite und die eigenthümliche Krümmung sonstiger Exidiopsis- und Exidiasporen ist nicht 
wahrzunelmen. Die Keimung indessen und die Kultur der aus den Sporen erzogenen Mycelien lassen uns über die Beurtheilung der Form keinen Zweifel bestehen. Es treten feinfädige Mycelien anf, welche mit reichlicher Fruktifikation in den Häkchenconidien von der bekannten Form und Grösse ihren Abschhuss finden.

Vielleicht beweist keine andere Form so schlagend wie diese, dass zm Bemtheilung derartiger Protobasidiomyceten die kiinstliche Knnltur der Sporen ein ganz unentbehrliches Hülfsmittel ist. Nur durch sie kann dieser gar nicht zu rerkennende Charakter, der in den gekriïmmten, winzigen, traubenartig auftretenden Conidien gegeben ist, zur Anschanmmg gebracht werden. Nach der Form der sporen wïrde man geneigt sein. den Pilz ron der Gattung Exidiopsis anszuschliessen.

Durch sporen, welche in ihrer Form ebenfalls an Tremellasporen erinnern und die Krümmung der für Exidia und Auricularia typischen Form nicht erkemnen lassen, ist eine weitere Exidiopsisform ansgezeichnet: Exidiopsis glabra nor. spec., welche vollkommen glatte, unregelmässig umgrenzte, kaum papierstarke. hanchartige Teberzïge darstellt. Ihre Basidien sind 18 " lang, 12 "breit, ihre sproren fast rund, $12 \times 10 \mu$ ganz rom Ansehen typischer 'Tremellasporen. Von Warzen oder Papillen auf dem Hymenium ist nichts zu sehen. Schläuche, wie bei Ex. cerina oder verruculosa kommen im Hymenium nicht vor. Die Fäden: welche das ganze Gebilde in lockerer Verflechtung durchziehen, sind ganz ansserordentlich fein. Die sporen keimen mit rerhältnismässig starken (bis 4 ı) Keimschlänchen, im Gegensatz zu allen anderen nutersuchten Formen, deren Keimschlänche kamm ïber 1 « Stärke hinansgehen. In der Länge der Zeit wurden sie dann in kïnstlichen Kulturen immer feinfädiger; bis sie schliesslich ron den anderen Exidiopsis-Mycelien nicht mehr zu unterscheiden waren. Erst nach 14tägiger Kutur traten die charakteristischen Conidienträger mit Häkchenconidien reichlich in die Erscheinung und ermöghichten die richtige Beurtheilung dieses Pilzes. 
Exidiopsis ciliata nor. spec. ist muter allen ron mir gefundenen Arten der Gattumg die am höchsten entwickelte, diejenige, welche der Gattung Exidia am nächsten steht und einen Uebergang zu ilır vermittelt. Sie bildet rmmle oder r'mdlich lappige, bestimmt umselniebene Krusten von 1-2 mm grösster Dicke anf morschen, am Boden liegenden Rindenstïcken. Das grösste mir vorgekommene Fxemplar ist in natürlicher Grösse photographirt und anf 'Taf. II, 4 dargestellt. Die Masse des Pilzes kann man fast knorpelig-gallertig nennen. Die Kruste legt sich der Unterlage eng an und wiederholt deren Unebenheiten. Sie ist nicht durchweg von genau gleicher Dicke, und es kommen dadurch Unebenheiten ihrer Fläche zu Stande, welche schon etwas an die faltigen Windungen der Exidia- und Tremella-Fruchtkörver erinnern. Doch kommt Exidia ciliata ïber Andentumgen in diesem Simne kaum linaus. Den Namen erhielt der Pilz von der Beschaffenleit des Randes der hrluste. Diese erscheint, wie man mit Hïlfe der Lupe auch auf unserem Bilde an einzelnen Stellen sehen kann, regehnässig fein gewimpert. Dieser hand des Thallus ist sehr dünn. Man kann ihn leicht von der Unterlage abheben und unter das Mikroskop) bringen. Man erkenut dann, wie die Wimpern zu stande kommen. Die radial fortwachsenden Hyphen des Randes schliessen nämlich zu kegelfürmigen Bündeln zusammen; die Kegel stellen die Trimpern dar. Die ganze Fläche des Thallus ist auclı bei dieser Form mit kleinen, für das blosse Auge nur mïlısam erkennbaren, körnigen Papillen besetzt. Anch diese erweisen sich wieder wie in früheren Fällen bei genante Betrachtung als Bündel steriler Hyphen. Wir bemerken besonders an der Spitze dieser Bündel zallleiche, in bestimmter Weise angeschwollene Fadenenden mit ranler Oberfläche. genau denen entsprechend, welche auf den Papillen der Heterochate Sae Catharinae angetroffen wurden. Sie sind indessen hier von mehr ovaler gedrungener Gestalt als dort und haben 15-20 Länge bei $10 \mu$ grösster Breite, die Rauheit ihı'er Oberfläche 
kommt wohl durch ungleiche Nembranverdickung zn Stande. Ueber die Bedeutung dieser Gebilde lässt sich vorlänfig nicht einmal eine Vermuthung anfstellen. Patouillard hat sie bei mehreren seiner Heterochaete-Arten ebenfalls angetroffen und nennt sie pila cystidiformia. Es ist nicht zweifelhaft, dass auch der vorliegende Pilz zur Patonillardschen Gattung Heterochaete wiirde gestellt werden, wemn die Ergebnisse der künstlichen Kulturen seiner Sporen nicht eine andere Anffassung nothwendig machten.

Die Sporen sind die charakteristischen länglichen, etwas gekrümmten Exidia-Sporen; sie messen 12-15 $\mu$ in der Länge, $6 \mu$ in der Breite. Die Basidien sind fast kuglig mit 12-14 $\mu$ Durchmesser. I) Kinltur der Sporen ergab reich verzweigte, feinfädige Mycelien mit den büschelig angeordneten Häkchenconidien znerst an einzehnen Fäden, später an grösseren 'Trägern.

Alles was über Sekundärsporenbildung, 'Theilung der Sporen durch Scheidewände, Austreiben der Keimschlänche, frühere und spätere Erzeugung der Conidien je nach dem Grade der Concentration der Nährlösmng für Exidia durch Brefeld festgestellt ist, wurde in zahlreichen Kulturen der Exidiopsis ciliata bestätigt gefindell.

Ansser den angefiuhrten Exidiopsis-Arten habe ich in meinen Notizen noch vier Formen verzeichnet, von denen ich sicher bin, dass sie selbstständige Arten darstellen. Allen diesen kommen sporen zu von der für Exidiopsis im Allgemeinen bezeichnenden Gestalt, und es ist mir nicht zweifelhaft, dass sie in den Rahmen der Gattung gehören.

Ich habe anch mit illen Answiatversuche angestellt, aber das Anftreten der Häkchenconidien nicht festgestellt. Die Sporen

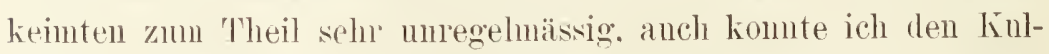
turen nicht immer die nöthige Anfmerksankeit zuwenden. da mich andere Beobachtungen in Ansprich nahmen, und viele wurden da- 
her durch Bakterieninvasion vernichtet. Es ist sehriwahrscheinlich, dass auch diesen Formen die Häkchenconidien nicht fehlen. Ich halte es aber für besser, sie nicht mit besonderen Namen zu bezeichnen, vielmehr die Benennung späteren Beobachtern zu überlassen, welche durch die Feststellung der Conidienfruktifikation ihre Zugehörigkeit zu Fxidiopsis darzuthun im Stande sein werden.

Bei gelegentlichem Durchsehen von Material, das ich von Exkursionen heimbrachte, fiur dessen genanere Untersuchung mir aber die Zeit fehlte, habe ich mich iiberzengt, dass die Exidiopsisformen im siddbrasilischen Walde sehr häufig sind, und wahrscheinlich ist die Anzahl ihrer Arten sehr bedeutend. Die Patouillardschen Heterochaete-Arten dïrften zum grossen Theile lierher gehören. Fs bleibt hier späteren Sammlern noch ein grosses Feld ron Beobachtungen offen, anf dem aber wissenschaftlich verwerthbare Ergebnisse nur dann zul erwarten sind, wenn die Untersuchungen an Ort und Stelle an dem frischen Material und unter Zuhiilfenalıme der kïnstlichen Kultur der Sporen ausgefiilurt werden. Zweifellos könnte ein Mykolog in Buitenzorg z. B. mit verhältnissmässig geringer Mühe unsere Kenntniss dieser und verwandter Arten noch beträchtlich erweitern.

Erwähnt sei hier auch, dass ein von Patouillard (Champignons de l'Équateur pug. III S. 15) unter denı Namen Tremella P'ululahuana beschriebener Pilz mit grösster Wahrscheinlichkeit zu Exillopsis zu rechnen ist. Fr' besitzt nach der Beschreibumg die charakteristische Sporenform der Exidiopsis, sein Habitus weist ihn ebenfalls dorthin und nicht minder die im Lager auftretenden vertikal angeordneten schlauchartigen Zellen. Ueber seine Nebenfiuchtform ist nichts bekannt. Dass Patouillard ihn zu T'remella stellt, bertuht anf einer Willkür, welche nur möglich ist, wenn man die wahren Charaktere dieser Gattung und der Gattung Tremella nicht kennt. Es ist mmöglich, irgend einen nur in trockenem Herbarzustande bekamnten Pilz mit Sicherheit entweder als Tremella oder als Exidia oder Exidionsis zu bezeichnen. 'Tremella lat Hefeconidien. Ohne diesen charakter' 
schwebt die Gattung in der Luft, wie Brefeld dentlich nachgewiesen hat. Es mag dem Systematiker noch so mbequem sein, ohne künstliche Kultur kann er hier die Etiketten für sein Herbarmaterial nicht richtig ausfüllen, ohne künstliche Kinltur keine Bestand versprechende nov. spee. gründen.

\section{(P. Sebacina.}

Die Gattung Sebacina, charakterisirt durch ilıre eigenartigen schimmelähnlichen Conidienträger, gehört als dritte Gattung in unsere Gruppe der Exidiopsideen, da sie, ohne zur eigentlichen Fruchtkïrperbildung vorgeschritten zu sein, nur glatte, wachsartige Veberziige auf dem substrate bildet. Mim veroleiche iiber diese Gittung die Beschreibung und Abbildungen bei Brefeld VII. Heft S. 102 und 'Taf. YI. Ferner anch 'T'ulisue Amn. se. nat. 5. série Tome XV s. 22:3-28. In Brasilien lıabe ich Angelnürige dieser Gattung nicht gefunden.

\section{Tremellineen.}

\section{a. Exillia Fries.}

Aus Furopa sind eine beträchtliche Anzahl von Arten der Gattung Exidia bekannt geworden, denen bisler nur eine Exidiopsis gegeniber stand. Fis war mir daher itherraschend, gerade die letztere Gattung in den Wäldern Südbrasiliens so hä̉nfig nnd in mannigfachem Wechsel der Gestalten anzutreffen, wie ich es eben geschildert labe, wälıend ich eigentliche Exidiaformen lange Zeit rergeblich suchte. Im Angust 1892 fand ich auf verwesenden Bambusblättern an Waldboden einen Pilz. dessen Zugehörigkeit zur Gattung Exidia alle Waluscheinlichleeit für sich hat. For bedeckte thalergrosse Flächen der Lnterlage mit einem weissglau glasig glïnzenden Ueberzuge. Salı man genaner zu, so erwies 
sich der Ueberzug zusammengesetzt aus einer grossen Anzahl kleiner selbstständiger Fruchtkörper, welche rundlich lappige Gestalt, meist nicht iiber $2 \mathrm{~mm}$ Durchmesser und auch nicht über $2 \mathrm{~mm}$ Stärke aufwiesen, und die gegenseitig mit ilıren Rändern sich beriihrten oder anch überdeckten. Jeder einzelne Fruchtkörper ist nur an einer Stelle durch einen freien Stiel der Unterlage angesetzt. Seine Oberfläche ist in der Mitte am lı̈̈chsten, bisweilen anch wellig faltig. Im ganzen ähnelt der Pilz ansserordentlich der ron Brefeld beschriebenen und Taf. T Fig. 12 im VII. Bande seines Werkes abgebildeten Exidia guttata. Die Basidien, welche in dichter schicht unter der Oberfläche stehen, sind oral, 14 "lang, 7-8 " breit, die Steriomen kamm doppelt so lang als die Basidien, ron muleichmässiger Stärke und oftmals verbogen, die Sporen von der charakteristischen, länglichen, etwas gebogenen Gestalt. $7-8$ " lang und 5 " breit. Sekmuärsporenbildung wird anf dem Hymenium angetroffen. Eine Keimung war weder in Wasser, noch in Nährlösung zn erzielen und die Häkchenconidien. welche rermuthlich auch dieser Form zukonmen. wurden nicht beobachtet. Aus diesen Gromds halte ich es für geboten, die nene Form noch nicht zu benennen.

Frgebnissreicher gestaltete sich die Untersuchung einer zweiten Art, welche ich zu verschiedenen Valen und an verschiedenen Standorten im lahre 1892 sammelte. Sie konnte als Exidia sicher festgestellt werden und erhielt den Namen Wxidia sucina nor. spec.

Anf die ersten Exemplare dieses Pilzes, welche ich an morschen Holzstiicken antraf, passte genan die eben fiil' die vorangehende Form gegebene Beschreibung. Nur war die Farbe der gallertigen Polsterchen hellgelblich anstatt weiss. Weitere Funde in den nächsten Tagen des Angust 1892 belehrten mich indessen, dass diese Form mit den oben beschriebenen Fruchtkörperbildungen ilıre höchst mögliche Entwickelung noch längst nicht erreicht hatte. Ich traf bald auch morsche Zweigstiicke, an denen 
dieselbe Form in denselben dünnen, aus kleinen Einzelkörpern zusammengesetzten Krusten vorkam, wo sie aber durch günstige Umstände des Substrats unterstiitzt seitwärts überführte in grössere, hufförmige, vom Substrate abstehende Bildungen. Auch diese sassen, wie die kleinen Frïchte, nur mit einem, freilich etwas dickeren Stiele an, brachen gewöhnlich aus Spalten der Rinde hervor, besissen aber einen viel mächtigeren, bis $2 \mathrm{~cm}$ breiten und über 1 cm dicken Körper aus Gallertmasse und trugen das Hymenium nur an der schon makroskopisch scharf ungrenzten Unterseite. Diese grösseren Fruchtkörper zeigten im durchscheinenden Lichte die Farbe hellen Bernsteins, wovon der Pilz seinen Namen erhielt. Es wiederholte sich bei dieser Exidia also die Erscheinung, welche wir am hänfigsten und dentlichsten ausgeprägt bei manchen Polyporeen kennen, dass sie nämlich aus der resupinaten Form unter geeigneten L'mständen in die seitlich abstehende Consolen- oder Hufform ïberführen. Noch höher und selbstständiger entwickelte Frnchtformen kommen bei manchen unserer europäischen Exidien, z. B. Fx. refanda, truncata, recisa, vor:

Die Basidien nuserer Fxidia sucina messen 10-12 « Durchmesser, die sporen sind 10-12 lang. 4-5 " breit und etwas gekrö̈mmt, mit einer Vaknole im Innern. Das Hymenimm besitzt eine ansgeprïgte Figenart in mugemein zalulreichen, von gelblichem Inhalte strotzenden Schlinuchen, welche dicht unter der Basidienschicht ron den foinen Fïden des Gallertgewebes ihren Ursprung nehmen. zwischen den Basidien dmechgehen und ïber diese himaus bis dicht muter die äusserste schicht des Fruchtkörpers reichen, ohne ïber sie himans ins Freie zu treten. Diese Schläuche verdicken sich ron miten nach oben nicht immer regelmïssig und elTeichen bis zu 8 " Durchmesser. nach oben nehmen sie wieder an Stärlke etwas ab. Ihre Länge schwankt sehr, dïrfte aber im Durchschnitt $60-80 \mu$ betragen. Sie erimern dmrchans an die bei mehreren Exidiopsis-Anten angetroffenen schläuche. 
Gleiche Bildungen beschreibt Patouillard für seine oben besprochene (s. S. 93) Tremella Pululahuana.

Unsere Exidia sucina wurde in zahlreichen Kulturen rom 26. Juli bis zum 6. August und vom 19. Angust bis zum 25. September gezogen. Die Sporen keimen lü̈hst unregelmässig mit einem sehr feinen Faden, in den sie, in der Regel ohne eine Scheidewand zu bilden, ihren Inhalt entleeren. Die ExidiaHäkchenconidien werden dann bisweilen, zumal in dümnen Nälı’lösungen, in unmittelbarer Nähe der gekeimten Spore an dem dïnnen Keimschlauche gebildet (vergl. Brefeld VII Taf. V Fig. 4 und 9). Andere besser ernährte wachsen weiter aus und bilden weitverzweigte, feinfädige. dichte Mrcehrasen, von denen schliesslich die besenartig verzweigten, reiche Conidienbüschel tragenden Fäden in die Luft sich erheben. Alle Einzelheiten stimmen mit den von Brefeld für die emropäischen Formen gemachten Angaben auf das genaneste überein. Die Kulturen mussten jedoch ïber einen Monat lang gepflegt werden, ehe lie Luftconidienbildung. erzielt wurde.

Die stärksten und grössten Fruchtkürper zeigten sogenannte Papillen anf der Hymenialfläche, die kleineren waren ganz glatt, ein nener Beweis für die Bedeutungslosigkeit der Papillen für die Gattungs- und Artunterscheidungen.

Da ich im Vorangehenden stets anf die Brefeldschen Untersuchungen iiber Exidia verwiesen habe. die Bildung der Häkchenconidien wieder'um zu beschreiben und abzubilden für umnöthig hielt, und anstatt dessen mit dem Hinweise auf Brefelds Figuren mir genügen liess, so kann ich nicht umhin, zum Schlusse anf eine Bemerkung einzugehen, welche Costantin ïber jene Untersuchungen gemacht hat (Observat. critiques sur les heterobasidiés Journ. de bot. II S. $229 \mathrm{ff}$.), die, weln sie richtig wäre, mein Verfahren als unzulässig elscheinen lassen müsste.

Costantin sagt a. a. O.: ., Les antenrs (sc. Brefeld, Jstrínffi und Olsen) ont figuré la germination des basidiospores (sc. de l'Fxidia) 
dans un milien nutritif; elle est absolument identique à celle des Auriculaires; mais ils n'ont pas représenté d'arbuscule conidifère comme dans le genre précédent. Ils disent dans le texte (S. 86) que les spores naissent très abondamment sur le mycélium, mais on ne sait pas exactement comment elles se forment sur leurs supports."

Hierauf ist zu erwidern, dass der französische Forscher die ron ihm kritisirte Arbeit doch wohl nicht genan genug berïcksichtigt hat, er miisste sonst auf Seite 90 gefmnden laben, dass über die Bildung der Häkchenconidien jeder ron ihm gewünschte Aufschlnss gegeben ist. Da die Bildmng derselben, wie ich es an meinen brasilischen Formen bestätigen komnte. mit der bei Auricularia vorkommenden, bei Brefeld Taf. $T^{\top}$ durch Jstránffi trefflich dargestellten ganz und gar ïbereinstimmt, so komnte auf jene Figuren verwiesen werden. Es hiesse unnïtz Ram in Anspruch nehmen, wollte man dieselben conidienträger, die man nicht unterscheiden kamm, für jede der Formen einzeln darstellen. Somit glaube auch ich gerechtfertigt zu sein, wemm ich die Tafeh dieses Buches nicht mit abermaligen Abbildungen derselben Dinge füllte, welche von Brefeld und Jstrínffi s. Z. (Brefeld VII T'af. TV) so gut dargestellt sind, dass ich nur fürchten müsste, in der Ausfüln'mng linter jenen Zeichmungen zur weit zurückzubleiben.

\section{b. Ulocolla Brefeld.}

Die ron Brefeld aufgestellte Gattung Ulocolla (Brefeld TII S. 95̃ff.) steht der Gattung Exidia am nächsten durch die Form ilner Basidien und Sporen. Thre Frnclitkörper sind ron denen mancher Tremellen, z. B. Tr. undulata, kaum sicher zu unterscheiden. Die Gattung besitzt aber ein mntrügliches Merkmal in ihıen graden stäbchenförmigen, in Küpfchen angeordneten Conidien, welche an den aus den Sporen keimenden Mycelien gebildet werden (vergl. Brefeld a. a. 0.). Wie keine andere wohl, hat diese Gattung den Unwillen der Systemitiker alten Styles erregt, 
weil sie thatsächlich ohne das Hülfsmittel der künstlichen Kultur nicht sicher "bestimmt" werden kann.

\section{c. Craterocolla Brefeld.}

(Vergl. Brefeld VII S. 98.) Diese Gattung ist besonder's dadurch bemerkenswerth, dass ihre Conidien auf verzweigten Trägern gebildet werden und dass diese Träger' zu selbstständigen pyknidenartigen Fruchtkörpern zusammentreten. Costantin hat durch literar-historische Studien (Journal de bot. II S. 229) gefunden, dass die Gattmng eigentlich Ditangium Karst. heissen müsste. Sollte die Benemmong nach den sogenannten Gesetzen der Nomenklatur auch richtig sein. so erscheint sie mir doch sehr mnpraktisch. Wer sich ïber die Form unterrichten will, muss bei Brefeld nachsehen. Dort ist zum ersten Male klar und dentlich eine 'l'remellinee mit conidienfinchtköruern beschrieben und als Craterocolla benannt. Mit demselben Namen ist der Pilz bei Schnöter aufgeführt. Meiner Ansicht nach kann es nur Terwirrung stiften, wenn man den ganz ungenïgend definirten Begriff Ditangium wieder ansgraben will und iln. unterstïtat durch die Ergebnisse der Brefeldschen Untersuchung als das ansgiebt, was Brefeld ('raterocolla benannt hat, und was Ditangimm eben vorlier nie bedeutet hat.

\section{d. Tremella Dill, in der Begrenzung von Brefeld.}

Die Gattmog Tremella ist, wie Brefeld gezeigt hat, muter' den 'T'remellineen durch den Besitz von hefeartig in mendlichen Generationen fortsprossenden Conidien ansgezeichnet. Ob eine 'Tremellinee solche hefeartig sprossende Conidien besitzt, kamn nur' im Wege der künstlichen Kultur ilner Sporen entschieden werden. Fiir die Unterscheidung der äusserlich oft sehı ähnlichen Arten der Gattung 'Tremella ergaben sich sichere Anhaltspunkte ebenfalls nu' durch die kiunstliche Kultur. Es ist bekinnt, und wir werden bestätigt finden, dass die Form der Fruchtkörner im Rahmen dieser 
Gattung ausserordentlich unbestimmt ist und als sicheres Merkmal der Unterscheidung nicht benutzt werden kamm. Ja selbst die Maasse der Basidien sind nicht sicher, ausserdem bei durchans verschiedenen Arten oftmals gleich. Nur durch das Hülfsmittel der künstlichen Kultur gelang es mir, diese Gattung um eine grosse Anzahl bisher unbekannter südamerikanischer Arten zn vermehren und durch die genane Beobachttung der Conidienbildung, welche für jede Form eine andere, jedesmal aber bestimmte ist, ein für den vergleichenden Morphologen gewiss interessantes Material zusammenzutragen.

Die bisher veröffentlichten, bei Saccardo wohl annäherıd vollständig zusammengestellten Diagnosen ron 'Tremellen, welche entwickelungsgeschichtlich nicht untersucht wurden, sind zum grössten Theile aus den dargelegten Gründen gänzlich werthlos und unbranchbar. Nur wenn eine Form zufällig, wie z. B. Trr. fuciformis Berk., äusserlich so auffallende Merkmale darbietet, dass sie dadurch von allen Verwandten absticht — mond dies ist in der Gattung 'Tremella eben nicht die Regel —, gelingt die Identificirung' eines nenen Fundes mit der schon reröffentlichten Beschreibung wenigstens mit einem hohen Grade von Wahıscheinlichkeit und Sicherheit.

Brefeld hat unter den Arten der Gattung Tremella solche unterschieden. welche Conidien auf den Fruchtkörpern selbst elzengen, und andere, bei denen dies nicht rorkommt. Beiderlei Arten wurden auch in Brasilien beobaclitet.

Von europäischen Arten gehören zur ersten Abtheilung 'T'ı: lutescens und mesenterica.

'Tremella Intescens Persoon, forma brasiliensis. Anl 3. Juli 1891 fand ich nach lange anhaltenden Regenwetter an einem Zaune, der, wie es in dortiger (Gegend ibblich ist, ans gespaltenen Stämmen der Euterpe errichtet War (am Wege von Blumenau nach (Gaspar) eine Tremella, welche ich als Tremella lutescens bezeichmen muss. Wir wissen ron dieser Fornu ans Brefelds eingehender Intersuchung, dass sie in ihren rerschiedenen Ent- 
wickelungsuständen änsserlich recht verschiedenes Ansehen zeigt. Die znerst auftretenden Fruchtkörper sind verhältnissmässig klein, mit dichten, engen. gehimartigen Windungen bedeckt und von bremend rother Farbe. Diese tragen nur Conidien. Nach einiger Zeit erscheinen zwischen den Conidienträgern die Basidien. Gleichzeitig werden die Fruchthörper aufgetrieben zu grösseren, blasig erweiterten Gebilden, sie nehmen 11 eine hellgelbe Farbe an, die Basidien überwiegen über die vorher allein vorlandenen Conidien. Alles dies traf zu fül' die brasilische 'T'remella, welche ich hier bespreche. Tch untersuchte sie genaner und kultivirte ilne Conidien und Sporen. Die Basidiensporen, welche wie bei der europäischen Form 12-15 "Durchmesser besassen, verhielten sich bei der Aussaat in Wasser und Nährlösungen bis in alle Einzelheiten genan. wie es ron Brefeld geschildert und abgebildet worden ist (Band VII, Taf. VII Fig. 7-11). Ein näheres Eingehen hieranf ist mnnöthig. Brefeld hat den Nachweis gefülnt, dass die ron der keimenden Spore gebildeten Conidien, welche hefeartig weitersprossen, wesensgleich sind mit den in den Conidienlagem der Fruclitkörper gebildeten, dass diese letzteren, wemn sie in Nälırlösung ïbertragen werden, sich genau wie jene verhalten. Nur constatirt er einen kleinen, aber sehr bemerkenswerthen Unterschied. Die Hefeconidien, die von den Sporen stammen, sprossen nicht, wie es bei anderen Formen der Fall ist (vergl. z. B. fuciformis) in endlosen Generationen weiter, sondern sie gehen nach verlältnissmässig kurzer Zeit, auch wemn ilmen reichliche Nährstoffe zur Verfügmung stehen, zur Fadenauskeimung über. Immerhin mögen wohl hundert Sprossgenerationen einander folgen ehe Fadenkeimung eintritt. Die Conidien der Fruchtkörper verhalten sich morphologisch ebenso, aber sie erzengen höchstens drei oder vier Sprossgenerationen und gehen dann sofort, also nach viel kürzerer Zeit, zur Fadenkeimung ïber.

Es war mir nun ron grossem Interesse, dass ich in zahlreichen Versuchen diesen an sich geringfügigen Unterschied anch 
bei meiner in Brasilien gewachsenen Tremella ganz sicher bestätigen komnte. Alsbald aber machte ich eine Beobachtung. welche die Ueberzengming von der völligen Gleichheit des südamerikanischen nud des emropäischen Pilzes fast zu erschüttern geeignet war. Wenn nämlich die ron Lagerconidien herstammenden Sprosszellen zn Fäden auskeimten, so bemerkte ich an jedel Scheidewand der Keimschlänche eine dentliche (vergl. Taf. IV Fig. 15) Schnalle, während bei Brefeld sich die ausdrïckliche Angabe findet, dass keine Schnallen rorkommen. Ich untersuchte num wiederholt die ans Sprossconidien von den Sporen herstammenden Mycelanfänge, und fand, dass an diesen die Schnallen zwar meist fehlten, jedoch bisweilen auch vereinzelt vorkamen. Fis möchte sich wohl verlohmen, musere emropäische Tr. lutescens nochmals darauf hiu zu untersuchen, ob nicht auch bei ihr gelegentlich die schnallen anzutreffen sind.

Die Fig. 15 Taf. IV stellt eine kleine Partie ans dem Hymenium unserer brasilischen 'l'remella dar. Im Vergleiche mit den Abbildnngen bei Brefeld 'Taf. VII Fig. 3-4 wird man geringe Unterschiede wahrnehmen, die alle in Worten ansudrücken unnütz weitschweifig sein wiirde. Interessant ist der Vergleich. Er belenchtet treffend die Schwierigkeit. welche sich dem gewissenhaften Beobachter anfdrängt, sobald es gilt, eine an so weit entlegenem standorte gefmudene Pilzform mit einer bereits bekaunten zu identificiren. In muserem Falle dürfte es praktisch mumöglich sein, auf den brasilischen Fund hin eine nene Art der Tremella zu begründen. Dennoch scheint es, dass in gewissen kleinen Einzelheiten die auf der anderen Erdlualfte in durchans anderen klimatischen und Fenchtigkeitsverhältnissen lebende Form $\mathrm{Ab}$ weichnngen anfweist, deren Torhandensein an sich weniger wunderbar ist, als eine rollkommene Uebereinstimmung sein diirfte. (Tergl. anch das ïber die forma brasiliensis von Pilacte Petersii Gesagte s. (63.)

Zn den mit Conidienlagern anf den Fruchtkörpern rersehenen 
Tremella-Arten gehört eine zweite, welche ich nur einmal, in Oktober 1891 gesammelt habe und auch nicht mit einem nenen Namen belege. Das Material ist mir verloren gegangen und Präparate konnte ich nicht aufbewahren, weil Hochwasser und eine nothwendig gewordene Terlegung meiner Arbeitsräume mich damals empfindlich schädigten. So besitze ich von dieser 'T'remella nur einige Zeichnmgen und Notizen. Was die Farbe und For'n der Fruchtkörper und die Grösse der Hymeniumtheile anlangt, zeigt sie eine völlige Uebereiustimmung mit 'T'r. mesenterica. Mit dieser stimnt sie auch darin ïberein, dass auf ilırem Fruchtkörper Conidienträger unteruischt mit den Basidien in höchst unregehmässiger Anordnumg zusammen vorkommen. Ausgezeichnet ist sie durch Śchnallen an deu Scheidewänden der Hyphen, welche fuir 'Tr' mesenterica bisher noch nirgends erwähnt worden sind. All dies wïrde jedoch die Erwähnumg dieser mit 'Tr. mesenterica jedenfalls ganz nahe rerwandten Form nicht rechtfertigen. Indessen erscheint mir eine Beobachtung der Erwähmung werth, welche hier einmal genacht wude. Unter den Basidien sind, wie mich sorgsame Untersuchung sicher iiberzengte, solche mit nu' einer Scheidewand und zwei Sterigmen sehr häufig. Die eine Scheidewand steht schräg (Taf. IT Fig. 10) und die Basidie gleicht in der Form bisweilen der zweitheiligen Basidie ron Sirobasidium. Ich hatte eines Nachmittags Schnitte durch das Hymenium dieser Trenella in Wasser gelegt, es waren daran Basidien in den verschiedenen Stadien der Entwickelumg; noch ungetheilt, mit Scheidewand ohme Sterigmen, mit eben austreibenden Sterigmen u. s. w., vergleichweise deutlich zu beobachten. Als ich an anderen Morgen diese Schnitte wieder'um betrachtete, so fand ich, dass in mehreren Fällen die Conidienbildung, welche an den in Wassel anfgefangenen Sporen in der für' 'Tr. mesenterica bekamten Weise vor sich geht, zuriickgegriffen hatte auf eben austreibende Sterigmen junger Basidien (Taf. IV Fig. 10). Die Sterigmen Waren selı kurz geblieben und schnürten an ihrem Eude Conidien ab. 
In dem Anstreiben eines Keimschlanches, welcher nach kurzer Erstreckmlg mit der Bildnng einer Sekundärspore abschliesst, kömnen wir gewissermassen eine Verlängerung des Sporenzustandes erblicken (s. o. S. 34 das Citat ans Tulasne). Eine solche Terlängermug wird notluwendig, wemn die Spore sich nicht in einer Lage befindet, die für conidienbildung günstig und geeignet ist. Umgekehrt ist es in dem eben beschriebenen Falle. Hier ist durch die besonderen Umstände schon die Basidie in eine der Conidienbildung giinstige äussere Bedingung versetzt, und sofort sehen wir, dass der Sporenzustand kamm durch das nur erst kurze Sterigma angedentet, in seinem weiteren Verlaufe aber ganz übersprongen wird. Es kommt gar nicht zur Bildung der spore, sondern die Conidienbildung tritt bereits an dem Sterigma selbst anf. Diese Beobachtung gewinnt noch an Interesse, wemn man sie im Tergleiche mit der bei Sirobasidium Brefeldianum gemachten, Taf. VI Fig. 46 dargestellten, in Vergleich setzt, wo gleichfalls eine Basidientheilzelle vielleicht in einer als Rückschlag anfzufassenden Weise die Sporenbildung rersäunte und einen conidientragenden Faden hervorbrachte.

In der Reihe der nit conidienlager'n auf den Fruchtkörpern ansgestatteten 'Tremellen verdient weiterhin eine Form Erwähnung, welche mir nicht vollständig genug bekannt geworden ist, 1 m eine selbstständige Benemung nach meiner Ansicht zu rechtfertigen. von der aber Einzehleiten der Erscheinung um deswillen zu rerzeichnen sind, weil sie das Gesammtbild der bei 'Tremella-Arten bisher bekannt gewordenen Conidienformen ein wenig erweitern. lch fand im Februar 1892, wieder'm an morschem Holze eine Reihe ron lenchtend orangegelben Frnchtkörpern, welche makroskropisch ron denen der Tremella lutescens nicht zu miterseheiden waren. Die gallertige Grundmasse der Fruchtkörper zeigt dieselben, hier etwa 3-4 " starken, reich verzweigten, frei in Gallerte eingebetteten Hyphen. wie andere Tremellen. Die gesammte Oberfläche aber deckt ein ïppiges Conidienlager. Hier 
verlaufen die Fäden dicht gedrängt parallel in radialer Richtımg. und zergliedern sich in kurze, fast isodiametrische, meist etwas angeschwollene Theilzellen. Ton diesen Fadengliedern gehen nach allen Richtungen sehr feine Sterigmen aus, welche je eine kuglige Conidie von 3 " Durchmesser erzeugen (s. Taf. IV Fig. 14). Die Fäden sind von den Conidien oft ringsum vollständig eingehïllt; bringt man sie in Wasser und bedeckt sie mit einem Deckglase, so fallen die meisten Conidien ab, während die Sterigmen sitzen bleiben, jedoch wegen ihrer Feinheit nur mit starker Vergrösserıng wahrgenommen werden. Die im Freien aufgefundenen Fruchtkörper lassen ausser den dichten Conidienkrusten nichts erkennen. Als ich sie einige Tage unter feuchter Glocke im Zimmer gehalten hatte, traten an manchen Stellen gerade wie bei 'Tr. lutescens Glättungen der früher ganz engen und dichten Falten auf. Gleichzeitig wurde hier die Farbe etwas heller, und ich fand num auch Basidienanlagen (s. d. Fig.). Die Basidien theilten sich weiterhin über Kreuz und an vielen traten anch je rier Sterigmen aus, zur Bildung ron Basidiensporen kam es aber nicht. Die Conidien säete ich zu verscliedenen Malen in Wasser und in Nährlösung aus. Aber es trat keine Sprossung oder Keimung ein. Da Tremella durch die Hefesprossung ror allem charakterisirt wird und da bei allen sonst hier in Europa und in Siidamerika gefundenen Tremella-Arten diese Sprossung in den ron mir angewandten Nährlösungen schnell und leicht auftrat (vergl. nur als Ausuahme Tr. dysenterica), so ist es sehr wahrscheinlich, dass der hier besprochene Pilz eine selbstständige Tremellinen-Gattung darstellt, wofür auch die Conidienbildung an deutliclten Sterigmen durchaus spricht. Er wïrde von Tremella mit demselben Rechte und derselben Nothwendigkeit zu trennen sein. wie es bei Ulocolla geschehen ist. Eine Entscheidung darüber wird aber nicht getroffen werden können, ehe nicht die Basidiensporen und ilıre Keimung zur Beobachtung gebracht sind.

Noch viel vorsichtiger und zurückhaltender als gegeniiber 
dieser For'm, bei welcher wenigstens das Torhandensein typischer Tremellinenbasidien nachgewiesen werden komnte, muss sich die Beobachtmng anderen Conidienformen gegenïber verhalten, bei denen zugehörige Basidien nicht gefunden werden. Mag anch immer die änssere Erscheinnng noch so sehr dafür sprechen, dass derartige Formen, wie sie bei jahrelang fortgesetztem Sammeln und Beobachten im Walde läufig angetroffen werden, zu dieser oder jener Gruppe von Pilzen gehören, so bleiben solche Funde doch wissenschaftlich werthlos. Wir kömnen von ilmen keine Förderung unserer Einsichten in den Aufbau des natiirlichen Systems der Pilze erwarten, um so weniger, als wir wissen, dass äusserlich sehr ähnliche Conidienformen bei Ascomyceten und Basidiomyceten gleicherweise rorkommen kömen. Ich hahe während meines Aufenthalts in Blumenau eine Reihe ron tremellaartigen Conidienfrüchten im Walde beobachtet. An einem fanlenden feuchtliegenden Stamme habe ich eine solche 21/2. Tahre lang sich stets nen erzengen sehen. Sie bildete weisse r'undliche Schleimklïmpchen und enthielt dimne, in Gallerte eingebettete Fäden, welche armlenchterartig verzweigt waren und an ihren Spitzen Conidien bildeten. In Zwischenrämmen ron jedesmal einigen Wochen habe ich sie regelmässig untersucht, aber niemals die Spur einer höheren Fruchtform daran gefunden. Eine andere Form wieder stellte Bildnngen dar, wenig resschieden ron den eben beschriebenen, der Tremella lutescens ähnlichen. Aber so sehr sie auch in ihrer ganzen Tracht einer Tremella ähnelte. Basidien wurden nicht daran gefunden. Hierher gehört anch die sogenannte Delortia Patonillard, welche bei Blumenau im IValde eine sehr häufige Erscheinnug ist und ïber die ich oben (S. 35) schon berichtet habe. Will man solehe murollständig bekannte Conidienformen beschreiben, so können sie ihren Platz nur unter den Fungi imperfecti finden, wohin nebst Delortia z. B. anch Septobasidium gehört (vergl. oben S. 35). Es fehlt jeder Anlalt dafïr, dass diese Formen den Protobasidionyceten einzureilıen sind. Ich habe auf diese 
Dinge hintreisen miissen, damit mir nicht der Torwurf gemacht werde, ich hätte jene Gattungen ignorirt. Zahlreiche derartige, nach Lage unserer bisherigen Kenntnisse nicht richtig zu benrtheilende Formen sind mir während meiner Arbeiten in Brasilien vorgekommen. Ton manchen, die durch merkwïrdige Formgestaltung auffielen, habe ich Material und Notizen bewahrt. Ich halte es aber nicht für nützlich, mit neuen Namen für solche nuvollkommen bekannten Dinge die Literatur zu beschweren und späteren Forschern, die in der Lage sein werden, die richtige Stellung dieser Pilze und Systeme aufzuklären, die Arbeit zu erschweren.

Tritt irgendwo eimmal eine unvollständig bekannte Conidienform als schädlicher Parasit auf. wird sie von erheblicher praktischer Bedentung. damn wird es im Interesse der Terständigung nöthig, sie auch zu benemnen. Liegt solch ein Fall aber nicht vor; so scheint mir die Termehrmng der Arten der Fungi imperfecti ein umiitzes Begimmen. Ian kömte mit demselben Rechte Blätter oder Rindenstücke ron noch unbekannten Urwaldbänmen sammeln und danach neue Dicotyledonen benemnen, indem man späteren Sammlern die Mühe zumuthet, wemn sie die Blüthen und Früchte untersucht haben, nachzusehen, ob die zugehörigen Blätter mit einer der schon beschriebenen imperfecten Dicotyledonenspecies iibereinstimmen.

Tremella compacta nor. spec. ist eine Form, welche grösste Anfmerksamkeit verdient, eimmal wegen gewisser Unregelmässigkeiten in ihrem Hymenium, welche uns zur Beurtheilung der Protobasidiomycetenbasidien sehr werthrolle Fingerzeige liefern, sodam wegen der ganz eigenartigen (onidienerzengung. Ich reihe sie den mit Conidien auf den Fruchtkörpern versehenen Tremellen an; in vieler Beziehnng bildet sie von diesen einen Uebergang zn den ïbrigen Formen, welche Conidien nur erst bei der Keimun! der Sporen hervorbringen. Unsere Figur (Taf. I Fig. 2) stellt den Pilz in natürlicher Grösse dar, links in der Aussenansicht, 
rechts ein längs durchschnittenes Stiick. Er bricht aus der Rinde ganz morscher, fast schon von innen verwester, am Boden liegender Stämme hervor und zeigt, zumal in der Jugend, gehirnartige Windungen und Falten, die anfänglich enge sind und allmählich mit stärkerer Ausbildung des Hymeniums sich glätten und wölben. Die ganze Masse des Fruchtkörpers ist von knorpeliger, ziemlich fester Beschaffenheit und hat ein glasig gallertiges Ansehen. Die Farbe ist hell ocker (Saccardo Nr. 29 in heller Schattirung). Junge Fruchtkörper sind ganz massiv; wem die Windungen der Oberfläche sich später weiter aufwölben und glätten, so entstehen in ihrem Innern einzehe, nicht mit einander in Verbindung stehende Hohlräume, wie unsere Fignr es deutlich zeigt. Wegen seines verhältnissmässig festen knorpeligen Kernes würde der Pilz zur früheren Gattung Naematelia zu stellen gewesen sein. Doch hat Brefeld gezeigt, dass diese Gattung eine Existenzberechtigung nicht beauspruchen kamm. Das Hymenium bedeckt in gleichmässiger Schicht die ganze glänzende, fast wie mit einer Glasur überzogene Oberfläche des Pilzes. Die Mrehrzahl der Basidien, welche wir antreffen, sind typische Tremellabasidien (Taf. IV Fig. 12 c links) von 12-14 " Durchmesser, die Sterigmen sind wie gewölnnlich ron ungleicher, bis 50 " ansteigender Länge, sie tragen die Sporen mit seitlichem Spitzchen. Die Sporen zeigen die gewöhnliche ovalıundiche Gestalt und haben 6-7 " " Durchmesser. Beim Durchmustern vieler Schnitte durch das Hymenium bemerkt man $11 m$ aber, dass abweichend gebildete Basidien hier recht häufig vorkommen. Die Basidien haben eine deutliche Neigung zur länglichen Gestalt. Häufig finden sich solche, welche nur eine Scheidewand ansbilden und dann zwei Sterigmen hervorbringen, und hier steht die Wand dam in der Regel sehr schräg, mitunter fast horizontal, so wie wir sie bei Sirobasidium gefunden laben. Das Allermerkwürdigste ist aber. dass anch zwei Scheidewände in manchen Basidien rorkonmen, welche sich nicht kreuzweise schneiden (s. Fig. 12c). Je eine 
Basidie wurde gefunden, welche zwei fast horizontal und parallel stehende Wände aufwies und bei der dann die oberste Basidientheilzelle durch eine dritte schräg stehende Wand in zwei Hälften getheilt war (Fig. $12 \mathrm{c}$ rechts). Solche Basidien, wie die hier dargestellten bilden unzweifelhafte Zwischenglieder zwischen Auriculariaceen- und Tremellaceenbasidien; sie beweisen uns handgreiflich die nahe Terwandtschaft dieser beiden, in ihren Extremen scheinbar so grundrerschiedenen Basidientypen, sie bilden einen Beweis für die Einheitlichkeit der Klasse der Protobasidiomyceten. Sie ergänzen in willkommenster Weise die bereits bei Sirobasidium festgestellten Anschauungen ïber den nahen Zusammenhang der verschiedenen Protobasidienformen unter einander.

Die Sporen keimen, indem sie kleine rundliche Hefen aussprossen lassen, meist nur je eine. Die Hefezelle fällt ab, wenn sie erst 2-3 $\iota$ Durchmesser hat, schwillt an bis zu einem Durchmesser von 4-5 $\mu$ und lässt wieder'um eine Tochterhefe hervorsprossen. Sprossverbände kommen nicht zu Stande (s. Fig. 12 f.). Die Hefebildung geht sehr schnell vor sich und der Kulturtropfen füllt sich in 24 Stunden mit einem granen Niederschlage der runden, etwa $4 \mu$ Durchmesser haltenden Hefen. Ich habe diese Hefen wochenlang in Reihenkulturen gepflegt, ohne jemals eine Fadenauskeimung zu sehen. In schwachen Nährlösungen kommt es vor, dass die Sporen stark aufschwellen, monströse Formen annehmen, auch wohl ein feines Sterigma mit einer Sekundärspore treiben (Fig. 12d). Auch kommen bisweilen, aber nicht regelmässig bei der Keimung der Sporen Bilder wie Fig. $12 \mathrm{e}$ vor, wo also in der Form noch unregelmässige, von der spore nicht gleich abfallende Sprosszellen gebildet werden, welche ihrerseits dann die abfallenden typischen Hefezellen erzengen.

An der Oberfläche, im Hymenium, zwischen den Basidien, findet sich keine Spur von Conidien. Nacht man aber dümne Schnitte durch beliebige Stellen des Innern der fleischigen, gallertigen 
Fruchthörpermasse, so erhält man Bilder wie das in Fig. 12a wiedergegebene. Die Hyphen verlaufen hier, wie bei allen 'Tremellen, eingebettet in Gallerte. Sie sind reich septirt und die einzelnen Gliederzellen sind vielfach bauchig angeschwollen. Nun bemerkt man an den Enden und anch kurz ror den Enden der meisten Theilzellen conidienartige Sprosszellen, welche (s. d. Fig.) eine nicht ganz gleiche, aber wenig um 3-4 « Länge herumschwankende Grösse und ovale Form besitzen. Sie sitzen an den Fäden olne Sterigmen. Man findet sie in gleicher Weise ïberall, ans welchen Theilen des Fruchthörpers man anch die Probe schneiden mag. Nur in ganz jungen Fruchthörpern, welche noch keine reifen Basidien tragen, fehlen anch diese conidienartigen Bildnngen. Die Anwesenheit dieser Conidien erscheint znn̈̈chst muverständlich. Man begreift nicht, was sie sollen mitten in dem festen Fruchtfleisch, wo sie keine Möglichkeit haben. abzufallen oder sich weiter zu entwickeln. Finen Aufschlıss über ilır Wesen erhalten wir aber, wemn wir ans einem frischen Fruchthörper mit einem sorgsam gereinigten Messer derartige Schnitte entnehmen und in Nährlösung ïbertragen. Hier bemerken wir schon nach 24 Stunden, dass die zerrissenen Hyphen ruhig weiter wachsen und lange Keimschläuche bilden, an deren Scheidewänden meist, jedoch nicht mit unbedingter Regehmässigkeit, Schnallen zu bemerken sind (Fig. 12b). Aus den vorhel erwähnten zweifelhaften Conidien aber gehen nene Sprosszellen hervor. welche ihrerseits wieder Hefen erzeugen. Diese an den Fäden des geschlossenen Fruchthörpers gebildeten Conidien rerhalten sich jetzt in jedem Betracht röllig gleich wie die Basidiensporen. wenn sie in Nährlösung ansgesäet wurden. So wie dort fallen auch hier die Hefen sehr schnell und leicht ab. In dem Kulturtropfen bemerkt man jede der ursprünglichen sprossconidien umgeben von einem mudurchsichtigen Hanfen zusammenliegender Hefezellen. Deckt man, um eine Zeichnnung anfertigen zul kïmnen. ein Deckglas darüber, so schwimmen natiurlich die meisten losen Hefen daron. 
und man erhält das in unserer Fig. 12b dargestellte Bild. Die Uebereinstimmung der aussprossenden Conidien mit den aus den Spren hervorgegangenen Bildungen, wie sie in Fig. $12 \mathrm{f}$. dargestellt sind, ist einlenchtend. Die hier gebildeten Hefen verhalten sich in weiterer Kultur genan wie die aus den Sporen herstammenden.

Genau dasselbe, was hier in unseren künstlichen Kulturen erzielt wird, wenn wir Schnitte aus, dem Innern eines noch festen Fruchtkörpers in Nälırlösung übertragen, genan dasselbe wird sich in der Natur vollziehen, wemn der Fruchtkörper überreif wird und dann in flüssige schleimmasse sich verwandelt. Dann gewimnen jene oben beschriebenen (Fig. 12 a) Sprossconidien Ratum und beste Gelegenheit, Hefen in unbegrenzten Massen aussprossen zu lassen, und diese Hefen können sich in den zerfliessenden Schleim des Fruchthörpers nach allen Seiten ausbreitell.

So bietet uns die Tremella conpacta einen ganz nenen und eigenartigen Typus der Conidienerzengung dar, dessen Verständniss durch die Berücksichtigung der Besonderheiten dieses gallertigen, bei der Reife zerfliessenden Tremella-Fruchtkörpers ermöglicht wird.

'Tr. undulata Hoffimann (= Tr. frondosa Fr.). Auf der Taf. II Fig. 1 habe ich in halber natürlicher Grösse ein photographisches Abbild dieses stattlichen Zitterpilzes wiedergegeben. wie er nach mehreren Regentagen an einem morschen Stamme auf der sogenamıten scharfen Ecke bei Blumenan am 1. März 1893 gesammelt wurde. Die rothbraune Farbe und die grosslappige Ausbildung der Fruchtkörper machte die nahe Verwandtschaft des Pilzes mit den ron Fries als „Mesenteriformes" zusammengefassten T'remella-Arten sehr wahrscheinlich. Im Systema mycologicum II S. 212 finden sich die drei hier in Betracht kommenden Arten fimbriata, frondosa und foliacea aufgeführt, denen sich in den Hymenomycetes Europaei S. 690 noch Tr. nigrescens anschliesst. 
Die von der Farbe und der Gestalt der Fruchtkörper hergenommenen Untersclieidungsmerkmale dieser Formen lassen eine sichere Trennung nicht zu. Inzwischen ist die Tr. foliacea durch Brefelds Untersuchungen als nete Gattung Ulocolla durch eigenartige Conidienfruktifikation erkannt und abgetrennt worden. An demselben Stamme, ja an demselben Rindenspalt, ans der der hier abgebildete Fruchtkörper herrorgebrochen ist, hatte ich einen Monat früher einen kleineren Fruchtkörper gesammelt, auf den die Beschreibung der 'Tr. frondosa Fr. passte: basi plicata, lobis gyroso-undulatis. Das abgebildete Exemplar dagegen, welches unzweifelhaft auf dasselbe unter der Rinde in dicker Schicht regetirende Mycel zurïckging (bei 'Tr. foliacea, gleich Ulocolla foliacea Brefeld, die in der 'Tracht grosse Aehnlichkeit mit dem uns hier rorliegenden Pilze aufweist, heisst er darum sehr treffend: Junior sub cortice nidulat applanata) entsprach genau der 'Tr. fimbriata, wie man sich an der Photographie leicht überzeugen kann: corrugata, lobis flaccidis, margine incisis, undulato-fimbriatis. Schröter lıat nu schon S. 396 der "Pilze Schlesiens" eine jedenfalls selı richtige Zusammenziehung eintreten lassen, indem er für den Namen 'T'r. frondosa Fr. den älteren Hoffmannschen T'r. undulata (1787) wiederherstellte. welch letzteren Fries selbst als synonym zu seiner fimbriata auffülnrte. Eine sichere Beurtheihung der Form ist aber erst möglich geworden durch Brefelds Untersuchungen, in denen die Resultate der Kultur auf das genaneste angegeben sind (Bd. TH S. 120-123).

Indem ich nun gleichfalls die Kulturen der brasilischen Tremella einleitete, so überzengte ich mich von der Uebereinstimmung meines Blumenaner Pilzes mit dem ron Brefeld unter dem Namen Tr. frondosa Fr. a. a. O. untersuchten. Die Basidien haben $12 \mu$ grössten Durchmesser. Die Grösse der Sporen fand ich in Uebereinstimmung mit der Schröterschen Angabe nur 5-7 $\mu$. Die Hefen sprossen mimmittelbar aus der spore und fallen alsbald ab. un ïppig weiter zu surossen. Alle Einzelheiten der lieimungserscheinmgen 
in Wasser und Nährlösung, wie sie bei Brefeld a. a. O. angegeben sind, bestätigte ich in vielen Kulturen, und es kamn hiernach wohl für sicher gelten, dass wir die Tr. nndulata Hoffmam ('T'r. frondosa Fr.) den gleicherweise in Europa und Sülamerika vorkommenden Pilzen anzureihen haben, deren Zahl mit der Zeit immer grösser zu werden scheint.

Trie schwer es bei unseren Pilzen ist, die Tebereinstimmung eines in Südamerika gefundenen mit einer enropäischen Art über allen Zweifel sicher zu stellen, darauf habe ich schon bei Pilacre Petersii, f. bras. und bei Tremella lutescens f. bras. hingewiesen. Dennoch ist es ron hohem Werthe, allmählich durch derartige Tntersuchungen immer mehr Material für eine Mycogeographie zusammen zu bringen. Zweifellos wird die Anzahl der auf der ganzen Exde oder wenigstens in bestimmten Breiten rings um die Erde vorkommenden Pilze sich stetig melnen. Florengebiete, die unter den Phanerogamen kaum einige wenige Formen gemeinsam haben, werden eine grosse Anzahl ron Pilzen gleicherweise besitzen, und welche Schlüsse ein weiteres nach dieser Richtming fortgesetztes Studium ermöglichen wird, lässt sich vorläufig nur ahnen. Jedenfalls verlohnt es der Mïhe, derartiges Material zu sammeln.

Tremella auricularia nor. spec. Diese Tremella bietet uns wieder'um ein Beispiel, welches klar zeigt, wie ohne künstliche Knltur der Sporen eine sichere Beurtheilung dieser in ihrer Fruchtkörpergestalt so wandelbaren Pilze gar nicht möglich ist. Sie hat die grösste Aehnlichkeit mit der Tremella undulata in Form, Farbe und Grösse. Wie jene bricht sie ans der morschen Rinde abgestorbener Bämme herror. Sie bildet bereits unter der Rinde dicke, unfürmliche Gallertpolster, welche die überliegenden Rindenschuppen oft stark empordrücken. Die herrorbrechenden blattartigen, rundlichen, bramen Lappen gleichen denen der Tremella undulata, sind aber ein wenig fester, knorpeliger als jene. Sie sind wellig verbogen und es finden sich Bildungen dartunter, welche durch Form, knorpelige Beschaffenheit und Farbe tänschend an Schimper's Mittheilungen, Heft 8. 
kleine glatte Fruchtkörper der Amicularia auricula .Tudae erimmern. Ton dieser Aehmlichkeit wurde der Artname hergeleitet. Die bei jung angelegten Fruchtkinpern liellere Farbe (Saceardo ('hromotaxia 11 mit einem stich nach 31) wird bei dem schnell eintretenden Erweichen nud Zerfliessen dunkler. Die Basidien und Sporen bieten nichts Besonderes. Erstere haben im Durchschnitt 15 " Inuchmesser, die birnenfömigen Sporen 10-12 $\mu$. Diese Maasse sind nun fieilich etwas grössel als bei 'T'r. undulata, indessen wïnde ich doch grosses Bedenken getragen haben, darauthin allein eine neue 'Tremella zu begründen. Bei Cntersuchung vieler' Tremellen nimmt man gar bald wahr, dass die Abmessungen besonders der Sporen kieineswegs so beständig sind. wie es im Allgemeinen bei Basidiensporen der Fall zu sein pflegt. Es kommt ferner hinzu, dass die keimende spore bald mehr. bald weniger anzuschwellen pflegt, dass ferner eine in W'asser ausgekeimte. nachdem sie eine Peilıe ron Conidien herrorgebracht hat, leicht zusammenfällt und kleiner erscheint. Auch ergeben sich geringe Unterschiede in den Maassen, wem man frisches Material mit solchem, das lange trocken aufbewalnt wurde, rergleicht. Die Sporemmasse an sich sind also nicht genïgend für eine Charakterisirung der Tremella-Arten. Beobachtet man nun aber die Keimmo nnserer 'Tr. anricularia. so ist in ersten Angenblicke klar. dass sie ron 'T'r. monlulata getrennt werden muss. Bei dieser letzteren sahen wir, dass die Hefeconidien, so wie es Brefeld heschrieben und abgebildet (Bref. VII. Taf. 8 Fig. 2-4) hat. unmittelbar ans der Spore sprossen, dann abfallen nud weiter sprossen. Bei Tr. anricularia berleckt sich dagegen die spore mit rundlichen Aussackungen (I'af. IV Fig. 16 dieses Heftes), welche mit ilır rerbunden bleiben, und erst an diesen Anssackungen werden die Hefen gebildet, welche demnätehst abfallen und lefeartig in unendlichen Generationen anssprossen. Dies Verhalten ist dasselbe, welches wir von 'T'1, lntescens hes kemmen (Bref. V']I. 'T'af. VII Fig. 9 u. 10 und 'Taf. IT Fig. 1j dieses Heftes). Der Durchmesser der Aus- 
sackungen betıägt 4-6 Kulturen schnell dicke, grane Niederschläge billen, haben 3 ॥ Durchmesser. Gelegentliche diimne und schwächliche Fadenauskeinungen wurden zumal in erschöpften Nährlösıngen beobachtet. Die Reinkulturen der Hefen setzte ich etwa 14 Tage lang fort und brach dann die Tersuche ab. Die erste Beobachtung' dieser 'Tremella fand in Anril 1892 statt, die Tersuche wuden mit neuem, im December desselben Jahres gesammelten Material mit gleichem Ergebniss nochmals wiederlıolt. Sekundärsporenbildung war hier wie fast stets häufig.

Tremella fuciformis Berk. Eine grosse Anzahl ron Beschreibungen nener Tremella-Arten ist, wie schon erwähnt, werthlos und für die Wiedererkennung der Art unbrauchbar, weil genaue Angaben über die Gestaltung des Hymeniums, über die Form der Basidien, Sterigmen und Sporen fehlen, ganz zu geschweigen von dem überall enpfindlich auftretenden Mangel an Angaben ïber die Keimungserscheinungen, und weil in der äusseren Formgestaltung der Fruchtkörper bei dieser Gattung meist kein Anlualt für eine bezeichnende Besclureibung gefunden werden kann. Fast überall haben wir es mit mehr oder weniger unbestimmt geformten gallertigen Massen zu thun, an deren Oberfläche gehirnartige Trindnugen und Falten auftreten. Diese allgemeine Beschreibung gilt gleichmässig für eine selı grosse Anzahl löclıst verschiedener Tremella-Formen. Die 'T'remella, um welche es sich hier handelt, besitzt dagegen eine so bestimmte Form, dass sie daran allein olne genane Untersuchung nit ziemlicher Sicherleit wieder erkannt werden kamn, und nu diesem Umstande verdankt sie es, dass sie nicht von jedem nachfolgenden Sammler unter neuem Namen beschrieben wird, sonder'n ihren ersten Namen belıält, den Berkeley ilır in Jalıe 1856 in Hook. London Journ. 1856 S. 277, Dec. of fungi Nr. 614 mit einer (wissenschaftlich werthlosen) sehr kurzen Diagnose beigelegt lat. Diese Diagnose lantete: Alba, caespitosa, 2,5 cm et ultra alta, repetite lobata vel furcata 
cum lobis, ultimis exceptis, flabelliformi-dilatata. Nach dieser Beschreibnng wäre nuser Pilz wohl kamm wieder erkannt worden, wemn nicht der Autor noch die Bemerkung darunter gesetzt lı̈tte: Chondrum crispum aemulat. Diese letzte Bemerkung fülırte Herrn P. Hemings auf den richtigen Weg, als er im August 1890 im Palmenhanse des botanischen Gartens zu Berlin auf einem Holzstiicke, an dem eine epiphytische Aracee kultivirt wurde, eine grosse, schöne, weisse Tremella fand, ..fast von Aussehen mnd Grösse einer gefüllten weissen Azaleenblüthe". Wahrscheinlich war die Tremella mit eben jenem Holzstïcke ans Kamermu nach Berlin eingeführt worden. Sehr interessant war es mm, dass der fremde Einwanderer sich in den folgenden .Tahren in mehreren Warmläusern des botanischen Gartens verbreitete und anch an Stammstïcken rerschiedener emropäischer Laubhözer', so an Ulmen, Fschen, Pflaumen u. s. w. auftrat. Herr Hennings berichtete über den schönen Fmnd auf der Versammlung des Botanischen Vereins für die Provinz Brandenburg im Jahre $189+$ zu Templin. Er komnte ron einem [Tmenstammstück, dessen eine Seite etwa einen Fuss hoch mit dem Pilze bewachsen war. von Ende Oktober 1893 bis Anfang Mai 1894 fist regehmassig alle acht Tage Fruchthörper ernten. Das auf der genannten Versammlung zur Ansicht rorgelegte Stiick wal anf einem Pflammenstamme gewachsen nnd dnrch besondere Grösse nnd schönlneit ansgezeichnet. Es maass in frischem Zustande reichlich $50 \mathrm{~cm}$ im Umfange. $15 \mathrm{~cm}$ im Durchmesser. $7 \mathrm{~cm}$ in der Höhe (alles nach Herrn Hemings Angaben).

Niemand in der Versammlung war wohl unmittelbarer ron

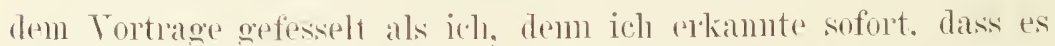
sich $1 m$ eine 'T'remella handelte, welche ich in der Emgebmng' von Blunenau zal allen Zeiten des dalnes an geschlagenen oder faulenden Holzstïcken verschiedener Herknnft hänfig gesammolt nnd monatelang kultivint latte. Anffallenderweise fülnte sie anch in meinen vorlänfigen Aufzeichnmegen den Namen Tr. car:agheniformis; dem als Dr. Fritz Müller mich einmal besuchte und 
mich mit diesem Zitterpilze beschäftigt fand, meinte er: „Die sieht ja genan wie Caraghen ans." Einell besselen Beweis für das Zntreffende der 1856 vonj Berkeley gegebenen Bemerkung , ('hondrmm crispum aemulat" konnte ich nicht wïnschen.

Bemerkenswerth für die Form ist noch die ron Herrn Hennings zuerst liervorgehobene chromgelbe Farbe des nnteren strunkartigen Theiles grosser Frnchtkörjer, mit welchem sie der Unterlage anhaften. nnd anch diese Farbe entsann ich mich dentlich, bei vielen brasilischen Stïcken bemerkt zu laben.*) Die Untersuchmngiles Hymenimms elgab aber nun anch die nothwendig nachznweisende völlige Uehereinstimmmng des Pilzes ans dem Botanischen Garten zn Berlin mit meinen brasilischen Frundstücken, in den Basidien, Sterigmen mon sporen.

Das Hymenium bedeckt die Lappen des Pilzes allseitig. Die rundlichen Basidien haben 9-12 „1 Inrchmesser. Unter den normal viertheiligen werden nicht eben selten solche, die nul zweitheilig sind, bisweilen anch dreitheilige angetroffen (rergl. Brefeld S. 89). Die Länge der Sterigmen ist, wie gewölnlich, schwankend. Ausnalmsweise wurden sie bis 60 "lang gefunden, die meisten erreichen kanm die Hälfte dieser Länge. Die Sporen sind von der charakteristischen T'remella-Gestalt und haben 5-7 „ı Durchmesser. Sie werden von reifen Frnchtkörrern in ungeheneren Mengen abgeworfen und können leicht rein anfgefangen werden. In der Keimmng schliessen sie sich am niächsten an 'Tr. mesenterica an. Wie bei dieser, so sprossen auch hier' in Wasser, wie in Nährlösungen kleine, etwa 2 " lange, ovale Hefen mumittelbar ans der Spore, olne dass eine sterigmaartige Anssacknng vorherginge, wie sie fïr' 'Tremella lutescens 11. a. so charakteristiscl ist. Die Hefen fallen alsbald ron der spore ab nund sprossen weiter. Nin selten sieht man eine bereits an der Spitze weitersprossende Hefe der Spore noch ansitzen. Nie-

*) Eine in ähnlicher Weise auftretente, aber grünliche Fürbung zeigt Tremella genistae Lib. (vergl, Brefell VII, Taf. VIII Fig. 8). 
mals kommen grössere zusammenlı̈ngende Sprossverbände vor, jede neue Zelle lïst sich sofort ron der Mutterzelle ab. In Nährlösung geht die Sprossung so schnell voran, dass im Laufe einer einzigen Nacht der Kinlturtropfen sich mit einem makioskopisch sichtbaren dichten. granen Niederschlage füllt. Die Hefen sammeln sich am Boden des Kulturtropfens, wälnrend die Basidiensporen nur oben schwimmen. Die allerersten aus der Basidienspore keimenden Sprosszellen sind bisweilen etwas länger als angegeben und gleichen kurzen Fadenstücken, aber schon die nächstgebildeten nehmen die bestimmte Form nnd Grösse an. Die so gebildete echte Hefe habe ich rom 12. April 1891 an bis in den Angust in Kultur gehalot. Jedesmal nach zwei Tagen, wemn ein Kulturtropfen mit dem Hefeniederschlag erfüllt war, übertrug ich einige wenige Hefen darans in einen neuen Tropfen. In dieser ganzen Zeit blieb die Hefe constant, niemals traten Fadenanskeimungen ein. Sekundärsporenbildungen kamen läıfig vor, sowohl in Wasser, wie auch in Nährlösungen. Fs ereignete sich regelmässig. dass in den Aussaaten der grösste Theil der Sporen mit Hefen keimte. während ein kleinerer 'Theil derselben Spren, die sich in demselben Fliissigkeitstropfen befanden, einen Keimschlanch trieb, an dessen Ende die Sekundärspore gebildet wurde. Hierbei wurde einige Nale festgestellt, lass der Keimschlauch sich gabelte und an jedem seiner Enden je eine Sekmndärspore anftrat (Taf. IV Fig. 13). Dieselbe Beobachtung ist auch schon bei T'r. anricularia gemacht worden (Taf. IV Fig. 16). Es ist dabei zul erwähnen, dass solche Gabelungen auch bei Sterigmen rolkommen (s. z. B. T'ulasne Ann. sc. nat. 1853 Bd. 19, 3. Série Pl. 12 Fig. 9). Wir erkennen hieran wiederum, dass die Sekmndärsporenbildung nichts ist, als eine Wiederholung des Vorganges, welcher sich beim Austreiben des Sterigmas und Bildung der Spore ans dem Inhalte der Basidientheilzelle abspielt (s. anch oben Seite 32-34). Befindet sich eine abgefallene spore in einer ungïnstigen Lage, nuter einer Flüssigkeitsschichte z. B., welche ilı 
die Kémmng numöglich macht, so hat sie in der Wiederholnng desselben Vorganges, welchem sie ihıe Entritehung nnd ans Tichtbefördel'ung' aus dem inneren gallertiger Fruchtkörper rerdankte, ein niitzliches Mittel, eine günstigere Lage für die Keimung zu erreichen.

Die Photographie Taf. T Fig. 5 stellt ein kleines, bei Bhımenall gesammeltes Exemplar des Pilzes dar. Ton der Wiedergabe der Zeichnungen, welche die Keimung und Hefesprossung darstellen, meinte ich hier, wie anch bei den meisten folgenden Arten absehen zn sollen, da wir diese Torgänge bei Brefeld in mustergültiger WTeise bereits dargestellt vorfinden, und die jeweils vorkommenden Abreichungen bei den einzelnen Formen sich durch Worte genïgend klar darstellen lassen.

Tremella fibulifera nor. spec. ist nach meinen Beobachtungen die in der Trugebung Blumenaus luänfigste aller Tremellinen, welche ich zu alleu Zeiten des Jahres an fanlendem Holze vou Palmiten (Euterpe) und Imbauben (Cecropia), aber auch auf anderem unbekannten Substrate sammelte. Die Fig: 3 Taf. II giebt meine nach einem schönen frischen Exemplar angefertigte Photographie in natürlicher Grösse wieder. Ként man einen Standort dieser Tremella, so brancht man iln nur mach jedem starken Regengusse wieder aufzusuchen, $1 m$ in oftmaliger Wiederholung Fruchtkörper sammeln zu können. Diese Firnchtkörper, deren Gestalt durch die Abbildung dargestellt ist, sind ansserordentlich zart, weiss, glibbrig, wässerig; fast durchscheinend und ron sehr kurzer Daner. Sie zerfliessen manchmal schon nach einem 'Tage zu einel breiigen Masse. Unter den bekannten Formen dürfte diese äusserlich mit Tr. alabastrina Brefeld die grösste Aelnnlichkeit haben.

Trem man einen 'Theil ihres ganz weichen Fruchthörpers zerdriickt und unter das Mikroskop bringt, so sieht man an fast jerler Scheidewand der durch die Gallerte rerlanfenden Hyphen eine sehr grosse Schmallenzelle. In solcher Regelmässigkeit mmi Häufigkeit wie hier, habe ich die Schnallen bei keiner anderen 
Tremella gefunden, und desshalb die neue For'm 'T'r: fibulifera benannt. Anffällig sind die Schmallen noch dadurch, dass sie nicht. wie sonst meist, sich den Hyphenwandungen anlegen, sondern von ihmen abstehen und also ein wirkliches Oehr bilden. Die Basidien lıben 12-16 $\mu$ Dnrchmesser, die Sterigmen von wechselnder Länge erreichen 140 ", sie sind in der mehrfach beschriebenen Treise nach dem Ende kenlig verdickt, dann fein zngespitzt, nnd tragen mit dem seitlich anliegenden spitzchen die typische T'remellaspore von 7-10 « Durchmesser. Die zn wiederholten Malen angestellten mod eimmal durch zwei Monate fortgesetzten Kulturen ergaben folgende Resultate: Sekundärsporenbildung wurle nie beobachtet; bei Keimmng im Wasser bilden sich an der Spore wenige, meist nicht mehr als drei, rmmoliche Anssackungen ron $4 \mu$ Durchmesser. an diesen Aussacknngen bilden sich nach dem 'Tyms der' Tremella lutescens kleine Conidien ron $2 \mu$ Dmrchmesser in grosser Zahl. welche abfallen, aber nicht weiter sprossen. Diese Bildungen gehen so lange fort, bis der Inlatt der Syore and der Anschwellungen röllig rerzelıt ist. Bei der Keimmng in Nährlösmng schwillt die spore ein wenig an und bedeckt sich ringsum mit zahlleichen Aussackmngen. Diese erzengen Conidien in ausserordentlich grosser Zahl, welche ahfallen, damm anschwellen zu rmnder Form von 3.5 ". Durchmessel mnd mun hefeartig mubegrenzt Woitersurossen. Die Hefe bildet grosse Sprossterbände, Welche aber selur leicht. z. B. hoim Anflegen des Derkglases, ans einander fallen. Es kommt gelegentlich ror, dass suäter abfallende Conidien anch mmittelbar nehen den grösseren nicht abfallenden Auswackungen an der Keimspore gebildet werden.

Ein pinziges Mal wude ein nur selır kleiner Fruchtkörper dieser Art gefunden, dessen Gallerte duch nud dnuch hell griülich gefärbt war. Im n̈brigen nntersehied er sich nicht, anch in der Keinnung der sporen nicht, von der gewöhnlichen weissen Form.

Tremella anomala nor. spece ist von mir nur in seln mo- 
scheinbaren, wenig auffalligen Fruchtkörpern gefunden worden, sie lenkte aber meine besondere Aufmerksankeit anf sich durch die Form ilner Heforonidien. welche durchans eigenartig ist mond unter den bisher bekannten 'T'remellaformen ilnes gleichen nicht laat. Unsere Tremella fand sich an todten Zweigen am Boden des Waldes und bildete dort kleine. nur dümme Schleimklümpchen mit gehirnartigen Windungen und Falten auf der Oberfläche, wie sie so vielen anderen 'Tremellen auch zukommen. Thre Farbe ist lell, fast durchscheinend, schmutzig gelblich. Die grösten Fruchtkïrler latten nicht meln als $11_{2}$ cn Länge bei $1 / 2$ cm Breite. Die L'ntersuchnng des Hymenimms. welches die ganze Oberfläche ïberzieht, liess den für die Gattung im allgemeinen typischen Bau erkennen. Die kugligen Basidien laben 10 "D Durchmesser, die länge der Sterigmen schwankt sehr, bis zum vierfachen des Basidiendurchmesser's, dit' runden, mit dem charakteristischen Spitzchen ansitzenden Sporen haben 6 ॥ Durchmesser. Die vom Fruchtkörper abgeworfenen nnd aufgefangenen sporen keimen schon nach wenigen Stunden in fenchter Luft oder in Wasser mit einem schwächlichen Keimschlanche ('Taf. IT Fig. 11 b). In geeigneten dïmmen Nährlösungen treten aus der spore, und zwar meist an mehreren stellen auf eimmal, hefesprossartige Zellen. Sie treten aus einer feinen Oeffnmog der spore. verdicken sicli dam, spitzen sich wieder zu, erreichen nur geringe Länge und lassen dann in gleicher Treise neue Sprosse herrortreten, ohne sich ron der Keimspore zu trennen. Die Sprosszellen lraben sehr moleiche Gestalt und Grösse (s. d. Fig. 11), einige sind gerade, andere gekriummt, auch ist auffällig, dass der Ort der Aussprossung noch nicht genan bestimmt ist; obschon er meist an der Spritze liegt, so können doch anch seitwärts Sprosse anstreten. wie die Fig. zeigen.

Bereits am zweiten auf die Aussat folgenden 'Tage sind um jede gekeimte Spore hermm ziemlich reichverzweigte Sprossverbände gebildet (Fig. 11a), die um so ïpuiger entwickelt sind, je stärker die angewandte Nähılösung war. Hie und da finden sich nun 
anch ans dem Verbande freigewordene einzehne umherliegende Sprosszellen, die ihrerseits in derselben Weise weitersprossen (s. d. Fig.).

Tom dritten Tage ab bemerkt man an den neu entstehenden Hefezellen eine grössere Bestimmtheit und Gleichmässigkeit der Form und Grösse. Die durchschnittlichen Maasse sind jetzt etwa $6 \mu$ Länge bei $1^{1 / 2} \mu$ Breite. Anch ist der Ort der Aussprossung num in der Melnzahl der Fälle bestimmt und auf die spitzen Enden beschränkt. Der Zusammenhang der gebildeten Sprosskolonien ist ungewöhnlich fest. zumal wenn starke Nährlösungen angewendet werden. Hier bilden sich dicke, mdurchsichtige Klumpen von Sprossverbänden, in denen natïrlich bald die Keimspore nicht mehr zu sehen ist. Zerdriickt man solche Klumpen unter dem Deckglase, so zerfallen auch dann noch nicht die Terbände, vielmehr sieht man jetzt Fäden von aneinander gereihten Sprossen, welche durchaus an reich septirte und an den Wänden eingeschnürte Hyphen erimnern, wie solche bei Ascomyceten häufig: vorkommen und im X. Bande der Brefeldschen Untersuchungen melırfach dargestellt worden sind.

Im grossen Ganzen gewinnt es den Anschein, als sei die Hefesprossumg bei dieser Form noch auf einer geringeren Höhe der Ansbildung, als sie den meisten iibrigen Tremellen eigen ist.

Da von den entwickelungsgeschichtlich bisher untersuchten Formen keine diese längliche Gestalt der Hefen zeigt und auch keine so fest zusammenhängende Sprosskolonien bildet, so lielt ich es für nothwendig, in diesem Falle die erforderlichen Zeichmungen (Fig. 11) leeizugeben.

Die Kulturen wurden iiber einen Nonat lang (Juni-Juli 1891) gepflegt. Nur in seltenen Fällen traten bei Erschöpfung der Nähırlösungen schwache Fadenkeimungen der Conidien anf.

Tremella spectabilis nor. spec. neme ich die anselmlichste der bei Blumenan beobachteten echten Tremella-Arten. Sie wurde nur ein einziges Nal, am 19. Juni 1892, also in der küllleren Jahreszeit, an morschem Holze (im 'Thal der Velha) in melneren 
Exemplaren gefunden. Melntägiger Regen war vorangegangen (39 $\mathrm{mm}$ Regenhöhe an den sechs vorhergehenden Tagen). Der Pilz, dessen schönstes Stück auf Taf. III Fig. 2 in º/io der natürlichen Grösse abgebildet ist, bildet mnregelmässige Anläufungen von mit einander verwachsenen, grossen, glatten, blasig aufgetriebenen, innen hohlen, gallertigen, doch ziemlich festen Falten und Lappen. Die Farbe war hell ockergelb (Saccardo Chromotaxia 29). Der ganze Pilz ist mit dem Hymenium überdeckt, welches alle typischen Eigenthümlichkeiten der Gattung Tremella aufweist. Die Sporen sind länglich, $10 \mu$ lang, 5-6 $\mu$ breit, die Basidien laben 13-15 « Durchmesser, die Sterigmen sind ron selı ungleicher, bis zu 50 " ansteigender Länge. Die kolbige Anschwellung derselben unter der Spitze war hier selır stark und oftmals fast monströs. anch jene verzweigten Sterigmen, welche bei T'ulasne und Brefeld schon oftmals abgebildet sind (vergl. z. B. Brefeld VII, 'Taf. VII Fig. 14) kamen lier ganz besonder's häufig vor.

Die Spore, in Nährlösung aufgefangen, schwillt wenig an und lässt wenige, nicht mehr als drei, Sprossconidien austreten, welche sofort abfallen. Nachträglich mögen noch melır gebildet werden, doch findet man nicht mehr auf einmal der Spore ansitzend. Die primären abgefallenen Conidien laben längliche Gestalt und sprossen hefeartig sofort weiter. Allmälılich nimmt die gebildete Hefe eine bestimmte, und zwar kuglige Form mit 4-5 « Durchmesser an und erfïllt mit derartigen Sprosszellen im Laufe ron zwei Tagen den ganzen Kulturtropfen. Aber es kommen nicht die kleinsten Hefecolonien zu Stande. Jede Sprosszelle trennt sich sofort ron der Mutterzelle, ehe sie wiederum aussprosst. Einzig und allein an der Spore bleiben bisweilen zwei oder drei Sprosszellen länger sitzen, und diese erreichen auch wohl berlentendere Grösse (bis $9 \mu$ ) als sie den späteren Hefen eigenthïmlich ist. Die Hefen wurden mur eine Woche lang in reinen Kulturen weiter gezüchtet. Fadenkeimung trat niclit ein. 
Tremella fucoides nov. spec. bildet anf morschem Holze unregelmässige, im Ganzen längliche, zittrig gallertige, gelbbranne, nach den Enden zu stmmpf, zweitheilig oder anch geweilartig endende hohle, bis zu $3 \mathrm{~cm}$ lange, $1^{1} / 2 \mathrm{~cm}$ im Durchmesser laltende Blasen mit dümnen, durchscheinenden Wänden; sie stehen zu mehreren in büschelartigen Gruppen beisammen und sind oftmals am Grunde mit einander rerwachsen. Die anf Taf. II Fig. 2 in $\%$ der natiirlichen Grösse dargestellten Stiicke wurden am 21. März 1892 gesammelt (im Thale der Velha). Wenige Tage später wurde dieselbe Form an einer weit entlegenen Stelle, und im Februar 1893 wiederum an einem anderen Standorte gefunden. Die Fruchtkörper schiessen nach reguerischem Wetter in sehr kuzer Zeit hervor, und ihr Torkommen scheint anf die warme Jahreszeit beschränkt zu seiı. Die Wandstätke der durehsichtigen hohlen Lappen beträgt nn $1 / 2 \mathrm{~mm}$. Die Tremella erimert in ihrem Aeusseren an Fucus vesiculosus und wurde hiernach benamnt. Die Basidien haben etwas mehr lïngliche Form, als sonst bei Tremellen die Regel ist, und messen 10-15 "u im Durchmesser. Die Länge der sterigmen ist sehr unbestimmt. Sie reichen oft noch eine rerhältnismässig bedentende Strecke über das Hymenimu hinans und erteichen in den gemessenen Fällen bis $100 "$ Länge. Die Sporen sind $8 \mu$ lang. 6-7 " breit (Taf. IV Fig. 17). Keimt die spore in feuchten Raume, so sprossen umittelbar Conidien aus. 'Tritt die Keimung aber in Wasser oder Nährlösung ein, so treibt aus der Spore eine Art dimnen Sterigmas, welehes an seiner Spritze die Conidien bildet, die alsbald allfallen und hefentig weitersprossen; solche Bildungen erimnern sehr an die Conidienbildmg bei Dacryonyces, wie sie sich z. B. bei Brefeld VII, Taf. X Fig. 8 und 11 dargestellt finden; oder aber es tritt ans der spore ein meln oder weniger anwachsender, in der Form wenig bestimmter Keimschlauch, an dem die Conidien anftreten. Auch beile Keimungsarten an ein und derselben Spore wurden beobachtet (vergl. Fig. 17 Taf. IV). Die Hefen, deren 
normale Länge $6 \mu$ ist, sprossen in unendlichen Generationen weiter; grössere Hefeverbände kommen nicht zu Stande. Der Ort der Aussurossung liegt nicht immer regelmässig an den Polen der eiförmigen Zellen. Anch diese 'l'remella also besitzt eigenartige mnd bestimmte Merkmale in der Art ihrer Conidienerzengung.

Es ist nicht unmöglich, dass die ron Fries (Nov. Symb. Myc. Mant. S. 125) beschriebene. von Liebmann in Mexico gesammelte Tremella inflata mit unserer Form nahe verwandt oder gleichbedentend ist. Eine Gewissheit hierïber ist indessen nicht zu erlangen, da in Anbetracht der unbestimmten wechselnden Formen aller Tremellen ohne Krnltur der Sroren eine sichere Unterscheidung der Arten ganz ansgeschlossen ist.

Tremella damaccornis nor. spec. ist besonders bemerkenswerth durch die äussere Form und Konsistenz ihrer Fruchtkörper, welche durchans an gewisse Dacryomyceten (Calocera) erinnert, aber weit abweicht ron der für Tremella sonst charakteristischen Erscheinung. Aus trockenen Rindenstiicken bricht der Pilz (T'af. IT Fig. 9) nach feuchtem Wetter hervor und entwickelt sich zu kleinen, umregehmässig gestalteten, mit geweihartigen (an die Schanfeln des Damhirsches erinnernden) Endigmngen versehenen, anfrecht stehenden Lappen, welche an den beobachteten Stïcken nicht ïber $11 \mathrm{~mm}$ Höhe und ebensoviel Breitenausdehmmng erreichten. Sie sind knorpelig, gallertig, zähe, von hellgelber, durchsichtiger Farbe (Saccardo 24 durchsichtig) mit einem leichten Stich ins Grinliche. Diese Farbe ist auf die dichte Hymenimmschicht beschränkt, welche den Frnchtkörper allseitig überkleidet. An älteren Exemplaren erscheinen manche Stellen gleichsam grau bereift von den zahlreichen abgeworfenen anfliegenden Sporen.

Die mikroskopische Untersuchung des Pilzes ergab ganz g'egen meine Erwartnng typische viertheilige T'remellabasidien von 7 bis $9 \mu$ Durchmesser, knrze Sterigmen von etwa $15 \mu$ Länge 1 md Sporen, welche die bekannte r'undlich-orale Form bei $5-7, \mu$ Durchmesser aufwiesen. 
Die Sporen keimten wenige Stunden nach der Aussaat und zeigten nicht alle genau gleiches Verhalten. Bei der überwiegenden Mehrzahl sprossen Hefen, nicht mehr wie drei auf einmal, unmittelbar ans der Sprore und lösen sich alsbald ab, um in unendlichen Generationen fortzusprossen. Es bilden sich grane Hefeniederschläge, die Hefen erlangen allnählich ziemlich constante Grösse, nämlich 4-5 $\mu$ Länge und $3 \mu$ Breite. Sprosskolonien werden nicht gebildet. Bei vielen Sporen entstehen kurze Keimschlänche $(1$ oder 2$)$, welche $3 \mu$ Dicke und etwa die dreifache Länge der Spore erreichen nnd an ihrem Ende dann ihrerseits Hefen anssprossen lassen. Anch kann gleichzeitig an einem Ende der Spore ein solcher Keimschlanch anstreten (welcher in seinem morphologischen Werthe den bei Tr. lntescens am schönsten ausgebildeten sterigmaartigen rmuden Ansackungen der Sporen entspricht), während das andere Ende numittelbar Hefen anstreten lässt. Sekundärsporenbildnng wird lıänfig beobaclıtet. Einfache kümmerliche Fadenauskeimnng von Sporen sowolıl als von Hefen kam gleichfalls vor. mnd zwar an ehesten in hoch concentrirten Nähnlüsungen. Doch bildeten sich niemals rerzweigte Mycelien. Ich zog die ungemein schnell sich vermehrenden Hefen in täglich nen angesetzten Reihenkulturen acht Tage lang nnd brach dann die V'ersuche ab. da die sonst gesammelten Erfahrungen ron einer Fortsetzung der zeitraubenden Arbeit katum weitere Ergebnisse erhoffen liessen.

Jeder Systematiker würde diese Form nath dem änsseren Ansehen zn den Darryonyceten verweisen. Wenn ihn damn die Untersuchnng des Hymenimms belehrte, dass sie bei den Tremellaceen ihren natiirlichen Platz zn finden habe, so würde er immer noch Bedenken tragen miissen, sie gerade der Gattmig 'Tremella anznschliessen, ron deren bekannten Tertretern sie sich so handgreiflich unterseheidet. Allein die Knltur der Sporen. welche mis die mnendlich sprossende Hefe liefert, lïst alle Zweifel mond bestimmt die echte Tremella. 
Tremella dysenterica nov. spec. Diese Form wrude zu wiederholten Malen im Februar und März 1892 und 1893 anf fanlenden, am Bachufer, fast im Tasser liegenden Zweigstïcken gesammelt. Sie bildet weichschleimige Gallertmassen von wenigen C'entimetern Ausdehnung in unregelmässiger Begrenzung und in allen beobachteten Fällen nicht mehr als 1 cm Höhe. Die Oberfläche ist mit verbogenen Windungen mud Falten bedeckt, wie sie z. B. von Tr. lutescens bekamnt sind. Diese Tremella hat ein sehr widerwärtiges Aeussere. Sie ist so schleimig glatt, dass es fast nicht möglieh ist, sie zu halten, um einen Schnitt zu machen, der das Hymenium zeigt. Thre Farbe geht ron einem hellen wässerig' gelblichen 'Tone durch dunkleres Gelb- bis zu dunklem Blutroth. Die blutrothe Farbe tritt aber anf dem im wesentlichen hässlich gelben Schleim nur in einzelnen Flecken und Striemen auf. Die Untersuchung zeigt, dass nur an diesen blutrothen Stellen, an denen die Faltungen der Oberfläche ausgeglättet sind, das Hymenium zu finden ist. Dies letztere zeigt alle Eigenthïmlichkeiten del Gattung. Die Basidien haben 10-12 $\mu$ Durchmesser, die Lünge der Sterigmen schwankt um $25 \mu$, die birnförmigen Sporen messen 6-9 $\mu$ Durchmesser. Sie keimen sehr leicht und bedecken sich dabei mit einer ganzen Anzahl von ringsum anssprossenden Conidien, welche $3 \mu$ Durchmesser elreichen und abfallen. Im Gegensatze zu allen anderen beobachteten 'Tremellen komnte ich veder in Wasser, noch in mannigfach veränderten Nährlösmngen, auch in der Zeit von drei Wochen nicht, jemals eine Weitersprossung oder Keimung der von der Spore ansgesprossten Conidien beobachten.

Es ist nun, wie wir wissen, die Gattung' 'Tremella durch den Besitz der in langen Generationen fortsprossenden Hefeconidien ganz besonders scharf charakterisirt. Danach könnte die Frage anfoeworfen werden, ob man die hier vorliegende Form auch zu 'Tlemella zu stellen berechtig't sei. So viel Arten der Gattung wir kennen lernten, so viel verschiedene 
Abwandlungen in der Art der Conidienbildung, in der Form ilnes Anssprossens, der Teppigkeit ilurer Vermelnung, des grösseren oder geringeren Zusammenhaltens der Sprosskolonien wnrden gefunden, und die sonst wohl eintönige und wenig reizvolle Untersuchung aller erhielt eben durch die vergleichende Betrachtung jener Verschiedenheiten ihren eigenthümlichen Werth. Es kam uns daher kanm Wunder nehmen, dass nun auch eine 'Tremella vorliegt, bei der die Fähigkeit zur Sprossconidienbildung sehr stark herabgemindert ist, ja im Erlöschen zu sein scheint. Da aber Bildung des Hymenimus, Bildung und Form der Sporen, sowie anch die Bildung der ersten Sprossconidien sich genan nach dem Typus von Tremella richten, so kamn der Unstand, dass in den angestellten Kinlturen sekundäre Hefebildungen nicht anftreten. uns nicht wohl bestimnen, die Form ron 'Tremella abzutrennen. Thr' wichtigstes Artmerkmal besitzt sie eben in der geringen sprossfähigkeit ilırer Conidien.

\section{e. Ayrocephalus P'ers.}

Die Gattmig Givocephalus, zuletzt ebenfills ron Brefeld neu mul sorgsam mitersucht mols als Gattmg der Tremellineen sicher erkaunt (vergl. Bref. V'II S. 130-131), geht in der Fruchthörpergestaltung iiber die beschriebenen Formen hinans. Sie bildet trichterformige gestielte Fruchthörper. Welche das Hymenimm an der Tnterseite tragen, sie wiederholt nuter len Protobasidiomyceten die For'm mancher gestielten kreisel- oder trichterförmigen 'Thelephoreen, wie sie besonders unter den Tropen in vielen Formen vertreten sind, bei nus in craterellus cornucopioides iluren bestbekimuten Vertreter besitzen. Nebenfuchtformen sind noch nicht anfgefunden, da die Sporen bisher nicht zul lieinung zи bringen waren.

Irenu wir allmählieh immer dentlicher sehen, wie dieselben

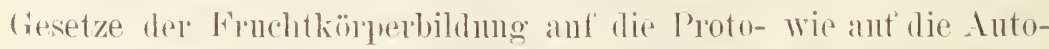
basidiomyceten Anwendung finden, bei beiden, ganz mabbängig 
von einander, äusserlich ähnliche, doch nicht verwandte Gestalten hervorbringend, so können wir in den beschriebenen Exidiopsisformen und in Gyrocephalus gewissermassen Prototelephoreen, in Tremella damaecornis eine Protoclavariee erkennen. Die allerauffallendste Bestätigung der Richtigkeit dieser Auffassungen ergiebt indessen die Betrachtung der beiden folgenden Gruppen.

\section{Protopolyporeen.}

\section{Protomerulius nov. gen.}

Protomerulius brasiliensis nor. spec. Kein Fund irgend eines brasilischen Pilzes lat mir eine grössere Ueberraschung gebracht, als der dieses merkwiirdigen Pilzes. Ich fand einen echten Merulius, kein Mykolog hätte auch bei sorgsamster Betrachtung mit der Lupe Bedenken getragen, ihn zu Merulius zu stellen, jede gute Diagnose von Merulius passte auf ihn, aber die genaue mikroskopische Untersuchung liess einen Protobasidiomyceten erkennen, der Tremellabasidien besass. Ich habe den Pilz in den Jahren 1891, 1892, 1893, dreimal, im August, im Januar und im März, jedesmal an einem anderen Standorte, aber alle dreimal auf demselben Substrat, nämlich auf den am Boden liegenden, modernden Resten des wilden Mamãobaumes (Jacaratia dodecaphylla) gefunden. Bricht ein solcher Baum zusammen, so liegen die Reste seiner festen Rinde in grossen unregelmässig zerbrochenen 'Tafeln über eimander und dazwischen fault die schwammige Masse des auffallend weichen Holzkörper's. Diese war an den betreffenden Fundstellen ganz durchwuchert von einem weissen Iycel, welches strangartig sich nach allen Seiten der Unterlage anliegend ausbreitete, nach den Enden zu in feine Fasern sich auflösend (Taf. III Fig. 4). Die Hyphen, welche dies Mycel zusammensetzen, sind etwa $3 \mu$ stark und schnallenlos. Schimper's Mittheilungen, Heft 8. 
Vielfach scheiden sich auf ilmen Krystallklimmehen ans, die wohl ans oxalsanrem Kalk bestehen dinrften, denı sie lösen sich bei Salzsïmreznsatz olme Bransen auf. Dies Mycel ïber\%ieht die untere, nach dem Boden zon gewendete Seite des Substrats, also der Rindenplatten des Mamãobanmes. Hie und da, wo es am üppigsten entwickelt ist, sieht man anf ilm ein Netz feiner leistenartiger Vorsprimge entstehen (Taf.' III Fig. 4 in der Mitte rechts), den Anfang des Hymenimms; mnd wemn man in diesem Znstande die mikroskopische Untersuchnng vornimmt, so findet man die Leisten und die von ihnen eingeschlossenen Vertiefungen ausgekleidet mit dem Hymenimm, welches die T'remellabasidien zeigt, wie sie in Fig. 36 'laf. I dargestellt worden sind. Diese Figuren sprechen fö̈r sich selbst, ich habe ihmen mur die Maasse der Basidien und Sporen hinzu zu setzen. Die Basidien sind rerhältnissmässig klein, sie haben mur $7-8$ " Durchmesser, dabei sehr dïmne Membranen. Es bedarf feiner sorgfältiger Schnitte und der Betrachtumg mit guten Limsensystemen. mm sich zu überzengen, dass jede Basidie über Krenz dnrch Wände getheilt ist in vier Theilzellen, von denen jede ein sterigma hervorbringt; die Sterigmen sind 7-8 4 lang, die oralen sporen nur 4-5 $\mu$. Das Hymenium ist in dem jngendlichen Znstande der Fig. 4 Taf. III ein echtes Polyporeenlymenium. Allmïhlich nun wachsen die Netzbalken in die Höhe, immer senkrecht nach unten gerichtet, mnd erzengen ein Gewirl ron Platten und Rölnen, wie es fïr ältere Meruliusfruchtkörper charakteristisch ist, und bei vielen anderen Polyporeen auch rorkommt (Fig, 3 'T'af. III). Die rein weisse Farbe gelıt in den älteren Theilen in ein schmutziges Hellgelb ïber. Ich setze die Friessche Diagnose der Gattung Merulius zum Vergleiche hierher: sie passt Wort fïr Wort zu unserem Protomerulius: (Hym. Europ. S. 591.) „Hymenophorum e mycelio contexto mucedineo formatum, hymenio teetmm ceraceo-molli, contiguo, superficie plicis obtusis reticulato, incomplete poroso. demmm gyroso obsoleteque dentato." Auch dass die gewöhnliche resupinate Form 
an Stellen ïppigen Tachsthmms in die consolenförmig abstehende übergelen kann, habe ich bei Protomerulius festgestellt. Die (oberseite der Console war in solchen Falle rein weiss und zeighe eines selowach angedentete Zommg. Als ich Holzstücke, die von dem Pilze durchzogen waren, einige l'age in der Botanisiotrommel anfbewahet loatte, Wall das Mycel iuppig ans dem Substrate lerausgewatelsen und latte fanstacke, lockere, Hockige, weisse Mycelnassen gebildet, wie sie eben für Merulius charakteristisch sind. Reich Auscheidung von Wasser in Tröpfelem an dem Mycel worde beobachtet.

Kuram, wir haben hier unter den 'T'remellaceen einen nenen 'T'ypus, der in geradrzu wunderbarer ITeise bis in alle Finzelleiten die Form eines verbiiltnissuatssig loch organisiden Antobasidionfyceten wiederholt. Die völige Ueberemstimmmong in der äusseren Gestalt ist nicht auf malue Blutsverwandtschaft zurieckzuführen, sondern ist die Wirkung gleicher Labensbedingungen, gleicher Bediurnisse, gleicher Entwikelungsgesetze, welehe in zwei verschiedenen Formenreilen zum grleichen '/iele linführte. Auf dit weitere Parallele nit Auricularia auricula Judae unter den Auriculariaceen genïge es hier nur hinzuweisen. Sie drangt sich von selbst auf. Eine Keimung der reichlich in Wasser and Nährlösung aufgefangenen Sporen wal nicht zu erziclen. Lebel etwaige Nebenfruchtformen ist mir daher nichts bekannt geworden.

\section{Protohydneen.}

\section{a. Protohylumu nov. grem.}

Protohydum cartilaginemm mov. spece ist in $3 / 4$ seiner natiurlichen Grösse durch die auf der 'T'at'. III Fig. 1 wiedergegebene Plotogra]nhie dargestellt. Ich fand den Pilz im Juni 1891 auf einem an Boden liegenden morsclen, armstarken Ast, den er mit einer hellgelblichen, schon von weitem sichtbaren 
Kruste bedeckt. Makroskopisch erkennen wir ein resupinates Hydnum. Der weithin sich erstreckende Ueberzug des Pilzes bestand ans einzelnen, je für sich ınregelmässig begrenzten Lappen, von denen manche Handtellergrösse erreichten. Von der Unterlage waren die Lappen sehr leicht unverletzt abzuheben. Ihre ganze Fläche ist dicht besetzt mit bis zu $5 \mathrm{~mm}$ langen, dickfleischigen, stumpfen Höckern, welche sich auf einem gemeinsamen Lager von etwa $3 \mathrm{~mm}$ Stärke erheben. Die ganze Nasse des hellgelblich weissen Pilzes lat zähgallertige Consistenz, der Querschnitt glänzt, fast opalisirend. Ein Stück des Querschnitts in natïrlicher Grösse ist in Fig. 35a gezeichnet, um die Form der Stacheln und die Dicke des Lagers dentlicher, als es durch die Photographie möglich war, darzustellen. Die im Innern des Pilzes regellos in der Gallertmasse verlanfenden Hyphen ordnen sich nach den Aussenflächen zil mehr oder weniger parallel, mnd zwischen ilmen erscheinen die. Anlagen der Basidien als kolbige Verdickungen (Fig. 35b.) Die Basidien theilen sich nach T'remellaceenart, wie es näher durch die Fig. 35 c ausgeführt wird. Im reifen Zustande haben sie längliche Gestalt nud sind oben mnd runten an Schnittpmkte der 'Theilungswände ein wenig eingezogen (s. d. Fig:). Thre Länge beträgt 15 $\mu$, die Breite 9-10 $\mu$. Sie sind in die Gallerte des Frnchthörpers so tief eingebettet. wie es dmch die Zeichnung Fig. 35c links angedentet ist. Die vier Sterigmen ragen frei iiber die Hymenialfläche herror. Sie bringen je eine längliche spore ron 9 " länge und $4-5$ " Breite hervor, welche im Gegensatz zn den meisten Tremellaceensporen genau gerade, mit ihrer Längsachse in der Verlängerung des Sterigma anfsitzt. Eine Keimung der Sporen herbeizuführen, gelang leider nicht.

Der merkwiirdige Pilz nimmt unter den Tremellaceen eine ganz selbstständige, durch die Eigenart seiner Fruchtkörperbildung höchst bemerkenswerthe Stellung ein. Durch den oben beschriebenen Ban seiner Basidien und Sporeu entfernt el sich ziemlich weit vou allen anderen bekamnten Arten der Familie. 
Ja, selbst mit der nächsten Gattung Tremellodon, mit der er das hydnumartige Hymenium gemein hat, dürfte er wohl nicht in allzu nahem verwandtschaftlichen Zusammenhange stehen. Häufig scheint sein Vorkommen, wenigstens bei Blumenau, nicht zu sein; denu trotzdem er nicht leicht zu übersehen ist, gelang es mir in den zweieinhalb Jahren, welche nach dem ersten Funde mir noch in Brasilien vergingen, beim eifrigsten Suchen nicht, ihn wieder zn finden. Reichliches Material von jener ersten Fundstelle wurde in Alkohol aufbewahrt.

\section{b. Tremellodon Persoon.}

Tremellodon gelatinosum Pers. ist schon seit langer Zeit als die höchst entwickelte Pilzform bekamnt, welche getheilte Basidien besitzt. Es ist eine echte Hydnee ihrem Aeusseren nach, mit 'Tremellaceenbasidien. Aber die eigenthïmliche Bedeutung, welche dieser Form für die Auffassung der Protobasidiomyceten als einer durchaus selbstständigen, den Autobasidiomyceten ebenbürtigen Organismenreihe zukommt, ist nirgends genïgend hervorgehoben. Jetzt erst, nachdem wir in Protomerulius eine Protopolyporee, in Protolydnum noch eine zweite Protohydnee kemmen gelernt, nachdem wir bis auf die Agaricinen beinahe sämmtliche Typen der Autobasidiomyceten nuter den wahren, als solche sicher erkannten Protobasidiomyceten wiedergefunden haben, jetzt erst erhält anch die Betrachtung von Tremellodon ein erhöhtes Interesse. Es war mir daher von grösstem Werthe, dass ich den Pilz schon bei einem meiner allerersten Ausflüge in die Wälder von Blımenan an einem morschen, quer iiber den Weg gefallenen Baumstamm antraf. Hier konnte ich Fruchtkörper zwei volle Jahre hindurch ernten. Sie entstanden regehmässig in Zwischenräumen von 4 bis 8 Wochen an derselben Stelle des Stammes, bis zu dessen gänzlichem Zerfalle. Es ist danach nicht zweifelhaft, dass das Mycel in dem morschen Holze sich lange Zeit ernährt und erhält. Die Fruchtkörper brechen als kleine, grau wässerige, gallertige Perlen 
aus der Rinde hervor. Schon wenn sie kaum ïber $1 \mathrm{~mm}$ Durchmesser erreicht laben, findet man an ihnen sporentragende Basidien. Sie sitzen nur an dem vorderen und dem nacl unten gerichteten Theile des anfangs kugligen kleinen Fruchtkörpers. Dieser bedeckt sich bei weiterem Wachsthum nun an seiner ganzen Oberfläche mit Haaren, welche zu Bündeln zusammentreten und ilm eine rauhe Oberfläche, verleihen. Die spitz zulaufenden Bündel von Haaren sind anfänglich anf der Ober- und Unterseite unterschiedlos gleich. Weiterhin jedoch macht sich in ihrem Verhalten eine erhebliche V'erschiedenheit geltend. Anf der Oberseite nehmen sie nur wenig an Stärke zu und bekommen allmäl1lich eine dumkelgrane Farbe. auf der Unterseite lagegen wachsen sie in die Länge und werden zu den spitzen, bis $6 \mathrm{~mm}$ langen Stachehn, welche das Hymenium der Hydneen charakterisiren. Die Basidien, welche anfangs, wie ich oben anführte, anf dem sehr kleinen, noch glatten Fruchtkörper gebildet waren, erscheinen allmällich in immer grösserer Zahl und rücken an den Stacheln in die Höhe. Sie bedecken dieselben schliesslich nach allen Seiten, stehen aber nach den Spitzen zn in dïnnerer mi unregehmässiger Vertheilung. Die Stacheln unseres P'ilzes sind also morphologisch nichts als Haare oder vielmehr Bündel ron Haaren, welche allmällich zи immer bedeutenderer Grösse heranwudhsen und zu Trägern der Basidien wurden. In dieser Auffassung ist die Bemerkung nicht ohne huteresse, dass als Ausmahme einmal eine „varietas undique aculeata“ .Jacqu. Misc. I 'T' 9 aufgeführt wird.

Die in Brasilien nmmnehr anfgefundenen Pilze sind von den europäischen in keiner Weise verschieden. Für die Beschreibung der Art kann daher lediglich auf die systematische Literatur verwiesen werden. Eine protensartige Terschiedenheit in der Gestalt der Fruchtlörper. (Fries sagt schon dariber: „forma quan maxime variabile, stipitatum [ad terram] et sessile.) beobachtete ich auch in Brasilien. Eines der höchst entwickelten gestielten Exemplare habe ich auf der Taf $V$ Fig. 34 a wiedergegeben. Dies 
war an der Erde gewachsen. Auch der kleine Fruchtkörper" welcher in Fig. $34 \mathrm{~b}$ links in der Torderansicht und daneben im Längsschnitte skizzirt ist. War aus der Erde gewachsen. Er stand am Fusse und fast ïberdeckt von dem Lnftwurzelwerke eines Farrenbaumes, an einer sicher bestimmten Stelle. In Zwischenräumen von jedesmal ungefähr 8 Wochen beobachtete ich viermal an genau derselben, leicht aufzufindenden Stelle je einen neuen Fruchtkörper derselben Gestalt und Grösse. Die Bildung des Fruchtkörpers vollzog sich in mehreren genau beobachteten Fällen innerhalb 8-14 Tagen. Die aus morschem Holze hervorbrechenden sind wohl meist flach scheiben-, muschel- oder ohrförmig und ungestielt. Sie kömmen beträchtliche Grösse, bis zu $10 \mathrm{~cm}$ Durchmesser, erreichen. Eine andere aus morschem Holze herrorbrechende Fruchtkörperform mit scharf begrenztem Hymenium stellt der Querschnitt Fig. 34b rechts dar. Die sterile Oberfläche sehr ïpıiger Fruchtkörper ist oft fast sammtartig.

Die rundlichen Basidien, welche nicht in genau gleichmässiger Höhe, sondern bald näher der Oberfläche, bald tiefer im Hyphengeflechte entstehen, haben 10-12 " Durchmesser. In der Regel sind sie nach dem Typus der Tremellabasidie über Krenz getheilt. Doch finden sich nicht selten Unregehmässigkeiten, zwei oder dreitheilige Basidien, von denen einige in den Abbildungen Fig. 34 wiedergegeben sind. Die Sterigmen schwanken von $\mathrm{der}^{1} / \mathrm{2}^{-}$bis 6fachen Länge des Sporendurchmessers, welcher $4-6 \mu$ beträgt. Die Sporen sind farblos, fast kuglig, ihre Membran ist sehr fein warzig, was nur bei starker Tergrösserung (1000 etwa) erkannt werden kann. Bei den vielfachen. ron mir angestellten Keimungsrersuchen in Wasser sowohl als in geeigneten Nährlösungen gelang es nur in seltenen Fällen und erst am sechsten Tage nach der Anssat, schwache Keimfäden aus einigen Sporen treten zu sehen, welche kleine, wenig verzweigte. sterile Mycelien bildeten und damn zu Grunde gingen.

Es ist eine auch sonst bei manchen 'Tremellaceen beobachtete, 
aber bei Tremellodon besonders deutliche und fast regelmässige Erscheinung, dass die Theilzellen der Basidie, wie die Carpelle eines Fruchtknotens auseinanderklaffen. Auch hierfür habe ich einige Beispiele in den Fig. 34 der Taf. V abgebildet. Ueber die möglichen Nebenfruchtformen gerade der höchsten und in Hinsicht auf die Fruchtkörperentwickelung interessantesten zuletzt besprochenen drei Tremellaceen ist es bisher nicht gelungen, etwas zu ermitteln. Gerade bei diesen scheinen die Sporen an bestimmte Keimzeit angepasst zu sein. 


\section{VI. \\ Hyaloriaceen.}

\section{Hyaloria nov. gen.}

Hyaloria Pilacre nov. spec. Es konnte eine willkommenere Ergänzung für die Formenkenntniss der Protobasidiomyceten nicht gedacht werden, als sie durch die zierliche Hyaloria (Taf. I Fig. 3) vermittelt wird. Noch war der angiokarpe Fruchtkörpertypus, den die Pilacraceen mit quergetheilten langen Basidien darbieten, unter den mit Tremellabasidien ausgerïsteten Pilzen nicht bekannt. Hier nun tritt er in die Erscheinung. Hyaloria ist ein Gegenstück zu Pilacre, hat aber iiber Kreuz getheilte rundliche Basidien.

Der Pilz wurde in den Jahren 1890-93 zu vielen Malen in reichlichen Mengen gefunden. Stets trat er in grossen Trupps auf und stets an ganz morschem, fast verfaulten, am Boden liegenden Holze, das meist natïrlich nicht zu bestimmen war. Einmal war es ein ganz verfaulter Palmenstamm der Euterpe, auf dem ich reiche Ernte hielt. Die einzelnen Fruchtkörper erscheinen in Gestalt glasheller, fast durchsichtiger Säulchen, die sich nach oben wenig verjüngen (vergl. die Abbildung). Hat das Säulchen die Höhe von wenigen Millimetern erreicht, so sieht man an seiner Spitze einen ebenfalls glasartigen Kopf entstehen, welcher 
etwas dicker als die Spitze des Säulchens ist. Dieser Kopf sieht stets feucht glänzend aus, der Stiel dagegen matt. Die Säulchen treten biischelweise vereint auf und bilden oftmals, nach allen Seiten von einem Anheftungspunkte ausstrahlend, einen unregelmässigen zierlichen Stern, wie man auch in der Abbildung sieht. Mit zunehmendem Alter wird der Kopf milchglasartig undurchsichtig, während der Stiel wässerig hell bleibt. Bei besonders iipuigen Exemplaren kamn der Kopf auch wohl aus mehreren kleineren Köpfchen zusammengesetzt sein, die damn einen blumenkohlartigen Anblick gewähren.

Die ganze Bildung erreichte in keinem der beobachteten Fälle mehr als 2 cm Höhe. Dabei betrug der Durchmesser der einzelnen Säulchen bis $4 \mathrm{~mm}$. Ganz junge Fruchtkörper bestehen aus gleichartigem wirren Geflecht diimster, in Gallerte eingebetteter Hyphen, an denen irgendwelche bestimmte Richtung nicht zu erkennen ist, nur nach der Spitze zu ordnen sich die Fäden allmälılich radial. Unter der Spitze erscheint alsdann schon in sehr jugendlichen Zuständen eine peripherische Zone dichter gedrängter Fäden (Taf. Y Fig. 37a), und in dieser, die sich allmählich während der Bildung des oben erwähnten Köpfchens zum Hymenium ausbildet, entstehen die Basidien, ammähernd in einer Schichte, eingesenkt in das weit über sie hinausragende Gewirr steriler Hyphen (Fig. $37 \mathrm{~b}$ ). Man erkennt unschwer die Aehnlichkeit, welche diese Form mit Pilacre besitzt. Man rergleiche nur unsere Figur mit der von Pilacre Petersii durch Jstránffi gezeichneten in Brefelds Band VII, Taf. I Fig. 5. Hier' wie dort ragen sterile Fäden über die Schicht der Basidien hinaus. Bei Pilacre rollen sie sich zu Locken und bilden die Peridie, hier bei Hyaloria bleiben sie glatt. schliessen nicht zu einer festeren Hülle zusammen, bilden aber, durch eine schleimige Flïssigkeit verklebt und rerbunden, eine Decke ïber der Basidienschichte, welche es verhindert, dass jemals etwa eine sprore abgeschleudert werden kann. Wohl aber ist der Raum zwischen diesen Fäden 
stets angefïllt mit einer grossen Menge von den Basidien schon abgelöster Sporen. Die Untersuchung des Hymeniums bietet eben wegen dieser losen undurchsichtigen Sporenmassen, dann aber auch darum recht grosse Schwierigkeiten, weil der Fruchtkörper so ausserordentlich glatt und schlïpfrig, desshalb kaum zu halten und zu schneiden ist, und endlich, weil die Membranen der Basidien von ausserordentlicher Feinheit sind. Die länglich runden Basidien haben etwa $14 \mu$ grössten Durchmesser, die Länge der Sterigmen beträgt etwa $9 \mu$ und ist bei weitem nicht so schwankend, wie bei den meisten anderen T'remellaceen, wo die Sporen bis zum äusseren Rande des Fruchtkörpers durch das Sterigma gehoben werden mïssen. Anf den Sterigmen sitzen die länglich ovalen Sporen von durchschnittlich $7 \mu$ Länge, nicht mit dem von anderen Tremellaceen her so wolıl bekannten seitlichen Spitzchen, sondern grade auf. Die Spore entsteht als Anschwellung am oberen Ende des Sterigmas, und die Wand, welche sie bei der Reife abtremnt, liegt ein kleines Stïckchen zurïck in dem Sterigma, so wie es bei Fig. 37c dentlich zu sehen ist. Die abgenommene Conidie trägt demnach ein kurzes, aber grades Spitzchen. Sehr auffallend ist anch die ungleichmässige Gestalt und Grösse der Sporen bei diesem Pilze, welche in den Figuren zur Anschaumg gebracht ist. Zweisporige Basidien, wie bei Fig. $37 \mathrm{~d}$, wurden ansnahmsweise beobachtet. Man sieht dort anch eine Basidie, bei der alles Protoplasma in die obere Hälfte der nach dem Muster von Sirobasidium getheilten zweizelligen Basidie gewandert ist, und wo diese allein eine Spore hervorgebracht hat, während aus der unteren nicht einmal ein Sterigma hervortrat. Ein Auseinanderklaffen der Basidientheilzellen kommt auch gelegentlich vor, ist aber längst nicht so häufig, wie z. B. bei Tremellodon.

Da von diesem Pilze natürlich die Sporen nicht abgeworfen werden können, so war es nicht möglich, reine Aussaaten zu gewinnen. Ich versuchte, mit einer Nadel dem schleimigen Köpfchen, welches eine ungeheure Menge von Sporen enthält, solche 


\section{$-140-$}

zu entnehmen und auszusäen. Stets aber kamen auf diese Weise Bakterien in die Kulturen, und imnerhalb zwei Tagen waren sie verdorben. In dieser Zeit trat niemals eine Sporenkeimung ein. Ich wiederholte diese Versuche zu vielen Malen, aber leider gelang es nie, die Keimung zu beobachten, und so bleiben wir auch bezüglich der etwaigen Nebenfruchtformen dieser bisher einzigen angiokarpen Protobasidiomycetenform mit Tremellabasidien vorläufig im Ungewissen. Indessen bleibt es immer von hohem Interesse, festgestellt zu haben, dass der angiokarpe Typus anch dieser Formenreihe nicht fehlt. 


\section{Uebersicht der Ergebnisse.}

Das Fundament, auf dem die vorliegende Arbeit sich aufbaut, ist von Brefeld gelegt, hauptsächlich im VII. und VIII. Bande seiner Untersnchmngen. Diese erstreckten sich nur auf europäische Pilze. Ich ging hinaus in den brasilischen Wald mit der Hoffnung, Pilzformen zu finden und der künstlichen Kultur zu unterwerfen, welche den von meinem verehrten Lehrer errichteten Bau eines natürlichen Systemes der Pilze zu erweitern. zu ergänzen, zu festigen geeignet wären. Soweit die gewonnenen Ergebnisse auf Protobasidiomyceten Bezug haben, sind sie in zusammenhängender Darstellung hier vorgetragen.

Wie Brefeld selbst eine derartige Arbeit vorausbestimmt, ihre möglichen Erfolge vorschauend erwogen hat, das geht aus folgender Stelle S. 132 seines VII. Bandes hervor, die ich als Grundlage unserer Schlussbetrachtung hierher setze. Es heisst dort mit Bezug auf die Protobasidiomyceten:

„Wahrscheinlicher Weise werden sowohl die Zahl. der Familien „der Klasse, wie anch die engeren Glieder der einzelnen Familien „mit der Zeit weitere Ergänzungen erfahren. Unter den Formen „der jetzigen Gattung Hypochnus dürften sich solche finden, welche „getheilte Basidien haben, vielleicht auch noch Formen dieser Art „bestehen, die nicht gefunden sind, aus welchen dann eine neue 
„Familie der Protobasidiomyceten ausgeschieden werden kamı. "Die Formen der einzehnen Familien gehen gewiss weit ibber die "hier beschriebenen hinaus. Auch bei uns wird noch manches ge„funden werden, was bisher iibersehen ist, wenn man nur vor,sichtig und genau danach sucht; jedenfalls aber wird „durch die Formen des Auslandes, wenn sie einmal "herangezogen werden, eine starke Bereicherung „eintreten."

Eine solche Bereicherung im Simne der vorstehenden Ausführungen ist als ein Hauptergebniss der vorliegenden Mittheihngen zu betrachten. Es scheint in der That, dass die Protobasidiomyceten in den Tropen ganz besonders zahlieich vertreten sind. Die grosse Zahl neuer Gattungen und Arten, welche ich in der verhältnissmässig kurzen Arbeitszeit von $2^{2}{ }_{4}$. Jahren auffand, spricht dafïr; und diese Wahrnehmung wird in erwünschter Weise bestätigt durch die mehrfach erwähnten Sammlungen von Lagerheims in Ecuador. Auch der genannte Forscher spricht sich dahin aus: „Dans l'équateur les Heterobasidiés semblent particulièrement riches en types spéciaux" (Journal de bot. 1892 Nr. 24.).

Ueberblicken wir nun in Kürze zuerst die wichtigsten Erweiterungen, welche der Formenschat\% der Protobasidiomyceten durch unsere Arbeit gewonnen hat. Es gab in der Klasse zweierlei Basidien, Auriculariabasidien mit wagerechten, Tremellabasidien mit senkrechten, sich kreuzenden Wänden; alle genau bekannten Basidien waren viertheilig mit rier Sterigmen und Sporen. Der Unterschied beider schien so gross und so durchgreifend, dass man auf ihn hin eine Theilung in Schizobasidieen und Phragmobasidieen begründen wollte. Jetzt haben wir die zweitheiligen Basidien von Sirobasidium Brefeldianum kennen gelernt, welche einen Uebergang vermitteh, und durch keine jener beiden Bezeichnungen genau würden getroffen werden. Die eigenartige und neue Basidienform machte es nötig, eine neue Familie der Siro- 


\section{$-143-$}

basidiaceen zu schaffen. Diese Familie ist zudem durch die Anordnung der Basidien in langen Ketten vor allen anderen ausgezeichnet, und diesen Charakter zeigen auch ihre zuerst von von Lagerheim und Patonillard veröffentlichten Mitglieder Sirobasidium albidum und sanguineum, deren Basidien übrigens mit denen der 'Tremellaceen übereinstimmen.

Eine weitere neue Familie musste für die Gattung Hyaloria begrïndet werden unter dem Namen Hyaloriaceen. Der angiokarpe Fruchtkörpertypus, der bis dahin nur für die Pilacraceen bekannt war, für Formen mit Auriculariabasidien, er fand sich abermals vor', ausgestattet mit Basidien der 'T'remella-Form.

So ist Brefelds Voralssage über die wahrscheinliche Vermehrung der Fannilien erfüllt, zu den vier bestehenden, den Auriculariaceen, Uredinaceen, Pilacraceen und Tremellaceen treten zwei neue hinzu, die Sirobasidiaceen und Hyaloriaceen.

Erhebliche Erweiterungen erfuhren die For'menkreise der einzelnen Familien. Jene hypochnusartigen Pilze, deren Existenz Brefeld vermuthete, mit freien, noch nicht zu Lagern, geschweige denn Fruchtkörpern vereinigten Protobasidien, sie wurden aufgefunden, und zwar unter den Auriculariaceen ebensowohl wie unter den 'Tremellaceen. Dort komnte für sie die neue Gruppe der Stypinelleen, hier die der Stypelleen ansgeschieden werden. Wenn durch diese Gruppen der Umfang der Protobasidiomyceten nach unten zu, nach den niedersten unvollkommensten Formen hin erweitert wurde, so brachten die Protopolyporeen und Protohydneen ungeahnte Bereicherung nach der entgegengesetzten Seite. Man wusste, dass in der Gattung Auricularia tropische Formen vorkommen, welche ein netzig-wabiges, polyporeenartig ansgebildetes Hymenium besitzen. Aber eine Polyporee, wie der neu aufgefundene Protomerulius, der getheilte Tremellabasidien zeigt aut einem Fruchtkörper von so bestimmter Gestaltung; dass man Wort für Wort die makroskopische Diagnose der Autobasidiomyceten- 
gattung Merulius auf ihn anwenden kann, lag kaum im Bereiche der für möglich gehaltenen Formen.

Zu 'Tremellodon, bisher dem einzigen Protobasidiomyceten mit hydneenartigem Fruchtkörper, bildet das nene Protohydnum eine werthvolle Ergänzung.

Unter den nenen Arten der Gattung Tremella lernten wir die Tr. damaecornis kemnen, welche in ihrem Aeusseren von den Verwandten weit abweicht und den Typus der Clavarieen unter den Protobasidiomyceten zu vertreten scheint.

So ist also der Formenreichthum, wemn wir zunächst die fertigen basidientragenden Fruchtkörper allein berücksichtigen, jetzt derartig vermehrt, dass wir sagen kömnen, es fehlt unter den Protobasidiomyceten keine Gestaltung, welche der reichen Klasse der Autobasidiomyceten eigenthümlich ist, mit alleiniger Ausnahme der Agaricinen. Der grösseren artenreicheren Ǩlasse der Autobasidiomyceten gegeniiber gewinnt die vorläufig und wahrscheinlich wohl iiberhaupt artenärmere der Protobasidiomyceten durch die nenen Funde eine festere Stellung, eine vollendetere Abrundnng.

Bis hierher sind die angeführten Ergebnisse die Frncht der Sammlungen in Südbrasilien; aufmerksames Suchen im Walde und mikroskopische Betrachtung der Ausbente förderte sie zu Tage. Das Ziel meiner Bestrebungen war aber damit nur zum allergeringsten Theile erreicht. Die kïinstliche Kunltur der Pilze des Urwaldes, die entwickelungsgeschichtliche Untersuchnng und die vergleichend morphologische Betrachtung der so gewonnenen Ergebnisse, das war es, was ich ror allem erstrebte. Nur um dieses Zieles willen hatte ich mir für längere Zeit einen festen Wohnsitz gewählt, auf weites Umherstreifen und sammehndes Durchsuchen grösserer Gebietsstrecken verzichtend zu Gunsten eines nach Möglichkeit gut eingerichteten Laboratorimms. Und gerade für die Protobasidionyceten war der so betretene Weg der einzig gangbare, zum Ziele führende. Brefeld hatte durch seine Arbeiten 
gezeigt und an mehreren Stellen seines Werkes ausdrücklich gesagt, dass hier ohne die kïnstliche Kultur, ohne die Berïcksichtigung der nur durch sie zu entdeckenden Nebenfruchtformen nicht weiter zu kommen sei. er hatte in das frïher unentwirbare Irrsal der Formen nur in dieser IT'eise Klarheit gebracht.

Die Protobasidiomyceten sind reich an Nebenfuchtformen. Ueberall, wo die kiinstliche Kultur der sporen gelang, wurden auch Nebenfruchtformen entdeckt. Wo war früher eine Grenze zwischen den Gattungen Exidia mol 'T'remella, was war der' Charakter ron Natmatelia? Schwankende. msichere nnd bedeutungslose änsserliche Merkmale waren zur Begriindung dieser Gattungen verwendet, und die zahlreichen nenen Formen, die in der vorliegenden Arbeit beschrieben sind. hätten anf Grund der alten Diagnosen nirgends sicher eingereiht werden können. Brefeld fand den gemeinsamen Charakter aller 'Tremellen in dem Besitze von Hefeconidien, den aller Exidien in dem Besitze ron Häkchenconidien, die mit Fäden auskeimen, er vereinigte Naematelia mit Tremella, weil sie die Hefen besitzt, und er schied Ulocolla und Craterocolla ans dem Umfange der alten Gattung. Tremella aus, weil sie besondere eigenartige Conidien haben. Nun war eine sichere Grumblage fïr die Beurtheilung der neuentdeckten hierher gehörigen Formen gewonnen. Anch alle brasilischen Protobasidiomyceten, deren Kultur gelang, brachten Nebenfruchtformen in die Erscheinung, und durch sie fïgten sie sich den bekannten emropäischen Gattungen sicher und zreifellos an. Wir haben nicht weniger als acht neue Arten der Gattung Tremella kennen gelernt, von ausserordentlich verschiedener Gestalt der Fruchtkörper. Wie hätten wir sie sicher als Arten der Gattmng erkemnen sollen, wenn sie nicht alle geeint und gegen die Exidien abgegrenzt wären durch den geneinsamen Besitz der Hefeconidien, die zwar in einzelnen die mannigfachsten und darum nur um so interessanteren Abwandlungen ihrer Gestaltung aufwiesen, in dem unbegrenzten Sprossvermögen in Nährlösungen Schimper's Mittheilungen, Heft 8. 
aber fast ausnahmslos iibereinstimmten. Und wie alle brasilischen bisher unbekannten Tremellaformen die Hefesprossung der Conidien zeigten gleich den europäischen, so fanden wir die eigenartigen Häkchenconidien wieder bei den Exidia-Arten, genan in der Form und Anordnung, wie sie Brefeld fïr mnsere Exidien geschildert und abgebildet lat, so genau, dass jene Abbildungen ohne weiteres anch für die Pilze des brasilischen Waldes gelten kïmnen. Es konnte keine bessere Bestätigung gewünscht werden dafür, dasss den Conidien in ihrer bestimmten Gestaltung für die betreffenden Gattungen thatsächlich der Werth und die durchgreifende Bedeutung zukommen. welche ihnen ron Brefeld zuerst beigelegt worden sind.

Es wäre aber wunderbar gewesen. Wenn unter den zahlreichen neuen Protobasidiomyceten sich nicht auch solche gefnnden lä̈tten. welche den bisher bekannten Kireis der Nebenfruchtformen erweiterten. In diesem sime war es zunächst ron Wertl, das Torkommen der Hefeconidien bei einer Auriculariacee, Platygloea blastomyces, festzustellen, weil bisher diese sonst in fast allen Familien der Mesomyceten und Mycomyceten anftretende Nebenfruclitform für keine Auriculariacee bekannt geworden war.

Nicht minder bedentsam erscheint das Vorkommen jener kleinen, nicht keimfähigen. in grosen Massen geblideten. von gallertiger Substanz znsammengehaltenen Conidien (der früheren spermatien). bei der neuen Gattung Saccoblastia. Durch ilıre Autfindung erlält die nahe rerwandtschaftliche Beziehnug der Amiculariaceen zu den Uredinaceen. welche bisher ans der Gestalt der Basidie allein gefolgert werten musste, eine nente sichere Stïtze, die um so fester wird, als der eigenthiumliche sack, ans dem die Basidie der Saccoblastia-Arten herrorgeht. eine weitere nurerkennbare Beziehnug zu der T'elentospore der Uredinaceen anfweist.

Fïr die nenbegriundete familie der Sirobasidiaceen ergab die Kultur als Nebenfinchtform ebenfalls Hefeconidien. 
Die allerwerthrollsten Ergebnisse aber erhielten wir ans der Untersuchung der Pilacrella delectans. Die grossen am Ende und seitlich an den Fäden des Mrcels gebildeten Conidien, welche alsbald üppig wieder zu Mycelien auswachsen, stellen hier einen besonder's unter den Ascomyceten weitrerbreiteten, unter den Protobasidiomyceten indessen bisher noch nicht rertretenen Typus dar, dessen Anffindung von der allergrössten Bedeutung war; denn aus den Fäden, welche diese Conidien zmüchst in unregehmässiger Anordnung erzengten. liess sich die Entstehung der Auriculariaceenbasidie in der ungezwungensten und natürlichsten Weise herleiten. wie wir oben gesehen haben. Weiter fanden wir bei Pilacrella dieselben nicht keimfähigen (conidien (Spermatien) rertreten, wie bei Saccoblastia und bei den Uredinaceen. und es gelang durch unmittelbare Beobachtung der Nachweis, dass diese früher sogenannten Spermatien mit den grossen, keimfühigen Conidien wesensgleich, an denselben Fadenspitzen. wie jene abgegliedert werden, mit anderen Worten. dass wir hier vor unseren Angen die Spaltung einer Conidienform in zwei nene sich vollziehen sehen, ron denen jede für sich selbstständig weiter fortbesteht und weiter sich fortbildet. Dieselbe Erscheinung der Spaltung einer Conidienform in zwei ist bei den Ascomyceten mehrfach beobachtet und unserem Verständniss erschlossen. Es sei un an die Erscheinungen bei mehreren Diaporthe-Arten erinnert (vergl. Brefeld IX Seite $35 \mathrm{ff}$. und ron Tarel, Morphologie seite 67). Unser Fall hat ein besonderes Interesse dadurch. dass es sich um Conidien (Spermatien) handelt, welche den allgemein bekannten und rerbreiteten Microconidien (suermatien) der Uredinaceen entsprechen und deren echte Conidiemnatur. an der freilich hent wohl nur noch wenige Mykologen zweifeh, recht handgreiftich darlegen.

Wir kehren noch einmal zu den grossen Conidien der Pilacrella zurück. Ihre besondere Bedeutung liegt darin, dass wir, wie ich gezeigt habe (Seite 60), aus dieser Conidienform ganz 
nmmittelbar nnd vor mseren Angen die Steigerung rom Conidienträger zur Basidie sich vollziehen sehen, dass wir durch sie also eine ganz genane Torstellung daron enlalten, wie im besonderen die farlenförmige, wagerecht getheilte Auriculariaceenbasidie zu Stande gekommen ist.

Derartige Fälle, wo neben der Basidie noch der basidienähnliche Conidienträger sich erlalten hat, sind naturgemäss selten; jeder einzelne ist beachtenswerth. Es wird nothwendig, sie hier sämmtlich kurz zu iiberschanen und vergleichend mit den neu gewomnenen 'Thatsachen zu betrachten. um diese letzteren nach der ihnen zukommenden Bedentung richtig werthen zn kömen.

Der erste Fall, derjenige, an dessen Untersuchung sich die Aufklärung ïber das ITesen der Basidie unnittelbar anschloss. ist in Pilacre Petersii gegeben, nnd in der klassischen Untersuchnng im TII. Bande des Brefeldschen Werkes bis in alle Einzelheiten dargestellt. Dort besteht neben der Basidie ein fadenförmiger Conidienträger, Welcher an seiner spitze eine Conidie bildet, damm diese zur seite schiebend weiter wächst, wiedernm an der nenen spitze eine Conidie erzengt, diese abermals zur Seite drängend vorrïckt mul in gleicher Art fortwachsend eine nubestimmte. bis ïber 30 ansteigende Zahl von Conidien hervorbringt. Die Beziehnngen dieser Conidienform zu der typischen Anricnlariaceenbasidie des Pilacre sind murerkennbare, allein ein nunittelbarer Tebergang ron jener zu dieser ist nicht voldanden und kann anch nicht erwartet werden. Brefeld sagt darüber: "Ws liegt mir fern und muss einer klaren Vorstellnug „fern liegen, anzmnelnuen, dass ans den jetzt bestehenden conidien„trägerı von Pilacre sich die lochgegliederte Basilienfucht ans.gebildet habe. Als die spaltmug in zwei Fruchtformen einmal "eingetreten war, lat wohl jede ron diesen den eigenen Gang ,der Differenzirnng eingeschlatgen, die conidien ron jetzt ent„sprechen also schwerlich mehr genan der (irmudform, welche be„stand, ehe diese Spaltung sich rollzog** (Rand T7I Seite 59). 
Der zweite Fall betrifft die Antobasidie von Heterobasidion annosum (Brefeld TIII Seite $154 \mathrm{ff}$.). Hier besteht neben der ungetheilten viersporigen Basidie ein kopfig-keuliger Conidienträger von ganz ähnlicher Gestalt, der nur durch die unbestimmte Zahl seiner Conidien von der Basidie selbst sich unterscheidet, in dieser unbestimmten Zahl aber so erheblich hin und herschwankt, dass er in einzelnen Fällen anch einmal die Vierzahl der Conidien und damit eine völlige Gleichheit mit der Basidie erreichen kann. Bei Heterobasidion ist also ein Conidienträger hent noch vorhanden, der als Stammform der zugehörigen Basidie unmittelbar betrachtet werden muss, der die Entstehungsgeschichte der Autobasidie uns greifbar ror Angen fiihrt.

In genau derselben mmittelbaren Weise, wie die Entstehungsgeschichte einer Autobasidie durch Heterobasidion annosum velanschanlicht wird, erläutert uns Pilacrella delectans die Entstehung der Auriculariabaside ans einem heut noch neben ihr erhaltenen Conidienträger.

Einen anderen Fall, der unter den Antobasidien in gewissem Simne Pilacre entspricht, habe ich im VI. Hefte dieser Mittheilnngen fïr die Rozites gongylophora, den Pilz der Schleppameisen, anfgedeckt. Dort sind neben der Basidie sogar zwei Conidienfruchtformen vorhanden, ron denen in ihrer hentigen Gestalt die Basidie jedenfalls nicht mehr liergeleitet werden kamn. Seit die Spaltmig der ursprïnglich einheitlichen Conidienform in den Conidienträger einerseits, die Basidie andererseits sich rollzog, machte der erstere eine weitere Steigerung zu löherer Formausbildung durch, ja es trat eine abermalige Spaltung ein, es entstanden zwei neben einander weiter sich entwickelnde Conidienträgerformen.

Wie Brefeld schon im TIII. Bande hel'rorgehoben lat, so führt jede der rerschiedenen heut bestehenden Formen ron typischen Basidien zurïck anf Conidienträger ron jedesmal verschiedener Gestaltung. Aber anch die in so unendlicher Mannigfaltigkeit verbreitete, scheinbar immer gleiche viersporige Anto- 
basidie wird nicht in allen Fällen gleichen Ursprungs sein. Betrachten wir' die fiir Tomentella flava bekannt gewordenen Conidienträger (Brefeld VIII, Taf. I Fig. 11). so ist ihre Basidienähnlichkeit zwar ausser Frage. es erscheint aber dann sicher, dass z. B. die viersporige Autobasidie der Tomentella auf einen anders gebauten Conidienträger zuriickfiihrt, als die ebenfalls viersporige Basidie von Heterobasidion.

Die Conidienträger waren jedenfalls schon in mannigfachen Abwandlungen vorhanden, in reicher Formenfiille, ehe es Basidien gab, und jede der verschiedenen Formen schritt nnter dem gleichen ïberall wirksamen, uns in seinem Tresen mud Zweck vorläufig unverständlichen Bildungsgesetze allmählich voran zur Bestimmtheit der Form und Sporenanzahl.

Ein lehrreiches Beispiel fiir eine neue selbstständige Basidienentstehungsgeschichte hat Boulanger in der ..Rerue génér. de bot.

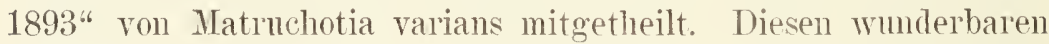
Pilz habe ich schon in den Jahren 1891 und 1892 in Brasilien vielfach beobaclıtet und kultivirt. Seine Basidien sind zweisporig und stehen frei an den Enden und seitwärts der Mycelfäden. Wenn man reiche Kulturen durchmustert. so erkennt man die typische zweisporige Basidie mühelos, sie ist in ïberwiegender Anzahl rorhanden. Dazwischen aber finden sich in geringerer Anzahl Conidienträger, welche ebenso wie die Basidie gehant und angeordnet sind, aber je 1, 3, 4 oder 5 Conidien erzengen. Ans dem Vergleiche vieler Kuntmen des Pilzes sieht man ganz zweifellos, wie gegen diese mmegelmässigen Conidienträger, von d(nlen der e inzelue zweisporige nicht zn unterscheiden ist. dieser letztere demnoch als besonderer Fall, als Basidie, sich ahhebt durch die gleichmässigere mud regehmässigere Gestalt mind die Ceberzahl seines Vorkommens.

Ton lö̈chstem Interesse war es mir num. dass ich im Jahre 1893 eine Natruchotia entdeckte (Natruchotia complens nor. spec.). welche bei gleicher äusserer Frscheinmg. gleichem Habitus mi Vorkommen, wie die erwähnte, sich dadurch nuterschied, dass bei 
ihr die riersporige Basidie zur Herrschaft gelangt war. Neben den viersporigen, in der Form bestimmten Basidien fanden sich auch zwei-, drei- und fünfsporige Conidienträger; die zweisporigen waren nicht verschieden von den Basidien der Matruchotia varians, aber sie kamen als seltene Ausuahmen ror und zeigten keine Bestimmtheit der Form, genau wie bei Matruchotia rarians auch vereinzelte riersporige Conidienträger vorkommen, welche wiederum den Basidien ron M. complens ganz gleich sind. Hier liegt der bemerkenswerthe und in den Rahmen nnserer Betrachtnng ergänzend einzufiigende Fall ror, dass zweierlei Basidien, die zweisporige und die viersporige, anf dieselbe Conidienform sich zurückfiihren lassen. In Matruchotia varians ist aussertem die Entstehmo der zweisporigen Pasidie, welche unter den Autobasidiomyceten (z. B. bei Clavarieen. aber auch bei Agaricineen) häufig rorkonunt, für einen bestimmten Fall aufgedeckt. Wenu man die zweisporigen Basidien dieses Pilzes betrachtet, so erscheint es recht wahrscheinlich, dass auch die festbestimmte zweisporige Basidie der Dacryomyceten von ähnlichen C'onidienträgern sich herleitet, und es hat diese Torstellung jedenfalls mehr Wahrscheinlichkeit fïr sich, als die andere, welche sie ron Protobasidien durch Terlust der Theilwände entstehen lässt. Im allgeneinen sprechen alle bisherigen Erfahrungen dafür. dass die Basidie in ihrer jeweiligen bestimmten Form die höchste Entwickelungsstufe des Conidienträgers darstellt, welche einer weiteren Entwickelung nicht fähig ist, welche, nachdem sie eimmal entstanden war, unverändert fiir alle Folgezeit bestelen bleibt. T'nter den bekannten Thatsachen spricht keine dafïr, dass eine Protobasidie sich durch Verlust der 'Theilwände nachträglich zur Autobasidie umgestalten könne. So will es mir auch wahrscheinlicher scheinen, dass die längliche Antobasidie von Tulostoma anf einen eigenen Ursprung, auf Conidienträger, etwa wie die ron Pilacre zuriickfiilne, als dass sie aus der Anriculariaceen-. im besonderen der Pilacrebasidie durch Verlust der Theilwäude entstanden sei. 
Anf welcherlei Conidienträger endlich die Tremellaceenbasidie zurïckgehe, darïber waren bisher kine Aufklärungen zu gewinnen. Für diese Frage ist unser sirobasidium Brefeldianum im Verein mit den beiden anderen Arten (albidum und sanguineum v. Lagerheim) derselben Gattung ron entscheidender Bedeutung.

Wir sehen an den Mycelfäden von S. Brefeldianum Conidien an den Fnden der Fäden, mnd auch seitwärts ohne Sterigma hefeartig aussprossend, und diese Conidien haben die Fähigkeit, hefeartig weiter zu sprossen. Eine Fadenendzelle kann solche Conidien in umbestinmter grosser Zahl hervorbringen. Wird die Conidienbildnug durch die Basidien abgelöst, so schwillt die Fadenendzelle stärker an als es frïher geschah, sie theilt sich durch eine schrägstehende Wand in zwei über einander stehende Zellen, ron denen jede nur eine Sprosszelle, spore, ohme Sterigma hervorbringt. Die abgefallenen Sporen kömmen gleich den Conidien hefeartig weitersprossen. Dass die Basidienbildung sich hier auch auf die rïckwärts gelegenen Fadenzellen ausdehnt, welche ebenfalls vordem Conidien erzeugen konnten, ist für die augenblicklich in Betracht kommende Frage nebensächlich. Die eine erste Scheidewand ist in ilner Richtung noch unbestimmt, sie kann ausmahmsweise wagerecht stehell, meist verläuft sie schräg; geht aber in manchen Fällen bis zur senkrechten stellnng (s. Fig. 44 Taf. VI links). Hier hat die Basidie schon eine Gestalt erreicht, welche wir unter den echten 'Tremellen mehrfach angetroffen haben. Nun aber kommt eine zweite, die erste klouzende Theilwand hinzu.*) nnd tritt regehnässig auf bei den von v. Iagerhein entdeckten Formen S. albidum nud sanguinemm, nud die typische Tremellabasidie ist fertig. ('onidienerzengung, sprossartig an beliebigen Fadenzellen wie bei sirobasidimn, fanden wir in ausgeprägter Form wieder bei 'Tremella compacta (Fig. 12a u. b Taf. T'). Dies

*) Genaner genommen sind es wohl zwei nene selbstständige Theilwände, die linznkommen, mud die nu dadurch. dass sie in ein nud derselhen Kante mit der ersten Theilwand sich schmeiden, den Eindruck einer die erste krenzenden $\mathrm{IT}^{\top}$ and machen. 
ist also eine Conidienstammform der Tremellabasidie. - Dass die viertheilige Tremellabasidie ans der zweitheiligen entstanden ist, dafür spricht das unzweifelhafte häufige Torkommen von zweisporigen Basidien bei echten Tremellen (rergl. z. B. Fig. 10, 12 c Taf. IT). Dass die später senkrecht stehende erste Irand früher wagerecht oder schräg gestanden hat, daran erimnern Torkommnisse, wie die in Fig. 12 c Taf. IV dargestellten, welche bei sorgsamem, freilich sehr miihevollem suchen sich noch rermehren liessen. Ich entsinne mich wenigstens dentlich, derartige Bildungen auch bei anderen Tremellen gelegentlich schon gesehen zu haben.

TTemm es nm also gelingt, alle die verschiedenen Typen der Basidie zurückzuführen auf je verschiedene Conidienträgerformen. so ist es selbstrerstandlich ein ganz rerfehltes Beginnen (wie Brefeld ïbrigens schon im VIIT. Bande es ansgesprochen hat), alle Basidiomyceten in eine fortlaufende Entwickelungsceihe einordnen zu wollen, wie man das frïher versucht hat. Wir werden vielmeli, je mehr unsere Kemntniss der Formen und ihrer Entwickelungsgeschichte zunimmt, $14 m$ so melı rerschiedene, neben einander fortlanfende und je für sich zu verschiedener Höhe gesteigerte Reihen erkemen, welche anf weit zuriickliegende, bei den conidientragenden Stammformen zu suchende gemeinsame Ahnen zurïckreisen. Der gemeinsame Besitz einer bestimmten Basidienform. z. B. der viersporigen Autobasidie, ist nicht Grund genug. alle Pilze, welche eine solche aufweisen, als Entwickelungsglieder einer Reihe anzusehen; denn die in den Endergebniss, in ilıen jetzigen Erscheinnugen also gleichen Basidien kömmen auf verschiedenen ITegen, aus rerschiedenen Conidienträgern hergeleitet werden (s. o. Seite 149-150).

Ebensowenig kann die gleiche oder ähnliche äussere Gestalt der Fruchtkörver fïr die nahe Blutsrerwandtscliaft zweier Arten etwas beweisen. Wie ich schon oben (Seite 22-23, 43-44. 131) angeführt habe. ist das Bammaterial für die Fruchtkörper der Pilze iiberall das gleiche, enfache Hyphen; nur selten kommt ein psendoparenchyma. 
tisches Gewebe zu Stande. Ebenso wie das Bammaterial sind aber auch die Bediurnisse, die äusseren Berlingungen. welche die schimmelartigen fruchtkörperlosen Bildungen zur Fruchthärperbildung treiben, im algemeinen die gleichen. Stets handelt es sich darnm, die sporentragenden 'Theile iiber das substrat zu erheben. sie der' Luft auszusetzen zu leichterer Verbreitung der Sporen. Ist der Fruchtkörper einmal gebildet, so macht sich das Bestreben geltend, durch möglichste Vergrösserung der Oberfläche eine möglichst grosse Zahl von Sporen zur Erzengung und Verbreitung zu bringen. Soll dabei nicht unverlältnissmässig viel Stoff anf den sterilen Theil des Fruchtkörpers rerwendet werden. so ist die Erreichung des Zieles nur möglich durelı Wellen. Falten. Lappen. Blätter, regelntässige grubige Tertiefmugen. Röluen oder stachehn in der hymenialen Fliiche. und alle diese Möglichkeiten finden wir verwirklicht. Sir treten in die Ershommer in den verschiedenen Reilıen, mabhängig von rinander. Taher finden wir parallele in der änsceren Form sich entequechembe Gattungen in den rerschiedenen Familien. In nuseren I'ntersnchungern trat diese Parallelitit besomders zwischen den 'Tremellaceen nud Auri-

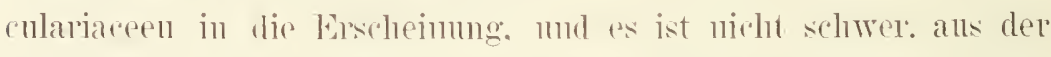
Menge dre Antobasidiomyceten noch eine dritte Parallele zu den genamnten herznstellen.

We entsprechen, wir wir näher ansefiihnt haben:

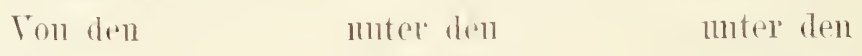

Anliculariacesn :

die Stypinelleren

die Plittygloeen

die Aurienlarieen

z. 'Tl.

die Anricnlarieen z.Th.

die Pilicraceen
Themellaceen dens strpelleen den Fxidiopsideen den Tremellineer

z. Th.

den Protopolyporeen die Protohydueen mil es entsprechem: den Hyaloriaceen
Antohasidionyceten dim Tomentelleen den nied. Telephoreen den Thelephoreen (Crpleella) z. Th. den Polyporeen den Hydneen d.Lycoperdaceenz.Tlı. 
In der gleichen oben ausgeführten Betrachtungsweise erklären sich natïrlich anch die mancherlei schon oft bemerkten und hervorgehobenen Formanklänge zwischen Basidiomyceten und Ascomyceten, wie z. B. zwischen Cyphella und Peziza, Verpa und Itlyphallus, Clavaria und Xylaria und viele andere. Formanklänge. die noch durch manche auffallende neue von mir in Brasilien anfgefundene in meinen näclssten Mittleilungen ergänzt werden sollen.

Wenn es num einerseits klar ist, dass die Aelnnlichkeit, ja die Gleichlheit in der Ausgestaltung des fertigen Fruchtkörpers für die Verwandtsclaft zweier Formen als beweisend nicht ins Feld gefülnt werden kamn, so ist doch auf der anderen Seite einlenchtend, dass mit grossem Nutzen die jeweilige Höhe der Fruchtkörperausbildung als Mittel dient, um innerhalb einer und derselben Entwickelnngseihe die Gattungen von einander für die praktische U'nterscheidung abzugrenzen. Dieser Gesichtspmkt ist für die Autobasidiomyceten von jeher massgebend gewesen, er bildet die Grundlage für die Scheidung der Thelephoreen, Clavarieen. Polyporee:, Agaricineen und Hydneen. In der vorliegenden Arbeit ist derselbe Gesichtspunkt nun auch für die Eintheilung und Gruppenabgrenzmo der Protobasidiomyceten zur Geltung gebracht, vornehmlich innerhalb der Familien der Auriculariaceen nud Tremellaceen. Ton ihm ans rechtfertigt sich die Aufstellmng der Stypinelleen und Stypelleen, die Abgrenzung der Platyglneen als besonderer Gruppe, die Abtremnmg der Exidiopsideen von den Tremellineen im engeren Simne, die Aufstellmmg der Protopolyporeen und Protohydneeu. Fine solche Gruppirung war vordem nicht möglich, weil die europäischen Protobasidionyceten keine oder nu ganz vereinzelte Vertreter der meisten dieser Gruppen besassen. Nit dem zunehmenden Reichthum an bekannten Formentypen innerhalb der Klasse ergab sich die nene Eintheilumg ganz von selbst.

Die Berïcksichtigung der Nebenfruchtformen erweist sich als 
nothwendig und werthvoll lauptsächlich zur Ungrenzung der eimzelnen Gattmingen - ich erimnere lier wiederum an die Schärfe und Klarheit, mit der die änsserlich oft so älnnlichen Angehörigen der Gattung Tremella und Exidia durch ihre Nebenfruchtformen gegen einander abgegrenzt sind. Darïber hinans können die Nebenfruchtformen allein für die Terwandtschaftsverhältnisse schon 1 m deswillen nichts beweisen. weil manche ron ihnen gleicherweise bei Pilzen der rerschiedensten Terwandtschaftsklassen angetroften werden; so sind manche ron Ustilagineen abstammende Hefen ron manchen bei Ascomyceten und anderen bei 'Tremellineen anftretenden kanm nnterscheidbar. nud die durchans gleichen Hälichenconidien, welche um Exidiopsis nud Exidla ein so festes Band hel Znsammengehörigkeit schliessen, kommen andererseits anch der weitabstehenden Gattmg Anricularia zu. Brefeld hat deshalb schon die Fruchthörperausbildung als oberstes Eintheilnngsprincip) eingesetzt, indem er die P'ilacraceen um ihres angiokarpen Fruchtkörpertypus willen von den gymukarpen 'Tremellaceen als eigene Familie abschied. Anf dem hierdurch angedenteten Trege bin ich bei der in dieser Arbeit anfgestellten Anordnmo weiter gegangen.

Enst in rellältnissmässig selu wenigen Fällen ist es gelmugen. den Entwickelungsang eines P'ilzes lïckenlos nurl vollständig in kïnstlicher Kultur zur Anschanumg zu bringene. Es darf daler lier nicht muerwähnt bleiben. dass die vorliegenden Ututersllchungen den bereits bekannten zwei nene derartige Beobachtungen anreilien. den einen von Pilacrella relectans, den anderen bei Sirobasidiun Brefeldianmm. In beiden finden wir bestätigt. dass die Basidienfincht den Entwickelnugsang des betreftemden Pilzes als lotzter nud höchster Zustand ahschliesst. nachdem der r/ustand der Conidienf'nktifikation längere oder kiuzere Zeit angedauert hat. Diese Reihenfolge des Anftetens steht in voilliger Teleremstimmung nit dem Gesetze. dass lie Entwickelumgsgoschichte des Einzelwesens die stammesgeschichte wiederholt. 
lat aber mit dem sogenannten Generationswechsel, einem in die Mykologie willkürlich nash naturphilosophischer Manier hineingetragenen Wahne, selbstrerständlich nichts zu thun. Die Untersuchung der Pilacrella gewann noch besonderen Reiz dadurch, dass bei ihr alle die rerschiedenen Tebergangsstufen, welche ron dem. freie Basidien tragenden Mycel bis zum entwickelten gestielten Fruchtkïrper denkbar sind, neben einander lent noch in geeigneten Kinluren auftreten und uns die stammesgeschichte dieses Fruchtkörpers greifbar deutlich ror Angen führen.

Versuchen wir zum Schlusse über den Stanmbaum der Protobasidiomyceten im Ganzen uns an der Hand der gewomnenen Ergebnisse eine Torstellung zu bilden, so muss zunächst betont werden, dass es auch hier wieder ein ganz verfelıltes Beginnen sein wiurde, alle sechs Familien in eine fortlaufende Entwickelungsreilıe einzuordnen. Wir haben die nahen Beziehungen kennen gelernt, welche zwischen Tredinaceen mo den niedersten Auriculariaceen mzweifelhaft bestehen. I)ie Gattung . Tola ist gewissermassen schon eine Tredinacee, deren Telentosporen nur noch keine feste Membran besitzen, und welche weder Uredosporen noch Aecidien, wohl aber die sogenannten spermatien, freilich noch nicht in geschlossenen Behältern, bildet. Ganz besonders in Hinblick auf die Gattungen Jola und Saccoblastia begegnet es keinen schwierigkeiten mehr, die Uredinaceen von den niedersten Auriculariaceen, ron stypelleen und Platygloeen herzuleiten. Ton jenem Ausgangspunkte an wïrden sie dann eine eigene selbstständige Entwickelungsrichtung eingeschlagen haben, die besonders durch die parasitische Lebensweise bedingt und beeinflusst wurde, und in der reicheren Entwickelung und Ausgestaltung der chlamydosporenfruchtform zum Ausdrucke kam. (Man vergleiche hierzu eingehend Brefeld: „Ueber den morphologischen Werth der Chlamydosporen bei den Rostpilzen VIII S. 229 ff.)

Weiterhin kann man sich wohl rorstellen. dass auch die Tor- 
falıen der Pilacraceen mit den Stypinelleen zusammengefallen seien. Tenigstens würde Pilacrella, wenn ron ihr nichts bekannt wäre, als las lose, in Nührlösungen sich entwickelnde Mycel mit freien grossen Conidien, und einzelnen, frei an den Fäden auftretenden Basidien, ein Znstand, den wir in Wirklichkeit als Uebergangsstadium vor uns gesehen haben (Taf. Y Fig. 30), sich ohne weiteres den stypinellen einordnem.

Lie Anffindung der Conidienträger von Pilacrella, welche schon nach so vielen Richtningen lin mus werthvolle Anfschlïsse vermittelte, erweist sich endlich bedentsam dadurch, dass sie die weitere Abstanmmug aller Anricnlariaceen ron den Hemibasidii Brefelds uns erläntert mnd bestatigt. Brefeld hat in den Hemibasidii. den bisherigen Ustilagineen die Stanmformen der Proto- mol Autobasidionyceten erkannt. Er theilt sie in Ustilagieen und Tilleticen, je nachdem der aus der Chlanytospore keimente basidienähnliche conidienträger mehrzellig ist und die Conidien seitwärts trägt (C'stiligo Carbo, Maidis, eruenta, Schizonella melanogramma, Tolyposporinm Jnnci), oder einzellig bleibt und die Conidien in Küpfchen an seiner spitze herrorbringt (Tilletia, Urocystis, Neovossia, T'uburcinia, Thecaphora). Man rergleiche $11 m$ die Hemibasidien. wie sie \%. B. bei Brefeld T, 'laf. IV Fig. 12, Fig. 13 oder Taf. T Fig. 3 oder Taf. I I Fig. 22 n. s. w. dargestellt sind, mit den Conidienträgern und Basidien der Pilacrella. nnd man wird eine ganz mbestreitbare Bestatigung der angegebenen Ableitung feststellen kömlen.

Was dic drei letzten Familien des Protobasidionyceten hetriffit. so ist nach den frïheren Anstïhlmmgen olne weiteres klar, dass sie in ilnen Basidien zu denen der vorhergehenden gewisse muerkenubare Bezielmugen zaigen. Solche treten besonders in der zweitleiligen. fast wagerecht getheilten Basidie von Sirobasidimm Brefeldiannm und bei rereinzelten Torkommnissen zu Tage, wie sie z. B. in den Figmren Thaf. IT Fig. 12 e dargestellt sind. Dennoch kamn man die sirobasidiaceen nicht von irgend 
einer der frïlneren Familien unmittelbar herleiten. Vielmehr führen sie auf selbstständigem Wege zurück auf die Ustilagieen, unter denen die gemeinsamen Torfahren aller Protobasidiomyceten zu suchen sein dürften. Fïr Sirobasidium Brefeldianum insbesondere sei z. B. anf Ustilago bromivora rerwiesen (Bref. V, Taf. X Fig: 1-8), bei dem zwreitheilige Conidienträger, ja auch die für Sirobasidium so bezeichnenden sehnallenzellen sich finden. Dass man von den Sirobasiliaceen die Tremellaceen ableiten kann. ist schon näher ansigefïhnt worden (S. 152). F Für die Abstammung der Hyaloriaceen haben wir an den bekannten Thatsachen keinen festen Anlalt, indessen begegnet es nach dem Vurgange der Pilacraceen keinen Schwierigkeiten, anzunehmen. dass ilı Stammzweig von den 'Tremellaceen bei deren niedersten Formen entsprungen sid. Fin Schema des stammbanmes der Protobasidiomyceten würde sich also vorläufig etwa in der folgenden Wreise entwerfen lassell: 


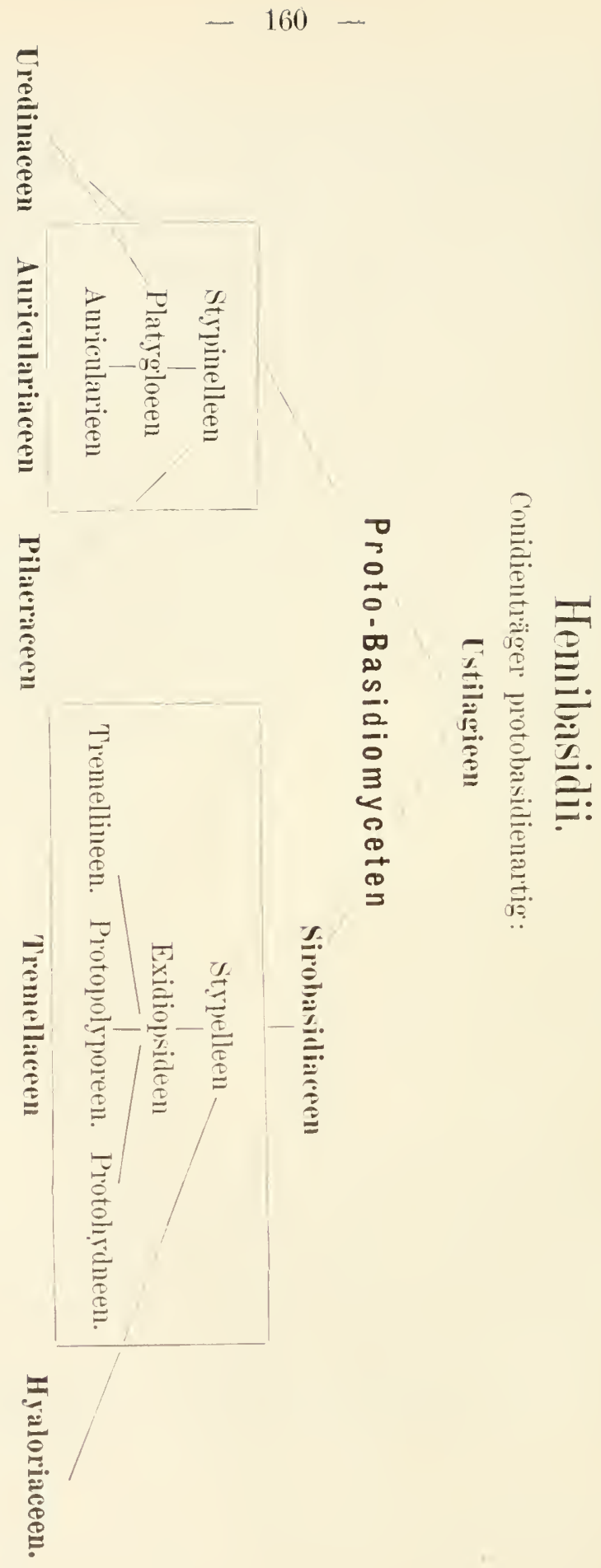




\title{
Zusammenstellmug der durch die vorliegende Arbeit veränderten mnd der Beschreibmaen nener Gattungen und Arten.
}

\author{
Ifan vergleiche ïber die Charakterisirung der sechs Familien der \\ Protobasidiomyceten when Seite :-11.
}

\section{Auriculariaceen.}

(Seite 12.)

\section{Stypinelleen.}

Ohne Fruchtkörperbildung. Basidien frei an den Fäden.

a) Stypinella Schröter. Die Gattungsdiagnose in ,Schlesische Pilze 1889“ S. 383 lautet: „Fruchtlager flach, wergartig, unbegrenzt, aus locker verflochtenen, groben, dickwandigen $\mathrm{H}_{y p h e n}$ gebildet. Basidien isolirt stehend, bogenförmig zurückgekrümmt, durch Querwände in senkrechte Abtheilungen getheilt, welche pfriemliche Sterigmen treiben, an deren Spitze einfache Sporen gebildet werden." Aus dieser Gattungsbeschreibung miissen die Worte: „bogenförmig zurïckgekrümmt" wegfallen.

1. Stypinella orthobasidion nov. spec.

Unregelmässige, rundlich umschriebene, lockere, weisse Flöckchen von wenigen Millimetern Durchmesser und kaum $1 \mathrm{~mm}$ Dicke. In grosser Zahl neben einander auf morschen Rindenstücken. Hyphen dickwandig, $6 \mu$ stark, regelnüssig mit Schnallen. Basidien g e rade, ca. $30 \mu$ lang, pfriemförmige Sterigmen von 2,5 "Länge, länglich ovale Sporen von 7 ॥ Iänge, 5 „ Breite. Sekundärsporenbildung 
häufig. Am Waldboden. Blumenau Brasilien. Hierher gehört Helicohasidium Pat., welches als Gattung nicht bestehen bleiben kann (vergl. Seite 15).

b. Sa c c oblastia nov. g e n. Unregelmässige, kaum $1 \mathrm{~mm}$ starke, weisse, lockere Hyphengeflechte auf morschem Holze und Rinden. Basidien frei und einzeln, die Tragzelle der Basidie trägt einen seitwärts aussprossenden, blasenartigen Sack, dessen Inhalt für die auswachsende Basidie verbraucht wird und in dieselbe vollständig hineinwandert.

2. Saccoblastia ovispora nov. spec.

Hyphen etwa $6 \mu$ stark, ohne Schnallen. Sack birnenförmig, etwa $30 \mu$ lang und $8 \mu$ breit. Basidien $100 \mu$ lang, umregelmässig verbogen. Pfriemförmige, kurze Sterigmen, alle von gleicher Jänge. Sporen oval, $13 \mu$ lang, 7 -9 « breit. Sekundärsporenbildung häufig. Spore theilt sich bei der Keimung durch eine Scheidewand. Nebenfruchtform: Kleine runde, in grossen Mengen an freien Hyphenenden erzeugte, nicht keimfähige Conidien (Spermatien). An morschen Rinden im Walde bei Blumenau. Brasilien.

3. Saccoblastia sphaerospora nov. spec.

Hyphen wie bei der vorigen Art, etwas dickwandiger. Der Sack kuglig, $11 \mu$ Durchmesser. Länge der Basidien 45-60 . Kurze fadenförmige Sterigmen, alle von ungefähr gleicher Länge, rundliche Sporen von $6-8$ ॥ Durchmesser, welche mit einfachen Keimschläuchen keimen. Nebenfruchtformen nicht bekannt.

Vorkommen wie bei der vorigen Art.

\section{Platygloeen.}

Die Basidien sind zu einem mehr oder weniger glatten thelephoreenartigen Hymenium zusammengeordnet. Die Fruchtkörper bestehen aus einer der Unterlage angeschmiegten weichen, wachsartigen oder schleimig gallertigen Kruste.

a. Tola nov. gen. Die Basidien schliessen lagerartig zusammen, stehen aber noch nicht alle gleichmässig in einer Höhe. Sie entspringen aus ciner Tragzelle, welche eine besondere, eiförmig angeschwollene Gestalt zeigt und den Telentosporen der Uredinaceen entspricht. 


\section{Jola Hookeriarum nov. spec.}

Parasitisch an Moos-Kapseln und -Stengeln von Hookeria-Arten, wo der Pilz in trockenem Zustande einen kaum sichtbaren, feinen weissen Flaum, in feuchtem Zustande einen schleimig glänzenden, feinen Ueberzug bildet. Basidien bis $90 \mu$ lang. Bei ihrer Bildung wird der ganze Inhalt der die Basidie tragenden Zelle aufgebrancht. Sterigmen dick, fadenförmig, von ungleicher Länge, Sporen lang, sichelförmig gebogen, 28-36 $\mu$ lang, $6 \mu$ breit. Sekundärsporenbildung häufig. Nebenfruchtformen nicht beobachtet.

Auf Hookeria albata und jungermanniopsis gefunden. Blumenau, Brasilien.

b. Platygloea Schröter (= Tachaphantium Brefeld)s. d. Gattungsdiagnose bei Schröter "Schles. Pilze" S. 384.

\section{Platygloea blastomyces nov. spee.}

Grauweisse, schwach gelblich angehanchte, unregelmässig umgrenzte wachsartige, etwa $5 \mathrm{~mm}$ dicke Polsterchen auf morschen Rinden. Hyphen sehr fein, dicht verflochten. Basidien fadenförmig, bis $200 \mu$ lang, Sterigmen fein fadenförmig von wechselnder Länge. Längliche Sporen, $12 \mu$ lang, $6 \mu$ breit. Sekundärsporenbildung häufig. Spore keimt, ohne dass eine Scheidewand auftritt, mit Keimschläuchen oder mit Erzengung von Hefeconidien. Die als Hefen unbegrenzt fortsprossenden Conidien sind oval und haben höchstens $8 \mu$ Länge bei $4 \mu$ Breite.

An morschen Rindenstücken im Walde bei Blumenau, Brasilien.

Hierher gehört wahrscheinlich: Campylobasidium v. Lagerheim (Ludwig, „Lehrbuch der nied. Cryptog." S. 474). Besehreibung fehlt.

Helicogloea Pat. ist durchaus gleich Platygloea und hat keine Gattungsberechtigung (vergl, oben S. 32).

Septobasidium Pat. ist nicht genügend bekannt, um unter den Protobasidiomyceten aufgeführt werden zu können (vergl. oben S. 35).

Delortia Pat. ist gar kein Protobasidiomycet (vergl, oben S. 35).

Urobasidium Giesenhagen (Flora 1890) ist ebenfalls kein Protobasidiomycet (s. oben S. 36).

\section{Anricularieen.}

Feste, von der Unterlage abstehende Fruchtkörper mit einseitig ausgebildetem glatten oder wabigen oder polyporcenartig ausgebildeten Hymenium. 


\section{Auricularia auricula Judae L.}

Es ist im Texte ansführlich nachgewiesen, dass diese Auricularia in sich begreift die Auricularia sambucina Mart., sowie Laschia delicata $\mathrm{Fr}$. = L. tremellosa Fr., wahrscheinlich auch L. velutina und nitida. Dies ist die höchst entwickelte Auriculariacee, eine sehr varialole Form. Thre Fruchtkörper schwanken in der Farbe von reinem weiss durch röthlich gelb, lederbraun bis schwarz, in der Grösse von ganz kleinen Bildungen bis zu Handtellergrösse. Das Hymenium kann ganz glatt, thelephoreenartig sein, dann durch Falten gerunzelt, cndlich sogar regelmässig netzig grubig, polyporeenartig.

Scheint über die ganze Erde verbreitet zu sein.

\section{Uredinaceen.}

(Seite 46.)

\section{Pilacraceen.}

(Seite 48.)

a. Pilacrella Schrötcr. ,Schles. Pilze“ S. 384. In der Gattungsdiagnose dort heisst es ,Sterigmen sehr kurz"; anstatt dessen ist zu setzen: ,,sehr kurz oder fehlend".

7. Pilacrella delectans nov. spec.

In grossen Trupps gesellig an Wundstellen stehender Stämme oder auf faulenden Stämmen oder Blattscheiden der Euterpe oleracea. Gestielte Köpfchen, etwa $5 \mathrm{~mm}$ hoch. Der Stiel wasserhell, fast durchsichtig. Köpfehen weiss, undurchsichtig. 3/4 mm Durchmesser. Basidien in gleichmässiger Schichte das Köpfehen umkleidend, umgeben von einem kelchartigen, nach obcn mely oder weniger znsammenschliessenden Kranze steriler Fäden. In dicsem Kranze von Fäden wird ein Tröpfchen schleimiger Flüssigkeit festgehalten, in dem die Sporen, welche nicht abgeschleutert werden, vertheilt sind. Basidien ca. $60 \mu$ lang, 5- 6 " $/$ dick, im oleren Drittel gekrimmt. Sporen olne Sterigmen aus den Theilzellen der Basidie vortretend, 14- 18 ॥ lang, 7-8 breit. Die Form besitzt zweierlei Conilien, welche auf gemeinsamen Ursprmug zurückgchen: kleinc, nicht keimfïhige, welche von cinzelnen Fadenspitzen des Mycels in grossen Mengeu hinter einander abgeschuiirt werden, rumdlich 2 " Durchmesscr; grosse sporenähnliche von länglicher Form, 12-26 " Länge, 6-9 " Breite, die sofort und 
leicht auskeimen. Von diesen letzteren leiten sich die Basidien in heut noch sicher festzustellender Weise ab.

Im Walde bei Blumenau, Brasilien, luäufig.

8. Pilacre Petersii in der Charaterisirumg von Brefeld, forma brasiliensis.

Von der suropäischen durch kleinere Statur, kaum über $1^{1 / a} \mathrm{~mm}$ Höhe, wenig kleinere Sporen und dadurch verschieden, dass in künstlichen Kulturen die zugehörige Conidienform nicht erzielt werden kounte.

An trockenem morschen Holze im Walde und an trockenem Holze (Cedrela!) im Inneren rou Gebäuden. Blumenau, Brasilien.

\section{Sirobasidiaceen.}

(Seite 65.)

Sirobasidium v. Lagerheim et Patouillard.

Die Gattungsdiagnose der Autoren (Journ. de bot. 16. Dec. 1892) lantet: ,Fungi gelatinosi, pulvinati, ubique hymenio vestiti; basidia ex apice hypharum oriunda globosa vel ovoidea longitudinaliter quadripartita in catenulas disposita quarum articuli inferni juniores; e quacunque parte basidii spora unica continua fusiformis acrogena sessilis exoritur. Germinatio sporae ignota." Aus dieser Diagnose müssen, nachdem der Charakter der Sirobasidiaceen im allgemeinen (wie oben S. 10) festgestellt ist, die Worte: „longitudinaliter quadripartita“, ferner' "acrogena" und die Bemer'kung "Germinatio sporae ignota" wegfallen.

9. Sirobasidium Brefeldianum nov. spec.

Kleine weisse, glasighelle, kaum über $3 \mathrm{~mm}$ Durchmesser haltende, tropfenartige Bildungen auf faulendem Holze. Die Basidien zerfallen durch eine schräg stehende Wand in zwei Zellen. Bis über ein Dutzend Basidien werden hinter einander gebildet. Die ansitzenden Sporen länglich, 22-24 " lang und $\vec{\tau}-8$ " breit, abgeschleudert nehmen sie Kugelgestalt an. Sie keimen mit Bildung von Keimschläuchen oder Hefeconidien, welch letztere iu langen Generationen weitersprossen. Aus der mit Keimschlauch keimenden Spore geht ein Mycel hervor, welches an seinen Zweigspitzen wiederum Hefeconidien bildet, endlich aber wiederum zur Basidienbildung übergeht. Die normalen Hefen haben rundliche Gestalt und 6-8 "D Durchmesser. Sie keimen gelegentlich auch wieder mit Fäden aus.

Im Walde bei Blumenau, Brasilien. 


\section{Tremellaceen.}

(Seite 75.)

\section{Stypelleen.}

Entsprechen den Stypinelleen unter den Auriculariaceen. Basidien frei und einzeln an den Mycelfäden; ohne Fruchtkörperbildung.

Stypella nov. gen. Charaktere der Gruppe. Einzige Gattung.

10. Stypella papillata nov. spec.

Kleine weisse, kaum $1 / 2 \mathrm{~mm}$ starke, umregelmässig begrenzte, feuclit glasige Ueberzügc, bei Lupenvergrösserung rauh von umregelmässig angeordnetcn, winzigen Papillen, zusammengesetzt aus lockcr verflochtenen, sehr feinen Hyphen, zwischen denen einzelne bis zu $200 \mu$ lange, $10 "$ "starke schlauchartige Bildungen verlaufen, welche uiber das wergartige Lager hinausragen. Basidien rundlich, $9 \mu$ Durchmesser, über Kreuz in vier Theilzellen zerfallend, Sterigmen $9 \mu$ lang, Sporen rundlich, 4 « Durchmesser, Sckundärsporen lıäufig. Nebenfruchtfor'm unbekannt.

An morschen Holz- und Rindenstüclichen am Boden des Waldes. Blumenau, Brasilien.

11. Stypclla minor. nov. spec.

Aeusserlich von der vorigen nicht unterscheidbar. Anstatt der Schläuche finden sich hier zwischen den meist ganz ausserordentlich dünnen Fäden Bündel ron stärkcren Hyphen, etwa $3 \mu$ stark, welche, über die Fläche hinausragend, die feinen Papillen bilden. Basidien nur 4-5 $\mu$ Durchmesser, sonst wie beim vorigen. Sterigmen etwa $7 \mu$ Länge, Sporen oval, $6 \mu$ lang, $3 \mu$ breit.

Vorkommen wie bei der vorigen Art.

\section{Exidiopsideen.}

Entspreclien den l'latygloeen unter den Auriculariaceen. Die Basidien treten zu glatten Lagern zusammen. Die Anfänge der Fruchtkörperbildung sind zu bcmerken, bleiben aber meist auf die Ausbildung eines dïnen, bisweilen wachsartigen, dem Substrate eng angeschmiegten Uebcrzuges beschränkt.

a. Hetcrocliate Patouillard. Die Gattungsdiagnose ist obcn (S. S0) mitgethcilt und besprochen. Es gehörcn hicrher alle Exidiopsidcen, bci denen cs noch nicht gelungen ist, die Keimung und 
Conidienbildung zu beobachten, und welche durch verhältnissmässig starke Papillen (setulae) ausgezeichnet sind. Die Gattung hat demnach nur vorläufigen praktischen Werth. Viele ihrer Angehörigen werden sicher im Laufe der Zeit als zu Exidiopsis gehörig erkannt werden.

12. Heterochaete Sae Catharinae nov. spec.

Rein weisse, kaum $1 \mathrm{~mm}$ starke, umregelmässig umschriebene Polsterchen von wenigen Nillimetern Durclimesser auf morschen Rinden, dicht besetzt mit kleinen Stacheln, welche den Anblick eines winzigen resupinaten Hydnum gewähı'en. Hölıe der aus sterilen, nach den Enden eigentliümlich cystidenartig verdickten Fäden zusammengesetzten Stacheln $150 \mu$. Die cystidenartigen Enden ragen 20 " über die Stacheln ins Freie hinaus, haben bis $7 \mu$ Durchmesser, dabei eine unregelmässig verdickte Membran. Basidien länghich oval, $21 \mu$ lang, $12 \mu$ breit. Sporen gleich denen von Exidiopsis, $12-15 \mu$ lang.

Blumenau, Brasilien.

b. Exidiopsis. Flatte hauchartige, häutige, bisweilen etwas stärkere, wachsartige, dem Substrate aus morschem Holze eng anliegende, glatte Ueberzüge, mit einem aus gedrängten, in einer Schichte stehenden Basidien gebildeten Hymenium. Die Mycelien erzeugeu als Nebenfruchtform winzige, häkchenförmig gekrümmte Conidien, welche bei üppigem Wachsthum in traubiger Anordnung an verzweigten Conidienträgern auftreten. Grösse der Häkchen fast überall gleich, nämlich ungefähı 3 « lang. Diese Conidienfruktifikation ist in vollständig ununterscheidbarer Form charakteristisch für die Gattungeu Auricularia, Exidia und Exidiopsis und findet sich dargestellt und bis in alle Einzelheiten und Variationen getreu abgebildet bei Brefeld Heft VII Taf. IV u. V.

13. Exidiopsis cerina nov. spec.

Papierdünne, grane, wachsweiche, gelatinöse Ueberzüge an morschem Holz. Vollkonmen glatt. Basidien oval mit $12 \mu$ grösstem Durchmesser, Sporen länglich, schwach gekrümmt, 8-9 „ lang, 6 „ breit. Pallisadenartig angeordnete Schlanchzellen im Hymenium, senkrecht zu dessen Fläche, über die sie nicht hinausragen, von $22-30 \mu$ Länge, $7 \mu$ Breite, mit dunkel gelbliclıem Inhalt gefüllt. Sekundärsporenbildung läufig. Die Häkchenconidien der Gattung sind nachgewiesen.

Blumenau, Brasilien. 
14. Exidiopsis verruculosa nov. spec.

Feine weisse, kaum seidenpapierstarke Häute mit unregelmässiger Umgrenzung áuf morscher Rinde, äusserst feiu gekörnelt von winzigen Papillen, die aus sterilen Fäden gebildet sind. Basidien $10 \mu$ Durchmesser. Sterigmen 10 " lang. Länge der ein wenig gekrümmten Sporen 9-10 $\mu$, Breite $4 \mu$. Sekundärsporenbildung häufig. Conidien der Gattung nachgewiesen.

Blumenau, Brasilien.

15. Exidiopsis tremellispora nov. spec.

Grane, wachsartig weiche, schwach gallertige Ueberzinge auf morscher Rinde und Holz. Fein gekörnelt durch winzige, kaum $100 \mu$ hohe Papillen aus sterilen Hyphenbïndeln. Schläuclıe wie bei Ex. cerina, aber viel läıger, bis $100 \mu$, bei einer Dicke von $4-8 \mu$, uiber die Hymeniumfläche linausragend. Basidien r'undlich, 20-22 " Durchmesser, Länge der Sterigmen selır schwankend, Gestalt der Sporen melı der birnenförmigen der Tremella-Arten älınelnd, $16 \mu$ Länge, 11 « Breite. Die Conidien der Gattung sind beobachtet.

Blumenau, Brasilien.

16. Exidiopsis glabra nov. spec.

Vollkommen glatte, unregelmässig umgrenzte, lauuchartig dünne Ueberziige. Basidien 18 "laug, 12 " breit. Spore fast rund, $12 \mu$ lang, $10 \mu$ breit. Weder Papillen, noch Schläuche vorlanden. Die Conidien der Gattung sind nacligewiesen.

Blumenau, Brasilien.

17. Exidiopsis ciliata nov. spec.

Rundlich oder rundlich lappig unschriebene, bis $2 \mathrm{~mm}$ starke, weisse, fast kuorpelig gallertige Lappen ron mehreren Centimetern Durchuesser auf morscher, au Boden liegender Riude. Der Rand der Kruste fein und regehuässig gewimpert. Die ganze Fläche mit selır feinen, körneligen Papillen besetzt, welche aus sterilen, nach den Enden cystidenartig verdickten Fäden bestehen. Diese scheinbaren Cystiden laben 15-20 « Länge bei $10 \mu$ grösster Breite. Basidien kuglig, 12-14 « Durchmesser. Sporen länglich gekrümmt, 12-15 $\mu$ lang, $6 \mu$ breit. Conidien der Gattung naehgewiesen.

Blumenan, Brasilien. 


\section{Tremellineen.}

$\mathrm{Zu}$ den Tremellineen rechnen wir alle Tremellaceen, welchen eine eigentliche Fruchtkörperbildung mit einem glatten Hymenium eigen ist, bei denen also der Zustand einer einfachen, dem Substrat anliegenden Haut durch Bildung eines meist stark gallertigen Körpers überschritten wird, eine höhere Formausbildung des Hymeniums indessen noch nicht Platz greift. Sie sind die Thelephoreen unter den Tremellaceen und entsprechen bis zu einem gewissen Grade den Auricularieen.

a. Exidia. Hierher gehören alle Tremellineen, welche die Häkchenconidien als Nebenfruchtform besitzen. Die Exidien zeigeu ausserdem als Gattungsmerkmal sehr oft, doch nicht immer Papillen auf dem Hymenium, schlauchartige Zellen zwischen den Basidien und Sporen von länglich ovaler, etwas eingekrümmter Form.

18. Exidiasucina nov. spec.

Gallertige, hell bernsteingelbe Polsterchen von unregelmässiger Gestalt, aus Spalten morscher Rinde hervorbrechend, und bei günstiger Ernährung übergehend in hufförmig abstehende, consolenartige Fruchtkörper, welche das Hymenium an der Unterseite tragen, von einer stielartigen Stelle aus sich verbreiternd. Zahlreiche, vou gelblichem Inhalte erfüllte Schlauchzellen gehen zwischen den Basidien durch bis zur Aussenfläche. Sie sind $66-80 \mu$ lang, $6-8 \mu$ stark. Basidien 10-12 $\mu$ Durchmesser, Sporen $10-12 \mu$ lang, 4-5 $\mu$ breit, gekrümmt. Conidien der Gattung nachgewiesen.

Blumenau, Brasilien.

b. Tremella Dill. in der Begrenzung von Brefeld.

Begreift unter sich alle Tremellineen, welche Hefeconidien bilden. Die Sporen sind meist birnförmig oder rundlich. Schlauchzellen zwischen den Basidien sind noch bei keiner Tremella beobachtet. Fruchtkörper fast stets stark gallertig und sehr unregelmässig gebildet.

19. Tremella lutescens Persoon - forma brasiliensis.

Weicht ab von der europäischen dadurch, dass an den von auskeimenden Hefeconidien herkommenden Mycelien Schnallenzellen auftreten, welche sonst nicht beobachtet wurden.

An morschen Hölzern. Blumenau, Brasilien. 
20. Tremella compacta nov. spec.

Kugelig gallertige, feste knollige, mit unregelmässigen Falten und Buchtungen an der Oberfläche versehene, aus morschen Rinden vorbrechende Fruchtkörper von hellockergelber Farbe und mehreren Centimetern Durchmesser (Taf. I Fig. 2). Junge Fruchtkörper ganz massiv, in älteren Hohlräume, entsprechend den Buckeln der Oberfläche. Basidien 12-14 $\mu$ Durchmesser, Sporen 6-7 Durchmesser. Sporenkeimung mit ummittelbarer Hefeerzeugung. Hefen rundlich 4-5 " Durchmesser, ohre Sprossverbände. Im Inneru der Fruchtkörper, welche im Alter zerfliessen, werden von beliebigen Hyphen Sprosszellen gebildet, welche hefeartig weiter zu sprossen vermögen, genau wie die von den Sporen herstammenden Hefen. Schmallenzellen an den Hyphen.

Blumenau, Brasilien.

21. Tremella auricularia nor. spec.

Blattartige rundliche, oftmals ohrförmige, knorpelig gallertige, braune Lappen von mehreren Centimetern Durchmesser, welche dachziegelig oder schuppenartig angeordnet aus morscher Rinde hervorbrechen und sich gewöhnlich zurückleiten lassen auf eine starke, unter der Rinde ausgebildete Gallertmasse. Grosse äussere Aehnlichkeit mit Tremella undulata Hoffmann. Basidien 15 " Durchmesser, die birnenförmigen Sporen 10-12 "Durchmesser. Die keimende Spore bedeckt sich mit rundlichen Aussackungen von 4-6 Durchmesser. welche mit ilnr verbunden bleiben, und erst aus diesen sprossen die Hefen, welche abfallen. Sie sind rundlich, haben $3 \leadsto$ Durehmesser und bilden keinc zusammenhängenden Verbảnde.

Blumenau, Brasilien.

22. 'Tremella fuciformis Berk.

Die Diagnose ist obcn (S. 115) mitgetheilt (Taf. I Fig. 5) Sie ist durch folgende Augaben zu ergänzen: Basidien 9-12 $\mu$ Durchmesser, Sporen $5-7 \mu$ Durchmesser. Ovale Hefen von $2 \mu$ Durchmesser sprossen unnittelbar aus der Spore und rermehren sich in unendlichen Generationen, ohne Sprossverbände zu bilden.

Blumenau, Brasilien, an sehr verschiedenen faulenden Hölzern des Waldes häufig.

23. Tremclla fibulifera nov. spec.

Fruchtkörper ausserordentlich zart, weiss zittrig, fast durch- 
scheinend wässrig, unregelmässig buehtig, lappige Klumpen bildend, deren Durchmesser bis zu $10 \mathrm{~cm}$ ansteigen kann (Taf. II Fig. 3). Schnell zerfliessend. Schnallen an jeder Selreidewand der Hyphen. Basidien 12-16 "Durehmesser, Sporen 7-10 $\mu$. Die Spore bildet bei der Keimung Aussaekungen von $4 \mu$ Durehmesser, welehe nieht abfallen, und erst von diesen sprossen die rundliehen Hefen von $3,5 \mu$ Durchmesser aus, welehe sich in unendliehen Generationen weiter vermehren.

Im Walde bei Blumenau, Brasilien, an morselren und faulenden Hölzern versehiedener Art sehr häufig.

\section{Tremella anomala uov. spee.}

An morschen dünnen Wweigen am Boden des Waldes helle, fast durehseheinende, sehmutzig gelbliehe Sehleimklümpehen geringer Ausdehnung mit gehirnartigen Windungen und Falten auf der Oberfläehe. Basidien kuglig 10 " Durehmesser, Sporen $6 \mu$. Aus der Spore treten Sprosszellen, welehe nicht abfallen, sondern ansitzend weiter sprossen. So bilden sieh um die Spore herum zieulieh festverbundene, endlieh undurelısiehtige Klumpen von Sprosszellen, welche letztere länglielı spindelförmig $6 \mu$ lang, $1 / / 2 \mu$ breit sind.

Im Walde bei Blumenau, Brasilicn.

25. Tremella speetabilis nov. spee.

Hell oekergelbe, über faustgrosse, unregelmässige Zusammenhäufungen von mit einander verwaehsenen grossen, glatten, blasig aufgetriebenen, hohlen Falten und Lappen (Taf. III Fig. 2). Basidien 13-15 „ Durchmesser. Sporen länglich 10 "lang, 5-6 $\mu$ breit, keimen mit unmittelbarer Erzeugung von Hefezellen, welche sofort abfallen und weiter sprossen, ohne jemals Sprossverbände zu bilden. Kuglige Hefen von $4-5 \mu$ Durchmesser.

Blumenau, Brasilien.

26. Tremella fucoides nov. spec.

Unregelmässige, im Ganzen längliehe, zittrig gallertige, gelbbraune, naeh den Enden zu stumpf zweitheilig oder aueh geweilrartig endende hohle, bis zu $3 \mathrm{~cm}$ lange Blasen mit durchschcincnden Wänden, zu mehreren in büsehelartige Gruppen vereint (Taf. II Fig. 2). Basidien länglieh oval 10-15 $\mu$ Durehmesser. Sporen $8 \mu$ lang, $6-7 \mu$ breit; bilden die Hefen entweder unmittelbar oder an kurzen, 
dünnen, sterigmaartigen Fäden. Rundliche Hefen von $6 \mu$ Durchmesser, die keine Verbände bilden.

Blumenau, Brasilien.

27. Tremella damaecornis nov. spec.

Kaum über 1 cm grosse, unregelmässig gestaltete, mit geweihartigen Endigungen versehene, aufrecht stehende, knorpelig gallertige, vom Hymenium allseitig überzogene Lappen und Säulchen von hell. gelber Farbe (Taf. IV Fig. 9). Basidien $7-9 \mu$ Durchmesser. Sporen $5-7 \mu$. Lassen die Hefen entweder unmittelbar oder am Ende kurzer Keimschläuche aussprossen. Ovale Hefen von $4-5 \mu$ Länge und $3 \mu$ Breite, welche unendlich weiter sprossen ohne Verbände.

Blumenau, Brasilien.

28. 'Tremella dysenterica nov. spec.

Weichschleimige Gallertmassen von wenigen Centimetern Ausdehnung an sehr nassen Holzstückclien. Farbe hell wässrig, gelblich bis dunkelgelb mit blutrothen Streifen und Striemen. Nur die blutrothen Stellen tragen das Hymenium. Basidien 10-12 $\mu$ Durchmesser. Sporeu 6-9 $\mu$. Bilden unmittelbar aussprossende, rundliche Conidien vou $3 \mu$ Durchmesser, welche in derselben Nährlösung, in der sie gebildet werden, im Gegensatz zu allen anderen Tremella-Arten nicht weiter sprossen.

An faulenden, an Bachrändern liegenden Holzstückchen im Walde bei Blumenau, Brasilien.

\section{Protopolyporeen.}

Tremellaceen mit einem nach dem Muster der Polyporeen ausgebildeten Hymenium.

\section{Protomerulius nov. gen.}

In allen Stücken der Gattung Merulius makroskopisch gleich, doch mit Tremellineenbasidien.

29. Protomerulius brasiliensis nov. spec.

Weiss. Mycel durchzieht die morschen Reste von Jacaratia dodecaphylla und breitet sich darauf stralılenförmig, fast strangartig aus. Hyphen $3 \mu$ stark, schnallenlos. Basidien nur $7-8 \mu$ Durchmesser, über Kreuz viergetheilt. Ovale Sporen von $4-5 \mu$.

Im Walde bei Blumenau, Brasilien. 


\section{Protohydneen.}

Tremellaceen mit einem nach dem Muster der Hydneen ausgebildeten Hymenium.

$$
\text { Protolydnum uov. gen. }
$$

Fruchtkörper resupinat, von wachsartiger Beschaffenheit, dicht besetzt mit stumpf legelförmigen, vom Hymenium bedeckten Erhebungen.

30. Protohydnum cartilagineum nor. spec.

Hellgelbliche, bis $3 \mathrm{~mm}$ dicke, wachsartig weiche, morsche Aeste überzieheude Kruste von nuregelmässiger Umgrenzung, bis zu Handtellergrösse. Dicke, stumpfkegelförmige, bis $5 \mathrm{~mm}$ hohe Erhebungen, dicht gedrängt anf der Oberfläche (Taf. III Fig. 1). Basidien länglich, $15 \mu$ lang, oben und unten etwas eingedriickt, $9-10 \mu$ breit, Länge der Sterigmen $30 \mu$. Die Sporen sitzen gerade auf den Sterigmen, sind 9 « lang, $4-5 \mu$ breit.

Blumenau, Brasilien.

\section{Hyaloriaceen.}

(Seite 137.)

Hyaloria nov. gen.

Gesellig, büschel- oder gruppenweise anftretende, gestielte, am Ende schwach kopfig verdickte, gallertige Pilze, Basidien, Sterigmen und Sporen sind eingesenkt in ein sie iiberragendes Gewir von sterilen Fäden, welche ein nmmittellares Freiwerden der Sporen nicht zulassen. Die Sporen werden daher auch nicht abgeschleudert.

31. Hyaloria Pilacre nov. spec.

Hell wässerige bis milchglasartige Säulchen, bis $2 \mathrm{~cm}$ hoch bei $4 \mathrm{~mm}$ grösstem Durchnesser. Der etwas verdickte Kopf feuclıt glänzend (Taf. I Fig. 3). Die tief nuter der Oberfläche, aber in einer Schicht angelegten Basidien länglich, 14 "lang, 7 " breit, Sterigmen ziemlich gleichmässig, 9 $\mu$ lang, Sporen länglich oval, $7 \mu$ lang, findeu sich in grossen Mengen frei zwischen den peridienartig das Hymenium überdeckenden Hyphen. 
Blumenau, Brasilien. Besonders üppig an faulenden Palmiten (Euterpe).

Ausserdem sind zwei neue Autobasidiomyceten in der Arbeit erwähnt, nämlich :

1. Henningsia geminella nov. gen. et nov. spec. (eine Polyporee) (Seite 44),

2. Matruchotia complens. nov. spec. (Seite 150). 


\section{Erklärung der Abbildungen.}

\section{Tafel I.}

Fig. 1. Auricularia auricula Julae (Limné 1753: Tremella Au. J., Auricularia sambucina Martins). ${ }^{1} / 2$ der natiurlichen Grösse. Aufgenommen den 13. April 1891 zu Blumenzu. Fïnf Fruchtkörper, welche den Uebergang rom ganz glatten bis zn tem mit einem regelmässigen wabig netzigen Hymenium zeigen.

Fig. 2. Tremella compacta nov. spec. Natïrliche Grösse. Ein ganzer und eiu längs durchschnittener Fruchtlï̈rper. Aufgenommen ‘len 17. Mär\% 1892 zu Blumenau.

Fig. 3. Hyaloria Pilacre nov. gen. et nov. spec. Natïrliche Grösse. Anfgenommen den 23. Juli 1891 zu Blunenau.

Fig. 4. Pilacre Petersii (Berk. et Br.) Brefeld; forma brasiliensis. Natiurliche Grüsse. Aufgenommen 15. Juli 1891 zu Blumenau.

Fig. 5. Tremella fuciformis Berk. Natürliche Grösse. Aufgenommen den 25. Januar 1893 zu Blumenan.

\section{Tafel II.}

Fig. 1. Tremella undulata Hoffmanı. 1/2 der natïrlichen Grösse. Aufgenommen den 1. Mäız 1893 zи Blımenau.

Fig. 2. Tremella fucoides nov. spec. $2 / 3$ der natïrlichen Grösse. Die Abbildung stellt zwei Exemplare dar, welche enge zusammengeschoben sind aus Rüicksichten des Raumes; in Wirklichkeit waren sie an demselben Stamme, aber in einiger Entfernung von einander gewachsen. Das obere ist an der Anheftumgsstelle abgenomuen, und man sieht nichts mehr von der Rinde, welcher es anfsass. An dem unteren sieht man links ein Stïck der Rindenschuppe, nnter der die Tremella hervorbrach. Aufgenommen den 20. Мärz 1892 zı Blımenau.

Fig. 3. Tremella fibulifera nov. spec. Natürliche Grösse. Aufgenommen den 16. Oktober 1891 zu Blumenau.

Fig. 4. Exiliopsis ciliata nov. spec. Natürliche Grösse. Aufgenommen den 1. März 1893 zи Blımenan.

\section{Tafol III.}

Fig. 1. Protohydnum cartilagineum nov. gen. et nov. spec. ${ }^{3 / 4}$ der natï1lichen Grösse. Aufgenonmen den 16. Juni 1891 zu Blumenan.

Fig. 2. Tremella spectabilis nov. spec. $\% / 10$ der natürlichen Grösse. Anfgenommen den 20. Juni 1892 zu Blumenau.

Fig. 3 1. 4. Protomerulius brasiliensis nov. gen. et nov. spec. Natïrliche Grösse. Aufgenonmen ilen 24. Angust 1891 zu Blumenan. 


\section{Tafel IV.}

Fig. 1. Stypinella orthobasidion nov. spec. Schnallentragende Fadenenden mit Basidien. Zwei Basidien (rechts) laben Sporen abgeworfen und sind inhaltlos mit sehr dünnen Wänden. Abgeworfene Sporen, von denen eine die Sekundïrspore bildet. Tergr. 1:500.

Fig. 2. Saccoblastia sphaerospora nov. gen. et nov. spec. Basidien mit den entleerten sackartigen Bildungen (Telentosporen) an Grunde. Eine eben ans dem Sacke hervorsprossende junge Basilie. Abgefallene Sporen keimend. Tergr. $1: 500$.

Fig. 3. Saccoblastia ovispora nor. gen. et nor. spec. a) Fäden mit Basidien. Links eine entleerte, zusammenschrmmpfende Basidie. An der die Basidie tragenten Zelle der hirnenförmige Sack. Verorössermu 1:220. b) c) d) Aer birnenförmige Sack und die Basidie in rerschierlenen Entwickelungszustänlen. Tergr. 1:500. e) Keimung der Spore. Scheidewandbildnng, Sekmulärsporenbildung; nnd Bildnng der Conidien (Spermatien) an der Spore numittelbar orler an den Keimschlänchen. Vergr. 1:500. f) Gekeimte Spore mit den ringsmm liegenden, mter einander durch eine musichtbare Gallertmasse rerklebten Conilien (Spermatien). Tergr. 1:220.

Fig. 4. Jola Hookeriarmm nor. gen. et nor. spee. a) Zwei ron dem Pilze befallene Hoosfrichte. Natiurliche Grösse. b) Basidienbildung. Rnullich angeschwollene Tragzellen (Telentosporen) der Basidien. Tergr. 1:560. c) Spitze einer Basidie, Bildung der Spore. Tergr. 1:500. d) Basidie mit Sterigmen ror der Sporenlihdmng. Vergr. $1: 500$, e) Die aus dem gallertigen Lager ins Freie ragenden Sporen. Tergr. 1:500. f) Abgefallene, nicht gekeinte sporen. Tergr. 1:500. g) Sekmudärsporenbildımg: Vergr. $1: 500$.

Fig. 5. Platygluea blastomyces nor. spec. a) Fruchtkiirwer auf Rinde. Natïrliche Grösse. b) Fadenförmige Basillien. Bei der rechts befindlichen ist die mnterste Theilzelle entleert mul das sterigma zur C'usichtbarkeit geschwumlen. Vergr. 1:500, c) Die ans dem Lager hervorragenden sporen. Vergr. $1: 5(0$, d) Kemmug der sporen, Sekmulärsporenbildme; Bihmug der weitersprosienden Hefeconidien. Tergr. 1:500. e) Firimung der Hefeconidien. Terors. 1:500.

Fig. 6. Stypella papillata nor. gen. et nur. spec. Ein Theil ans iem lockeren Fardengeflecht des Pilzes, durchzogen von den oben hervorragenten, sehlanchartigen Zellen mol mit Basidien frei an ilen Fädlen. Vergr. 1 : 270. Daneben eine spore, welele die Ansatzstelle an Sterigma erkennen lïsst, mul zwei nur durch je eine schoilewanl getheilte Basilien. Vergr. $1: 1000$.

Fig: 7. Stypella minor. nor. gen, et. nor. spec. Theil des lockeren Fadengeflechts des Pilzes nit mregehnitssig angeordneten Basidien und den bindelweise hervorragenden stärkeren Hyphen. lergr. 1:270.

Fig. 8. Ileterorhate Sae Catharinae nor. spec. Längsichnit durch den oberen Theil des Frnchthörpers. welcher die Anordunng der Basidien und 
drei (hier als setulae von Patouillard bezeichnete) Papillen zeigt. Vergr. 1: 150. Daneben eine entleerte Basidie und eine reife Spore. Vergr. $1: 500$.

Fig. 9. Tremella damaecornis. ${ }^{4 / 3}$ der natiürlichen Grösse.

Fig. 10. Zwei Basidien einer mit Tr. mesenterica nahe rerwandten Form; Zuriìckgreifen der Conirlienbildung auf die Sterigmen der Basidien, welche häufig nur eine Scheidewand besitzen. Vergr. $1: 500$.

Fig. 11. Tremella anomala nov. spec. a) Die gekeimte Spore. umgeben von den fest zusammenhaltenden länglichen Hefesprosszellen. Vergr. 1:500. b) Die Wasserkeimung der Sporen, Vergr. 1:500; darunter Sporen, die in verschiedener Weise mit zunächst noch unregelmässig gestalteten Sprosszellen auskeimen, und keimende Hefezellen. Vergr. 1:500,

Fig. 12. Tremella compacta nov, spec. a) Fädlen aus dem Innern des festen Fruchtkörpers mit den conidienartigen Sprosszellen seitlich der Fäden. Vergr. 1 : 500. b) Auskeimung einer solchen Fadengruppe, wie a, in Nährlösung, die Keimfäden besitzen Schnallen. Von den conidienartigen Sprosszellen geht reiche Hefesprossung ans. Vergr. 1:500. c) Die Basidien; links eine normal gebildete, dann ahweichende Ausnahmefälle, welche die Verwanltschaft des Auriculariaceentypus mit dem der Tremellaceen erläutern. Vergr. $1: 500$. d) Sekundärsporenbildung und ungewöhnliche Anschwellung der Sporen. Vergr. 1:500. e) Keimende Spore mit noch unregelmässig grossen und anhaftenden Sprossconidien. Vergr. 1:500. f) Normale Keimung der Sporen mit sofort abfallenden Hefezellen. Vergr. 1: 500 . g) Weiter sprossende Hefen, welche constante Grösse annehmen. Vergr. 1:500.

Fig. 13. Tremella fuciformis Berk. Ein normaler und zwei ungewöhnliche Fälle der Sekundärsporenbildung. Vergr. 1:600.

Fig. 14. Eigenartige Conidienform einer vorläufig nicht benannten nenen Tremelline. Die Conidien sitzen auf kurzen Sterigmen. Vergr. 1:500.

Fig. 15. Tremella lutescens (forma brasiliensis). Basidie und Conidienträger von Blumenaner Exemplaren. Daneben anskeimende Hefezellen, welche ron den Conidien des Fruchtkörpers herstammen. An jeder Scheidewand des Keimschlauchs eine Schnalle; eine Hefen erzeugende Spore. Vergr. $1: 600$.

Fig. 16. Tremella Auricularia nov. spec. Eine Hefen erzengende Spore mit den festsitzenden sterigmaartigen Aussackungen; zwei ausnahmsweise aufgetretene Fälle von doppelter und dreifacher Sekundärsporenbildung. Vergr. $1: 500$.

Fig. 17. Tremella fucoides nov. spec. Auskeimung der Sporen und Hefebildung. Vergr. $1: 500$.

\section{Tafel V.}

Fig. 18 bis 33. Pilacrella delectans nov. spec.

Fig. 18. Der Kopf eines im Freien gefundenen Fruchtkörpers in einen Wassertropfen gelegt, umgeben von den alsbald sich ablösenden Sporemmassen. Vergr. $1: 70$. 
Fig. 19. Eines der Haare, welche die Hülle des Kopfes bilden, in Zusammenhang mit dem Ansatze einer Basidie. Vergr. 1:200.

Fig. 20. Basidien des Pilzes und 6 abgefallene Sporen. Vergr. 1:500.

Fig. 21. Auskeimende Basidienspore. Vergr, 1:500.

Fig. 22. Desgl. wie vor. An den Verzweigungen des Mycels werden grosse Conidien gebildet. Vergr. 1:500.

Fig. 23. Bildung der Conidien an den Fäden des Mycels. Vergr. 1:500.

Fig. 24. Keimung einer Basidienspore mit kurzen Mycelfäden, welche an ihren zugespitzten Enden spermatienartige Conidien abschnüren. Vergr. $1: 500$.

Fig. 25. Allmähliche Abschnürung der spermatienartigen Conidien, welche sich vor der abschnïrenden Spitze (durch unsichtbare Gallertsubstanz verklebt) in eine Doppelreihe ordnen. a) Um 9 Uhr, b) nm 9 Uhr 20 Nin., c) um 9 Uhr 40 Min., d) um 10 Uhr 20 Nin. Vergr. 1:500.

Fig. 26. Drei auskeimende Conidien. Die grossen Conidien können unmittelbar aussprossen. Bildung grosser und kleiner Conidien (Spermatien) an demselben, noch sehr kleinen Vycel. Vergr. 1:500.

Fig. 27. Die vor einer abschnürenden Fadenspitze liegenden kleinen Conidien (Spermatien) schwellen allmählich an (a). Sehr lange Reihe verklebter Spermatien (b). Grosse und kleine Conidien werden dicht neben einander (d), ja bei c sogar von demselben Fadenende nach einauder abgeschuïrt. Vergr. $1: 500$.

Fig. 28 und 29. Die Conidienbildung im allmählichen Uebergange zur Basidienbildung. Vergr. 1:500.

Fig. 30. Die erste Basidie erscheint an einem bisher nur Conidien tragenden Farlensysteme. Vergr. 1:

Fig. 31. Auf dem Objektträger erzogener Fruchtkörper des Pilzes, der noch nicht zur Köpfchenbildung vorgeschritten ist, sondern die Basidien vorzugsweise in dem mittleren Theile trägt. Vergr. 1:115.

Fig. 32. Reifer, auf dem Objektträger erzogener Fruchtkörper, welcher als selten ïppige Ausuahme auf einem Stiele vier getrennte, von Hülleu umgebene Köpfehen anfweist. Vergr. 1:9.

Fig. 33. Normaler einköpfiger, auf dem Ohjektträger erzogener Fruchtkörper. Vergr. 1:9.

Fig. 34. Tremellodon gelatinosum aus Blumenan, a) Langgestielter Fruchtkörper des Pilzes. Natürliche Grösse. b) Andere (auch ein ungestielter) Fruchthörperformen. Natürliche Grösse. Daneben Basidien und Sporen; Unregelmässigkeiten in der Basidienbildnng; Zerfall der Basidientheilzellen. Vergr. $1: 500$.

Fig. 35. Protohydunm cartilagineum nov. gell. et nov. spec. a) Querschnitt durch den Fruchtkörper. Natürliche Grösse. b) Querschnitt durch das Hymenium mit Basidienanlagen. c) Basidien. Vergr. 1:560.

Fig. 36. Protomerulius brasiliensis nov. gen. et nov. spec. Schräger Schnitt durch das Hymenium, und einzelne Basidien. Vergr. 1:650.

Fig. 37. Hyaloria Pilacre nov, gen. et nov, spec. a) Längsschnitt durch einen jungen Fruchtkörper. Vergr. 1:5. b) Theil eines Längsschnittes durch 
den Kopf des Pilzes. Vergr. 1:80. c) bis e) Basidien- und Sporenbildung. Vergr. $1: 1080$.

\section{Tafel VI.}

Alle Figuren von Sirobasidium Brefeldianum nov. spec.

Fig. 38. Ein Theil der Fadenverzweigungen und Endigungen ans einer sehr jungen Anlage des Pilzes. Vergr. 1: วั00.

Fig. 39. Eine ansgekeimte Spore des Pilzes, aus der ein Mycel entstanden ist, welches an einzelnen Mycelspitzen Conidien abschniurt. Vergr. 1:500.

Fig. 40. Hefesprossung, als Ansnahme Fardenkeimung der so gebildeten Conidien. Vergr. $1: 500$.

Fig. 41. Ein Theil der die Basidienketten tragenden Fäden ans dem reifen Zustande des Pilzes. Vergr. 1:220.

Fig. 42. Ausnahmsweise in grösserer Zahl zusammeuhängende Hefeconidien. Andere keimen zu kurzen Fäden aus und lassen dann wieder Hefen auskeimen. Vergr. 1:500.

Fig. 43. Auskeimung zweier Basidiensporen. Vergr. 1: 500 .

Fig. 44. Basidienbildung. Eine Basidie mit ansnahnsweise senkrechter Scheidewand. Vergr. 1: 500 .

Fig. 45. Freie, z. Th. unregelmässige Basidienbildungen. Vergr. 1:500.

Fig. 46. Unregelmässigkeit bei der Basidienbildung. Vergr. 1:500.

Fig. 47. Hefen, welche lange Sprossgenerationen durchgemacht haben, keimen mit feinen Fäden aus. Vergr. 1:500.

Fig. 48. Die regelmässige Basidienbildung in ihren verschiedenen Zuständen und Formen. Vergr. 1:500.

Fig. 49. a) Die abgeworfenen runden Sporen. b) Die abgepflückten ovalen Sporen. Dazwischen Verschiedenheiten der Sporenkeimung. Vergr. 1:500. 


1.

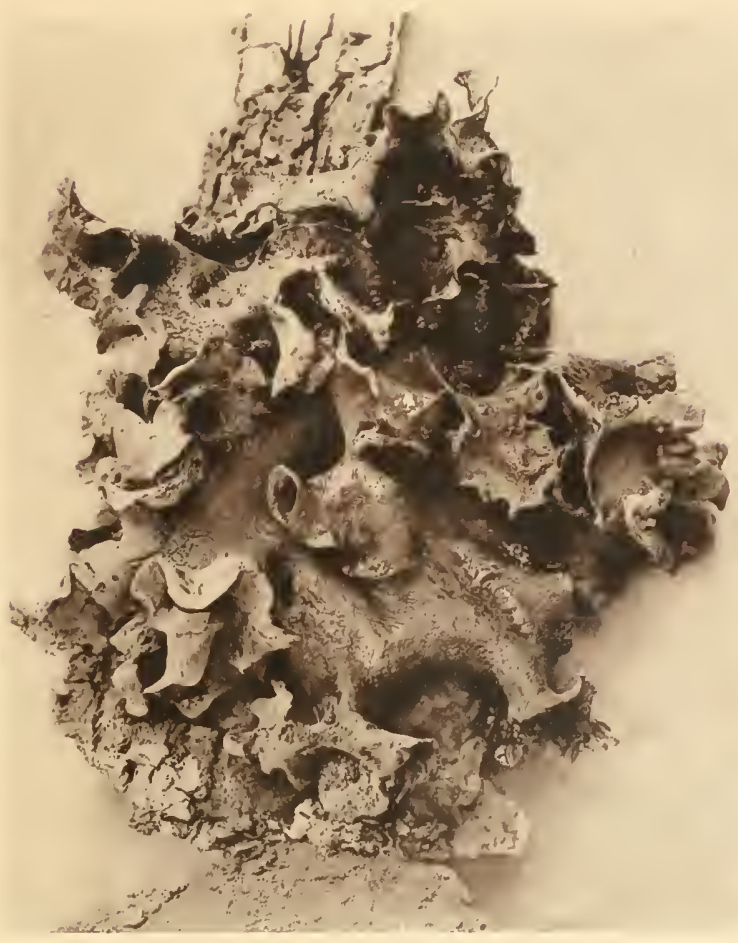

3

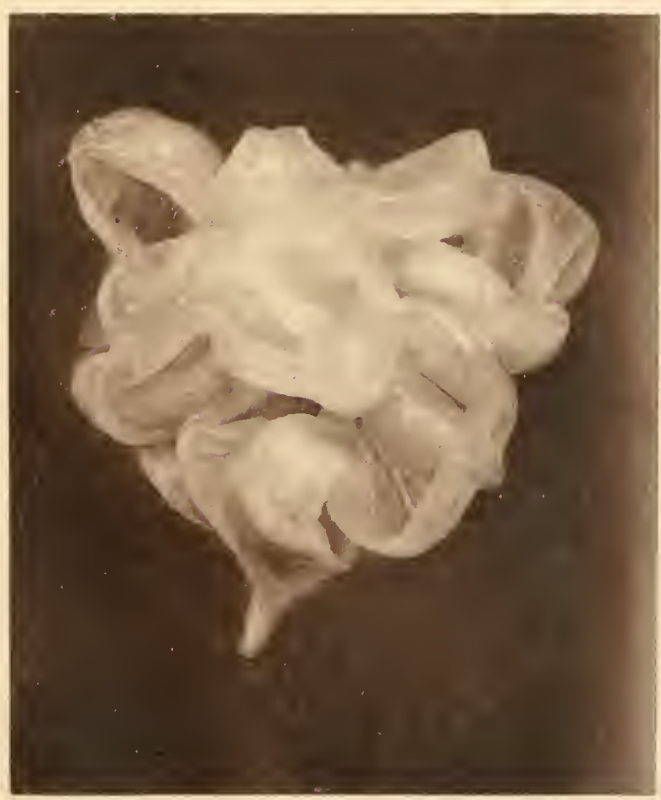

2.

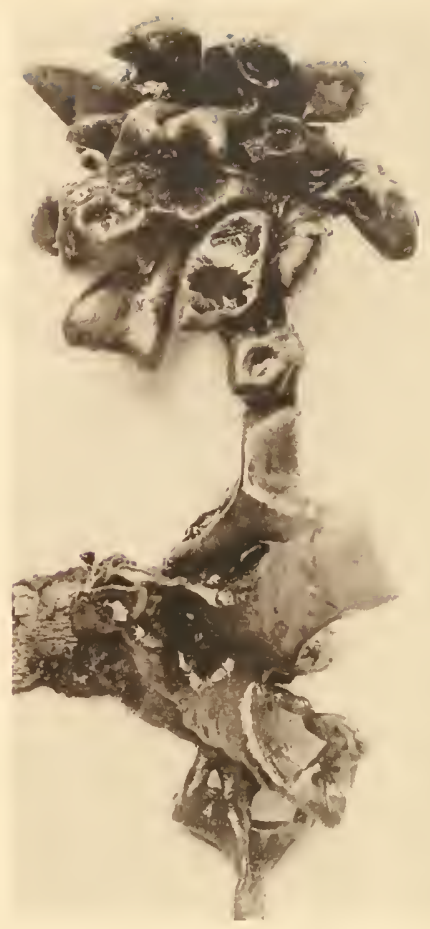

4.

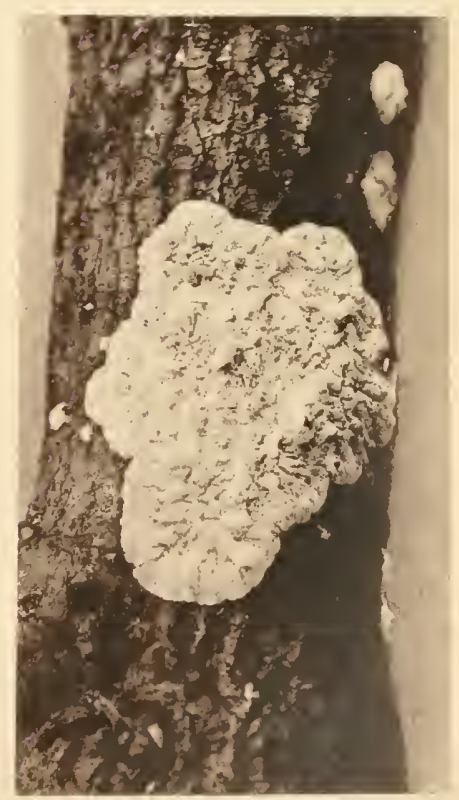

1. Tremella undulata, forma brasiliensis. 2. Tremella fucoides. 3. Tremella fibulifera. 4. Exidiopsis ciliata. 


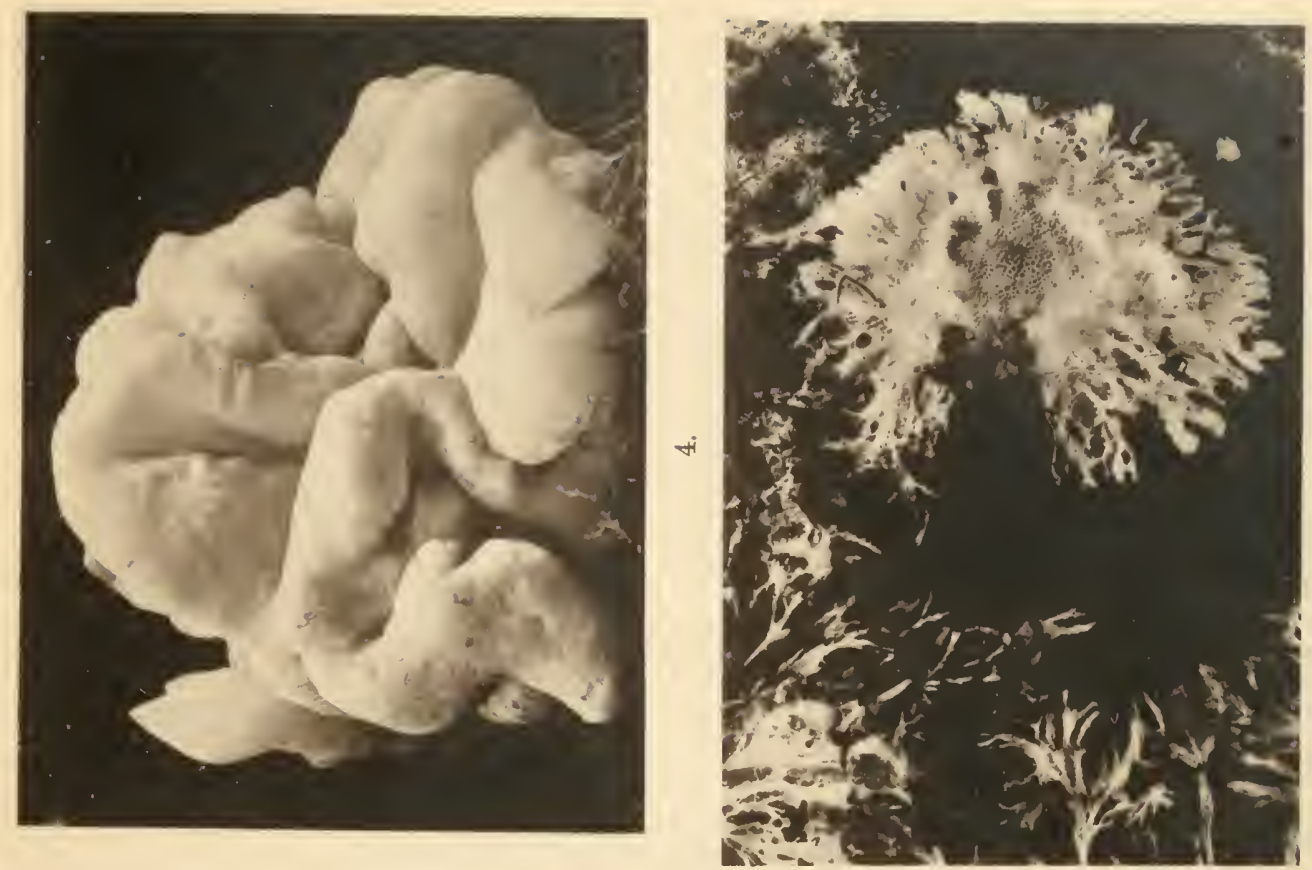

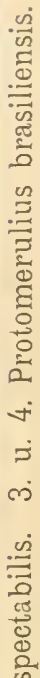

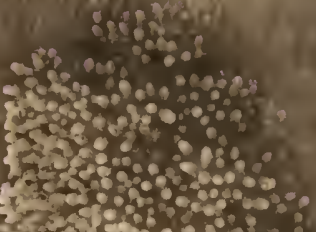

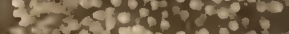

F.2.

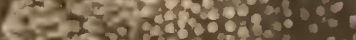

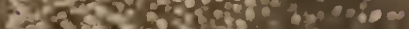

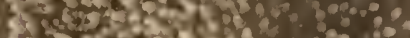

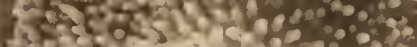

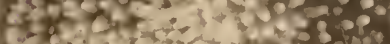

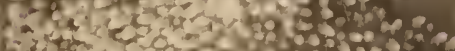

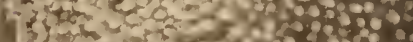

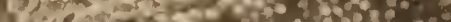

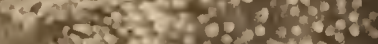

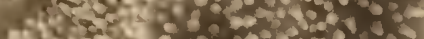

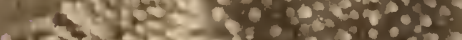

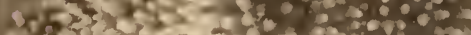

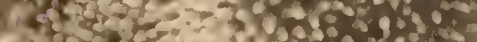

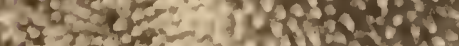

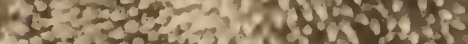

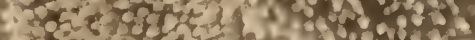

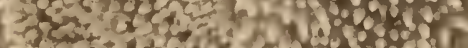

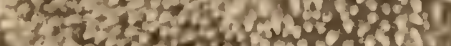

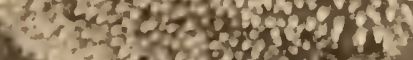

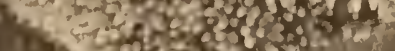

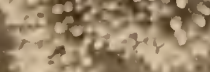

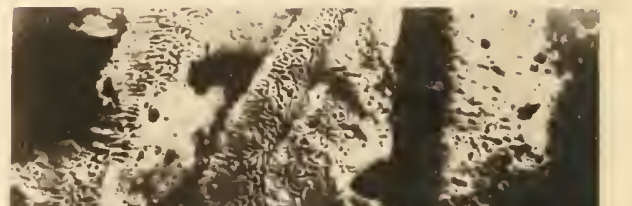

(5)

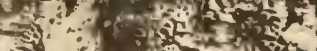

1.

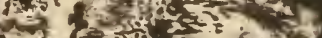

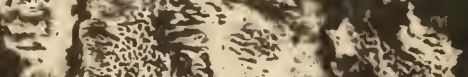

i.

(1)

$60^{\circ}$

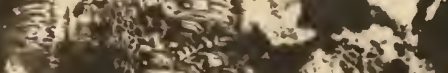

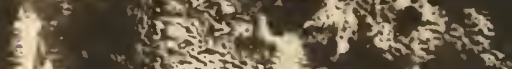

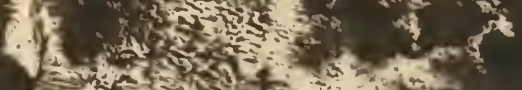

7.

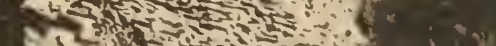

2.

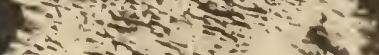

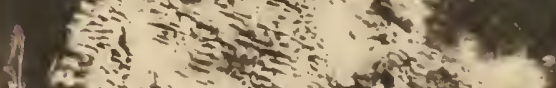

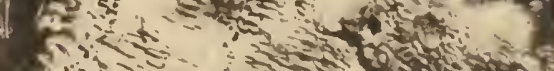

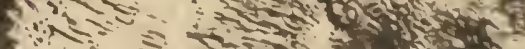

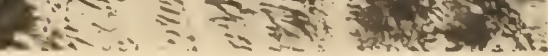




Iio,.2.

$$
\text { b }
$$

Hiọ. .̄.
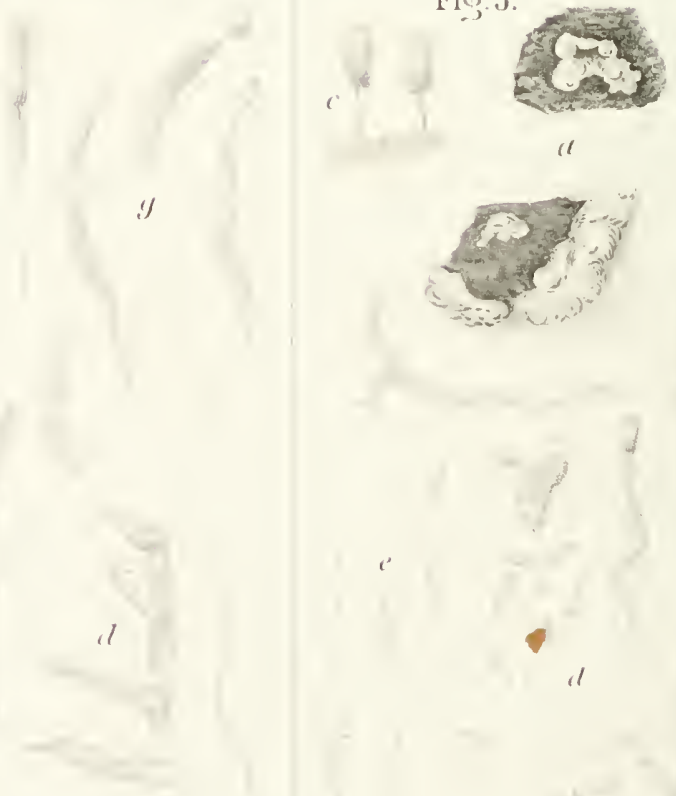
Fị. 6.

간산 $-3$ $+\sum^{3} \sum^{2}$
Fị̀.

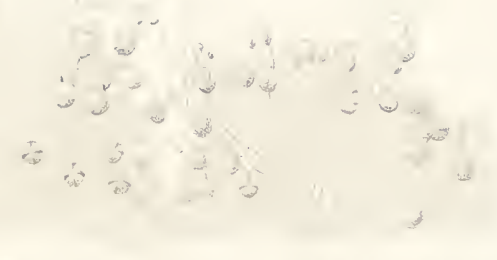

Fi⿱宀 9.

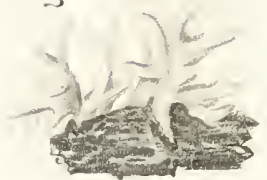

Fis.11.
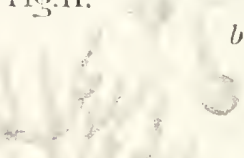

.x.

Hig. 8.

Fiọ. 10.

Fig 12.
Iics, 15.

Fis 16.

Fis 13.

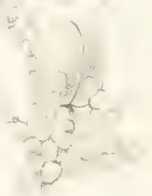

t.
Iij) 1't.
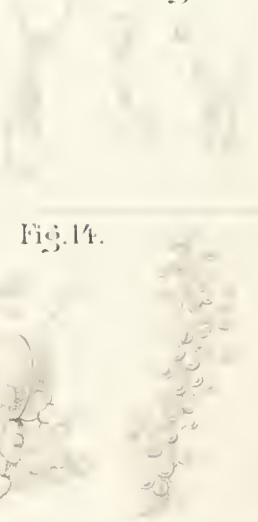


Fig. 22.

\section{Fis.21}

Fig. 25

Fig. 18.

Fie. 19

Iiio. 2't

d

c $108: 20$ b) gl: $10 . \mathrm{Y}$ 9r:2n' Fig. 29.

Fig. 23.

Fis, 26

$$
\text { Fic } 27
$$

\section{1}

Fio, 28. 
Fio. 32.

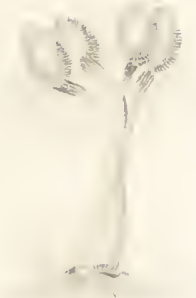

Fio. 30.

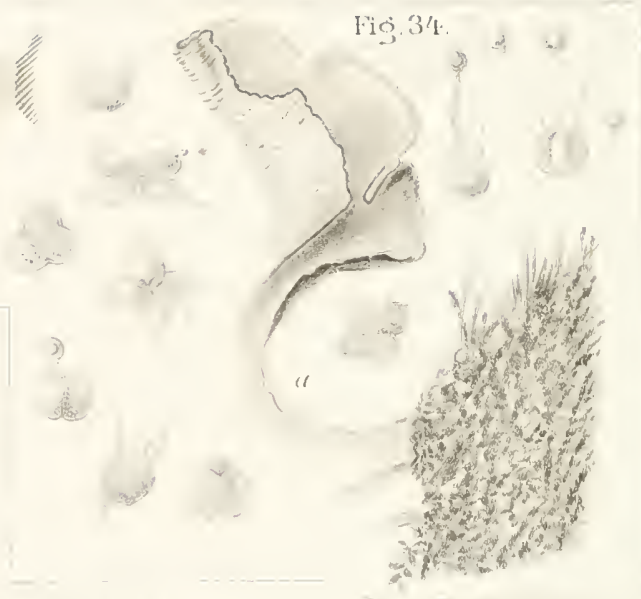

Fis.35.

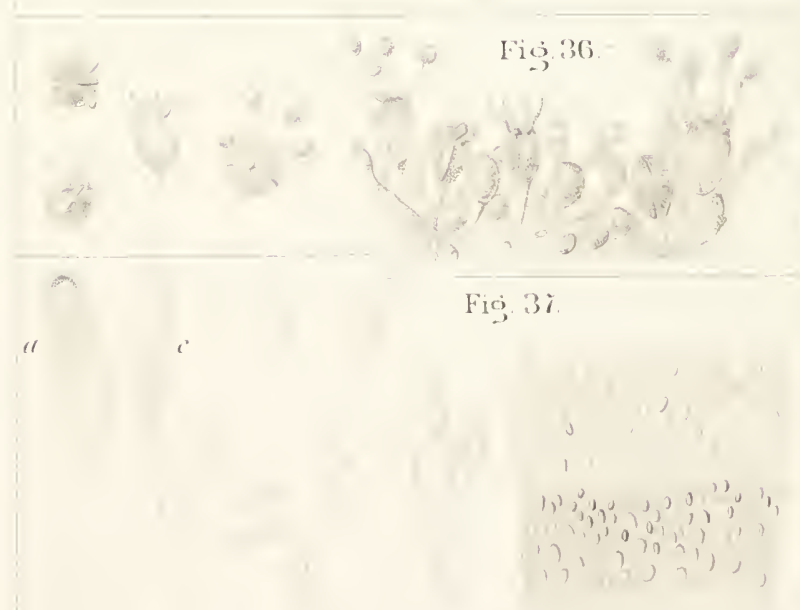

Fin 31.

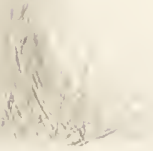

d

(1) 

Fio 39

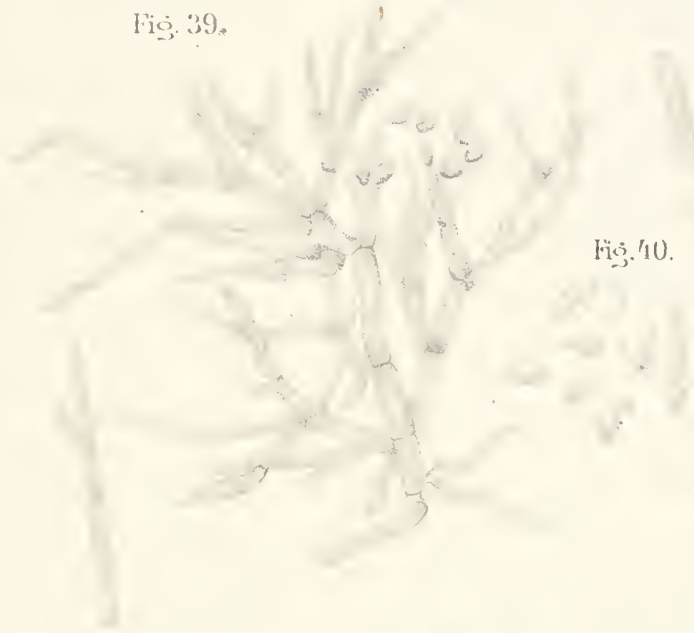

Fic, 11 .

Fiọ, '13.
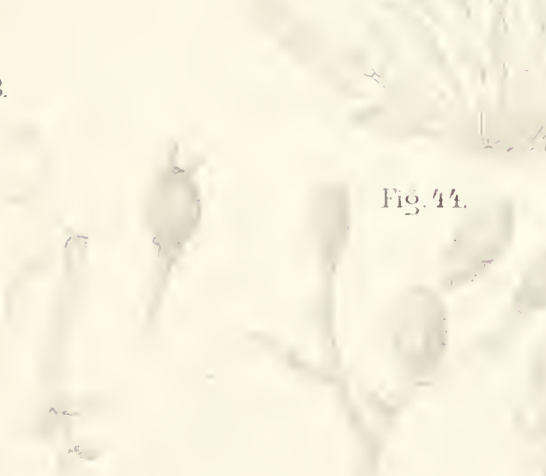

Fis. 45

Fie ${ }^{4}$
Fic; 38.

l'io, 't?.

liog.tí.

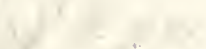









\section{QK626. M6}

Moller, Alfred/Protobasidiomyceten. Unte

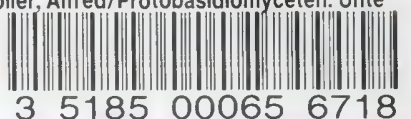




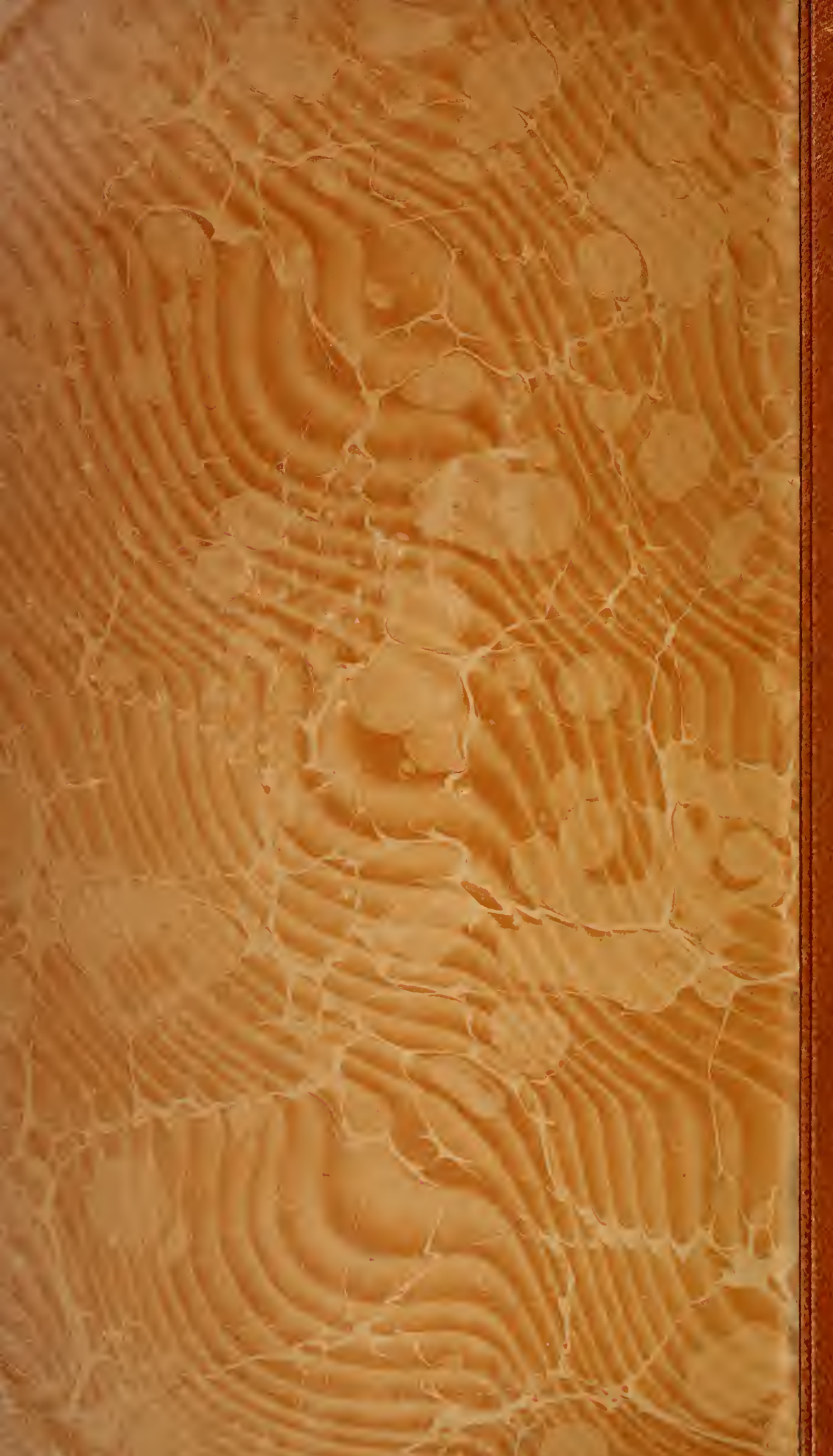

